\title{
Die Bedeutung von Stanniocalcin 2 im humanen Neuroblastom
}

\author{
Dissertation
}

zur Erlangung des mathematisch-naturwissenschaftlichen Doktorgrades

"Doctor rerum naturalium"

der Georg-August-Universität Göttingen

\author{
vorgelegt von \\ Sonja Lena Volland \\ aus Rotenburg an der Fulda
}

Göttingen 2008 
D7

Referent: $\quad$ Prof. Dr. Bernd Herrmann

Korreferent: $\quad$ PD Dr. Dieter Kube

Tag der mündlichen Prüfung: $\quad$ 21.01.2009 
Tage, wenn sie scheinbar uns entgleiten, gleiten leise doch in uns hinein. Aber wir verwandeln alle Zeiten, denn wir sehnen uns zu sein ...

Rainer Maria Rilke, 1907 


\section{Inhaltsverzeichnis}

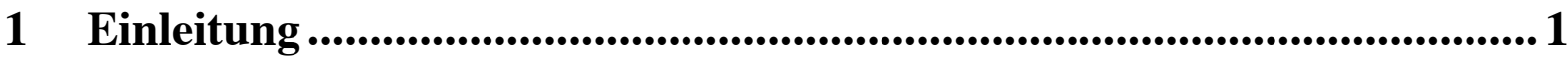

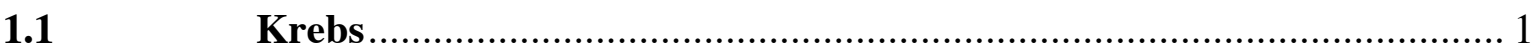

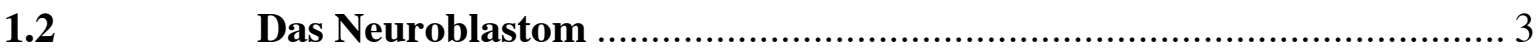

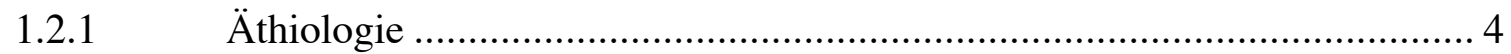

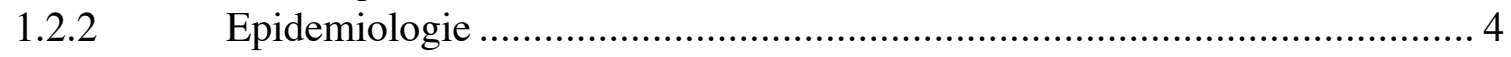

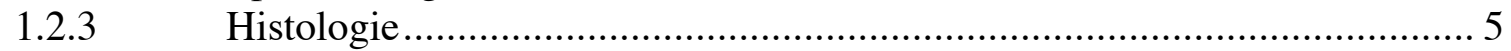

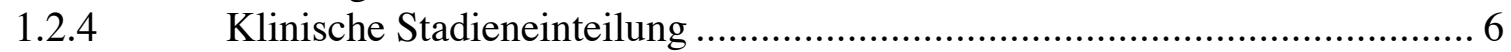

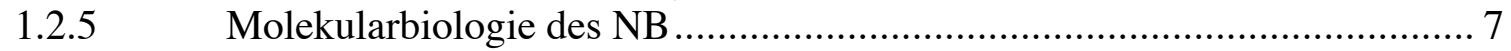

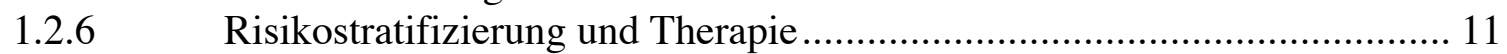

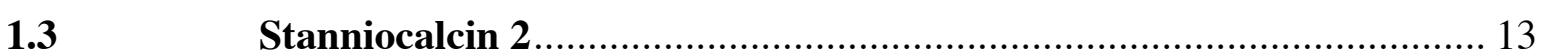

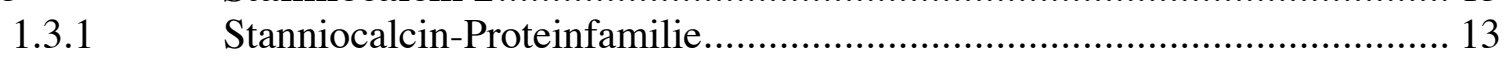

1.3.2 Chromosomale Lokalisation und Genstruktur ....................................... 14

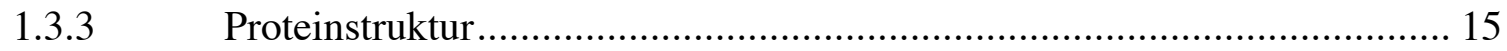

1.3.4 STC-Funktion: Vom Fisch zum Menschen ......................................... 15

1.3.5 STC1 und STC2 bei Menschen und Säugetieren ................................... 16

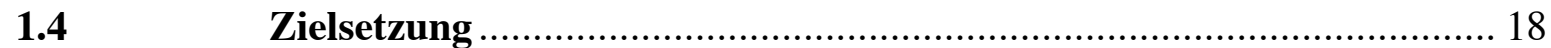

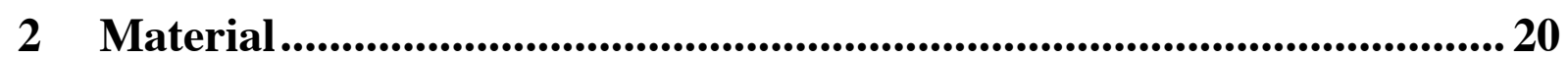

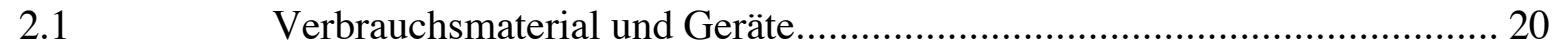

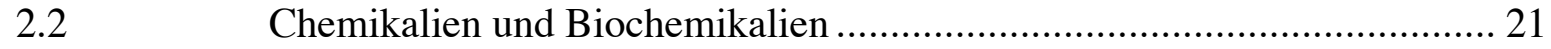

2.3 Gebrauchsfertige Reaktionssysteme (Kit's) .......................................... 23

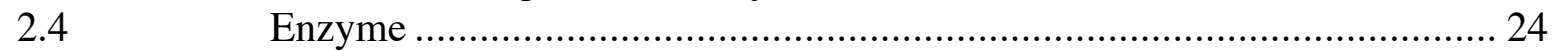

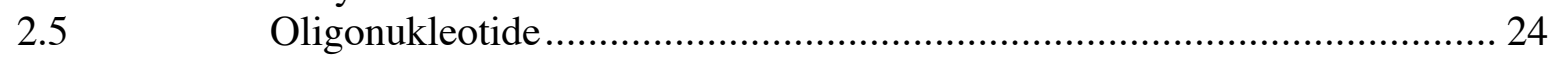

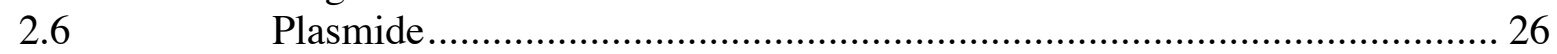

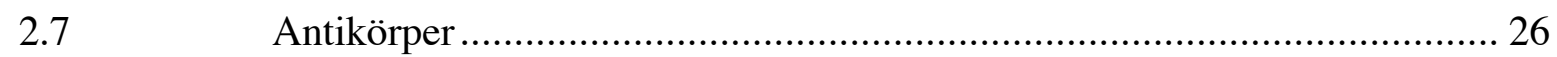

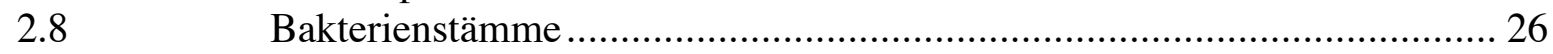

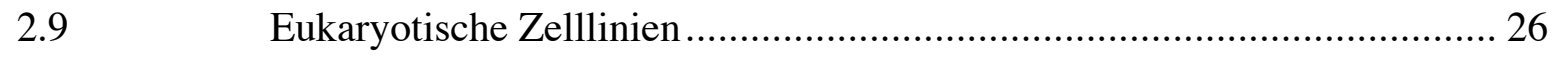

2.10 Zellkulturmedien und Puffer.............................................................. 28

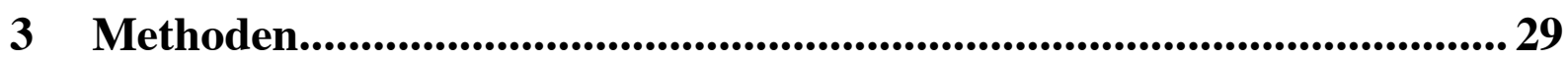

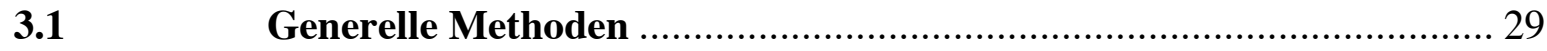

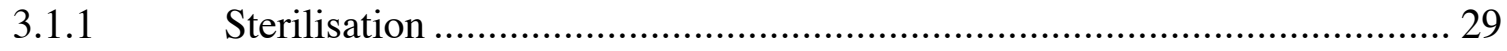

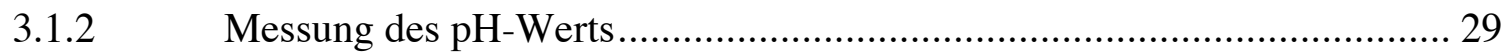

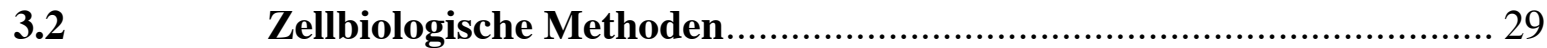

3.2.1 Kultivierung von Bakterien................................................................ 29

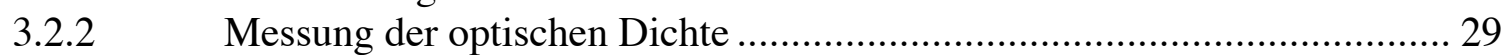

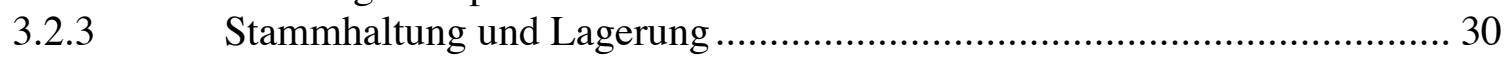

3.2.4 Kultivierung von eukaryotischen Zellen .............................................. 30

3.2.5 Stammhaltung, Lagerung und Rekultivierung eukaryotischer Zellen......... 30

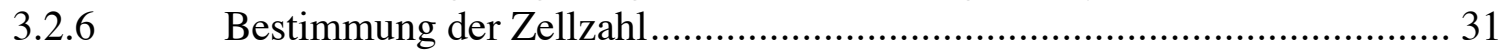

3.2.7 Ernte von Zellkultur-Überständen...................................................... 31 
3.2.8 Transfektion eukaryotischer Zellen .................................................. 31

3.2.9 Isolierung stabiler Einzelzelltransfektanten ....................................... 32

3.3

3.3.1

Molekularbiologische Methoden.................................................... 32

3.3 .2

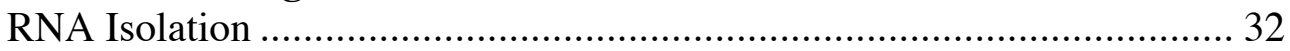

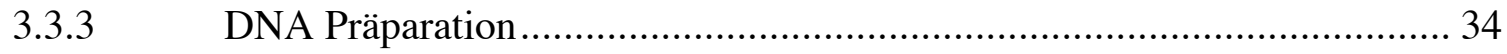

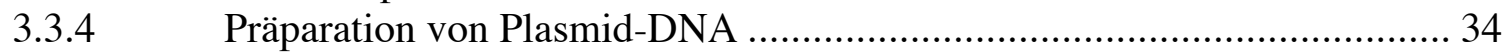

3.3.5 Konzentrationsbestimmung und Reinheitskontrolle von Nukleinsäuren .... 34

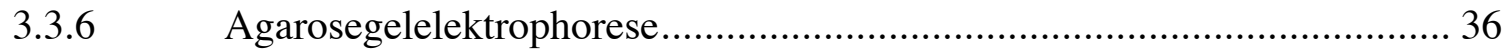

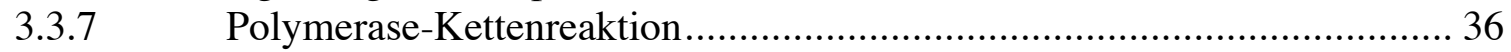

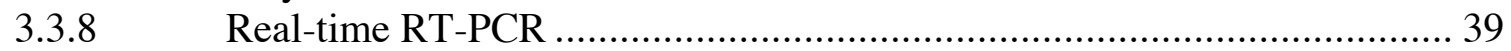

3.3.9 Bestimmung der relativen Transkriptmenge......................................... 40

3.3.10 Aufreinigung von PCR-Produkten ..................................................... 40

3.3.11 Extraktion von DNA-Fragmenten aus Agarosegelen............................... 41

3.3.12 Enzymatische Modifikation von Nukleinsäuren .................................... 41

3.3.12.1 Spaltung von DNA durch Restriktionsendonukleasen ........................... 41

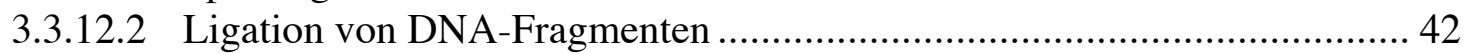

3.3.13 Transformation durch Hitzeschock ....................................................... 43

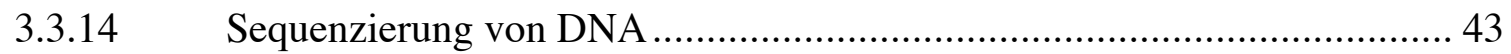

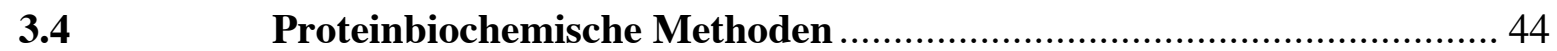

3.4.1 Bestimmung der Proteinkonzentration ................................................. 44

3.4.2 Dialyse von Proteinlösungen .......................................................... 45

3.4.3 Konzentration von Zellkultur-Überständen ........................................... 46

3.4.4 Probenvorbereitung für SDS-PAGE................................................. 46

3.4.5 SDS-Polyacrylamidgelelektrophorese (SDS-PAGE) ............................... 47

3.4.6 Coomassie-Färbung von SDS-Polyacrylamid-Gelen .............................. 48

3.4.7 Silberfärbung von SDS-Polyacrylamid-Gelen.................................... 49

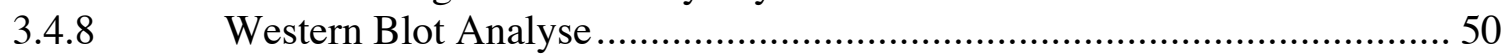

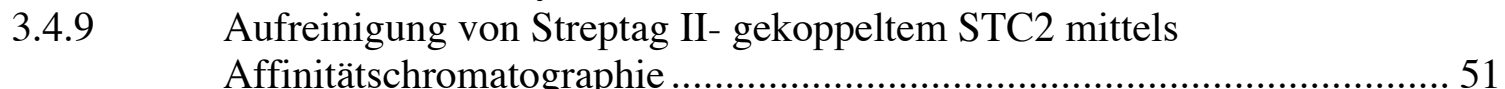

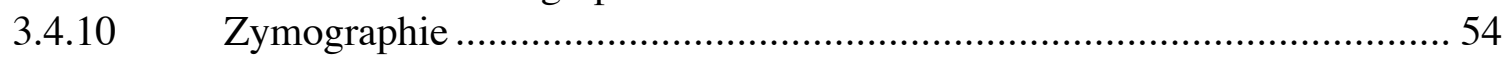

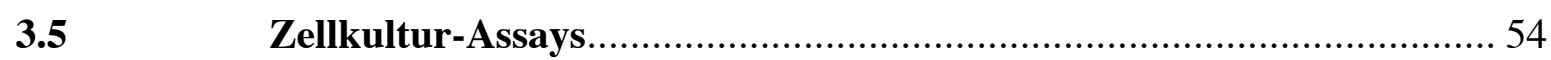

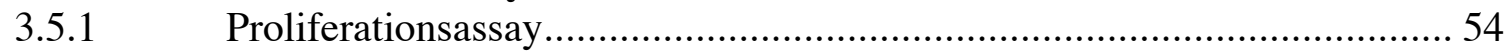

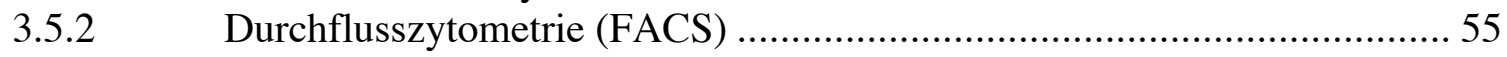

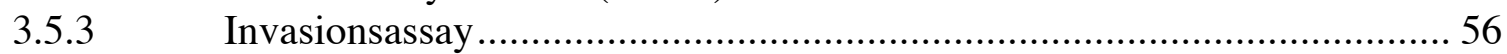

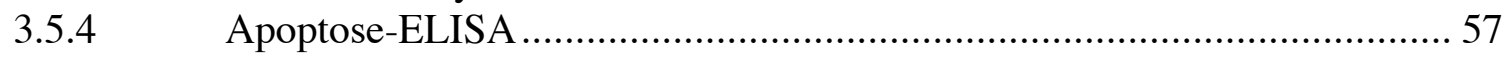

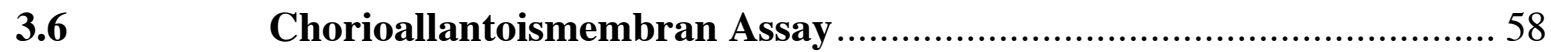

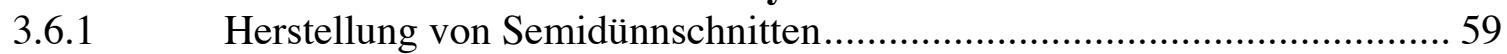

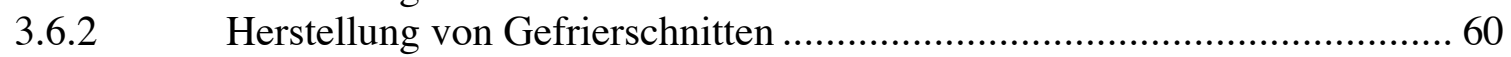

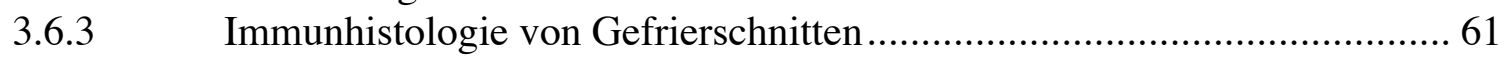

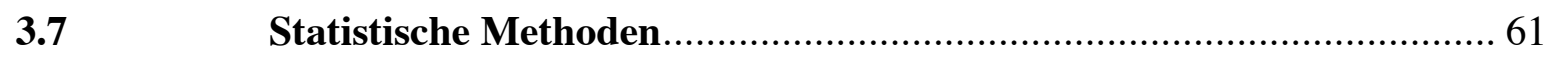

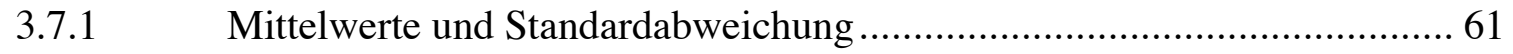

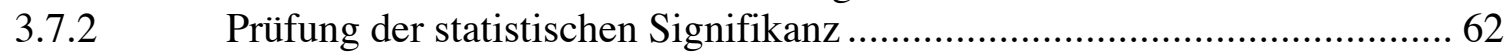

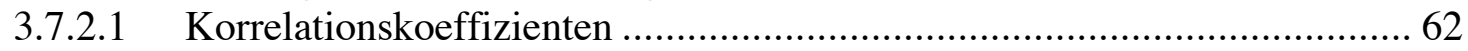

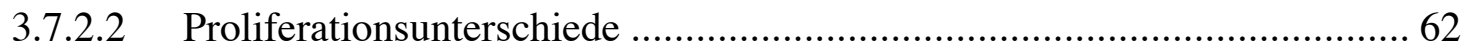

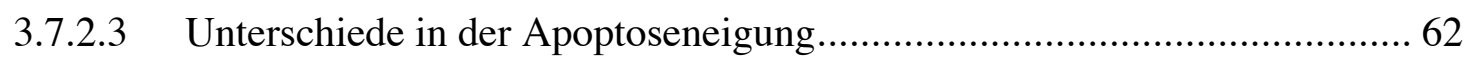


4.1 Untersuchungen der STC2-Expression in humanen NB-Zelllinien...... 64

4.1.1 STC2-mRNA-Expression in humanen NB-Zelllinien................................6 64

4.1.2 STC2-Proteinexpression in humanen NB-Zelllinien ............................... 65

4.1.3 Alternative STC2-Transkripte in humanen NB-Zelllinien ....................... 66

4.1.3.1 Sequenzierung von STC2-Transkripten aus humanen NB-Zelllinien......... 66

4.1.3.2 Amplifikation alternativer STC2-Transkripte mittels Multiplex RT-PCR.. 67

4.1.3.3 Nachweis alternativer STC2-Transkripte mittels Real-time RT-PCR ........ 68

4.1.4 Die STC2-Gesamtmenge korreliert nicht mit dem Auftreten alternativer

STC2-Transkripte ........................................................................ 69

4.1.5 Nachweis von Sequenzvariationen in der Intronregion des STC2-Gens ..... 71

4.2 Überexpression von STC2 in humanen SH-SY5Y NB-Zellen............... 72

4.2.1 Herstellung von STC2-Expressionsvektoren ......................................... 72

4.2.2 STC2-Transfektion der humanen NB-Zelllinie SH-SY5Y ...................... 72

4.2.3 Nachweis der STC2-Expression in transfizierten SH-SY5Y NB-Zellen .... 73

4.2.4 STC2 liegt im Überstand von transfizierten SH-SY5Y als Dimer vor ....... 74

4.2.5 STC2-Expression vermindert die Adhärenz von SH-SY5Y-Zellen ........... 75

4.2.6 STC2-Expression inhibiert die Proliferation von SH-SY5Y-Zellen ........... 75

4.2.7 STC2-Expression in SH-SY5Y führt zu erhöhter DNA-Replikation ......... 76

4.2.8 STC2-Expression in SH-SY5Y erhöht die Zahl nicht vitaler Zellen im Überstand .......................................................................................... 77

4.2.9 STC2-Expression in SH-SY5Y erhöht die Basis-Apoptose der Zellen ...... 80

4.2.9.1 In STC2-exprimierenden SH-SY5Y ist die Apoptose nach Staurosporin-

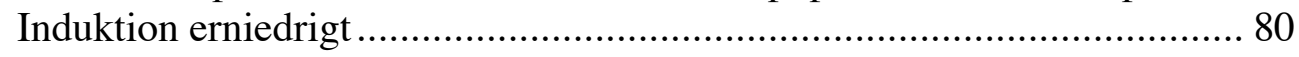

4.2.10 STC2-Expression erhöht die Invasivität von SH-SY5Y-Zellen in vitro ..... 81

4.2.10.1 In STC2-exprimierenden SH-SY5Y ist die Aktivität der MMP 2 erhöht ... 82

4.2.11 In vivo-Effekte der STC2-Expression in SH-SY5Y-Zellen....................... 83

4.2.11.1 Die Morphologie der STC2-exprimierenden Tumoren ist verändert.......... 84

4.2.11.2 STC2-Expression in SH-SY5Y korreliert in vivo mit invasivem Verhalten und erhöhter Blutigkeit ..................................................................... 85

4.2.11.3 Gefäßbildung und -Arrosion in STC2-exprimierenden Tumoren................ 86

4.3 Untersuchungen der Effekte von gereinigtem rekombinantem STC2 . 87

4.3.1 Untersuchung und Dialyse des rekombinanten STC2 aus E. coli.............. 87

4.3.2 STC2rek liegt nach der Dialyse teilweise als Dimer vor............................ 88

4.3.3 STC2rek induziert Effekte auf der CAM von Hühnerembryonen .............. 89

4.3.4 STC2rek induziert Blutungen und die Bildung von Granulationsgewebe .. 90

4.4 Korrelation von STC2-Expression und ungünstigen Faktoren im NB. 91

4.4.1 STC2-Expression ist in metastasierenden Stadium 4 Tumoren erhöht....... 91

4.4.2 STC2-Expression korreliert in NB-Zelllinien mit MYCN-Expression....... 92

4.4.3 STC2-Expression korreliert in Primärtumoren mit MYCN-Amplifikation . 93 


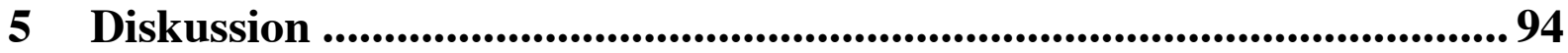

S.1 STC2-Expression im humanen Neuroblastom....................................... 94

5.2 Korrelation von STC2 mit klinisch relevanten Faktoren........................... 95

5.3 STC2-Überexpression in humanen NB-Zellen ................................... 96

5.4 Einfluss von STC2 auf Proliferation und Apoptose von NB-Zellen.......... 97

5.5 Einfluss von STC2 auf Tumorbildung und Invasivität von NB-Zellen ...... 98

5.6 Überprüfung der STC2-Effekte mit rekombinantem Protein .................. 100

$5.7 \quad$ Alternative STC2-Transkripte im Neuroblastom ................................. 101

5.8 Die duale Rolle von STC2 bei der Tumorprogression ........................... 104

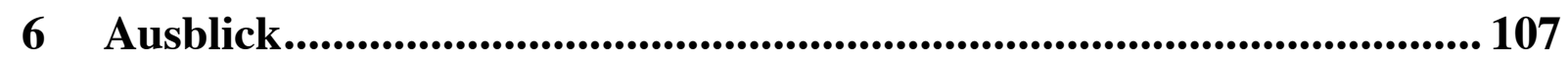

$7 \quad$ Zusammenfassung ......................................................................................... 109

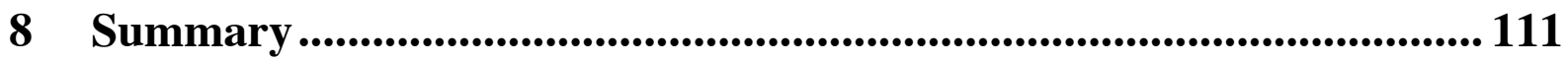

9 Literaturverzeichnis ................................................................................... 112

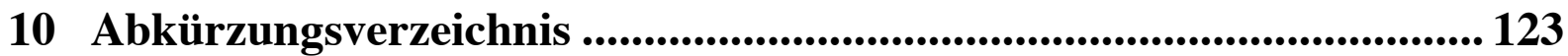

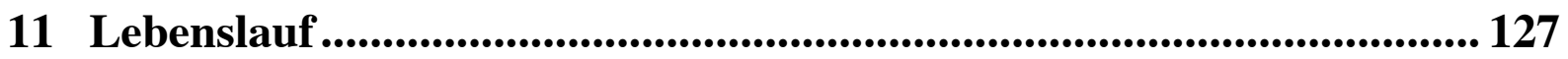

12 Veröffentlichungen ....................................................................................... 128

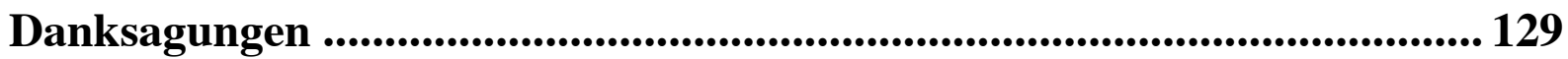




\section{Einleitung}

\subsection{Krebs}

Im deutschen Krebsregister werden unter dem Begriff Krebs mehr als 100 verschiedene bösartige Neubildungen (maligne Neoplasien) erfasst. Diese Erkrankungen zeichnen sich durch ein unkontrolliertes Wachstum der betroffenen Zellen aus, das durch die Mutation von Genen hervorgerufen wird. Krebs kann seine schädigende Wirkung lokal durch invasives oder nicht-invasives Wachstum (Verdrängung) ausüben. Der Hauptgrund für den Tod von Krebspatienten ist allerdings die Bildung von Metastasen und damit die Ausbreitung des Tumors im Körper (Woodhouse et al., 1997). Durch Angiogenese (Blutgefäßbildung) wird die Versorgung des Primärtumors und somit das Tumorwachstum verbessert (Srivastava et al., 1986) und außerdem die Wahrscheinlichkeit erhöht, dass Tumorzellen in den Blutkreislauf eindringen können (Woodhouse et al., 1997). In vergleichbarer Weise erhöht Tumor-induzierte Lymphangiogenese die Wahrscheinlichkeit, dass Tumorzellen sich über das Lymphsystem absiedeln (Wilting et al., 2005). Ein geringer Teil (0,05\%) der im Blut zirkulierenden Zellen ist dann in der Lage, sich an anderen Körperstellen anzusiedeln und Metastasen zu bilden (Woodhouse et al., 1997). Voraussetzung ist, dass die Zellen hohes Migrationspotential besitzen und dabei auch epitheliale Barrieren überwinden können. Der Mechanismus für dieses invasive Verhalten ähnelt dem von nicht-malignen Zellen beim Überqueren von Gewebegrenzen, etwa bei der Implantation des Trophoblasten im Uterus (Lala \& Graham, 1990) und der embryonalen Morphogenese (Talhouk et al., 1992). Der Unterschied bei Tumorzellen besteht darin, dass die physiologische Regulation dieser Mechanismen verloren gegangen ist (Woodhouse et al., 1997).

In einer gemeinschaftlichen Veröffentlichung des Robert Koch-Institut (RKI) und der Gesellschaft der epidemiologischen Krebsregister in Deutschland e. V. (GEKID) mit dem Titel „Krebs in Deutschland“ werden Daten zum nationalen Gesundheitszustand zusammen gefasst (RKI \& GEKID, 2008). Laut neuester Statistiken erkrankt fast jeder dritte Mensch im Laufe seines Lebens an Krebs, jeder Vierte davon verstirbt daran. Das mittlere Erkrankungsalter liegt bei 69 Jahren und das Sterbealter bei 71-75 Jahren. Davon ausgenommen ist der Krebs bei Kindern. Hier ist die Wahrscheinlichkeit vor dem fünften Lebensjahr zu erkranken doppelt so hoch wie bei 5 bis 14-Jährigen. Und obwohl nur ein Prozent der Krebserkrankungen bei Kindern auftreten, ist Krebs im Kindesalter wie bei Erwachsenen die zweithäufigste Todesursache. 
Für die Entstehung von Krebserkrankungen ist in der Regel eine Kombination von Genmutationen und äußeren Faktoren verantwortlich, von denen einige bereits gut untersucht sind: So konnte beispielsweise gezeigt werden, dass zwischen einem Drittel und einem Viertel aller Krebstodesfälle auf Rauchen zurück zu führen sind. Außerdem werden falsche Ernährung, chronische Infektionen, Alkoholabusus und Umwelteinflüsse als mögliche Faktoren untersucht (RKI \& GEKID, 2008). Die verschiedenen Belastungen wirken im Laufe des Lebens in vielfältiger Weise zusammen. Anders ist das bei Krebserkrankungen im Kindesalter. Hier liegen die Ursachen vermehrt auf entwicklungsgenetischer Ebene und sind in den meisten Fällen noch ungeklärt (Kaatsch et al., 2006). Umweltfaktoren scheinen nur bei bestimmten Entitäten eine Rolle zu spielen (Schüz \& Kaatsch, 2002; Schütz, 2002).

Generell ist das Erkrankungsspektrum bei Kindern ein gänzlich anderes als bei Erwachsenen, wo $80 \%$ aller Krebserkrankungen Karzinome sind, wie etwa Prostata- oder Brustkrebs, Lungenkrebs oder Tumoren des Darmepithels. Bei Kindern treten häufig embryonale Tumoren wie Neuroblastome (periphere Nervenzelltumoren) oder Retinoblastome auf (Abb. 1.1), und die größte Gruppe der Erkrankungen sind Leukämien und ZNS-Tumoren.

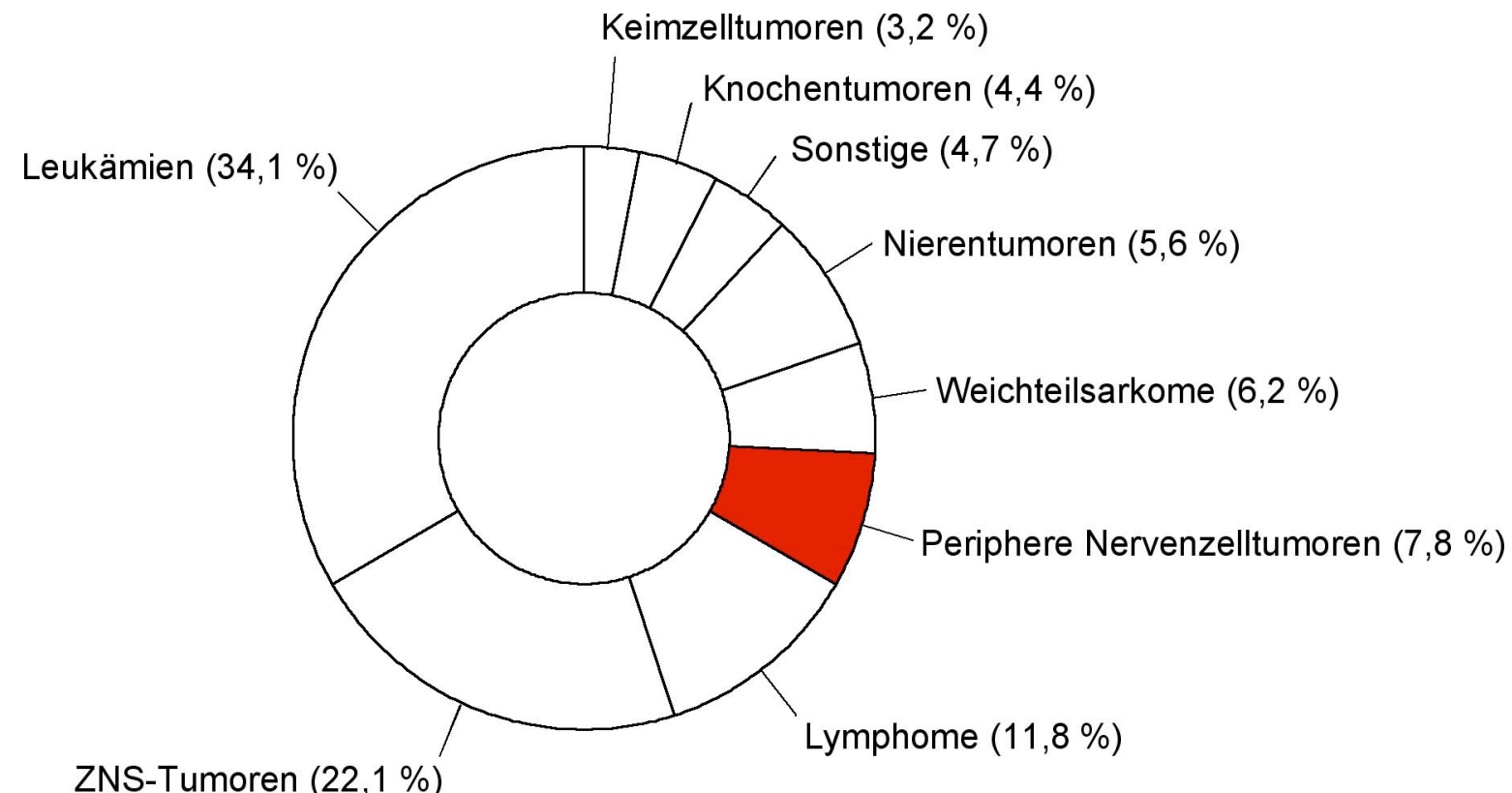

Abb. 1.1: Krebs bei Kindern in den Jahren 1997-2006 (RKI \& GEKID, 2008)

Die Zahl der Krebserkrankungen ist in den letzten 25 Jahren angestiegen, die Mortalität hat jedoch laut GEKID gleichzeitig deutschlandweit abgenommen. Auf der Grundlage neuer 
Forschungsergebnisse konnten Früherkennungsprogramme entwickelt oder Therapien verbessert werden.

\subsection{Das Neuroblastom}

Erstmals als abdominaler Tumor mit mikroskopischen Merkmalen eines Glioms durch Virchow (1863) beschrieben, wurde 1910 für diese Erkrankung der Name Neuroblastom (NB) von J.N. Wright eingeführt. Zuvor hatte F. Marchard bereits gezeigt, dass die Genese der Tumoren von sympathischen Nervenzellen der Neuralleiste ausgeht (Nieder \& Gauder, 1991). Mit fast $8 \%$ der Erkrankungen ist das zu den peripheren Nervenzelltumoren gehörende NB heute der häufigste solide extrakraniale Tumor im Kindesalter (Gurney et al., 1997; RKI \& GEKID, 2008). $15 \%$ der Krebs-abhängigen Todesfälle bei Kindern sind darauf zurück zu führen und kommen hauptsächlich aufgrund metastasierender Tumorprogression zu Stande (Brodeur, 2003; Schwab et al., 2003).

Das NB zeichnet sich besonders durch seine klinische Heterogenität aus, bei der, abhängig vom Alter der Patienten sowie der Tumorbiologie und Lokalisation, der Krankheitsverlauf extrem divergent ist (Maris et al., 2007). Spontane Tumorregression oder Differenzierung in Ganglioneuroblastome und gutartige Ganglioneurome treten dabei genauso auf wie hoch aggressive Tumorprogression (Ladenstein et al., 2006). Besonders deutlich zeigt sich diese Heterogenität beim $4 \mathrm{~s}$ Stadium ( $\mathrm{s}=$ spezial), das in $5 \%$ der Krankheitsfälle diagnostiziert wird. 4s-Tumoren sind kleine lokalisierte Primärtumoren mit Metastasen in Leber, Haut und Knochenmark, die fast immer eine Spontanregression zeigen (D'Angio et al., 1971; Maris et al., 2007; s. a. Kap. 1.2.4). Diese klinische Heterogenität findet sich auch auf molekularer Ebene wieder. Bei ca. $80 \%$ der humanen NB wurden genetische Veränderungen nachgewiesen, die teilweise bereits als prognostische Marker bei der Risikostratifizierung zum Einsatz kommen (Oberthür \& Hero, 2004). Der bislang verlässlichste genetische Marker ist die Amplifikation des Onkogens $M Y C N$, die stark mit fortgeschrittenem Tumorstadium und Therapieversagen korreliert (Brodeur et al., 1984; Seeger et al., 1985). Außerdem wird die Deletion des kurzen Arms von Chromosom 1 (1p) als prognostischer Marker eingesetzt (weitere Erläuterungen folgen in Kap. 1.2.5). Die Risikostratifizierung erfolgt für NB standardmäßig nach dem „NB 2004“--Protokoll der Gesellschaft für Pädiatrische Onkologie und Hämatologie (GPOH) (s. Kap. 1.2.6). Neben den genannten genetischen Markern beruht diese Einteilung auf dem klinischen Tumorstadium, das nach dem internationalen INSS- 
Klassifikationssystem eingeteilt wird (s. Kap. 1.2.4), sowie dem Alter der Patienten bei Diagnose.

\subsection{1 Äthiologie}

Die genauen Ursachen der Entstehung des NB sind bis heute unbekannt. Für das Auftreten der meisten pädiatrischen Tumoren werden spontane Fehlfunktionen während der normalen Wachstums- und Entwicklungsprozesse verantwortlich gemacht (Maris \& Denny, 2002). Die Folgen dieser Fehlfunktionen sind beim NB chromosomale Aberrationen und Veränderungen in der DNA-Ploidität der Tumorzellen (s. Kap 1.2.5; Maris et al., 2007). Es wird geschätzt, dass fast $22 \%$ der NB-Fälle auf eine autosomal-dominant vererbte Keimbahn-Mutation zurück gehen (Knudson \& Strong, 1972; Brodeur, 2003). Außerdem konnte bei 0,3 \% der NB-Patienten eine Prädisposition zur Entwicklung der Erkrankung und ein familiär gehäuftes Auftreten beobachtet werden (Berthold et al., 2003). Kopplungsanalysen deuten an, dass der Locus 16p12-13 der Grund für die Vererbung der Erkrankung in einigen Hochrisikofamilien ist (Maris et al., 2002). Studien der Risikofaktoren kamen bisher nicht zu konsistenten Ergebnissen. Der Einfluss von Umweltbedingungen und elterlichem Stress wurde untersucht, eindeutige Beweise für eine Korrelation konnten aber nicht gefunden werden (Olshan et al., 1999). Für Kinder, insbesondere Jungen, die in utero Geschlechtshormonen ausgesetzt waren, gibt es einen schwachen Zusammenhang mit einem erhöhten Risiko (Ladenstein et al., 2006).

\subsubsection{Epidemiologie}

Laut Deutschem Kinderkrebsregister (DKKR) treten jährlich ca. 1.800 neue Krebserkrankungen bei Kindern in Deutschland auf. Die peripheren Nervenzelltumoren, bei denen es sich hauptsächlich um NB handelt, sind bei diesen Neuerkrankungen mit 7,8 \% und somit etwa 140 Neuerkrankungen pro Jahr vertreten (s. a. Abb. 1.1). In den USA liegt die Inzidenz des NB bei 1:7.000 Lebendgeburten und ca. 700 neue NB-Fälle werden dort jährlich diagnostiziert (Brodeur \& Maris, 2002).

NB entstehen aus sympatho-adrenergen Vorläuferzellen und können überall im sympathischen Nervensystem auftreten (Maris et al., 2007). Die meisten Primärtumoren (ca. $65 \%$ ) entstehen im Abdomen, mindestens die Hälfte davon im Nebennierenmark, weitere Tumoren sind in Nacken, Brust und Becken gelegen (Brodeur \& Maris, 2006). Nahezu die Hälfte der NB sind bei Diagnosestellung bereits metastasiert (Maris et al., 2007). Metastasen befinden sich hauptsächlich im Knochenmark (80-90 \%) und den Knochen (50-70 \%). Lokale 
Lymphknoten sind ebenfalls häufiger betroffen und seltener sind auch entfernte Lymphknoten befallen. Im Tumorstadium 4s (s. a. Kap. 1.2 und 1.2.4) treten Metastasen vor allem in Leber und Haut auf, etwa $10 \%$ liegen intrakranial und in $5 \%$ der Fälle ist die Lunge befallen (Ladenstein et al., 2006).

Das NB gehört mit einem mittleren Diagnosealter von 18 Monaten zu den embryonalen Tumoren. $40 \%$ der NB werden vor Vollendung des ersten Lebensjahres diagnostiziert und 90 $\%$ bis zum sechsten Lebensjahr (Ladenstein et al., 2006). Das Alter bei Diagnose korreliert invers mit der Überlebenswahrscheinlichkeit und ist, wie bereits erwähnt, ein entscheidender Faktor bei der klinischen Risikostratifizierung (s. a. Kap. 1.2.6). Das 5-Jahres-Überleben bei Patienten der GPOH-Studie „NB 97“ zeigte in Abhängigkeit von den verschiedenen Risikogruppen eine große Variabilität: Für die Beobachtungspatienten mit günstiger Prognose lag es bei $96 \%$ und in der Standardrisikogruppe bei $87 \%$, während nur $50 \%$ der Patienten der Hochrisikogruppe überlebten. Fünfjähriges ereignisfreies Überleben konnte bei $84 \%, 72$ $\%$ bzw. $37 \%$ der Patienten beobachtet werden (Ladenstein et al., 2006).

\subsubsection{Histologie}

NB werden morphologisch als graue, noduläre Tumoren beschrieben, die von Pseudokapseln umgeben sind. Das Tumorinnere ist weich und zerfließend und enthält häufig Einblutungen, Verkalkungen und Nekrosen (Bachmann et al., 1990). Die als Neuroblasten bezeichneten schmalen, runden Tumorzellen zeigen keine oder nur wenige Hinweise auf eine neuronale Differenzierung. Partiell differenzierte neuroplastische Tumoren werden als Ganglioneuroblastome (GNB) bezeichnet. Bei Tumoren aus reifen Neuronen, die von einer dichten Schicht Schwannzellen umgeben sind, spricht man von einem Ganglioneurom (GN) (Ladenstein et al., 2006).

Der Grad dieser neuronalen Differenzierung ist von prognostischer Bedeutung, wobei ein hoher Differenzierungsgrad der Tumoren mit einer günstigen Prognose assoziiert ist. Die histologische Einteilung von neuroblastischen Tumoren wie NB, GNB und GN erfolgt nach der Internationalen Neuroblastom Pathologie Klassifikation (INPC) nach Shimada (Shimada et al., 1999). Hierbei wird neben dem Differenzierungsgrad der Neuroblasten der MitoseKaryorrhexie-Index (Anzahl der Mitosen und Karyorrhexien pro 5000 Zellen), das Alter der Patienten bei Diagnose und der Gehalt an Schwannzell-Stroma berücksichtigt. In den USA wird die so bestimmte Tumorhistologie für die Risikoklassifizierung von bestimmten 
Subgruppen hinzugezogen. In Deutschland wird die Tumorhistologie nach INPC-Regeln im Zuge des GPOH-Protokolls „NB 2004“ zwar erhoben, bei der Risikoklassifizierung aber bislang nicht berücksichtigt (persönliche Auskunft Dr. Barbara Hero, Studienverwaltung „NB 2004“, Pädiatrische Onkologie und Hämatologie, Kinderklink Köln). Die Klassifikation wird durchgeführt, um den internationalen Vergleich der Studienergebnisse zu ermöglichen.

Der Gehalt an Schwannzellen ist bei der INPC-Klassifikation berücksichtigt, da gezeigt werden konnte, dass diese Zellen eine antiproliferative und differenzierungsfördernde Wirkung auf Neuroblasten haben (Ladenstein et al., 2006). In allen Ganglioneuroblastomen und Ganglioneuromen können neben den differenzierten Tumorzellen auch Schwannzellen nachgewiesen werden. Es wird angenommen, dass NB-Zellen selbst mitogene, chemotaktische und differenzierungsinduzierende Faktoren ausschütten und dadurch Schwannzellen zur Proliferation und schließlich auch zur Differenzierung anregen können (Ambros \& Ambros, 2000). Der Auslöser für das Einsetzen dieses Differenzierungsprozesses ist allerdings noch unbekannt.

\subsubsection{Klinische Stadieneinteilung}

Die Gruppierung von NB in klinische Tumorstadien erfolgt seit dem Ende des 20. Jahrhunderts nach dem internationalen Klassifikationssystem INSS (International Neuroblastoma Staging System; Brodeur et al., 1993). Der wesentliche Unterschied zur zuvor verwendeten Evans-Klassifikation liegt darin, dass neben klinischen und radiologischen Untersuchungen auch chirurgische und histologische Kriterien einbezogen werden (Ladenstein et al., 2006). Außerdem wird durch die internationale Verwendung des INSS der Vergleich von weltweit durchgeführten NB-Studien erleichtert. Zur Diagnosestellung werden neben allgemeinen Basisuntersuchungen auch spezifische NB-Marker wie Katecholaminmetabolite in Serum oder Urin bestimmt. Die Lokalisierung der Tumoren wird mittels Ultraschall, Röntgen und Kernspinresonanztomographie (MRI) festgestellt und Metastasierung zusätzlich durch Szintigraphie dargestellt. Biopsien geben Auskunft über den Status des Knochenmarks und ermöglichen die histologische und genetische Klassifizierung der Tumoren. Die Tumorstadien 1-4 und 4s werden nach INSS wie folgt definiert: 
Stadium 1 Der Tumor ist auf die Ursprungsregion begrenzt und kann bis auf mikroskopisch sichtbare Rückstände komplett entfernt werden. Ipsilaterale oder kontralaterale Lymphknoten sind mikroskopisch negativ.

Stadium 2a Der Tumor ist auf eine Seite des Körpers begrenzt und kann nicht komplett entfernt werden. Ipsilaterale oder kontralaterale Lymphknoten sind mikroskopisch negativ.

Stadium $2 b \quad$ Der Tumor ist auf eine Seite des Körpers begrenzt und kann oder kann nicht komplett entfernt werden. Ipsilaterale Lymphknoten zeigen Hinweise auf die Erkrankung, aber kontralaterale Lymphknoten sind mikroskopisch negativ.

Stadium 3 Der Tumor überschreitet die Mittellinie und Lymphknoten in diesem Bereich sind befallen bzw. Lymphknoten auf beiden Seiten des Körpers sind befallen. Oder der Tumor ist auf eine Seite des Körpers begrenzt und kontralaterale Lymphknoten sind befallen.

Stadium 4 Der Tumor hat sich durch Metastasierung in Lymphknoten, Knochen, Knochenmark, Leber und / oder andere Organe ausgebreitet. Ausgeschlossen sind Stadium 4s -Tumoren

Stadium 4s Der Tumor ist, wie in den Stadien 1 und 2, auf die Ursprungsregion begrenzt, bildet aber Metastasen in Leber, Haut und/oder Knochenmark (limitiert auf Kinder jünger als $1 \mathrm{Jahr}$ ). Das Knochenmark darf außerdem nur geringfügig $(<10 \%)$ betroffen sein, ansonsten wird der Tumor als Stadium 4 beschrieben.

\subsubsection{Molekularbiologie des NB}

Bei einem Großteil der humanen NB wurden genetische Veränderungen wie chromosomale Aberrationen, Variationen in der Genexpression und in der Ploidität der Zellen nachgewiesen (Oberthür \& Hero, 2004). Es konnte gezeigt werden, dass diese Veränderungen mit klinischen Faktoren korrelieren und eine prognostische Aussagekraft besitzen. Die Amplifikation von MYCN, die Deletion der chromosomalen Abschnitte 1p- und 11q sowie der Zugewinn von genetischem Material auf Chromosom 17q sind die bislang bedeutendsten genetischen Aberrationen und werden im Folgenden nach Aussagekraft geordnet genauer beschrieben. Außerdem wird der Zusammenhang zwischen DNA-Ploidität der Tumorzellen und dem Krankheitsverlauf dargestellt.

\section{MYCN-Amplifikation}

In etwa $20 \%$ der Primärtumoren liegt das MYCN-Onkogen (Chromosom 2p24.1) in einer erhöhten Anzahl vor. Diese bis zu mehrere Hundert Kopien umfassende Genamplifikation ist der bislang zuverlässigste prognostische Faktor und korreliert stark mit fortgeschrittenem Tumorstadium und Therapieversagen (Brodeur et al., 1984; Seeger et al., 1985, Maris et al., 
2007). Auch bei Patienten mit ansonsten günstiger Prognose, etwa bei lokalisierten Tumoren oder im 4s Stadium, ist die $M Y C N$-Amplifikation mit einem ungünstigen Krankheitsverlauf assoziiert (Perez et al., 2000; Katzenstein et al., 1998). Eine in den USA durchgeführte Studie mit 3.000 Patienten zeigt deutlich, dass die MYCN-Amplifikation mit dem Stadium und der 3Jahres-Überlebenswahrscheinlichkeit der Patienten korreliert (s. Tab. 1.1). Passend dazu wurde in vitro gezeigt, dass die gezielte Hemmung von MYCN zu Wachstumsarrest, Apoptose oder Differenzierung von NB-Zellen führt (Kang et al., 2006; Nara et al., 2007).

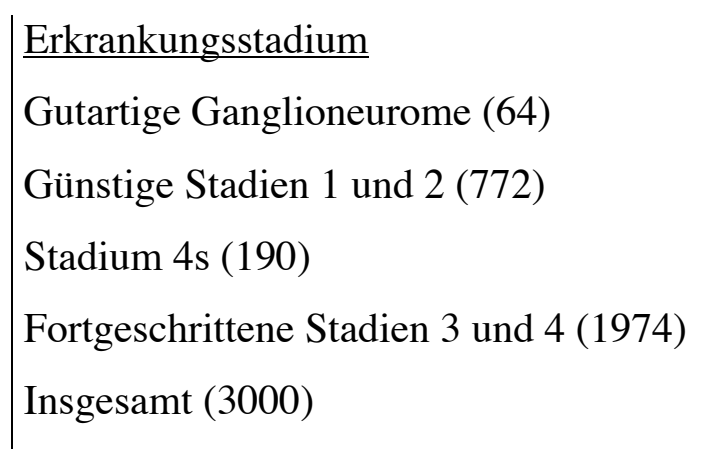

\begin{tabular}{|c|c|} 
MYCN-Ampl. & 3-Jahres-Überleben \\
\hline $0 \%$ & $100 \%$ \\
$4 \%$ & $90 \%$ \\
$8 \%$ & $80 \%$ \\
$31 \%$ & $30 \%$ \\
$22 \%$ & $50 \%$
\end{tabular}

Tab. 1.1: Daten von 3000 Patienten aus kooperativen NB-Studien in den USA (Brodeur, 2003)

MYCN ist ein nukleärer Transkriptionsfaktor, der während der Entwicklung des Zentralnervensystems, der Spinalganglien, der Lungen und der Nieren exprimiert wird (Stanton \& Parada, 1992). Sequenzanalysen des amplifizierten MYCN-Gens zeigen keine bedeutsamen Mutationen in der kodierenden Sequenz. Die Amplifikation resultiert somit in einer erhöhten Expression des Wildtyp-Proteins (Oberthür \& Zero, 2004). Wie diese erhöhte MYCN-Konzentration die Tumorprogression genau beeinflusst, wurde noch nicht geklärt. Bislang konnte gezeigt werden, dass die Amplifikation von $M Y C N$ mit erhöhter Angiogenese in humanen NB-Primärtumoren und experimentellen Tumoren korreliert (Riabatti et al., 2002) und die MYCN-Überexpression die Bildung von Angiogeneseinhibitoren wie beispielsweise Aktivin A erniedrigt (Fotsis et al., 1999; Breit et al., 2000). Eine erhöhte Aktivin A-Expression unterdrückt die Proliferation von humanen NB-Zellen mit $M Y C N$ Amplifikation und inhibiert so das NB-Wachstum in vivo (Schramm et al., 2005).

\section{1p-Deletion}

Eine weitere zur Risikostratifizierung verwendete chromosomale Aberration ist die Deletion des kurzen Arms von Chromosom 1. Diese Aberration kann in 25-35 \% der NB identifiziert werden und korreliert mit $M Y C N$-Amplifikation und fortgeschrittenen Krankheitsstadien 
(Ambros et al., 1995, Caron et al., 1996, Maris et al., 2007). Wahrscheinlich sind ein oder mehrere in dieser Region lokalisierte Gene an der Tumorprogression beteiligt, eine Charakterisierung war aber bislang noch nicht möglich (White et al., 2005). Ob die Deletion in 1p ein unabhängiger Indikator für die Prognose ist, wird kontrovers diskutiert (Maris et al., 2007). Zumindest gibt es Hinweise darauf, dass die Deletion der chromosomalen Region 1p36 ein erhöhtes Rückfallrisiko bei Patienten mit lokalen Tumoren voraussagt (Maris et al., 2000).

\section{1q-Deletion}

Die Deletion der chromosomalen Region 11q tritt bei 35-45 \% der NB auf. Diese Aberration wird selten in Tumoren mit MYCN-Amplifikation beobachtet (Guo et al., 1999), ist aber mit anderen ungünstigen Faktoren assoziiert. In einer Multivarianzanalyse der chromosomalen Regionen 1p36 und 11q23 wurde gefunden, dass der Verlust oder Zugewinn von 11qMaterial als unabhängiger prognostischer Marker mit einer erniedrigten Wahrscheinlichkeit für progressions- und ereignisfreies Überleben von Bedeutung ist (Attiyeh et al., 2005).

\section{7q-Zugewinn}

Mit über $50 \%$ ist der Zugewinn von genetischem Material in der Region 17q, der durch eine unbalancierte Translokation zwischen Chromosom 17 und den Chromosomen 1 oder 11 auftritt, die häufigste chromosomale Aberration in NB. Eine positive Korrelation mit ungünstigen Faktoren wie $M Y C N$-Amplifikation, 1p-Deletion und einem Diagnosealter von einem Jahr oder älter konnte gezeigt werden (Bown et al., 1999). Die genauen Folgen des 17q-Zugewinns sind noch unklar. Allerdings wurde gezeigt, dass bestimmte Gene wie SURVIVIN oder PPMID in den betroffenen Tumoren überexprimiert werden (Islam et al., 2000; Saito-Ohara et al., 2003). Die prognostische Signifikanz des Markers wird zur Zeit noch untersucht (Maris et al., 2007).

Weitere beim NB auftretende Chromosomenaberrationen sind der Verlust der Heterozygotie (loss of heterozygosity $=\mathrm{LOH}$ ) der chromosomalen Regionen 3p, 4p und 14q.

\section{DNA-Ploidität und Krankheitsverlauf}

NB können aufgrund ihres DNA-Gehalts in zwei verschiedene Subtypen eingeteilt werden: In ca. $55 \%$ der Tumoren wird ein triploider (nahe-triploider oder hyperploider) Chromosomensatz nachgewiesen, bei dem es zu einem Zugewinn ganzer Chromosomen kommt. Die restlichen $45 \%$ der Tumoren besitzen einen diploiden (nahe-diploiden) 
Chromosomensatz, weisen aber strukturelle Aberrationen wie die oben beschriebene $M Y C N$ Amplifikation oder 1p-Deletion auf (Ladenstein et al., 2006). Auch wenn durch diese Einteilung nicht deutlich wird, welche spezifischen Veränderungen vorliegen, kann der Ploiditätsstatus trotzdem zur Prognose des Krankheitsverlaufs bei Kindern unter zwei Jahren benutzt werden (Look et al., 1984 \& 1991). Tumoren von Patienten der niedrigen Stadien haben oft triploide Chromosomensätze und es wird vermutet, dass nicht-therapieinduzierte Regressions- und Reifungsprozesse auf die triploiden Untergruppen beschränkt sind (Ambros et al., 1996). Der Verlauf der NB-Erkrankung ist nach Ladenstein et al. (2006) stark abhängig vom Karyotyp der Tumoren und wird unter Einbeziehung der erläuterten genetischen Aberrationen wie folgt dargestellt (Abb. 1.2).

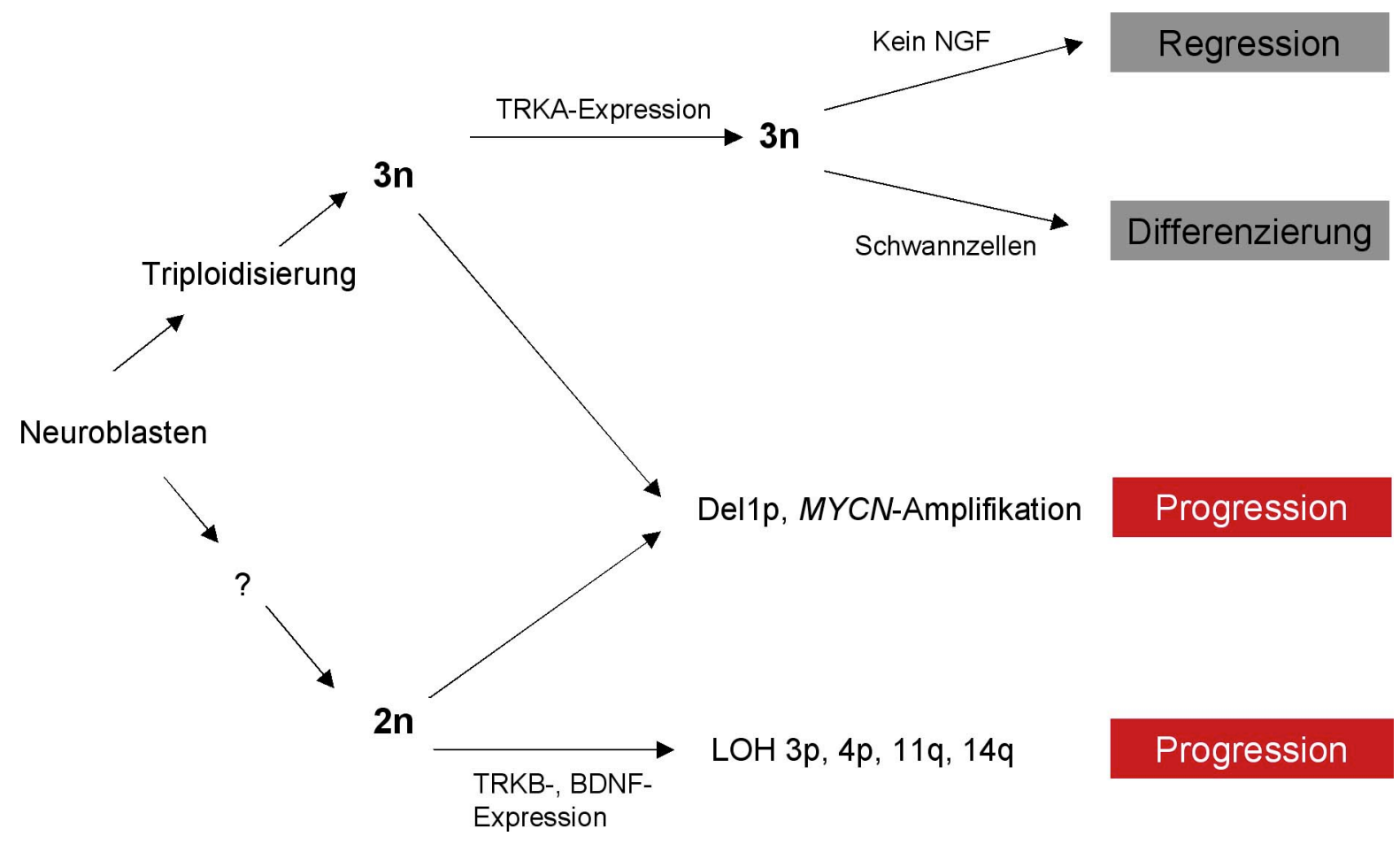

Abb. 1.2: Genese neuroblastischer Tumoren nach Ladenstein et al. (2006)

Wie Abbildung 1.2 zeigt, wird angenommen, dass eine Triploidisierung des Genoms (Kaneko \& Knudson, 2000) zu einem weniger malignen Phänotyp führt, bei dem fast ausschließlich numerische Chromosomenaberrationen gefunden werden können. Zusätzliche strukturelle Aberrationen wie die Amplifikation von $M Y C N$ oder 1p-Deletionen treten nur bei etwa $15 \%$ der triploiden Tumoren nachträglich auf und führen dann zu einer malignen Transformation. Diploide NB, bei denen das tumorinitiierende Ereignis noch unbekannt ist, werden abhängig von der Art ihrer strukturellen Aberrationen in zwei Gruppen eingeteilt: Tumoren mit $M Y C N$ - 
Amplifikationen und 1p-Deletionen werden dabei von Tumoren mit Aberrationen in den chromosomalen Regionen 3p, 4p, 11q oder 14q unterschieden. Beide Gruppen diploider Tumoren sind unabhängig vom Alter der Patienten bei Diagnose oder dem Tumorstadium aggressiv. Wie in der Abbildung vermerkt ist auch die Expression bestimmter Gene mit einer günstigen bzw. ungünstigen Prognose assoziiert. Der Neurotrophin-Rezeptor TRKA spielt durch die Regulation von Überleben, Wachstum und Differenzierung bei der Entwicklung des sympathischen Nervensystems eine wichtige Rolle (Nakagawara, 2001). Die Expression von TRKA ist im humanen NB eng mit einer günstigen Prognose korreliert und das Fehlen der TRKA-Expression mit einer ungünstigen Prognose (Kogner et al., 1993, Nakagawara et al., 1993). Wenn explantierte NB-Zellen mit hoher TRKA-Expression dem TRKA-Liganden NGF (nerve growth factor) ausgesetzt werden, ist eine Differenzierung der Zellen zu beobachten. In Abwesenheit von NGF gehen die Zellen in Apoptose (Nakagawara et al., 1993). Der Neurotrophin-Rezeptor TRKB ist dagegen mit einer ungünstigen Prognose korreliert. Die Expression von TRKB und dem TRKB-Liganden BDNF (brain-derived neurotrophic factor) kann vorwiegend in biologisch ungünstigen Tumoren mit $M Y C N$ Amplifikation nachgewiesen werden (Nakagawara et al., 1994).

Erste genetische Modelle versuchen den entscheidenden Unterschied zwischen den diploiden und triploiden Karyotypen zu erklären: Es wird angenommen, dass triploide Tumoren einen fundamentalen Defekt während der Mitose aufweisen, wodurch es zu einem Zugewinn ganzer Chromosomen kommt. Der Mitosedefekt könnte außerdem die günstige Prognose der Tumoren erklären. Bei diploiden NB wird von Defekten in der genomischen Stabilität ausgegangen, aufgrund derer es zu chromosomalen Umlagerungen, unbalancierten Translokationen und damit zu dem beschriebenen nahe-diploiden DNA-Gehalt kommt (Brodeur, 2003, Maris et al., 2007).

\subsubsection{Risikostratifizierung und Therapie}

Die Einteilung in Risikogruppen erfolgt für NB in Deutschland standardmäßig nach dem „NB 2004“-Protokoll der Gesellschaft für Pädiatrische Onkologie und Hämatologie (GPOH) und ist grundlegend für die Intensität und Länge der anschließenden Therapie. Abhängig vom klinischen Tumorstadium (Einteilung nach INSS, s. Kap. 1.2.4), dem Alter der Patienten bei Diagnose und den prognostischen Markern $M Y C N$-Amplifikation und 1p-Deletion werden die Patienten mit dem Ziel der Therapiereduktion in Beobachtungs-, Standard- und Hochrisikogruppen eingeteilt (s. Abb. 1.3). 


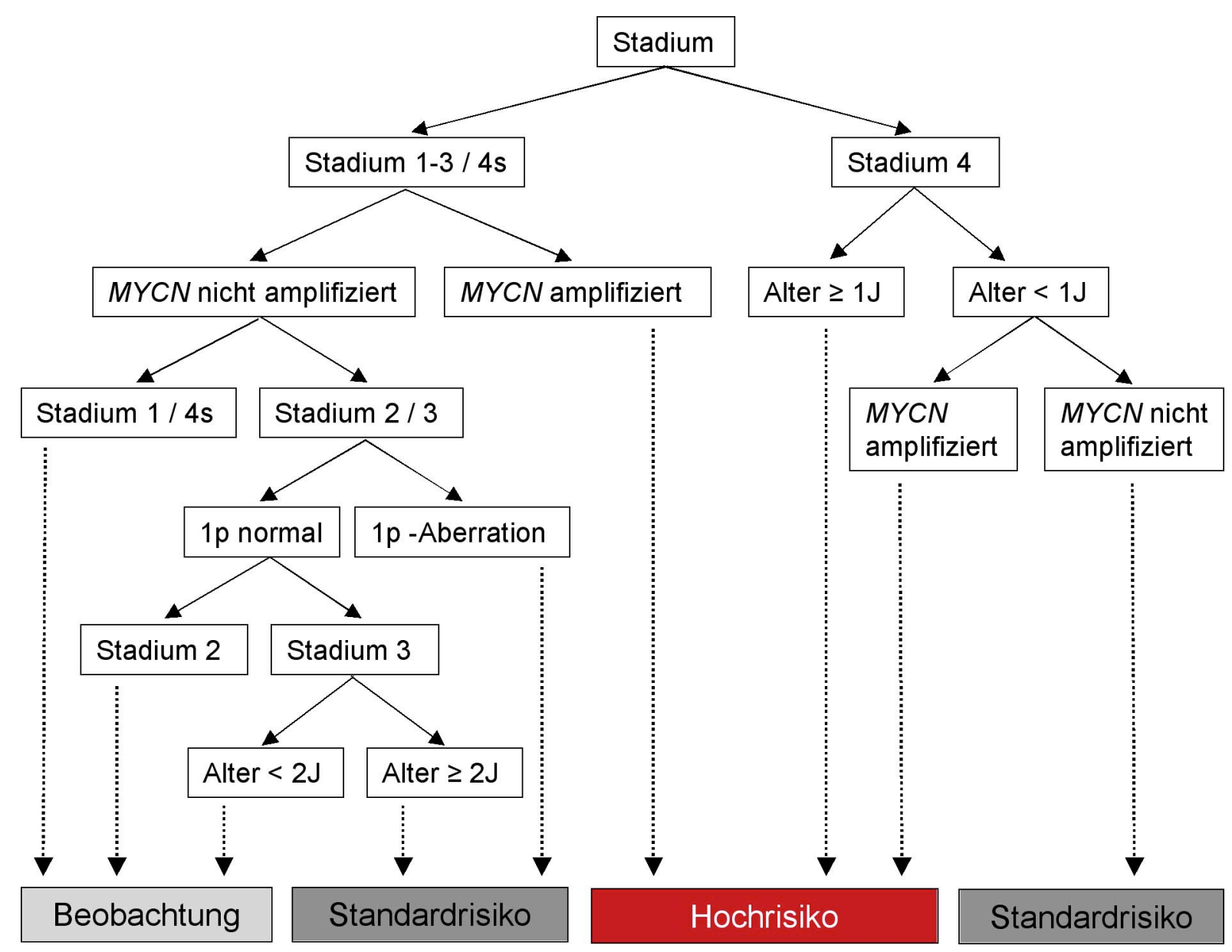

Abb. 1.3: Definition der Risikogruppen nach GPOH Protokoll NB 2004

Das erste GPOH-Protokoll zur systematischen Behandlung von NB wurde 1979 im Rahmen einer kooperativen Studie von der Gesellschaft für Pädiatrische Onkologie und Hämatologie $(\mathrm{GPOH})$ aufgestellt und seitdem kontinuierlich weiterentwickelt. 1995 wurde die Amplifikation von $M Y C N$ als erster genetischer Marker nachträglich in das GPOHBehandlungsprotokoll „NB 1990“ für Säuglinge aufgenommen und festgelegt, Chemotherapie nur in Fällen mit $M Y C N$-Amplifikation anzuwenden. Bei der erneuten Überarbeitung des Protokolls im Jahre 1997 wurde MYCN als allgemein gültiger Marker übernommen und $2004 \mathrm{kam}$ als zweiter genetischer Marker die 1p-Deletion hinzu (persönliche Auskunft Dr. Barbara Hero, Studienverwaltung „NB 2004“, Pädiatrische Onkologie und Hämatologie, Kinderklink Köln). Aufgrund fehlender Standardisierungen, geringem prognostischen Mehrwert oder weil größere klinische Studien noch ausstehen, konnten bislang keine weiteren genetischen Faktoren zur Risikoklassifizierung eingesetzt werden. 
Der Versuch die Therapie von NB durch Programme zur Früherkennung zu verbessern, blieb bislang erfolglos. Ein Screening, bei dem durch den Nachweis von Katecholaminmetaboliten im Urin klinisch noch stumme NB bei Säuglingen diagnostiziert wurden, führte zwar zu einem starken Anstieg der Inzidenz. Die Sterberate konnte dadurch jedoch nicht reduziert werden, da, wie bereits erwähnt, ein Großteil der Tumoren mit oder ohne Diagnose eine Spontanremission erfährt (Woods et al., 2002; Schilling et al., 2002). Diese Studien machen deutlich, wie wichtig die weitere genetische Charakterisierung von NB für die Diagnose und Therapie der Tumorentität ist. Die Identifizierung von neuen genetischen Markern kann helfen, hoch maligne Tumoren effizient zu bekämpfen und gleichzeitig bei Säuglingen und Kleinkindern mit niedrig-malignen Tumorstadien eine Therapiereduktion zu erzielen. Das Glykoproteinhormon Stanniocalcin 2 (STC2) ist ein viel versprechender Kandidat für diese Untersuchungen. Becker und Mitarbeiter konnten zeigen, dass in Keratoepithelintransfizierten NB-Zellen eine verstärkte STC2-Expression auftritt während gleichzeitig das Tumorwachstum inhibiert ist (Becker et al., 2006).

\subsection{Stanniocalcin 2}

STC2 wurde vor zehn Jahren erstmals in der Forschung erwähnt, dem Protein konnten aber bislang noch keine eindeutigen Funktionen zugeordnet werden. Verschiedene Veröffentlichungen weisen darauf hin, dass das Molekül eine Rolle bei der Tumorprogression spielt. So konnte beispielsweise gezeigt werden, dass die STC2-Expression bei Brustkrebs mit einer günstigen Prognose korreliert. Die Forschungsergebnisse aus der oben beschriebenen Veröffentlichung von Becker et al. (2006) haben den Zusammenhang zum NB hergestellt und den Anstoß gegeben, die Bedeutung von STC2 im humanen NB zu untersuchen und zu prüfen, ob die STC2-Expression mit einer günstigen Prognose korreliert. In den folgenden Abschnitten wird das Molekül vorgestellt und der momentane Wissensstand als Grundlage der vorliegenden Arbeit zusammengefasst.

\subsubsection{Stanniocalcin-Proteinfamilie}

Stanniocalcin (Stc) wurde erstmals beim Knochenfisch beschrieben, wo es von speziellen Drüsen, den Stanniuskörperchen (corpuscles of Stannius) sezerniert wird (Stannius, 1839). Die Annahme, dass das Molekül ausschließlich bei Fischen vorhanden ist, wurde durch Chang et al. (1995) widerlegt. Diese konnten bei Mensch und Maus eine cDNA identifizieren, deren vorausgesagte Aminosäuresequenz zu $60 \%$ mit dem Fischprotein übereinstimmt und in Anlehnung daran als STC beschrieben wurde. Ausgehend von der STC-Aminosäuresequenz 
wurde ein weiteres Protein bei Mensch und Maus identifiziert (Chang \& Reddel, 1998; DiMattia et al., 1998; Ishibashi et al., 1998). Dieses als STC2 beschriebene Molekül ist zu ca. $35 \%$ mit dem bei Fischen identifizierten Stc und dem ersten humanen STC-Protein (STC1) identisch. Kürzlich wurde ebenfalls ein zweites Stc bei Fischen (fStc2) entdeckt. Dieses besitzt eine 30 \%ige Übereinstimmung zum ersten Fisch Stc (fStc1) wurde jedoch noch nicht weiter untersucht. Phylogenetische Analysen und der Vergleich der Struktur der Stc-Gene von Wirbeltieren weisen darauf hin, dass es ein gemeinsames Vorläufergen gibt (Luo et al., 2005). Mittlerweile wurde Stc auch bei Ratte, Haushuhn (Gallus gallus domesticus), Krallenfrosch, Zebrafisch und Blutegel identifiziert (Mittapalli et al., 2006; Tanega et al., 2004).

\subsubsection{Chromosomale Lokalisation und Genstruktur}

Die vier Exons des humanen STC2-Gens sind auf Chromosom 5q35 lokalisiert und über einen Bereich von etwa 16.000 bp verteilt (Ishibashi et al., 1998; s. Abb. 1.4). Die Exon-IntronGrenzen zwischen humanem STC1 und STC2 sind dabei vollständig evolutionär konserviert (Chang et al., 2003).

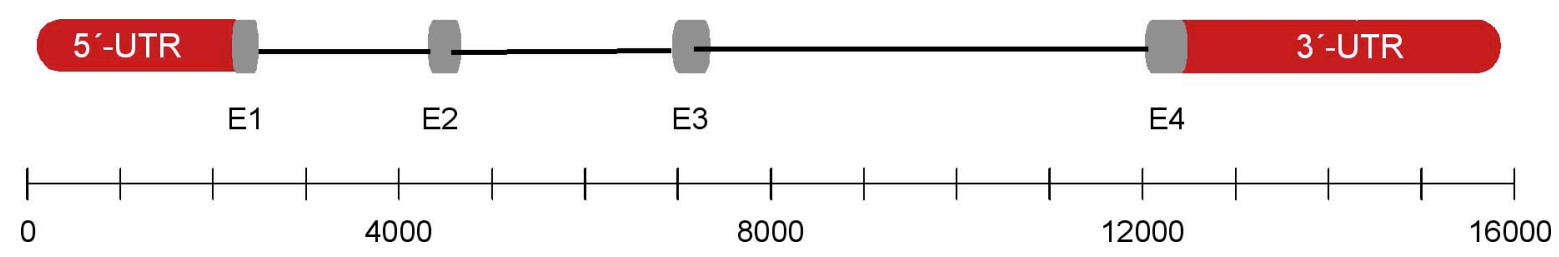

Abb. 1.4: Struktur des humanen STC2-Gens, dargestellt nach Angaben der NCBI-Datenbank (http://www.ncbi.nlm.nih.gov/entrez/viewer.fcgi?val=NM_003714.2). Der kodierende Bereich ist grau und die UTR rot dargestellt.

Die bereits gespleißte aber noch nicht polyadenylierte Prä-mRNA besteht aus knapp 5.400 bp mit einer 906 bp-langen kodierenden Sequenz (s. Abb. 1.5, Start-Stop). Die 3'-untranslatierte Region (3'-UTR) enthält zwei Polyadenylierungssignale (pA; 1687 bp und 4032 bp hinter dem Startcodon) und bietet somit die Möglichkeit zur alternativen Polyadenylierung. Bei Northern Blot Analysen wurden STC2-Transkripte von ca. 2 und 4,4 kb identifiziert (Chang et al., 2003). 


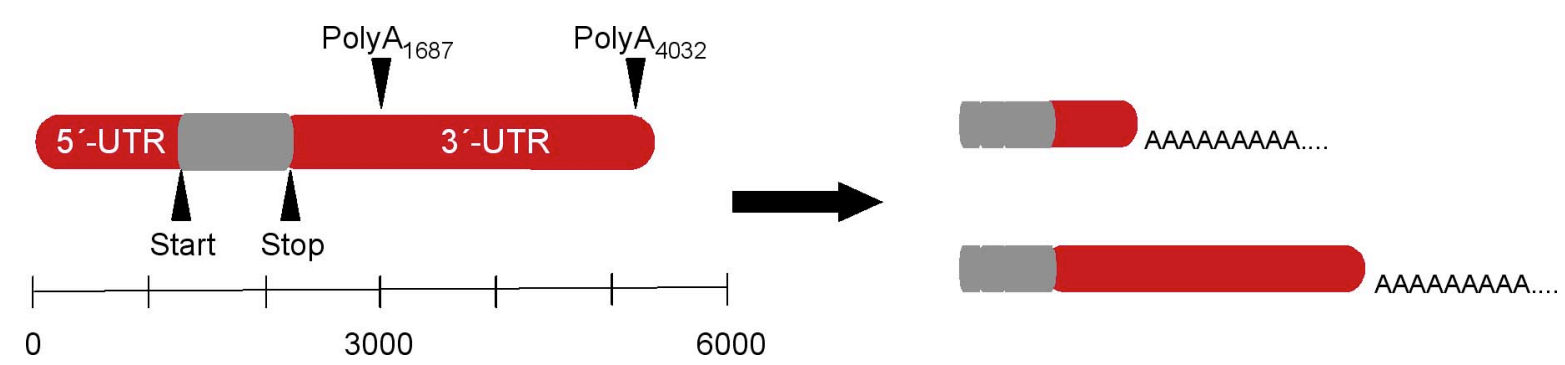

Abb. 1.5: Prä-mRNA-Struktur und alternative STC2-Transkripte dargestellt nach Angaben der NCBIDatenbank (http://www.ncbi.nlm.nih.gov/entrez/viewer.fcgi?val=NM_003714.2). Der kodierende Bereich ist grau und die UTR rot dargestellt.

Es ist bekannt, dass bestimmte regulatorische Elemente in der 3'-UTR die mRNA-Stabilität (Touriol et al., 1999), die translationale Effizienz (Knirsch \& Clerch, 2000) sowie die intrazelluläre Lokalisation (Kislauskis et al., 1994) von Transkripten beeinflussen können. Über derartige regulatorische Elemente in der 3'-UTR von STC2 liegen aber bislang noch keine Daten vor.

\subsubsection{Proteinstruktur}

Die STC2-Proteinsequenz besteht aus 302 Aminosäuren (AS). Nach der Prozessierung des 24-AS-langen Signalpeptids wird das reife Protein sezerniert. Eine Besonderheit liegt in der Konservierung von Cysteinresten: 10 der 15 Cysteine in STC2 sind auch in humanem STC1 und fStc1 vorhanden und an der Homodimerisierung des Proteins beteiligt (Moore et al., 1999). STC2 wird außerdem N-terminal glykosyliert (Luo et al., 2005) und nach der Sekretion an Serinresten phosphoryliert (Jellinek et al., 2000). Eine weitere Besonderheit von STC2 ist die Ansammlung von 15 Histidinen, wobei sich 4 davon am C-terminalen Ende des Proteins befinden (Moore et al., 1999). Die anhand der Aminosäuresequenz kalkulierte Größe des STC2-Proteins liegt bei $33 \mathrm{kDa}$ und beinhaltet das 2,6 kDa-lange Signalpeptid. Der isoelektrische Punkt des Proteins liegt laut Chang \& Reddel (1998) voraussichtlich bei 7,1. Humanes STC1 und STC2 zeigen keine signifikanten Homologien zu weiteren bekannten Proteinen und enthalten keine bekannten Proteinmotife (Wagner \& DiMattia, 2006).

\subsubsection{STC-Funktion: Vom Fisch zum Menschen}

Die Rolle von STC scheint sich evolutiv zu verändern (Ishibashi et al., 1998). Das Molekül wurde bei Fischen bereits gut untersucht und es konnte gezeigt werden, dass es eine antihypercalcämische Funktion ausübt: Die Calciumaufnahme über die Kiemen wird durch fStc1 
verlangsamt, wobei der extrazelluläre Calcium-Ionenspiegel von Membran-assoziierten Rezeptoren überwacht wird, die die fStc1-Ausschüttung kontrollieren (Radman et al , 2002). Der intestinale Calciumtransport wird ebenfalls durch fStc1 gehemmt (Sundell et al., 1992). Außerdem konnte gezeigt werden, dass die Reabsorption von anorganischem Phosphat gefördert wird (Lu et al., 1994), möglicherweise um Calcium zur Ablagerung im Knochen zu komplexieren (Wagner et al., 1997). Die Funktionen von STC1 und STC2 im Menschen sind hingegen noch unklar. Zwar konnte gezeigt werden, dass humanes STC1 den Calciumtransport in Fischkiemen hemmt (Wagner \& DiMattia, 2006) und die Überexpression in Mäusen eine Hyperphosphatämie bewirkt (Varghese et al., 2002). Eine wichtige oder ausschließliche Rolle im Mineralstoffwechsel, wie anfangs angenommen, ist allerdings unwahrscheinlich, da die Hemmung von Stc1 und Stc2 bei Mäusen nicht zu Veränderungen im Serum-Calcium und Phosphatspiegel führt (Gagliardi et al., 2005; Chang et al., 2008). Außerdem werden die bei Fischen für Stc beschriebenen Funktionen bei Menschen durch andere Hormone, wie z. B. Calcitonin ausgeübt. Die STC-Proteine werden im Menschen auch nicht von einem speziellen Drüsengewebe gebildet, wie den Stanniuskörperchen bei Fischen, sondern finden sich in verschiedenen embryonalen und adulten Geweben sowie in einigen Tumorzelllinien. Die höchsten STC1-Expressionen wurden in Ovarien, Nieren, Prostata und Schilddrüse nachgewiesen (Chang et al., 2003). STC2 wird unter anderem in Herz, Nieren, Pankreas und Skelettmuskel sowie im Uterus und der Prostata exprimiert (Chang et al., 2003; Wagner \& DiMattia, 2006). Das weite Expressionsspektrum der humanen STC-Proteine spricht ebenfalls dafür, dass Ihre Rolle beim Menschen über die beim Fisch beschriebenen endokrinen Funktionen hinausgeht.

\subsubsection{STC1 und STC2 bei Menschen und Säugetieren}

Trotz der beschriebenen Konservierung bestimmter struktureller Elemente gibt es deutliche Unterschiede zwischen humanem STC1 und STC2. Das humane STC2-Protein ist etwa $20 \%$ größer und hat, in Fischen angewendet, im Gegensatz zu humanem STC1 keinen Effekt auf die Kalziumaufnahme über die Kiemen (Wagner \& DiMattia, 2006). Stc1 wurde im Serum von Mäusen und Ratten während der Trächtigkeit gefunden, wogegen Stc2 nicht nachgewiesen werden konnte (Hasilo et al., 2005; Deol et al., 2000). STC1 ist in Leber- und Nierenzellen in den Mitochondrien lokalisiert (McCudden et al., 2002), während Stc2 in Maus-NB-Zellen (N2A-Zelllinie) im endoplasmatischen Retikulum und dem Golgi Apparat nachgewiesen werden konnte (Ito et al., 2004). STC2 wird in der Zellkultur immer im Überstand gefunden, während STC1 auch intrazellulär nachgewiesen wurde und 
möglicherweise ein externer Stimulus für die Sekretion erforderlich ist (Chang et al., 2003, Jellinek et al., 2000). Außerdem ist STC2 nur eingeschränkt in der Lage, STC1 von dem für das Molekül beschriebenen Rezeptor zu verdrängen (McCudden et al., 2002, Hasilo et al., 2005). Für STC2 konnte bislang noch kein Rezeptor oder Interaktionspartner identifiziert werden. In einigen Untersuchungen wurden STC1 und STC2 sogar gegenläufig reguliert gefunden: In undifferenzierten Maus-NB-Zellen N2A ist vor der Differenzierungsinduktion mit dbcAMP lediglich die Expression von Stc2 nachweisbar. Nach der Induktion neuronaler Differenzierung wird Stc1 verstärkt exprimiert, während Stc2 nur noch eine schwache Expression zeigt (Wong et al., 2002). Andererseits beschreiben Wagner \& DiMattia (2006) eine überlappende Funktion der Moleküle im Mausmodel. Die Überexpression von humanem STC1 bzw. STC2 in transgenen Mäusen (Varghese et al., 2002; Gagliardi et al., 2005) beeinflusst in beiden Fällen das Knorpel- und Knochenwachstum der Tiere und führt zu einer Wachstumsverzögerung, die laut Wagner \& DiMattia (2006) auf Veränderungen im zellulären Metabolismus zurück zu führen ist.

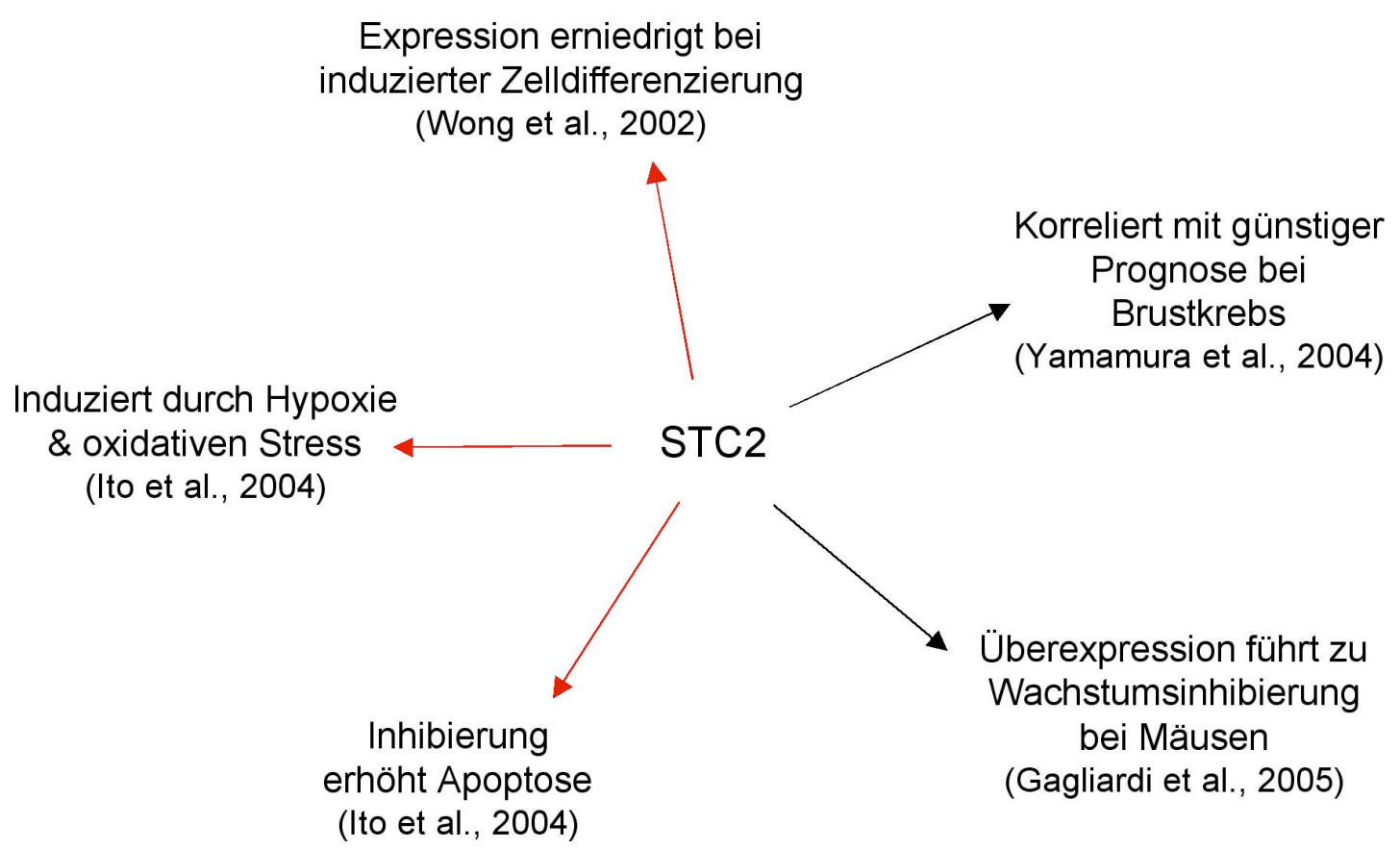

Abb. 1.6: Hinweise auf eine heterogene Rolle von STC2 bei Krebserkrankungen: Rote Pfeile kennzeichnen Effekte, die bei Krebs eine schlechte Prognose begünstigen, die schwarzen Pfeile sind kennzeichnend für günstige Bedingungen.

Die folgenden Veröffentlichungen über humanes STC2 weisen darauf hin, dass das Molekül bei Krebserkrankung in verschiedener Weise zu agieren scheint (s. Abb. 1.6). Ito et al. (2004) konnten zeigen, dass die Inhibierung von Stc2 Maus-NB-Zellen (N2A) empfänglicher für 
apoptotische Reize macht und die STC2-Expression in neuronalen Zellen durch Hypoxie und oxidativen Stress induziert wird. Im NB korreliert Zelldifferenzierung mit einer günstigen Entwicklung der Tumoren. Wie bereits erwähnt, wird in Maus-NB-Zellen durch Induktion der Zelldifferenzierung die Stc2-Expression erniedrigt (Wong et al., 2002). Bei Brustkrebs ist die Expression von STC2 dagegen mit einer günstigen Prognose korreliert (Yamamura et al., 2004). Die Wahrscheinlichkeit für ein fünfjähriges ereignisfreies Überleben bei Hormonrezeptor-positivem Brustkrebs ist für Patienten mit hoher STC2-Expression von 64 \% auf $90 \%$ erhöht. Und eine verstärkte STC2-Expression konnte auch in humanen NB-Zellen nachgewiesen werden, bei denen die Fähigkeit zur Tumorbildung gehemmt ist (Becker et al. , 2006). Das Expressionsprofil dieser NB-Zellen zeigte im Vergleich zum Wildtyp eine 2,5fache Erhöhung der STC2-Expression.

Aufgrund der Vorarbeiten von Becker et al. (2006) im NB und der Korrelation von STC2 mit einer günstigen Prognose bei Brustkrebs haben wir die Hypothese aufgestellt, dass STC2 eine Rolle im humanen NB spielt und die Expression des Moleküls mit einem günstigen Verlauf der Erkrankung in Zusammenhang stehen könnte.

\subsection{Zielsetzung}

Das Ziel meiner Arbeit ist es, die Funktion von STC2 im humanen Neuroblastom zu untersuchen und zu prüfen, ob STC2 mit einer günstigen Prognose korreliert. Beim Menschen konnte dem Molekül noch keine eindeutige physiologische Funktion zugeordnet werden und im Zusammenhang mit Krebserkrankungen wurden die Funktionen von STC2 widersprüchlich beschrieben. Beim humanen NB handelt es sich um eine klinisch und genetisch sehr heterogene Tumorentität. Viele Patienten in den schnell fortschreitenden Tumorstadien versterben trotz intensiver Therapie, während bei Kleinkindern mit günstigen Tumorstadien Differenzierung und spontane Tumorregression zu beobachten sind. Mit der Untersuchung von STC2 wird ein neues Molekül in die NB-Forschung eingebracht. Seine Aussagekraft zur Charakterisierung von Tumoren und seine Bedeutung für die Tumorprogression soll geprüft werden. Zur Umsetzung meiner Ziele wollte ich in NBZelllinien und Primärtumoren die Expression von STC2-mRNA und -Protein untersuchen und mit klinischen Markern korrelieren. Außerdem habe ich geplant, STC2 in humanen NBZellen zu überexprimieren, um anhand der transfizierten Zellen die Funktionen von STC2 in vitro und in vivo zu erforschen. Insbesondere wollte ich die transfizierten Zellen im Bezug auf Proliferation, Invasivität und ihre Fähigkeit zur Tumorbildung untersuchen. Die Verwendung 
von gereinigtem STC2-Protein ermöglicht außerdem, die Funktion des Moleküls isoliert zu betrachten und so Effekte sekundärer Faktoren zu minimieren. 


\section{Material}

Die im Zuge dieser Arbeit verwendeten Geräte, Chemikalien und Materialien werden im Folgenden aufgelistet:

\subsection{Verbrauchsmaterial und Geräte}

Die für den täglichen Laborbedarf verwendeten Verbrauchsmaterialien wie Reaktionsgefäße, Pipettenspitzen, Zellkulturplatten, etc. wurden von den Firmen Eppendorf (Hamburg), Sarstedt (Nürnbrecht), Sartorius (Göttingen), Greiner (Nürtingen), Brand (Wertheim) und Becton Dickinson (Heidelberg) bezogen. Die regelmäßig verwendeten Geräte sind in Tabelle 2.1 aufgeführt:

\begin{tabular}{|l|l|}
\hline Gerätetyp & Hersteller/Vertreiber \\
\hline Analysewaage Sartorius Excellence & Sartorius; Göttingen \\
\hline Autoklav FNR 3832 E & Fedegari; Albuzzano, Italien \\
\hline Blot Kammer Fastblot B44 & Biometra; Göttingen \\
\hline CO$_{2}$-Inkubator Typ 3336 & Forma Scientific; Marietta, OH \\
\hline Durchflusszytometer FACScan & Becton Dickenson; San Diego, CA \\
\hline Elektroporator EasyjecT plus D2000 & EquiBio; Kent, UK \\
\hline Entwicklermaschine Optimax Typ TR & MS Laborgeräte; Wiesloch \\
\hline Gelelektrophorese-Kammer H5 & BRL; Gaithersburg, MD \\
\hline Gradientencycler T-Gradient & Biometra; Göttingen \\
\hline Kamera DC 300 Fx & Leica Microsystems; Wetzlar \\
\hline Kryotom CM3050 S & Leica Microsystems; Wetzlar \\
\hline Mikroskop 5000B (Hellfeld \& Fluoreszenz) & Leica Microsystems; Wetzlar \\
\hline Mikroskop DMIRB (Hellfeld \& Fluoreszenz) & Leica Microsystems; Wetzlar \\
\hline Mikrotiterplatten-Lesegerät Tecan Sunrise & TECAN Deutschland GmbH; Crailsheim \\
\hline NanoDrop ND-1000 Spektralphotometer & Thermo Scientific; Wilmington, DE \\
\hline Neubauer-Zählkammer & Roth; Karlsruhe \\
\hline Partikelzähler Coulter 21 & Beckman Coulter GmbH; Krefeld \\
\hline pH-Meter & Pharmacia LKB Biotech.; Uppsala, Sweden \\
\hline Real-time PCR System ABI Prism & Applied Biosystem; Foster City, CA \\
\hline Schneidegerät Ultracut E & Reichert \& Jung; Heidelberg \\
\hline Schüttler Environm. Incubator Shaker G24 & New Brunswick Scientific; Edison, NJ \\
\hline Sequenzierer 3100 Avant Genetic Analyzer & Applied Biosystem; Foster City, CA \\
\hline
\end{tabular}




\begin{tabular}{|l|l|}
\hline Gerätetyp & Hersteller/Vertreiber \\
\hline Spannungsgerät Biorad Power Pac 3000 & Biorad; München \\
\hline Spannungsgerät Consort E455 & LMS GmbH; Dossenheim \\
\hline Stereomikroskop MZ FL III & Leica Microsystems; Wetzlar \\
\hline Sterilbank KR-105 & Kojair; Vilppula, Finnland \\
\hline Sterilbank LaminAir HB2448 & Heraeus Instruments GmbH; Osterode \\
\hline Thermocycler T3 & Biometra; Göttingen \\
\hline Thermomixer kompakt & Eppendorf; Hamburg \\
\hline Trockenschrank Typ B20 & Memmert; Schwabach \\
\hline UV-Transilluminator System & INTAS; Göttingen \\
\hline Vortex VF2 & Janke\&Kunkel; IKA-Labortechnik, Staufen \\
\hline Wasserbad Typ 1003 & Gesellschaft für Labortechnik; Burgwedel \\
\hline Zentrifuge 5415R & Eppendorf; Hamburg \\
\hline Zentrifuge 5810R & Eppendorf; Hamburg \\
\hline
\end{tabular}

Tab. 2.1: Geräte und ihre Hersteller

\subsection{Chemikalien und Biochemikalien}

Die im Rahmen meiner Arbeit verwendeten Substanzen wurden in Analysequalität von den im Folgenden angegebenen Firmen bezogen:

\begin{tabular}{|c|c|}
\hline Substanz & Hersteller/Vertreiber \\
\hline Aceton & Merck; Darmstadt \\
\hline Acrylamid-Lösung Rotiphorese Gel 30 & Roth; Karlsruhe \\
\hline $\mathrm{AgNO}_{3}$ & Merck; Darmstadt \\
\hline APS & Serva; Heidelberg \\
\hline ATP $(10 \mathrm{mM})$ & Roche; Mannheim \\
\hline Azur II-Farbstoff & Merck; Darmstadt \\
\hline BenchMark Prestained Protein Ladder & Invitrogen; Karlsruhe \\
\hline BenchMark Protein Ladder & Invitrogen; Karlsruhe \\
\hline Beta- $(\beta)$-Mercaptoethanol & Roth; Karlsruhe \\
\hline Borax & Merck; Darmstadt \\
\hline Bromphenolblau & Sigma-Aldrich; München \\
\hline Bsa & Sigma-Aldrich; München \\
\hline Bsa-Standardlösung & Pierce; Rockford, IL \\
\hline
\end{tabular}




\begin{tabular}{|c|c|}
\hline Substanz & Hersteller/Vertreiber \\
\hline $\mathrm{CaCl}_{2}$ & Sigma-Aldrich; München \\
\hline Chloroform & Sigma-Aldrich; München \\
\hline Coomassie-Brilliant-Blue R 250 & Merck; Darmstadt \\
\hline Coulter Isoton II Diluent & Beckman Coulter GmbH; Krefeld \\
\hline DDSA & Roth; Karlsruhe \\
\hline Desthiobiotin & IBA; Göttingen \\
\hline DMSO & Sigma-Aldrich; München \\
\hline DNA Gene Ruler & Invitrogen; Karlsruhe \\
\hline dNTP-Mix & Roth; Karlsruhe \\
\hline DPBS & Lonza; Basel, Schweiz \\
\hline DTT & Sigma-Aldrich; München \\
\hline EDTA & Sigma-Aldrich; München \\
\hline Eosin & Roth; Karlsruhe \\
\hline Essigsäure (Eisessig) & Merck; Darmstadt \\
\hline Ethanol & Roth; Karlsruhe \\
\hline Formamid & Merck; Darmstadt \\
\hline G418 (Geneticin) & Invitrogen; Karlsruhe \\
\hline Glutaraldehyd & Serva; Heidelberg \\
\hline Glycidether 100 & Roth; Karlsruhe \\
\hline Glycin & Gerbu; Gaiberg \\
\hline HABA & IBA; Göttingen \\
\hline Hämatoxylinlösung nach Gill II & Roth; Karlsruhe \\
\hline Harnstoff & Merck; Darmstadt \\
\hline $\mathrm{HCl}(1 \mathrm{~N})$ & Merck; Darmstadt \\
\hline Hefeextrakt & Roth, Karlsruhe \\
\hline HEPES (1 M) & Invitrogen; Karlsruhe \\
\hline Isopropanol & Roth; Karlsruhe \\
\hline $\mathrm{K}_{2} \mathrm{HPO}_{4}$ & Roth; Merck \\
\hline Kanamycin & Gerbu; Gaiberg \\
\hline $\mathrm{KCl}$ & Merck; Darmstadt \\
\hline $\mathrm{KH}_{2} \mathrm{PO}_{4}$ & Merck; Darmstadt \\
\hline Kristallviolett & Roth; Karlsruhe \\
\hline
\end{tabular}




\begin{tabular}{|c|c|}
\hline Substanz & Hersteller/Vertreiber \\
\hline Methanol & Roth; Karlsruhe \\
\hline Methylenblau & Merck; Darmstadt \\
\hline $\mathrm{MgSO}_{4}$ & Merck; Darmstadt \\
\hline Milchpulver (Non fat dry milk) & Biorad; München \\
\hline MNA & Roth; Karlsruhe \\
\hline $\mathrm{Na}_{2} \mathrm{CO}_{3}$ & Sigma-Aldrich; München \\
\hline $\mathrm{Na}_{2} \mathrm{HPO}_{4}$ & Merck; Darmstadt \\
\hline $\mathrm{Na}_{2} \mathrm{~S}_{2} \mathrm{O}_{3} \times 5 \mathrm{H}_{2} \mathrm{O}$ & Merck; Darmstadt \\
\hline NaCitrat & Merck; Darmstadt \\
\hline $\mathrm{NaCl}$ & Roth; Karlsruhe \\
\hline $\mathrm{NaN}_{3}$ & Merck; Darmstadt \\
\hline Osmium & Roth; Karlsruhe \\
\hline Paraformaldehyd & Sigma-Aldrich; München \\
\hline Propidiumiodid & Sigma-Aldrich; München \\
\hline Propylen & Sigma-Aldrich; München \\
\hline Rekombinantes STC2 aus E. coli & Abcam; Cambridge, UK \\
\hline RNase-Inhibitor rRNAsin & Promega; Madison, WI \\
\hline Saccharose & Merck; Darmstadt \\
\hline SDS & Gerbu; Gaiberg \\
\hline Staurosporin & Sigma-Aldrich; München \\
\hline Temed & Roth; Karlsruhe \\
\hline Tris & Roth; Karlsruhe \\
\hline Triton X 100 & Serva; Heidelberg \\
\hline Trizol & Invitrogen; Karlsruhe \\
\hline Tryphan Blau-Lösung $(0,4 \%)$ & Sigma-Aldrich; München \\
\hline Trypton & Roth; Karlsruhe \\
\hline Tween 20 & Roth; Karlsruhe \\
\hline
\end{tabular}

Tab. 2.2: Chemikalien und Biochemikalien

\subsection{Gebrauchsfertige Reaktionssysteme (Kit's)}

\begin{tabular}{|l|l|}
\hline Reaktionssysteme & Hersteller/Vertreiber \\
\hline BigDye Terminator v3.1 Cycle Sequencing Kit & Applied Biosystem; Foster City, CA \\
\hline
\end{tabular}




\begin{tabular}{|l|l|}
\hline Reaktionssysteme & Hersteller/Vertreiber \\
\hline Cell Death Detection ELISA & Roche; Mannheim \\
\hline DNeasy Kit & Qiagen; Hilden \\
\hline Mycoplasma PCR Detection Kit Venor GeM & Minerva Biolabs; Berlin \\
\hline Omniscript RT Kit & Qiagen; Hilden \\
\hline Plasmid Mini Kit & Qiagen; Hilden \\
\hline QIAquick Gel Extraction Kit & Qiagen; Hilden \\
\hline QIAquick PCR Purification Kit & Qiagen; Hilden \\
\hline SYBR Green JumpStart Taq ReadyMix & Sigma-Aldrich; München \\
\hline
\end{tabular}

Tab. 2.3: Gebrauchsfertige Reaktionssysteme

\subsection{Enzyme}

\begin{tabular}{|l|l|}
\hline Enzyme & Hersteller/Vertreiber \\
\hline Biotherm DNA Polymerase $(1 \mathrm{u} / \mu \mathrm{l})$ & Genecraft; www.genecraft.de \\
\hline DyNAzyme EXT II Polymerase $(5 \mathrm{u} / \mu \mathrm{l})$ & Finnzymes; Espoo, Finnland \\
\hline NheI-Restriktionsendonuklease & MBI Fermentas; St. Leon-Rot \\
\hline T4-Ligase & Roche; Mannheim \\
\hline XcmI- Restriktionsendonuklease & New England Biolabs; Frankfurt \\
\hline XhoI-Restriktionsendonuklease & MBI Fermentas; St. Leon-Rot \\
\hline
\end{tabular}

Tab. 2.4: Enzyme

\subsection{Oligonukleotide}

Die im Rahmen meiner Arbeit verwendeten Oligonukleotide (Primer) wurden standardmäßig von den Firmen ThermoFisher (Ulm) und IBA (Göttingen) synthetisiert. Die Basensequenzen sind im Folgenden aufgelistet.

\begin{tabular}{|l|l|}
\hline Primerbezeichnung & Basen-Sequenz (bzw. Hersteller) \\
\hline bAkas & 5'-GGATCTTCATGAGGTAGTCAGTC-3' \\
\hline bAks & 5'-CCTCGCCTTTGCCGATCC-3' \\
\hline bAkfwd & 5'-TGAAGATCAAGATCATTGCTCC-3' \\
\hline bAkrev & 5'-CACGAAAGCAATGCTATCACC-3' \\
\hline bAkfwdR (Real-time) & 5'-GCATCCCCCAAAGTTCACAA-3' \\
\hline bAkrevR (Real-time) & 5'-AGGACTGGGCCATTCTCCTT-3' \\
\hline E1fwd & 5'-CGGCTTCCTCCTGTAGTAGTTGA-3' \\
\hline
\end{tabular}




\begin{tabular}{|c|c|}
\hline Primerbezeichnung & Basen-Sequenz (bzw. Hersteller) \\
\hline E1rev & 5'-CGTGCCATCCCAAGAGTTTG-3' \\
\hline E2fwd & 5'-AAGGAGCCTGCAACCTCTGAT-3' \\
\hline E2rev & 5'-GTGGGCTTTGGAGACTGAGTT-3' \\
\hline E2seq & 5'-CCAGCATGGGTTAGAGTTTTG-3' \\
\hline E3fwd & 5'-AGGAGGGAGATGTGTTCGTCTA-3' \\
\hline E3rev & 5'-GGCTAAGGGGAAGATGAAGAGT-3' \\
\hline E4fwd & 5'-GGCTTGAAGTCATTTGAGAGAGA-3' \\
\hline E4rev & 5'-GCTCCCTTGAGTACGTGTAAGTG-3' \\
\hline MYCNfwd (Real-time) & 5'- CGGGCATGATCTGCAAGAA-3' \\
\hline MYCNrev (Real-time) & 5'-TCTTCGTCCGGGTAGAAGCA-3' \\
\hline pIRES2-rev2 & 5'-GCCAGTAACGTTAGGGGGGG-3' \\
\hline pIRES2-sen & 5'-GCAGAGCTGGTTTAGTGAACC-3' \\
\hline PolyT-Primer (Rev. T.) & 5'-AAAAAAAAAAAAAAAA-3' \\
\hline Random-Primer (Rev. T.) & Zufällige Hexamere (Invitrogen Karlsruhe) \\
\hline Stan-NheI & 5'-GTCTCTAGAGCTAGCATGTGTGCCGAGCGGCTG-3' \\
\hline $\begin{array}{l}\text { Stan-XhoI } \\
(+ \text { Streptag II-Sequenz) }\end{array}$ & $\begin{array}{l}\text { 5'-GACGAATTCCTCGAGTCATTTTTCGAACTGCGGGT } \\
\text { GGCTCCAAGCGCTCCTCCGGATATCAGAATACTC-3' }\end{array}$ \\
\hline Stc2ifwd & 5'-CTGCACGAACCCTACGTG-3' \\
\hline Stc2irev & 5'-GCTCTTGCTACCTCGCTC-3' \\
\hline Stc2isen & 5'-CAGAATACAGCGGAGATCC-3' \\
\hline Stc2-NheI & 5'-GGGAAAAGGCTAGCAAAAAGG-3' \\
\hline Stc2-XhoI & 5'-ACACACACCTCGAGGAAGTC-3' \\
\hline Stc2rev (Real-time) & 5'-TTGACCAAACAGTGCTGGATCT-3' \\
\hline Stc2sen (Real-time) & 5'-GGAGCTCCCAGCAGAAAGG-3' \\
\hline Stc2Lfwd (Real-time) & 5'-AACTCTGCCGTCCTAGCACAA-3' \\
\hline Stc2Lrev (Real-time) & 5'-AGCCAAGCCCTCTCGTTTG-3' \\
\hline Stc2p1 & 5'-TCCTCGTACCTTTGTCTTCTTTC-3' \\
\hline Stc2-Tvrev & 5'-GGCTGAGGGTCAAGGTGAGAT-3' \\
\hline TvpolyT & 5-TTTTTTTTTTTTTTTTTTTTTTTTTT-3' \\
\hline Tvprev1 & 5'-TTTTTTTTTTTTTTTTGTTTGAAAG-3' \\
\hline
\end{tabular}

Tab. 2.5: Oligonukleotide 


\subsection{Plasmide}

\begin{tabular}{|l|l|}
\hline Plasmide & Hersteller/Vertreiber \\
\hline pIRES2-EGFP-Expressionsvektor & Becton Dickinson; Heidelberg \\
\hline
\end{tabular}

Tab. 2.6: Plasmide

\subsection{Antikörper}

\begin{tabular}{|l|l|l|}
\hline Antikörper & Verdünnung & Hersteller/Vertreiber \\
\hline $\begin{array}{l}\text { STC2 (K17) sc-14352: Ziege } \\
\text { anti-Human (polyklonal) }\end{array}$ & $1: 2500$ & Santa Cruz Biotechnology; Santa Cruz, CA \\
\hline $\begin{array}{l}\text { StrepMAB-Classic: Maus } \\
\text { anti-Streptag II (monoklonal) }\end{array}$ & $1: 400$ & IBA; Göttingen \\
\hline $\begin{array}{l}\text { Maus anti-Aktin } \alpha-S M A \\
\text { (monoklonal) }\end{array}$ & $1: 2000$ & Sigma-Aldrich; München \\
\hline $\begin{array}{l}\text { Esel anti-Ziege IgG-HRP } \\
\text { Ziege anti-Maus IgG-HRP } \\
\text { (polyklonal) }\end{array}$ & $1: 15000$ & Santa Cruz Biotechnology; Santa Cruz, CA \\
\hline $\begin{array}{l}\text { Ziege anti-Maus IgG-Alexa } \\
\text { Fluor 594 }\end{array}$ & $1: 200$ & DakoCytomation; Glostrup, Dänemark \\
\hline
\end{tabular}

Tab. 2.7: Antikörper

\subsection{Bakterienstämme}

Zur Produktion und Selektion von Plasmiden wurden E. coli Top 10 (Invitrogen, Karlsruhe) verwendet.

\begin{tabular}{|l|l|l|}
\hline Stamm & Relevanter Geno-/Phänotyp & Referenzen \\
\hline $\begin{array}{l}\text { E. coli }(\text { Escherichia coli }) \\
\text { Top } 10\end{array}$ & Kan & $\begin{array}{l}\text { Casadaban \& Cohen, (1980), } \\
\text { Grant et al. (1990) }\end{array}$ \\
\hline
\end{tabular}

Tab. 2. 8: Bakterienstämme

\subsection{Eukaryotische Zelllinien}

\begin{tabular}{|l|l|}
\hline Zelllinie & Beschreibung \\
\hline CHLA 20 & Humane Neuroblastom-Zelllinie \\
\hline CHLA 90 & Humane Neuroblastom-Zelllinie \\
\hline CHP 100 & Humane Neuroblastom-Zelllinie \\
\hline CHP 134 & Humane Neuroblastom-Zelllinie \\
\hline GI-MEN & Humane Neuroblastom-Zelllinie \\
\hline
\end{tabular}




\begin{tabular}{|c|c|}
\hline Zelllinie & Beschreibung \\
\hline HEK 293 & Humane viral-immortalisierte embryonale Nierenzelllinie \\
\hline HEK 293-H10 & STC2-Streptag II-transfizierte HEK 293-Zellen \\
\hline HEK 293-H12 & STC2-Streptag II-transfizierte HEK 293-Zellen \\
\hline IMR 32 & Humane Neuroblastom-Zelllinie \\
\hline IMR 5 & Humane Neuroblastom-Zelllinie \\
\hline KB 24 & BigH3-transfizierte Kelly-Zellen \\
\hline $\mathrm{KCN}$ & Humane Neuroblastom-Zelllinie \\
\hline KELLY & Humane Neuroblastom-Zelllinie \\
\hline LAN 1 & Humane Neuroblastom-Zelllinie \\
\hline LAN 2 & Humane Neuroblastom-Zelllinie \\
\hline LAN 5 & Humane Neuroblastom-Zelllinie \\
\hline LAN 6 & Humane Neuroblastom-Zelllinie \\
\hline NB 69 & Humane Neuroblastom-Zelllinie \\
\hline NBLS & Humane Neuroblastom-Zelllinie \\
\hline NGP & Humane Neuroblastom-Zelllinie \\
\hline NLF & Humane Neuroblastom-Zelllinie \\
\hline NMB & Humane Neuroblastom-Zelllinie \\
\hline SH-EP & Humane Neuroblastom-Zelllinie \\
\hline SH-IN & Humane Neuroblastom-Zelllinie \\
\hline SH-SY5Y & $\begin{array}{l}\text { Humane Neuroblastom-Zelllinie (Biedler et al., 1978); } \\
\text { www.lgcpromochem-atcc.com }\end{array}$ \\
\hline SH-SY5Y-ST1 & STC2-transfizierte SH-SY5Y-Zellen \\
\hline SH-SY5Y-ST2 & STC2-transfizierte SH-SY5Y-Zellen \\
\hline SH-SY5Y-ST3 & STC2-transfizierte SH-SY5Y-Zellen \\
\hline SH-SY5Y-ST4 & STC2-transfizierte SH-SY5Y-Zellen \\
\hline SH-SY5Y-Vektor & pIRES2-EGFP-transfizierte SH-SY5Y-Zellen \\
\hline SK-N-AS & Humane Neuroblastom-Zelllinie \\
\hline SK-N-SH & Humane Neuroblastom-Zelllinie \\
\hline SMS-KAN & Humane Neuroblastom-Zelllinie \\
\hline
\end{tabular}

Tab. 2.9: Eukaryotische Zelllinien 


\subsection{Zellkulturmedien und Puffer}

\section{$\underline{\text { LB (Luria-Bertani)-Medium }}$}

Trypton

Hefeextrakt

$\mathrm{NaCl}$

$\mathrm{H}_{2} \mathrm{O}_{\text {dest. }}$
$10 \mathrm{~g}$

$5 \mathrm{~g}$

$10 \mathrm{~g}$

ad $1000 \mathrm{ml}$

Zur Herstellung von Agarplatten wurde dem Medium vor dem Autoklavieren Agar in einer Endkonzentration von 1,5\% (w/v) zugesetzt. Das Antibiotikum Kanamycin wurde sterilfiltriert und nach dem Autoklavieren in den noch flüssigen Agar (etwa $50^{\circ} \mathrm{C}$ ) gemischt. Die Lagerung des Mediums erfolgte bei RT, die Platten wurden bei $4^{\circ} \mathrm{C}$ gelagert.

\section{$\underline{\text { RPMI 1640-Medium }}$}

Das zur Kultivierung der eukaryotischen Zelllinien verwendete RPMI 1640-Medium wurde vor Gebrauch mit $10 \%$ FCS (Biochrome, Berlin) und $1 \%$ Penicillin-Streptomycin-Lösung (je $5000 \mathrm{u} / \mathrm{ml}$; Lonza, Basel, Schweiz) supplementiert. Die Lagerung erfolgte bei $4^{\circ} \mathrm{C}$.

Das zum Umsetzen von eukaryotischen Zellen verwendete DPBS und EDTA Trypsin wurde von der Firma Lonza (Basel, Schweiz) erworben und bei $4^{\circ} \mathrm{C}$ gelagert.

\section{Gefriermedium}

Das zum Herstellen von Stammkulturen verwendete Gefriermedium bestand aus $10 \%$ DMSO, 50 \% RPMI-Medium und 40 \% FCS. Nach dem Ansetzten wurde das Gefriermedium bei $4^{\circ} \mathrm{C}$ zwischengelagert. 


\section{Methoden}

\subsection{Generelle Methoden}

\subsubsection{Sterilisation}

Zur Inaktivierung von Mikroorganismen, Proteasen und DNasen wurden alle hitzestabilen Geräte und Lösungen durch Autoklavieren $\left(20 \min\right.$ bei $121^{\circ} \mathrm{C}$ und $\left.105 \mathrm{~Pa}\right)$ sterilisiert. Nicht autoklavierbare Materialien wurden mit 70 \%igem Ethanol (v/v) gespült oder mit 96 \%igem Ethanol (v/v) abgeflammt. Hitzelabile Substanzen (z.B. Antibiotika) wurden sterilen Lösungen in fester Form zugegeben und die entsprechenden Lösungen sterilfiltriert.

\subsubsection{Messung des pH-Werts}

Der pH-Wert wurde mittels einer Kaliumchlorid-Elektrode am pH-Meter bestimmt. Vor den Messungen wurde das Gerät für den entsprechenden Messbereich mit Eichlösungen ( $\mathrm{pH}$ 7,0 und pH 4,0 bzw. pH 9,0; Qualilab, Merck Eurolab GmbH) kalibriert.

\subsection{Zellbiologische Methoden}

\subsubsection{Kultivierung von Bakterien}

Die zur Vektorproduktion und Klonierung verwendeten E. coli (Escherichia coli) Top 10 Zellen wurden aerob bei $37^{\circ} \mathrm{C}$ in LB-Medium angezogen. Angeimpft wurde mit einer Einzelkolonie oder 1-2 \%ig. Um ausreichende Belüftung sicherzustellen, wurden die verwendeten Falcon-Röhrchen maximal bis zu einem Endvolumen von $25 \%$ gefüllt und die Kulturen auf einem Rotationsschüttler (120 rpm/min) angezogen. Sollten Einzelzellklone isoliert werden, wurde ein Verdünnungsausstrich der Bakteriensuspensionen auf LBAgarplatten über Nacht bei $37^{\circ} \mathrm{C}$ inkubiert. Im Medium, sowie auf den Platten, war zur Selektionierung Kanamycin $(50 \mu \mathrm{g} / \mathrm{ml})$ enthalten.

\subsubsection{Messung der optischen Dichte}

Die optische Dichte (OD) von Kulturen wurde in $1 \mathrm{ml}$ Plastikküvetten (Sarstedt) mit einer Schichtdicke von $1 \mathrm{~cm}$ bei $600 \mathrm{~nm}$ in einem Biophotometer (Eppendorf) gemessen. Als Nullwert diente unbeimpftes Medium. Um Messungenauigkeiten zu vermeiden, wurden die Proben mit Medium verdünnt, sobald eine OD von 0,3 überschritten war. 


\subsubsection{Stammhaltung und Lagerung}

Zur längerfristigen Lagerung von Bakterien wurden Stammkulturen in 10 \% DMSO angelegt. Die Zellsuspension wurde in ein Reaktionsgefäß gegeben und mit DMSO versetzt, kurz gemischt und in flüssigem Stickstoff schockgefroren. Die Stammkulturen wurden anschließend bei $-20^{\circ} \mathrm{C}$ oder $-80^{\circ} \mathrm{C}$ gelagert. Bewachsene Agarplatten konnten mit Parafilm $\mathrm{M}$ verschlossen bis zu einer Woche bei $4^{\circ} \mathrm{C}$ aufgehoben werden.

\subsubsection{Kultivierung von eukaryotischen Zellen}

Die in meiner Arbeit verwendeten eukaryotischen Zelllinien (s. Kap. 2.9) wurden in supplementiertem RPMI 1640-Medium (s. Kap. 2.10) bei $37^{\circ} \mathrm{C}$ und $5 \% \mathrm{CO}_{2}$ in einem befeuchtenden Inkubator auf Zellkulturplatten $(10 \mathrm{~cm} \mathrm{Ø)} \mathrm{angezogen.} \mathrm{Zur} \mathrm{Rekultivierung} \mathrm{oder}$ Anzucht größerer Zellmengen wurden $25 \mathrm{~cm}^{2}, 75 \mathrm{~cm}^{2}$ oder $175 \mathrm{~cm}^{2}$-Zellkulturflaschen mit Belüftungskappen verwendet. Die Zellen von konfluent-bewachsenen Platten wurden durch Umsetzen ausgedünnt. Dabei wurde der Überstand abgenommen, die adhärent-wachsenden Zellen mit DPBS gewaschen und durch Inkubation in EDTA Trypsin in Suspension gebracht. Durch die Zugabe von Medium konnte die Trypsinierung abgestoppt werden, da das agierende Trypsin durch das im Medium enthaltene FCS gesättigt wird. Die Zellen wurden anschließend durch Zentrifugation ( 5 min bei $190 \mathrm{~g}$ ) pelletiert und in frischem Medium resuspendiert und ausplattiert. Die übertragene Zellmenge war abhängig von der Proliferationsrate und der Stoffwechselaktivität der jeweiligen Zelllinie und lag zwischen $1 \times 10^{5}-1 \times 10^{6}$ Zellen. Der Zustand der Zellen wurde regelmäßig mikroskopisch kontrolliert und die Zellkultur auf Kontaminationen mit Mykoplasmen (Mycoplasma PCR Detection Kit) untersucht. Zur langfristigen Kultivierung von transfizierten Zellen wurde ein geringer Selektiondruck mit $100 \mu \mathrm{g} \mathrm{G} 418 / \mathrm{ml}$ aufrecht erhalten.

\subsubsection{Stammhaltung, Lagerung und Rekultivierung eukaryotischer Zellen}

Zur längerfristigen Lagerung der Zelllinien wurden Stammkulturen hergestellt und bei $-80^{\circ} \mathrm{C}$ oder in flüssigem Stickstoff gelagert. Die Zellen wurden durch Trypsinierung geerntet, zentrifugiert $\left(4^{\circ} \mathrm{C}, 190 \mathrm{~g}, 5 \mathrm{~min}\right)$ und in gekühltem Gefriermedium aufgenommen. Die Zellsuspension wurde in Kryoröhrchen aliquotiert $\left(2 \times 10^{6}\right.$ Zellen/ml) und in speziellen Isopropanol-gefüllten Gefriergefäßen (Nalgene Cryo $1^{\circ} \mathrm{C}$, Nunc) mit einer Rate von $1^{\circ} \mathrm{C} / \mathrm{min}$ eingefroren. Das im Medium enthaltene DMSO sowie das schrittweise Gefrieren verhinderte die zu schnelle Bildung von Eiskristallen, die zur Zerstörung der Zellen führen würde. Zur Rekultivierung wurden die Stammkulturen bei $37^{\circ} \mathrm{C}$ im Wasserbad aufgetaut und in RPMI- 
Medium übertragen. Anschließend wurden die Zellen durch Zentrifugation (190 g, 5 min) pelletiert und in frischem Medium ausplattiert.

\subsubsection{Bestimmung der Zellzahl}

Die Zahl eukaryotischer Zellen wurde am Partikelzähler oder mikroskopisch in NeubauerZählkammern $\left(0,0025 \mathrm{~mm}^{2}\right.$ x $\left.0,1 \mathrm{~mm}\right)$ bestimmt. Für beide Methoden wurden die adhärenten Zellen mit Trypsin geerntet. Zur Verwendung am Paritkelzähler wurde die Zellsupension 1:100 in isotonem Puffer (Coulter Isoton II Diluent) verdünnt und für die Analyse eingesetzt. Für die Zellzahlbestimmung in der Zählkammer wurde die Zellsupension je nach Dichte 1:21:20 mit Trypanblaulösung versetzt. Trypanblau ist ein saurer Farbstoff, der durch defekte Zellmembranen ins Cytosol eindringt und dort die Zellproteine der toten Zellen bindet. Die lebenden Zellen verbleiben ungefärbt und können so deutlich unterschieden werden. Die Zellen wurden direkt nach der Färbung ausgezählt, da Trypanblau bei längerer Inkubation cytotoxisch wirkt.

$\begin{array}{ll}\text { Trypanblaulösung } & \\ \text { Trypan Blau-Lösung }(0,4 \%) & 1 \text { vol. } \\ \text { DPBS } & 1 \text { vol. }\end{array}$

\subsubsection{Ernte von Zellkultur-Überständen}

Zum Nachweis sezernierter Proteine wurden die Zellkultur-Überstände von Zelllinien untersucht. An Tag 1 wurden abhängig von der Proliferationsrate der jeweiligen Zelllinien 5$10 \times 10^{6}$ Zellen ausplattiert und angezogen (s. Kap. 3.2.4). Das Serum-haltige RPMI-Medium wurde an Tag 3 gegen FCS-freies RPMI-Medium ausgetauscht, vorher wurden die Zellen kurz mit $10 \mathrm{ml}$ PBS gewaschen. An Tag 5 wurde das Medium abgenommen und bei $4^{\circ} \mathrm{C}$ und 3000 g für 10 min zentrifugiert, um so nicht-lösliche Bestandteile zu pelletieren. Der Überstand wurde in ein neues 15 ml-Röhrchen übertragen und direkt eingesetzt oder bis zur weiteren Verwendung bei $-20^{\circ} \mathrm{C}$ gelagert. Parallel wurden die adhärenten Zellen auf den jeweiligen Platten geerntet und gezählt, da die Menge der Zellen später als Bezugsgröße für die einzusetzende Verdünnung der Zellüberstände diente.

\subsubsection{Transfektion eukaryotischer Zellen}

Das Übertragen von Fremd-DNA in eukaryotische Zellen bezeichnet man als Transfektion. Im Rahmen meiner Arbeit wurden die untersuchten Zellen mittels Elektroporation transfiziert. Dabei wird ein Kondensator-generiertes elektrischen Feld dazu verwendet, mikroskopisch 
kleine Löcher in den Zellmembranen zu erzeugen (Neumann et al., 1972; Zimmermann et al., 1974). Diese bestehen nur für einige Millisekunden, was ausreichend ist, um freie DNA, aus der Umgebung der Zellen aufzunehmen. Die zu transfizierenden Zellen wurden durch Trypsinierung geerntet und die Zellzahl bestimmt. Nach der Zentrifugation (190 g, 5 min)

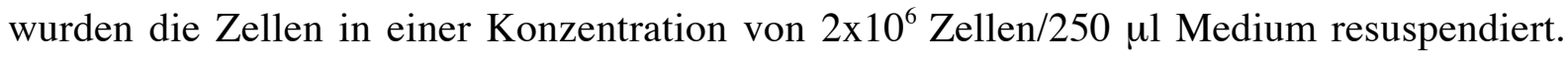
Das verwendete RPMI 1640-Medium enthielt zur Stabilisierung des pH-Wertes $25 \mathrm{mM}$ HEPES. Die gekühlten Elektroporationsküvetten (Eurogentec; Seraign, Belgien) wurden mit $2 \times 10^{6}$ Zellen befüllt und $10 \mu \mathrm{g}$ Plasmid-DNA zugesetzt. Nach einer kurzen Inkubation auf Eis wurde die Elektroporation am EasyjecT Elektroporator durchgeführt $(\mathrm{C}=1350 \mu \mathrm{F}, \mathrm{A}=250 \mathrm{~V}$, $\mathrm{R}=99 \mathrm{k} \Omega$ ). Die Zellen wurden anschließend direkt in RPMI-Medium mit $10 \mathrm{mM}$ HEPES aufgenommen und auf Zellkulturplatten $(10 \mathrm{~cm} \varnothing)$ ausplattiert. Da auf dem übertragenen Plasmid zusätzlich ein grün fluoreszierenden Proteins (enhanced green fluorescent protein, EGFP) kodiert war, konnte die Transfektionseffizienz mittels Fluoreszenz-Mikroskopie bestimmt werden. Nach $24 \mathrm{~h}$ wurde zur Selektion der erfolgreich transfizierten Zellen Geneticin (G418; 400-600 $\mu \mathrm{g} / \mathrm{ml}$ ) zum Kulturmedium zugesetzt. Dieses AminoglykosidAntibiotikum hemmt die Polypeptid Synthese der untransfizierten Zellen. Die transfizierten Zellen sind durch die Aktivität einer Plasmid-codierten Aminoglykosid-Phosphotransferase resistent, da diese Geneticin abbaut.

\subsubsection{Isolierung stabiler Einzelzelltransfektanten}

Zur Isolierung stabiler Einzelzellklone wurden die transfizierten Zellen vier Wochen mit 400$600 \mu \mathrm{g} \mathrm{G} 418 / \mathrm{ml}$ selektioniert und regelmäßig Phasenkontrast- und Fluoreszenzmikroskopisch überprüft. Kolonien, die aus einzelnen Zellen entstanden waren, wurden durch partielle Trypsinierung isoliert. Dazu wurden die Kolonien unter dem Mikroskop markiert, das Medium abgenommen und die Platten mit PBS gewaschen. Sterile WhatmannPapierstücke ( $5 \mathrm{~mm} \varnothing)$ wurden mit Trypsin getränkt und auf die markierten Kolonien gelegt. Nach einminütiger Inkubation konnte das Whatmann-Papier mit den trypsinierten Zellen in frisches Medium übertragen werden. Die Einzelzellklone wurden anschließend auf 24wellPlatten unter Selektionsdruck (400- $600 \mu \mathrm{g} \mathrm{G418/} \mathrm{ml)} \mathrm{angezogen} \mathrm{und} \mathrm{weiter} \mathrm{expandiert.}$

\subsection{Molekularbiologische Methoden}

\subsubsection{RNA Isolation}

Zur Isolation der Gesamt-RNA aus eukaryotischen Zellen wurde eine Extraktion mit Trizol (Guanidiniumthiocyanat-Phenol-Chloroform Extraktion) durchgeführt (Chomczynski \& 
Sacchi, 1987). Die für die RNA-Isolation verwendeten Zellen befanden sich in der Wachstumsphase. Die Zellkulturplatten $(\varnothing 10 \mathrm{~cm})$ wurden zweifach mit PBS gewaschen und direkt im Anschluss $2 \mathrm{ml}$ Trizol auf die Zellen gegeben, um so eine möglichst schnelle Konservierung des momentanen Transkriptionsstatus zu erzielen. Das in Trizol enthaltene Phenol und die chaotrophen Salze schützen die RNA und DNA während Zellmembranen zerstört und Proteine denaturiert werden. Die Zellen wurden anschließend abgeschabt und mit dem Trizol in ein Reaktionsgefäß überführt. Bei der folgenden Chloroform-Extraktion sammelt sich die RNA in der wässrigen Phase und kann so von der DNA und den restlichen Zellkomponenten getrennt werden. Die weitere Extraktion wurde nach Angaben des Herstellers durchgeführt und die isolierte RNA bei $-20^{\circ} \mathrm{C}$ oder $-80^{\circ} \mathrm{C}$ gelagert.

\subsubsection{Reverse Transkription}

Während der reversen Transkription wird aus mRNA (Messenger RNA) ein komplementärer cDNA-Strang (complementary DNA) transkribiert. Dieser Vorgang wird von einer RNAabhängigen DNA-Polymerase, der Reversen Transkriptase katalysiert. Ein RNA-DNAHybridstrang wird dabei generiert und die RNA anschließend hydrolysiert, so dass eine einzelsträngige cDNA bei der Synthese entsteht. Für die im Rahmen meiner Arbeit durchgeführten reversen Transkriptionen wurde der Qiagen Omniscript RT Kit nach den Angaben des Herstellers verwendet:

\begin{tabular}{|c|c|}
\hline $10 \times$ Omniscript RT Puffer & $2 \mu l$ \\
\hline dNTPs (5 mM) & $2 \mu l$ \\
\hline Primer $(50 \mathrm{mM})$ & $2 \mu l$ \\
\hline Omniscript RT (4 u/ $\mu \mathrm{l})$ & $1 \mu l$ \\
\hline $\mathrm{RNasin} 40 \mathrm{u} / \mu \mathrm{l}$ & $0,5 \mu l$ \\
\hline RNA & $\underline{2 \mu}$ \\
\hline${ }_{2} \mathrm{O}_{\text {dest }}$ & 20 \\
\hline
\end{tabular}

Standardreaktionen wurden mit Random-Primern (Gemisch aus Hexameren mit allen möglichen Basenabfolgen, s. Tab. 2.5) durchgeführt und zur Generierung möglichst langer cDNA-Fragmente wurden PolyT-Primer eingesetzt. Bei der Verwendung von PolyT-Primern wird cDNA ausgehend von der PolyA-Sequenz am 3'-Ende der Transkripte generiert. Zur Hemmung von RNasen wurde dem Ansatz außerdem der RNase-Inhibitor rRNasin zugefügt. Die Reaktion wurde für 90 min bei $37^{\circ} \mathrm{C}$ durchgeführt und das Enzym anschließend 5 min bei 
$95^{\circ} \mathrm{C}$ hitzeinaktiviert. Die resultierende cDNA wurde 1:5 mit $\mathrm{H}_{2} \mathrm{O}$ verdünnt und bis zur weiteren Verwendung bei $4^{\circ} \mathrm{C}$ gelagert.

\subsubsection{DNA Präparation}

Zur Präparation der Gesamt-DNA aus kultivierten NB-Zellen wurde der DNeasy Kit von Qiagen verwendet. Die Zellen wurden durch Trypsinierung von Zellkulturplatten geerntet und für 5 min bei $300 \mathrm{~g}$ abzentrifugiert. Das Zellpellet wurde in PBS resuspendiert und ein RNase-Verdau mit $4 \mu \mathrm{l}$ RNase A $(100 \mathrm{mg} / \mathrm{ml})$ für 3 min bei Raumtemperatur (RT) durchgeführt. Die weitere DNA Präparation erfolgte nach den Angaben des Herstellers. Die Zellen wurden lysiert und das Homogenisat auf eine Säule aufgetragen. Die DNA wird dabei selektiv an die Silica-Membran gebunden und konnte nach mehreren Waschschritten gereinigt und konzentriert von der Säule eluiert werden.

\subsubsection{Präparation von Plasmid-DNA}

Zur Präparation von Plasmid-DNA aus E. coli-Zellen wurde der Plamid Mini Kit der Firma Qiagen verwendet. $5 \mathrm{ml}$ LB-Medium wurden aus einer Stammkultur $\left(-80^{\circ} \mathrm{C}\right)$ oder mit einer Einzelkolonie angeimpft und über Nacht bei $37^{\circ} \mathrm{C}$ auf einem Rotationsschüttler inkubiert. 1,5$3 \mathrm{ml}$ der Übernachtkultur wurden für die folgende Plasmidpräparation eingesetzt. Diese erfolgte nach den Angaben des Herstellers. Während der alkalischen Lyse der Zellen wurde ein RNase-Verdau durchgeführt und die Suspension anschließend auf eine Säule mit Anionenaustauschharz aufgetragen. Die geringe Salzkonzentration und ein adäquater $\mathrm{pH}$ Wert im Puffer sorgten für eine Bindung der Plasmid-DNA an das Säulenmaterial. RNA, Proteine und andere Verunreinigungen wurden in mehreren Waschschritten mit einem moderat salzhaltigen Puffer vollständig entfernt. Die Plasmid-DNA konnte anschließend in einem Puffer mit hoher Salzkonzentration eluiert und durch anschließende IsopropanolPräzipitation entsalzt und konzentriert werden.

\subsubsection{Konzentrationsbestimmung und Reinheitskontrolle von Nukleinsäuren}

Die Konzentration von RNA- und DNA-Lösungen wurde photometrisch am NanoDrop ermittelt. Diese Technologie ermöglicht es, die Absorption sehr kleiner Volumina ohne vorherige Verdünnung zu bestimmen: $1 \mu \mathrm{l}$ der entsprechenden Probe wird auf ein Podest pipettiert und eine zweite Messplatte aufgelegt. Der Tropfen bleibt durch seine Oberflächenspannung zwischen den beiden Platten fixiert, und die Absorption kann bei verschiedenen Wellenlängen bestimmt werden. Anhand des definierten Messwegs durch den 
Tropfen $(1 \mathrm{~mm})$ lässt sich anschließend die Konzentration der Proben berechnen. Zur Bestimmung der Nukleinsäurekonzentration wurde die Absorption bei $260 \mathrm{~nm}$ gemessen und der Berechnung folgende Referenzkonzentrationen bei einer $\mathrm{OD}_{260}$ von 1 zu Grunde gelegt (Sambrook et al., 2001; 6.11 \& A20-21):

$$
\begin{array}{ll}
\text { Doppelsträngige DNA } & 50 \mu \mathrm{g} / \mathrm{ml} \\
\text { RNA } & 40 \mu \mathrm{g} / \mathrm{ml}
\end{array}
$$

Die Reinheit der Nukleinsäure-Lösung wurde durch die Bestimmung der optischen Dichte bei $230 \mathrm{~nm}$ und $280 \mathrm{~nm}$ überprüft. Für reine Nukleinsäure-Lösungen ist der Quotient $260 \mathrm{~nm} / 280$ nm größer als 1,8 und der Quotient $260 \mathrm{~nm} / 230 \mathrm{~nm}$ größer als 2. Verunreinigungen durch Proteine sind an einer Steigerung der Absorption bei $280 \mathrm{~nm}$ erkennbar. Polysaccharide, Phenole und andere aromatische Komponenten erhöhen die Absorption bei $230 \mathrm{~nm}$. Da die RNA Isolation mit Phenol-haltigem Trizol durchgeführt wurde, war es für diese Proben besonders wichtig, die Absorption bei $230 \mathrm{~nm}$ zu überprüfen. Phenol-Verunreinigungen können nachfolgende Reaktionen wie z.B. die reverse Transkription behindern.

Der Zustand und die Größe der gemessenen Nukleinsäure-Fragmente wurden außerdem mittels Agarosegelelektrophorese (s. Kap. 3.3.6) überprüft. Abbildung 3.1 zeigt die gelelektrophoretische Analyse von nicht degradierten RNA- (Spur 3 \& 4) und DNA-Proben (Spur 7, 8 \& 9). Bei Degradierung der Proben sind die Banden verschmiert und nicht klar von einander abzugrenzen. Außerdem sind ribosomale RNA-Untereinheiten (18S- und 28S-) auf Agarosegelen als charakteristisches Bandenmuster zu erkennen (Spur 3 \& 4). Die 2:1Verteilung der 28S- und 18S-Untereinheiten kann als Indikator für intakte RNA verwendet werden

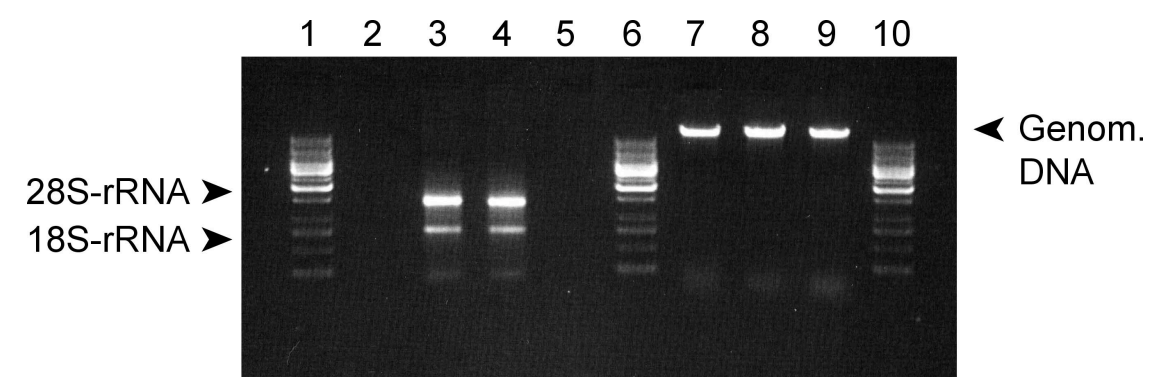

Abb. 3.1: Typische Agarosegelelektrophorese von RNA- (1 $\mu \mathrm{g}$; Spur 3,4) und DNA-Proben $(0,4 \mu \mathrm{g}$; Spur 7, 8, 9) zur Untersuchung von Reinheit und Konzentration. Auf Spur 1, 6, 10 wurde als Ladungsund Größenkontrolle ein 1 kb-DNA-Marker aufgetragen, die Spuren 2 und 5 wurden nicht beladen 


\subsubsection{Agarosegelelektrophorese}

Für analytische und präparative Zwecke wurden RNA und DNA-Fragmente durch horizontale Gelelektrophorese im elektrischen Feld aufgetrennt. Die verwendete Agarose wurde abhängig von der erwarteten Fragmentgröße 0,8-1,5 \%ig in TAE-Puffer angesetzt. Zur Visualisierung der Nukleinsäuren wurden 0,5 $\mu \mathrm{g} / \mathrm{ml}$ Ethidiumbromid (EtBr) in die noch flüssige Agarose $\left(50^{\circ} \mathrm{C}\right)$ gegeben. Der Farbstoff interkaliert mit der DNA und kann aufgrund seiner Fluoreszenz bei einer Wellenlänge von $254 \mathrm{~nm}$ nachgewiesen werden. Die DNA wurde mit 6x Ladepuffer versetzt, um während der Elektrophorese die Lauffront verfolgen und degradierende Enzyme durch das enthaltene EDTA inhibieren zu können. Zur späteren Auswertung und Größenbestimmung wurden außerdem $5 \mu$ l DNA-Längenstandard aufgetragen (s. Abb. 3.2). Die Auftrennung der Fragmente erfolgte bei 100-120 V für ca. 30 min. Die fluoreszierende DNA wurde anschließend an einem UV-Transilluminator-System dargestellt und fotografisch dokumentiert. $\mathrm{EtBr}$ ist lichtempfindlich, daher wurde die Stammlösung $(10 \mathrm{mg} / \mathrm{ml})$ lichtgeschützt gelagert.

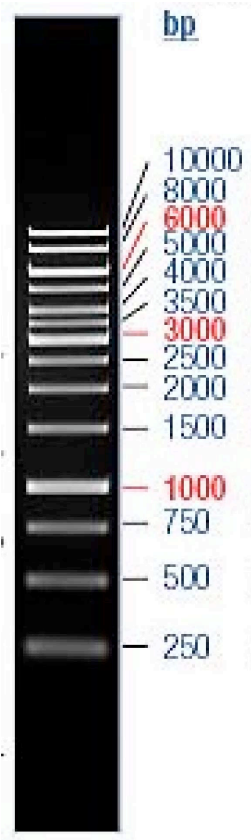

Abb. 3.2: $1-\mathrm{kb}$

DNA-Standard

(DNA Gene

Ruler, Invitrogen) 6x Ladepuffer (pH 7,0)

EDTA $\quad 1,0 \mathrm{mM}$

Harnstoff $\quad 7,0 \quad$ M

Saccharose (w/v) $\quad 50,0 \%$

Bromphenolblau (w/v) $\quad 0,1 \%$

$\mathrm{H}_{2} \mathrm{O}_{\text {dest. }} \quad$ ad $\quad 50 \mathrm{ml}$

Die autoklavierte Lösung wurde aliquotiert und bei $-20{ }^{\circ} \mathrm{C}$ gelagert.

50x TAE-Puffer

Tris/HCl $(\mathrm{pH} \mathrm{8,5)} 2 \mathrm{M}$

EDTA $\quad 50 \mathrm{mM}$

Essigsäure $1 \mathrm{M}$

$\mathrm{H}_{2} \mathrm{O}_{\text {dest. }} \quad$ ad $1000 \mathrm{ml}$

\subsubsection{Polymerase-Kettenreaktion}

Die Polymerase-Kettenreaktion (PCR) wird zur Vervielfältigung und Modifizierung spezifischer DNA-Abschnitte verwendet (Mullis et al., 1987; Saiki et al., 1988). Nach einer Hitzedenaturierung der doppelsträngigen DNA können sich kurze, der zu amplifizierenden 
Sequenz komplementäre Oligonukleotide (Primer) bei einer spezifischen Temperatur an die beiden Einzelstränge anlagern (Annealing). Ein hitzestabiles Enzym, die Taq-DNAPolymerase, verlängert die angelagerten Primer bei $72^{\circ} \mathrm{C}$ (Polymerisierung), und ein, der Vorlage (Template) komplementärer Strang entsteht. Die resultierende doppelsträngige DNA wird erneut denaturierte, und der Prozess der DNA-Amplifikation beginnt von vorne. Die Anzahl der DNA-Vorlagen verdoppelt sich in jedem Zyklus und der durch die Primer eingegrenzte DNA-Abschnitt wird idealerweise exponentiell vermehrt.

Die PCR-Produkte wurden für analytische oder präparative Zwecke eingesetzt: Fragmente die zur Klonierung verwendet werden sollten, wurden mittels DyNAzyme EXT DNA Polymerase amplifiziert. Hierbei handelt es sich um einen Polymerase-Mix aus DyNAzyme II DNA Polymerase und einem Enzym mit 3'-5'-Korrekturaktivität, das fehlintegrierte Nukleotide direkt während der Amplifikation entfernt. Für analytische Zwecke, z.B. zum Nachweis von STC2-Transkripten oder der Überprüfung von positiven Klonen, wurde die BioTherm DNA Polymerase von Genecraft verwendet. Die eingesetzten Oligonukleotide waren kommerziell erhältliche Vektorprimer oder wurden unter Berücksichtigung der folgenden Kriterien mit Hilfe des Computerprogramms Oligo 4.0 (Molecular Biology Insights, Cascade, CO; www.oligo.net) generiert. Idealerweise sollten die Primer eine Schmelztemperatur von $55^{\circ}$ $65^{\circ} \mathrm{C}$ haben und zwischen 18 und 24 Basenpaaren (bp) lang sein. Dimerbildung zwischen den Primern oder innerhalb eines Primers sollten nicht möglich sein und die komplementäre Sequenz durfte nur einmalig auf dem Template vorkommen. Nach Möglichkeit waren bei Standardprimern am 3'-Ende keine G- oder C-Basenpaare, um so durch eine schwache und damit spezifischere Bindung dieses Bereichs, eine Verlängerung fehlerhaft hybridisierter Primer zu verhindern. Zum Anfügen von Restriktionsschnittstellen während der Amplifikation wurden spezielle Primer verwendet, auf denen die Schnittstellen kodiert waren (Stc2-NheI/Stc2-XhoI und Stan-NheI/Stan-XhoI). Für Amplifikationen ausgehend von der PolyA-Sequenz am 3'-Ende der Transkripte wurden verankerte PolyT-Primer verwendet (TvprevI), bestehend aus T-Nukleotiden und der direkt vor dem PolyA-Signal liegenden Komplementärsequenz. Alle verwendeten Primer sind in Tab. 2.5 aufgelistet. Als Template wurde $1 \mu 1$ verdünnte cDNA (1:5), 1-100 ng Plasmid-DNA oder 600 ng genomische DNA eingesetzt. Die Standard-PCR-Reaktionen fanden in $50 \mu$ l-Ansätzen statt und wurden, um eine Fehlhybridisierung der Primer zu vermeiden, auf Eis pipettiert. 


\begin{tabular}{|c|c|}
\hline 10x Reaktionspuffer & $5 \mu 1$ \\
\hline dNTP-Gemisch (2 mM) & 5 \\
\hline Forward (fwd) Primer $(10 \mathrm{pmol} / \mu \mathrm{l})$ & $1-1,5$ \\
\hline Revers (rev) Primer (10 pmol/ $\mu \mathrm{l})$ & $1-1,5$ \\
\hline Template-DNA & 1 \\
\hline DNA-Polymerase & 1 \\
\hline $\mathrm{H}_{2} \mathrm{O}_{\text {dest. }}$ & \\
\hline
\end{tabular}

Für Multiplex PCR-Analysen wurden dem Ansatz zusätzlich $\beta$-Aktin-Primer (10 pmol/ $\mu \mathrm{l})$ zugesetzt. Die parallele Amplifikation des konstitutiv exprimierten $\beta$-AKTIN-Gens diente als Positivkontrolle. Die verwendeten 10x Puffer wurden zusammen mit der Polymerase erworben und waren auf die jeweiligen Enzyme abgestimmt. In Einzelfällen wurden dem PCR-Ansatz DMSO zum Öffnen schwieriger Templates oder $\mathrm{MgSO}_{4}$ zur Optimierung der Polymerase-Aktivität zugesetzt. Die PCR-Reaktion wurde in folgenden Schritten durchgeführt, wobei die Zyklen 2-4 abhängig vom Template 30 bis 35mal wiederholt wurden:

$\begin{array}{llrr}1 & \text { Initiale Denaturierung } & 95^{\circ} \mathrm{C} & 5 \mathrm{~min} \\ 2 & \text { Denaturierung } & 95^{\circ} \mathrm{C} & 0,5-1 \mathrm{~min} \\ 3 & \text { Anlagerung } & \mathrm{x}^{\circ} \mathrm{C} & 0,5-1 \mathrm{~min} \\ 4 & \text { Polymerisierung } & 72^{\circ} \mathrm{C} & 0,5-1 \mathrm{~min} \\ 5 & \text { Abschließende Polymerisierung } & 72^{\circ} \mathrm{C} & 10 \mathrm{~min}\end{array}$

Die Anlagerungstemperatur $\mathrm{x}$ ist abhängig von der Schmelztemperatur der Primer und sollte optimal $5^{\circ} \mathrm{C}$ unter dieser liegen. Zur Bestimmung der optimalen Anlagerungstemperatur wurden für jedes Primerpaar Reaktionen bei unterschiedlichen Temperaturen $\left(55^{\circ} \mathrm{C}-65^{\circ} \mathrm{C}\right)$ durchgeführt. Die gelelektrophoretische Überprüfung der PCR-Produkte zeigte, welche Temperatur für eine spezifische Amplifikation geeignet war. Die für die Denaturierung nötige Zeit ist abhängig von der Länge der zu amplifizierenden Sequenzen. Die Polymerisationszeit hängt neben der Sequenzlänge außerdem noch von der Syntheserate der eingesetzten DNAPolymerase ab. Nach Abschluss der Amplifikation wurde ein Aliquot des Reaktionsansatzes im Agarosegel (s. Kap. 3.3.6) überprüft. Falls weiter zu verwenden, wurde der restliche Ansatz kurzfristig bei $4{ }^{\circ} \mathrm{C}$ oder längerfristig bei $-20{ }^{\circ} \mathrm{C}$ gelagert. 


\subsubsection{Real-time RT-PCR}

Die Real-time RT-PCR (Higuchi et al., 1992) basiert auf dem Prinzip einer herkömmlichen PCR (s. Kap. 3.3.7) und bietet die Möglichkeit, nach jedem Zyklus (also in „Echtzeit“), die Menge der entstandenen Produkte zu messen. Dadurch ist die relative Quantifizierung bestimmter cDNAs und somit der Expression der entsprechenden Gene möglich. Der Fluoreszenzfarbstoff SYBR Green interkaliert mit DNA-Doppelsträngen, wodurch nach jedem erfolgreichen Zyklus die Verdopplung der Fluoreszenzintensität und damit auch der DNA-Menge gemessen werden kann. Für die Quantifizierung wird der sogenannte ct-Wert bestimmt, der Zyklus in dem die gemessene Fluoreszenz erstmalig signifikant über dem Hintergrund-Signal liegt. Dieser Zyklus befindet sich am Beginn der exponentiellen Phase und wird zum Vergleich der Expressionen verwendet, da nur in dieser Phase optimale Reaktionsbedingungen herrschen. Ein Nachteil bei der Verwendung interkalierender Farbstoffe wie SYBR-Green ist, dass nicht zwischen spezifischen PCR-Produkten und unspezifischen DNA-Fragmenten wie Primer-Dimeren oder Fehlamplifikaten unterschieden werden kann. Allerdings ist es möglich nach Ablauf der PCR eine Schmelzkurvenanalyse durchzuführen. Dabei wird die Länge der entstandenen Produkte anhand ihrer Schmelztemperaturen bestimmt. Zusätzliche Produkte können so identifiziert oder ausgeschlossen werden.

Zum Durchführen der Real-time RT-PCR habe ich SYBR Green JumpStart Taq ReadyMix nach Angaben des Herstellers verwendet. Die cDNA wurde 1:10 verdünnt und die beiden Primer (forward und reverse) 1:1 als Gemisch eingesetzt. Die Reaktionen wurden wie folgt pipettiert:

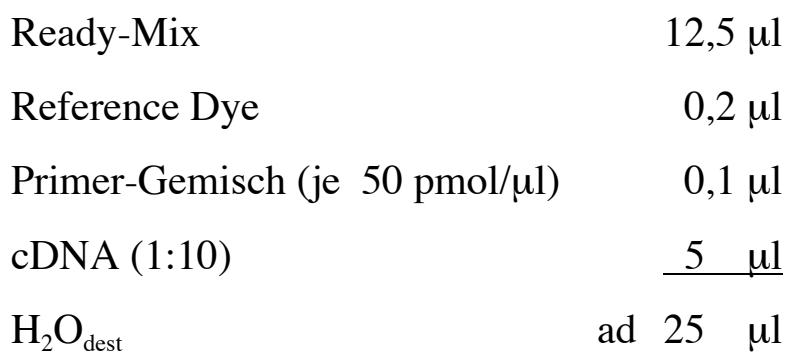

Um Pipettierfehler bei kleinen Volumina zu vermeiden, wurde für alle Reaktionen ein gemeinsamer Ansatz ohne cDNA (Master Mix) vorbereitet. Die cDNA wurde direkt in die verwendeten 96well-Platten (MicroAmp Platten; Applied Biosystems, Foster City, CA) pipettiert und der Master Mix zugefügt. Von jeder cDNA-Probe wurde eine 3-fach 
Bestimmung durchgeführt und Ansätze ohne cDNA (NTC, no template control) zur Kontrolle auf Verunreinigungen verwendet. Zur Generierung optimaler Primer wurde das Programm Primer Express 2.0 von Applied Biosystems (Foster City, CA) verwendet. Die PCRReaktionen wurde am ABI Prism Real-time PCR System durchgeführt.

\subsubsection{Bestimmung der relativen Transkriptmenge}

Die Auswertung der Real-time RT-PCR erfolgte nach Livak \& Schmittgen (2001). Um Variationen bezüglich der eingesetzten cDNA-Mengen zwischen den Proben auszugleichen, war eine interne Kontrolle nötig. Ein Referenzgen z.B. $\beta$-AKTIN, das in den untersuchten Proben gleichermaßen exprimiert wird, wurde ebenfalls unter entsprechenden Bedingungen amplifiziert. Die Auswertung der Messwerte wurde wie im Folgenden beschrieben nach der Delta-Delta-ct ( $\Delta \Delta \mathrm{ct})$-Methode durchgeführt: Durch Subtraktion der ct-Werte wurde die mRNA-Expression des Zielgens in Relation zur Expression des Referenzgens in der selben Probe gesetzt:

$$
\mathrm{ct}_{\text {Ziel }} \text { ct }_{\text {Referenz }}=\Delta \mathrm{ct}
$$

Dadurch werden die zu untersuchenden Proben normiert und somit vergleichbar gemacht. Um die Expression der Zielgene in unterschiedlichen Proben in Relation zueinander zu setzen, wird der $\Delta$ ct-Wert einer Vergleichsprobe (Kalibrator) von den anderen Proben subtrahiert:

$$
\Delta \text { ct }_{\text {Probe }}-\Delta \mathrm{ct}_{\text {Kalibrator }}=\Delta \Delta \mathrm{ct}_{\text {Probe }}
$$

Durch die Potenzierung der $\Delta \Delta$ ct-Werte wird die Genexpression des Kalibrators gleich 1 gesetzt $\left(2^{0}=1\right)$ :

$$
2^{-\Delta \Delta c t}=\text { Relative Genexpression }
$$

Die resultierenden $2^{-\Delta \Delta c t}$-Werte entsprechen der relativen Genexpression der untersuchten Proben und können graphisch dargestellt werden.

\subsubsection{Aufreinigung von PCR-Produkten}

PCR-Produkte wurden nach der Amplifikation mittels QIAquick PCR Purification Kit aufgereinigt, da verbliebene PCR-Komponenten (z.B. Primer und Enzyme) oder die herrschenden Pufferbedingungen bei nachfolgenden Reaktionen (z.B. Klonierungen) 
hinderlich sein können. Die DNA wurde in Anwesenheit hoher Salzkonzentration bei spezifischem pH-Wert $(\leq 7,5)$ an die Silica-Membran einer Säule gebunden. Nach mehreren Waschschritten wurden die PCR-Produkte gereinigt und konzentriert in $\mathrm{H}_{2} \mathrm{O}$ eluiert. Ein Aliquot wurde auf dem Agarosegel überprüft und das restliche Eluat kurzfristig bei $4^{\circ} \mathrm{C}$ oder längerfristig bei $-20^{\circ} \mathrm{C}$ gelagert.

\subsubsection{Extraktion von DNA-Fragmenten aus Agarosegelen}

Zur Isolierung und Reinigung von DNA-Fragmenten aus Agarosegelen wurde der QIAquick Gel Extraction Kit nach Angaben des Herstellers verwendet. Die Extraktion von DNA aus Agarosegelen war nötig, wenn in einem Ansatz verschiedene Fragmente enthalten waren, z.B. nach Restriktionsverdau oder bei unspezifischen PCR-Reaktionen. Die DNA-Fragmente wurden im Agarosegel (s. Kap. 3.3.6) aufgetrennt und die zu isolierende Bande ausgeschnitten. Um die DNA möglichst unversehrt aufzureinigen, wurde in den Agarosegelen während der Elektrophorese kein EtBr verwendet. Die Gele wurden in eine analytische und eine präparative Hälfte eingeteilt. Ein Aliquot der Probe wurde als Marker auf die analytische Seite aufgetragen, der Rest auf die präparative Seite. Nach der elektrophoretischen Auftrennung wurde das Gel halbiert und die analytische Hälfte in einem EtBr-Bad $(10 \mu \mathrm{g} / \mathrm{ml}$ $\left.\mathrm{H}_{2} \mathrm{O}\right)$ gefärbt. Die DNA-Banden wurden unter UV-Licht markiert und die Gelhälften anschließend wieder zusammen gefügt. Dadurch war es möglich, die zu isolierende Bande auf der präperativen Hälfte zu markieren, ohne die DNA in Kontakt mit EtBr oder UV-Licht zu bringen. Nach dem Lösen der Agarose konnten die DNA-Fragmente wie bereits in Kap. 3.3.9 beschrieben an QIAquick Säulen gebunden und so von den restlichen im Ansatz enthaltenen Komponenten getrennt werden.

\subsubsection{Enzymatische Modifikation von Nukleinsäuren}

\subsubsection{Spaltung von DNA durch Restriktionsendonukleasen}

Bei der sequenzspezifischen Spaltung von DNA werden lineare Fragmente mit definierten Enden erzeugt. Jede Restriktionsendonuklease erkennt eine spezifische Sequenz (Erkennungssequenz) und schneidet die DNA innerhalb oder in einem definierten Abstand zu dieser Region. Die beiden DNA-Stränge können an der selben Position gespalten werden (blunt end) oder wenige Basenpaare von einander entfernt. Zweites führt zu spezifischen DNA-Überhängen, wodurch eine anschließende Klonierung der Produkte erleichtert wird. 
Innerhalb meiner Doktorarbeit habe ich Restriktionsverdaue zur Herstellung von STC2Expressionskonstrukten und zur Überprüfung und Charakterisierung von Plasmiden durchgeführt. Der Verdau erfolgte in den von den Herstellern der Restriktionsenzyme mitgelieferten Puffersystemen bei den empfohlenen Temperaturen (s. Tab. 2.4). In analytischen Ansätzen betrug das Gesamtvolumen $20 \mu \mathrm{l}$, und 1-2 $\mu$ g DNA wurden mit 3-5 u Enzym/ $\mu$ g DNA für 2-4 h inkubiert. In präparativen Ansätzen wurden bis zu $5 \mu \mathrm{g}$ DNA in einem Volumen von insgesamt $50 \mu \mathrm{l}$ verdaut. Bei präparativen Verdauen war eine anschließende Inaktivierung der Restriktionsenzyme erforderlich und wurde den Herstellerangaben folgend ausgeführt. Für Doppelverdaue mit zwei Restriktionsenzymen wurden Produkte der Firma MBI Fermentas verwendet: Das angebotenen Y-TangoPuffersystem unterstützt die Aktivität verschiedener Restriktionsendonukleasen und konnte deshalb für den gleichzeitigen Verdau mit verschiedenen Enzymen verwendet werden. Die Spaltprodukte wurden im Agarosegel überprüft. Produkte präparativer Ansätze wurden aus dem Gel aufgereinigt (s. Kap. 3.3.10) und bis zur weiteren Verwendung kurzfristig bei $4^{\circ} \mathrm{C}$ oder längerfristig bei $-20^{\circ} \mathrm{C}$ gelagert.

\subsubsection{Ligation von DNA-Fragmenten}

Bei der Ligation werden Phosphodiesterbindungen zwischen doppelsträngigen DNAFragmenten mit freien 3'-Hydroxylenden und 5'-Phosphatenden geknüpft. Die dafür eingesetzten DNA-Fragmente wurden nach Restriktionsverdau aus dem Agarosegel aufgereinigt und in $\mathrm{H}_{2} \mathrm{O}$ eluiert für die Ligation verwendet. Vektor- und Insert-DNA wurden im Verhältnis von 1:4 eingesetzt. Das verwendete Enzym war eine T4-Ligase von Roche. Die Reaktion erfolgte im $20 \mu \mathrm{l}$ Ansatz in dem vom Hersteller mitgelieferten Puffersystem:

\begin{tabular}{|c|c|}
\hline Vektor-DNA & $0,2-2 \mu \mathrm{g}$ \\
\hline Insert-DNA & $0,8-8 \mu \mathrm{g}$ \\
\hline ATP $(10 \mathrm{mM})$ & $2 \mu 1$ \\
\hline 10x $\mathrm{T}_{4}$-Ligase-Puffer & $2 \mu 1$ \\
\hline $\mathrm{T}_{4}$-DNA-Ligase $(1 \mathrm{U} / \mu \mathrm{l})$ & $1 \mu \mathrm{l}$ \\
\hline $\mathrm{H}_{2} \mathrm{O}_{\text {dest }}$ & $20 \mu \mathrm{l}$ \\
\hline
\end{tabular}

Die Ligations-Ansätze wurden über Nacht bei $16^{\circ} \mathrm{C}$ inkubiert und direkt im Anschluss für die Transformation von E. coli-Zellen eingesetzt. 


\subsubsection{Transformation durch Hitzeschock}

Zur Vermehrung und Charakterisierung von STC2-Expressionskonstrukten und Vektorplasmiden wurden diese mittels Hitzeschock in E. coli Top 10-Zellen transformiert. Dazu wurden $100 \mu \mathrm{l}$ der kompetente $E$. coli-Zellen (Lagerung bei $-80{ }^{\circ} \mathrm{C}$ ) langsam auf Eis aufgetaut und ein gesamter Ligationsansatz oder $1 \mu \mathrm{g}$ Plasmid-DNA zugesetzt. Um die Anlagerung der DNA an die Zelloberfläche zu erlauben, erfolgte für 30 min eine Inkubation des Ansatzes auf Eis. Mit einem Hitzeschock (90 s bei $42^{\circ} \mathrm{C}$ ) wurde dann die Aufnahme der DNA induziert. Nach weiteren 5 min auf Eis wurden die Bakterien mit $400 \mu 1$ LB-Medium vermischt und zur Regeneration $1 \mathrm{~h}$ bei $37^{\circ} \mathrm{C}$ auf einem Schüttler inkubiert. Anschließend wurden die Bakterien auf Selektionsagar (Kanamycin $50 \mu \mathrm{g} / \mathrm{ml}$ ) ausplattiert und die Platten über Nacht bei $37^{\circ} \mathrm{C}$ inkubiert.

\subsubsection{Sequenzierung von DNA}

Die Bestimmung von DNA-Sequenzen wurde anhand der Didesoxymethode nach Sanger et al. (1977) durchgeführt. Hierbei wird der zu sequenzierende DNA-Abschnitt in einer modifizierten PCR-Reaktion amplifiziert. Für die PCR werden spezielle Didesoxynukleosidtriphosphate (ddNTPs) eingesetzt. Sie besitzen keine 3'-Hydroxygruppe, so dass nach ihrem Einbau in den wachsende DNA-Strang die Verlängerung abgebrochen wird. Der Einbau geschieht zufällig und so wird statistisch an jeder möglichen Position der zu generierenden DNA-Sequenz eine ddNTP-Base eingebaut. Jede der vier ddNTP-Basen (ddATP, ddTTP, ddGTP und ddCTP) ist mit einem anderen Fluoreszenzfarbstoff markiert. Die Fragmente werden in Kapillaren der Länge nach elektrophoretisch aufgetrennt, und die fluoreszierenden Basen können detektiert und identifiziert werden.

Im Verlauf meiner Doktorarbeit habe ich verschiedene DNA-Proben als Template für Sequenzierungen verwendet. Zur Überprüfung der STC2-Expressionskonstrukte wurde Plasmid-DNA verwendet. Für den Nachweis von alternativen STC2-Transkripten wurde mRNA revers transkribiert und die resultierende cDNA für die Reaktion eingesetzt. Außerdem wurde genomische DNA von humanen NB-Zellen für die Suche nach sequenziellen Unterschieden im STC2-Gen sequenziert. Für die Amplifikation wurde BigDye Terminator v3.1 Cycle Sequencing Kit verwendet. Wie folgend dargestellt wurde die Sequenzreaktion nach Angaben des Herstellers angesetzt und amplifiziert: 


\begin{tabular}{|c|c|c|c|c|}
\hline DNA-Template & $0,4 \mu \mathrm{g}$ & $\underline{\text { Schritt }}$ & Temperatur & Dauer \\
\hline 5x Sequenzierpuffer & $2 \mu 1$ & 1 & $96^{\circ} \mathrm{C}$ & $60 \mathrm{~s}$ \\
\hline Sequenz-Mix & $1 \quad \mu l$ & 2 & $96^{\circ} \mathrm{C}$ & $20 \mathrm{~s}$ \\
\hline Primer $(10 \mathrm{pmol} / \mu \mathrm{l})$ & $\underline{1 \mu l}$ & 3 & $55^{\circ} \mathrm{C}$ & $20 \mathrm{~s}$ \\
\hline $\mathrm{H}_{2} \mathrm{O}$ & $10 \mu l$ & 4 & $60^{\circ} \mathrm{C}$ & $240 \mathrm{~s}$ \\
\hline
\end{tabular}

Nach der initialen Denaturierung (1) wurden die Schritte 2-4 25mal wiederholt. Für die folgende Aufreinigung wurden die Ansätze in ein 1,5 ml-Reaktionsgefäß überführt und zur Fällung der PCR-Produkte $1 \mu$ l EDTA $(125 \mathrm{mM}), 1 \mu \mathrm{l}$ Natriumacetat $(3 \mathrm{M})$ und $50 \mu \mathrm{l}$ Ethanol (100\%) zugesetzt. Der Ansatz wurde 5 min bei RT inkubiert und anschließend 15 min bei $16.000 \mathrm{~g}$ abzentrifugiert. Der Überstand wurde verworfen und die DNA mit $70 \mu \mathrm{l}$ Ethanol (70\%) gewaschen. Nachdem der restliche Alkohol verdampft war, wurde das Pellet in $10 \mu \mathrm{l}$ Formamid resuspendiert und im Dunkeln bei $-20^{\circ} \mathrm{C}$ gelagert. Die anschließende Sequenzierung erfolgte mit dem Genetic Analyzer 3130 (Applied Biosystems). Zur späteren Bearbeitung der Sequenzen wurde das frei erhältliche Computerprogramm 4peaks (http://4peaks.en.softonic.com/mac) verwendet. Bei Sequenzüberlagerungen wurde die Auswertung der betroffenen Bereiche manuell fortgesetzt. Für jede Position der überlappenden Sequenz wurden die verschiedenen Fluoreszenzsignale identifiziert. Durch den Vergleich mit der NCBI-STC2-Gensequenz (http://www.ncbi.nlm.nih.gov/: Gene: STC2) konnte anschließend festgestellt werden, an welcher Position die Sequenzverschiebung, also eine Insertion oder Deletion von Basen, stattgefunden hat.

\subsection{Proteinbiochemische Methoden}

\subsubsection{Bestimmung der Proteinkonzentration}

Die Konzentration von Proteinlösungen (z.B. aufgereinigtem STC2) wurde durch Absorptionsmessung bei $280 \mathrm{~nm}$ am NanoDrop (s. Kap. 3.3.5) bestimmt. Verdünnungsreihen (0,125 - 1,5 mg /ml Lösungsmittel) mit Bsa oder rekombinantem STC2 (STC2rek) wurden zur Erstellung einer Standardkurve verwendet. Der Wert für das Lösungsmittel wurde gleich Null gesetzt und die Konzentration der Proteinlösung und der Verdünnungsreihe gegen einen im Gerät integrierten Standard gemessen. Die Konzentration der Proteinlösung konnte anschließend anhand der Steigung der Standardkurve bestimmt werden. Die Konzentration der Proteine wurde zusätzlich im SDS-Gel (s. Kap. 3.4.5) überprüft. Die Proteinlösungen wurden zusammen mit Bsa- oder STC2rek-Standardlösungen aufgetrennt (s. Kap. 3.4.5) und die Intensität der Proteinbanden nach Coomassie- oder Silberfärbung (s. Kap. 3.4.6-7) 
verglichen. Außerdem konnte die Reinheit der Proteinlösungen am NanoDrop anhand des dargestellten Wellenlängenspektrums und im SDS-Gel anhand des Bandenmusters überprüft werden.

\subsubsection{Dialyse von Proteinlösungen}

Die Dialyse ist eine Methode, mit der gezielt niedermolekulare Substanzen aus einer Lösung entfernt werden können (Sambrook \& Russel, 2001; A8.4). Durch den osmotischen Druck der über eine selektiv durchlässige Membran zwischen der Probe und dem Dialysepuffer herrscht, findet ein Stoffaustausch statt. Triebkraft für diese Reaktion sind unterschiedliche osmotische Potentiale der Lösungen, die sich durch Diffusion ausgleichen. Die Permeabilität der Membran entscheidet dabei, ab welcher Größe Substanzen diffundieren und welche zurück gehalten werden. Im Rahmen meiner Arbeit habe ich Dialysen durchgeführt, um Na-Azid aus STC2-Proteinlösungen zu entfernen oder einen Pufferaustausch vorzunehmen. Die verwendeten Dialyseschläuche (Medicell Interntional Ltd., London, UK) wurden vor der Benutzung in verschiedenen Lösungen abgekocht: Angefangen wurde mit einer Lösung aus $2 \%(\mathrm{w} / \mathrm{v}) \mathrm{NaHCO}_{3}$ und $1 \mathrm{mM}$ EDTA, dann folgte ein Waschschritt mit $\mathrm{H}_{2} \mathrm{O}_{\text {dest }}$ und anschließend wurde die Membran in einer $1 \mathrm{mM}$ EDTA-Lösung gekocht. Nach dem Abkühlen wurden die Schläuche mit $\mathrm{H}_{2} \mathrm{O}_{\text {dest }}$ gespült und 2x eine Stunde in $\mathrm{H}_{2} \mathrm{O}_{\text {dest }}$ gewaschen. Bis zur Verwendung erfolgte die Lagerung bei $4^{\circ} \mathrm{C}$ in $20 \%$ igem Ethanol.

Die zu dialysierende Proteinlösung (50-100 $\mu \mathrm{l})$ wurde in ein 0,5 ml-Reaktionsgefäß ohne Deckel überführt. Der vorbereitete Dialyseschlauch wurde erst mit $\mathrm{H}_{2} \mathrm{O}_{\text {dest }}$ und anschließend mit PBS gespült. Ein 4 x $4 \mathrm{~cm}$-großes Stück wurde steril ausgeschnitten und mit einem Silikonring möglichst faltenfrei über die Öffnung des Gefäßes gespannt. Das Gefäß wurde vorsichtig gedreht, so dass sich die Proteinlösung luftblasenfrei über der gespannten Dialysemembran befand. Der Puffer, gegen den dialysiert werden sollte, wurde in ein Becherglas gefüllt und das Reaktionsgefäß mit Hilfe einer Styropor-Halterung so im Glas befestigt, dass die Dialysemembran luftblasenfrei in den Puffer eintauchte. Die Dialyse wurde über Nacht unter leichtem Rühren bei $4^{\circ} \mathrm{C}$ durchgeführt. Die Lagerung der dialysierten Proteine erfolgte kurzfristig bei $4^{\circ} \mathrm{C}$ oder längerfristig bei $-20^{\circ} \mathrm{C}$. Die Ausschlussgrenze der verwendeten Dialyseschläuche lag bei 12-14 kDa. Für rekombinantes STC2 (in $10 \mathrm{mM}$ Tris, 0,1\% Triton, $10 \mathrm{mM}$ DTT und 0,002\% Na-Azid) wurde DPBS (Lonza, Basel, Schweiz) als Dialysepuffer eingesetzt. Das Verhältnis von Dialysepuffer und zu dialysierenden Protein betrug mindestens 1:1000. 


\subsubsection{Konzentration von Zellkultur-Überständen}

Zellkultur-Überstände wurden wie in Kap. 3.2.7 beschrieben geerntet und anschließend über Centricon und Microcon Ultracel Zellulose-Membranen (YM-10, Millipore GmbH, Schwalbach) aufkonzentriert. Zum relativen Vergleich der Proben wurde das Volumen der einzuengenden Überstände auf die Anzahl der sezernierenden Zellen in den jeweiligen Kulturgefäßen eingestellt. Dabei habe ich festgelegt, dass $2 \mathrm{ml}$ Überstand einer Zellzahl von $2 \times 10^{6}$ Zellen/ml entsprechen. So wurden beispielsweise bei einer gemessenen Zellzahl von $1 \times 10^{6}$ Zellen/ml $4 \mathrm{ml}$ des entsprechenden Überstands verwendet. Die Proben wurden auf 30$60 \mu 1$ konzentriert und wie in Kap. 3.4.4 beschrieben weiter bearbeitet. Sollten geringere Proteinmengen analysiert werden, wurden die konzentrierten Proben vor der Weiterbearbeitung aliquotiert und so mit $\mathrm{H}_{2} \mathrm{O}_{\text {dest }}$ verdünnt, dass alle untersuchten Proben im gleichen Volumen vorlagen.

\subsubsection{Probenvorbereitung für SDS-PAGE}

Gereinigte Proteine (z.B. rekombinantes STC2 oder Bsa) und konzentrierte ZellkulturÜberstände wurden vor der SDS-PAGE mit 6x SDS-Probenpuffer versetzt und für $10 \mathrm{~min}$ im Wasserbad gekocht.

\section{6x SDS-Probenpuffer}

$\begin{array}{lll}\text { Tris/HCl (pH 6,8) } & 0,35 \mathrm{M} & \text { Zur Auftrennung von Proteinen unter } \\ \text { SDS (w/v) } & 10 \% & \text { nicht-reduzierenden Bedingungen } \\ \text { Glycerin (v/v) } & 36 \% & \text { wurde der Probenpuffer ohne DTT } \\ \text { DTT (w/v) } & 9,3 \% & \text { angesetzt. } \\ \text { Bromphenolblau (w/v) } & 0,015 \% & \end{array}$

Für die Untersuchung von Gesamtzelllysaten wurden die Zellen durch Trypsinierung geerntet (s. Kap. 3.2.4) und nach einer Zentrifugation ( $5 \mathrm{~min}, 190 \mathrm{~g}$ ) in $\mathrm{H}_{2} 0$ oder kommerziell erworbenem Lämmli Probenpuffer $\left(95^{\circ} \mathrm{C}\right)$ resuspendiert. Anschließend wurden die Proben 10 min im Wasserbad gekocht. Die Lagerung erfolgte kurzfristig bei $4^{\circ} \mathrm{C}$ oder längerfristig bei $20^{\circ} \mathrm{C}$ 
Lämmli-Probenpuffer (modifiziert)

Tris/HCl (pH 6.8)

SDS

Glycerin

Bromphenolblau

$\beta$-Mercaptoethanol
Der Lämmli-Probenpuffer wurde ohne $62.5 \mathrm{mM}$ $2 \%$ $25 \%$ $0.01 \%$ $0,05 \%$
$\beta$-Mercaptoethanol erworben (Biorad Laboratories GmbH, München). Die Substanz wurde direkt vor der Verwendung frisch zugesetzt und der Puffer für $10 \mathrm{~min}$ auf $95^{\circ} \mathrm{C}$ erhitzt.

\subsubsection{SDS-Polyacrylamidgelelektrophorese (SDS-PAGE)}

Zum Nachweis und zur Bestimmung der molekularen Masse von Proteinen habe ich diese unter denaturierenden Bedingungen gelelektrophoretisch aufgetrennt (Laemmli et al., 1970). Das anionische Detergenz SDS zerstört die Sekundär-, Tertiär- und Quartärstruktur von Proteinen und lagert sich an die hydrophoben Regionen an. Dabei wird die Eigenladung des Proteins durch die negative Ladung der SDS Moleküle überdeckt und die Auftrennung der Proteine im elektrischen Feld nur noch durch die Masse bestimmt. Um die Trennungsleistung zu verbessern arbeitet man zusätzlich mit diskontinuierlichen Gelen, bestehend aus einem grobporigen Sammelgel und einem feinporigen Trenngel. Die Elektrophorese wurde in einer vertikalen Minigelkammer (Biorad Laboratories GmbH, München) mit 8 x $10 \mathrm{~cm}$ Glasplatten und $1 \mathrm{~mm}$ Abstandhaltern durchgeführt. Folgende Lösungen wurden für die SDS-PAGE verwendet:

Acrylamid (AA) -Lösung: $\quad$ Rotiphorese Gel 30 (30\% AA, 0,8\% Bis-AA; Roth, Karlsruhe)

Trenngelpuffer: 1,5 M Tris/HCl (pH 8,8)

Sammelgelpuffer: 0,5 M Tris/HCl (pH 6,8)

SDS-Lösung: $20 \%$ SDS in $\mathrm{H}_{2} \mathrm{O}_{\text {dest }}$ APS-Lösung: $10 \%$ APS in $\mathrm{H}_{2} \mathrm{O}_{\text {dest }}$ Temed:

$99 \%$ Temed (Roth, Karlsruhe)

$\begin{array}{lll}\text { Laufpuffer }(5 \mathrm{x}): & \text { Tris } & 0,125 \mathrm{M} \\ \text { (in } \mathrm{H}_{2} \mathrm{O}_{\text {dest }}, \mathrm{pH} \mathrm{8,3)} & \text { Glycin } & 1,25 \mathrm{M} \\ & \text { SDS } & 0,5 \quad \%\end{array}$


Abhängig von der Größe der zu analysierenden Proteine wurden unterschiedliche Acrylamidkonzentrationen im Trenngel verwendet. Die Zusammensetzung der SDS-Gele war wie im Folgenden aufgeführt:

\begin{tabular}{|l|c|c|c|}
\hline Lösung & \multicolumn{2}{|c|}{ Trenngel } & Sammelgel \\
\hline Acrylamidkonzentration & $12 \%$ & $15 \%$ & $4 \%$ \\
\hline $\mathrm{H}_{2} \mathrm{O}_{\text {dest. }}$ & $1,7 \mathrm{ml}$ & $1,2 \mathrm{ml}$ & $1,5 \mathrm{ml}$ \\
\hline Trenngelpuffer & $1,25 \mathrm{ml}$ & $1,25 \mathrm{ml}$ & - \\
\hline Sammelgelpuffer & - & - & $0,625 \mathrm{ml}$ \\
\hline SDS-Lösung & $25 \mu \mathrm{l}$ & $25 \mu \mathrm{l}$ & $12,5 \mu \mathrm{l}$ \\
\hline Acrylamid-Lösung & $2 \mathrm{ml}$ & $2,5 \mathrm{ml}$ & $0,325 \mathrm{ml}$ \\
\hline APS & $25 \mu \mathrm{l}$ & $25 \mu \mathrm{l}$ & $12,5 \mu \mathrm{l}$ \\
\hline TEMED & $2,5 \mu \mathrm{l}$ & $2,5 \mu \mathrm{l}$ & $2,5 \mu \mathrm{l}$ \\
\hline
\end{tabular}

Tab. 3.1 : Zusammensetzung von SDS-Polyacrylamidgelen

Die einzelnen Komponenten des Trenngels wurden gemischt und zwischen die mit $\mathrm{H}_{2} \mathrm{O}_{\text {dest. }}$ und $70 \%(\mathrm{v} / \mathrm{v})$ Ethanol gesäuberten Glasplatten gegossen. Direkt im Anschluss wurde das Gel mit Isopropanol überschichtet. Nach der Polymerisation wurde das Isopropanol abgegossen und die Reste mit Filterpapier entfernt. Die frisch angesetzte Sammelgellösung wurde über das Trenngel geschichtet und der Kamm zur Taschenformung luftblasenfrei eingesetzt. Vor dem Auftragen wurde der Kamm entfernt und das Gel in die mit Laufpuffer gefüllte Kammer gespannt. Bis zu $35 \mu$ der vorbereiteten Proben (s. Kap. 3.4.4) wurden in die Geltaschen pipettiert und bei konstanter Voltzahl (120-200 V) und RT aufgetrennt. Zur Bestimmung der Molekularmassen wurde zusätzlich zu den Proben ein Proteinstandard (5 $\mu$ l) aufgetragen. Sollte das Gel im Anschluß einer Coomassie- oder Silberfärbung unterzogen werden, wurde ein ungefärbter Marker verwendet (BenchMark Protein Ladder, Invitrogen), für Western Blot Analysen wurden bereits gefärbte Proteine (BenchMark, Prestained Protein Ladder, Invitrogen) verwendet.

\subsubsection{Coomassie-Färbung von SDS-Polyacrylamid-Gelen}

Die Coomassie-Färbung ist eine Methode zum Färben von Proteinen (Sambrook \& Russel, 2001; A8.46). Der verwendete Farbstoff Coomassie R-250 bildet mit den basischen und aromatischen Seitenketten von Aminosäuren einen unlöslichen Komplex, wodurch die aufgetrennten Proteine im Gel sichtbar werden. Die zu färbenden SDS-Polyacrylamid-Gele (s. 
Kap. 3.4.5) wurden je nach Dicke für 2-3 h in Coomassie-Färbelösung inkubiert. Diese enthält Alkohol zum Lösen des Farbstoffs und Säure zur Fixierung der Proteine im Gel. Da der Farbstoff während der Inkubation in das gesamte Gel eindringt, war es nötig, die Gele nach der Färbung für 3-5 h oder über Nacht in Entfärber-Lösung zu waschen. Der ungebundene Farbstoff wurde dadurch entfernt und die Protein-Farbstoff-Komplexe als Bandenmuster sichtbar. Anschließend wurden die Gele zur Dokumentation eingescannt.

Coomassie-Färbelösung

Entfärber-Lösung

Coomassie R $250(\mathrm{w} / \mathrm{v}) \quad 0,05 \%$

Isopropanol (v/v) $25 \%$

Isopropanol (v/v) $25 \%$

Essigsäure (v/v)

$10 \%$

Essigsäure (v/v)

$10 \%$

\subsubsection{Silberfärbung von SDS-Polyacrylamid-Gelen}

Bei der Silberfärbung (Blum et al., 1987) handelt es sich im Vergleich zur CoomassieFärbung um eine sehr empfindliche Färbemethode, mit der geringe Proteinmengen (bis zu 1 ng pro Bande) nachgewiesen werden können. Die Färbung wurde in folgenden Schritten bei ständiger Bewegung der Gele auf einer Wippe durchgeführt:

1. Mindestens $1 \mathrm{~h}$ Inkubation in Fixierlösung

2. $3 \times 1$ min waschen in $50 \%$ Ethanol (v/v)

3. 1 min Inkubation in Natrium-Thiosulfatlösung

4. $3 \times 10 \mathrm{~s}$ waschen mit $\mathrm{H}_{2} \mathrm{O}_{\text {dest. }}$

5. 20 min Inkubation in Imprägnierlösung

6. 2 × $10 \mathrm{~s}$ waschen mit $\mathrm{H}_{2} \mathrm{O}_{\text {dest. }}$

7. Behandlung mit Entwicklerlösung, bis die Banden im Gel deutlich sichtbar sind

8. $2 \times 10 \mathrm{~s}$ mit $\mathrm{H}_{2} \mathrm{O}_{\text {dest. }}$ waschen

9. Inkubation in Stopplösung bis eine leichte Trübung sichtbar wird

10. Mindestens 15 min in $\mathrm{H}_{2} \mathrm{O}_{\text {dest. }}$ waschen

Die behandelten Gele wurden zur Dokumentation direkt im Anschluss an die Färbung eingescannt, da die Gefahr des Nachdunkels besteht. 
Fixiererlösung

Methanol

Eisessig

Formaldehyd (37 \%, v/v)

$\mathrm{H}_{2} \mathrm{O}_{\text {dest. }}$

Imprägnierlösung

$\mathrm{AgNO}_{3}$

Formaldehyd (37\% [v/v])

$\mathrm{H}_{2} \mathrm{O}_{\text {dest. }}$

Lagerung bei $4{ }^{\circ} \mathrm{C}$
Na-Thiosulfatlösung

$500 \mathrm{ml} \quad \mathrm{Na}_{2} \mathrm{~S}_{2} \mathrm{O}_{3} \times 5 \mathrm{H}_{2} \mathrm{O}$

$0,2 \mathrm{~g}$

$120 \mathrm{ml}$

$\mathrm{H}_{2} \mathrm{O}_{\text {dest. }}$

ad $1000 \mathrm{ml}$

$$
0,5 \mathrm{ml} \quad \text { Lagerung bei } 4{ }^{\circ} \mathrm{C}
$$

ad $1000 \mathrm{ml}$

\section{Entwicklerlösung}

$2 \mathrm{~g}$

$\mathrm{Na}_{2} \mathrm{CO}_{3}$

$60 \mathrm{~g}$

$0,75 \mathrm{ml}$

Formaldehyd (37 \% [v/v])

$0,5 \mathrm{ml}$

ad $1000 \mathrm{ml}$

$\mathrm{Na}_{2} \mathrm{~S}_{2} \mathrm{O}_{3} \times 5 \mathrm{H}_{2} \mathrm{O}$

$4 \mathrm{mg}$

$\mathrm{H}_{2} \mathrm{O}_{\text {dest. }}$.

ad $1000 \mathrm{ml}$

Lagerung bei $4{ }^{\circ} \mathrm{C}$

Stopplösung

EDTA

$\mathrm{H}_{2} \mathrm{O}_{\text {dest. }}$

pH 7-8 mit $\mathrm{NaOH}$ eingestellt
$18,6 \mathrm{~g}$

ad $1000 \mathrm{ml}$

\subsubsection{Western Blot Analyse}

Der gezielte Nachweis bestimmter Proteinfraktionen erfolgte mittels Antikörperfärbung im Western Blot-Verfahren. Proteinlösungen wurden im SDS-Polyacrylamidgel aufgetrennt und die Proteinbanden anschließend durch Anlegen eines elektrischen Feldes auf eine PVDF (Polyvinyldifluorid)-Membran übertragen, wo sie für die anschließende Antikörperbindung zugänglich waren. Der Nachweis der Proteine erfolgte dann über eine Enzymreaktion: An den sekundären Antikörper war Merrettichperoxidase (HRP = horseradish peroxidase) gekoppelt, die die Oxidation von Luminol katalysiert. Die dabei freiwerdende Lumineszenz konnte auf einem Autoradiographie-Film detektiert und die gebundenen Proteine dadurch selektiv nachgewiesen werden.

\section{Blotten der Proteine: Konzentrierte}

Überstände oder gereinigte Proteine wurden mittels SDS-PAGE wie in Kap. 3.4.5 beschrieben aufgetrennt. Die Übertragung der Proteine vom Gel auf die Membran (,blotten“)

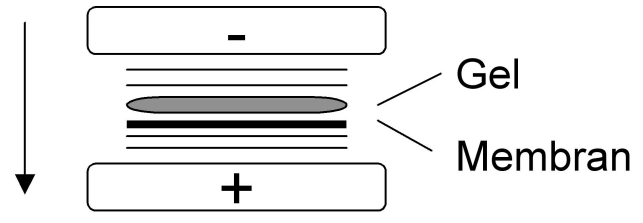

Abb. 3.3: Aufbau des Semi Dry Blots erfolgte im Semi Dry Blot-Verfahren (s. Abb. 3.3). Eine PVDF-Membran wurde in Methanol benetzt, anschließend in Transferpuffer äquilibriert und auf zwei Lagen mit Puffer getränktem 
Filterpapier gelegt. Anschließend wurde das Gel blasenfrei auf die Membran gelegt und wiederum mit zwei Lagen getränktem Filterpapier bedeckt. Der Stapel wurde dann in der Blot-Kammer (Fastblot B44, Biometra) zwischen Anodenplatte (unten) und Kathodenplatte (oben) eingeschlossen. Die Übertragung der Proteine erfolgte bei konstanter Stromstärke (44 $\mathrm{mA}$ ) für $1 \mathrm{~h}$ bei $\mathrm{RT}$.

\begin{tabular}{ll}
\hline Transferpuffer \\
Tris & $48 \mathrm{mM}$ \\
Glycin & $39 \mathrm{mM}$ \\
Methanol & $20 \%$ \\
\hline
\end{tabular}

Immundetektion der Proteine: Zum Blockieren unspezifischer Protein-Bindungsstellen wurde die Membran über Nacht bei $4^{\circ} \mathrm{C}$ auf einem Schüttler in Milchpulverlösung inkubiert. Der Nachweis von STC2 erfolgte am nächsten Tag mit polyklonalen Antikörpern (s. Tab. 2.7), die frisch in $10 \mathrm{ml}$ Milchpulver-Lösung verdünnt waren. Die Membran wurde für je 70 min bei RT auf einer Wippe nacheinander in primärem und sekundärem Antikörper inkubiert. Nach jeder Inkubation wurde die Membran kurz gespült und 2x 10 min in TBST-Lösung gewaschen. Der Nachweis der gebundenen Antikörper erfolgt mittels ECL Western Blotting Detection Reagent (Amersham GE Healthcare; Little Chalfont, UK): Je $1 \mathrm{ml}$ der Lösungen 1 und 2 wurden gemischt und die Membran sofort für 12 min darin inkubiert. Die Membran wurde entnommen und nach dem vorsichtigen Entfernen von überschüssiger Flüssigkeit in eine Autoradiographiekassette gelegt. In der Dunkelkammer wurde Röntgenfilm (Fuji Super RX, Fujifilm Europe GmbH, Düsseldorf) aufgelegt, dessen Expositionsdauer abhängig von der Signalintensität gewählt wurde. Die automatische Entwicklung der Filme fand in einer Optimax TR-Entwicklermaschine statt.

$10 \times$ TBS

$\mathrm{NaCl}$

Tris/ $\mathrm{HCl}(\mathrm{pH} 7,5)$
$1,5 \mathrm{M}$

$0,2 \mathrm{M}$
Milchpulverlösung

$\begin{array}{ll}\text { Milchpulver } & 5 \% \\ \text { Tween } & 0,02 \% \\ \text { TBS } & 1 \mathrm{x}\end{array}$

\subsubsection{Aufreinigung von Streptag II- gekoppeltem STC2 mittels Affinitätschromatographie}

Das Streptag-Aufreinigungssystem (IBA, Göttingen) basiert auf der hoch selektiven Bindung von Streptag II-Peptiden an Strep-Tactin (Voss \& Skerra, 1997). Die aus acht Aminosäuren bestehende Streptag II-Sequenz wird an das Zielprotein angefügt, sie behindert die biologische Aktivität der Fusionsproteine in der Regel nicht. Durch die selektive Bindung der 
Streptag II-Fusionsproteine an das Säulenmaterial Strep-Tactin können diese gereinigt und konzentriert werden. Die anschließende Elution von der Säule erfolgt durch die Verdrängung der Fusionsproteine mit höher-affinem Desthiobiotin.

Für die Expression von STC2 in der Zelllinie HEK 293 wurde dem Transkript die Streptag II kodierende DNA-Sequenz mittels spezieller Primer angefügt. Der Forward-Primer enthielt eine NheI-Schnittstelle (STAN-NheI) und der reverse Primer (STAN-XhoI) die Streptag IIkodierende Region sowie eine XhoI-Schnittstellen. Das Konstrukt wurde dann über NheI/XhoI-Doppelverdau in den Vektor pIRES2-EGFP kloniert und die Transfektion der Zellen und die Selektion von Einzelzellklonen wie für SH-SY5Y-Zellen beschrieben durchgeführt (s. Kap. 4.2.1.-2.). Die Aufreinigung des Fusionsproteins erfolgte aus serumfreien Zellkultur-Überständen. Polyprep Säulen (Biorad, München) wurden luftblasenfrei mit $4 \mathrm{ml}$ Strep-Tactin-Sepharose-Suspension beladen und das Säulenmaterial 3x mit $10 \mathrm{ml}$ Puffer W äquilibriert. Die aufgetauten Überstände (s. Kap. 3.2.7) wurden vor dem Auftragen auf die Säule bei $4^{\circ} \mathrm{C}$ und $3000 \mathrm{~g}$ für $10 \mathrm{~min}$ zentrifugiert, um unlösliche Rückstände zu entfernen. Die Fließgeschwindigkeit über die Säule betrug ca. 0,5 ml/min. Die gebundenen Fusionsproteine wurden 5x mit $2 \mathrm{ml}$ Puffer W gewaschen und anschließend mit 7 $\mathrm{ml}$ Puffer E in $1 \mathrm{ml}$ Fraktionen eluiert. Aliquots der gesammelten Fraktionen 1-7 wurden im Western Blot (s. Kap. 3.4.8) untersucht und die STC2-haltigen Fraktionen anschließend über Microcon Ultracel-Zellulose-Membranen (YM-10, Millipore GmbH, Schwalbach) aufkonzentriert. Die Proteinkonzentration und Reinheit wurde durch Messungen am NanoDrop und SDS-PAGE mit anschließender Silberfärbung bestimmt (s. Kap 3.4.1 und 3.4.4-7). Abbildung 3.4 zeigt die eluierten Proteinfraktionen nach Western Blot Analyse (a.) und Silberfärbung (b.). Durch die Silberfärbung konnte außerdem gezeigt werden, dass die Proteine keine weiteren Verunreinigungen enthielten. Die Analyse von nicht reduziertem STC2 im Vergleich zu reduziertem Protein wurde durchgeführt, um nachzuweisen, dass STC2 nach Aufreinigung als Dimer vorliegt (Abb. 3.4.c). Die Lagerung der konzentrierten Proteine erfolgte kurzfristig bei $4^{\circ} \mathrm{C}$ oder längerfristig bei $-20^{\circ} \mathrm{C}$. Zur Regeneration des Säulenmaterials wurde das Desthiobiotin mit Puffer R (3x $10 \mathrm{ml})$ von der Säule entfernt und diese bis zur nächsten Aufreinigung bei $4^{\circ} \mathrm{C}$ gelagert. 


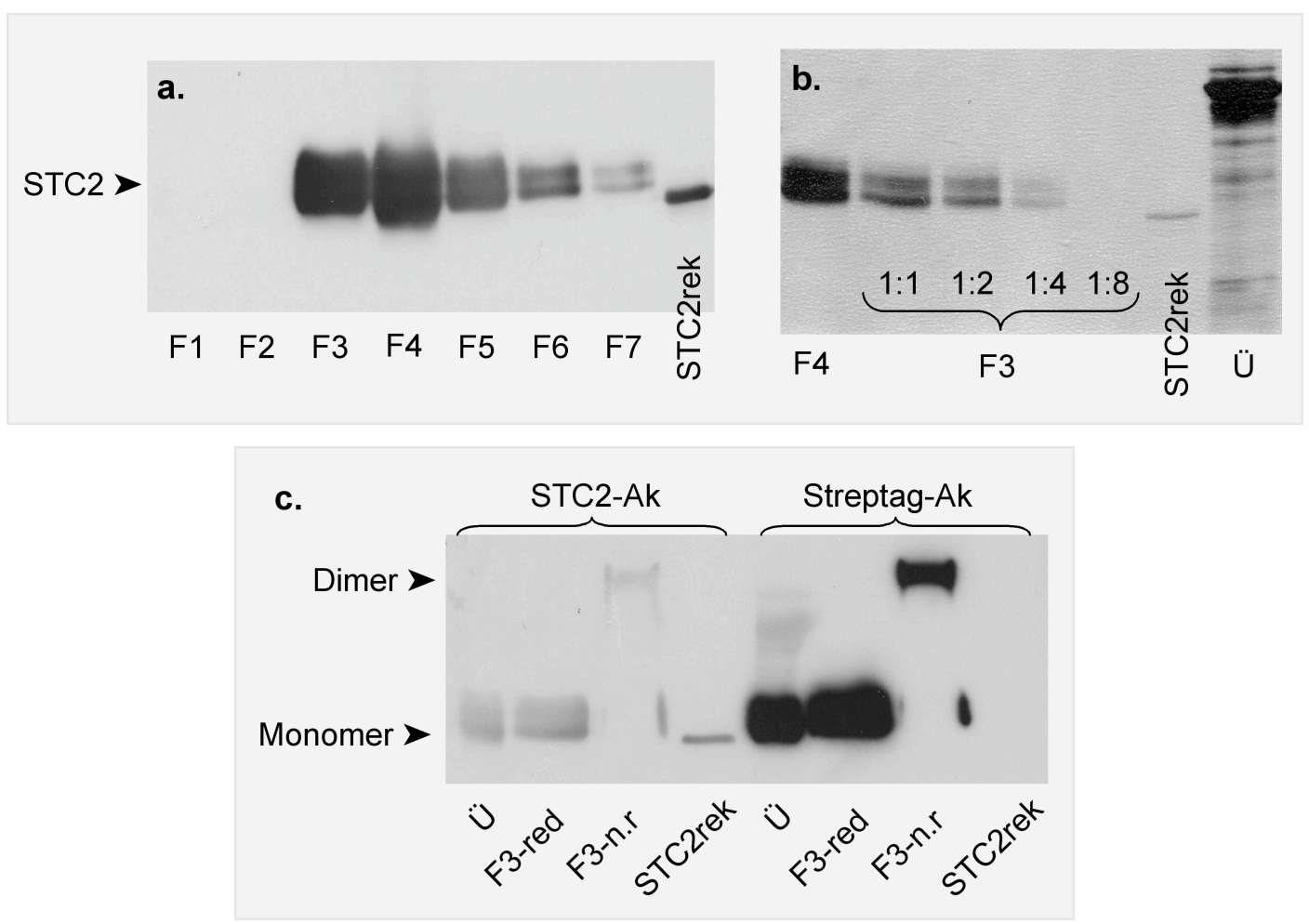

Abb. 3.4: STC2-Aufreinigung aus Überständen von transfizierten HEK-293-Zellen mittels AffinitätsSäulenchromatographie. (a.) Western Blot Analyse: Überstände der Transfektanten H10 und H12 wurden auf Strep-Tactin-Säulen aufgetragen, mehrfach gewaschen und die gebundenen Proteine anschließend mit Desthiobiotin-Puffer eluiert. Das Eluat wurde in 1-ml-Fraktionen gesammelt (F1-F7) und STC2 mittels polyklonaler STC2-Antikörper nachgewiesen. STC2rek (100 ng) wurde als Mengenstandard verwendet. (b.) SDS-PAGE und Silberfärbung wurden zur Bestimmung von Konzentration und Reinheit der aufgereinigten Fraktionen (F3 und F4) eingesetzt. Von F3 (30 $\mu$ l) wurde ein Verdünnungsreihe hergestellt $(1: 1 ; 1: 2,1: 4$ und 1:8) und mit einer definierten Menge STC2rek (200 ng) verglichen. Der für die Säulenaufreinigung eingesetzte Überstand (Ü) wurde ebenfalls aufgetrennt. (c.)Western Blot Analyse der reduzierten und nicht-reduzierten STC2Fraktionen vor und nach Affinitätschromatographie. $30 \mu \mathrm{l}$ der Fraktion F3 wurden unter reduzierenden und nicht-reduzierenden Bedingungen im SDS-Gel aufgetrennt. Der Proteinnachweis erfolgte durch polyklonale Stc2-Antikörper (STC2-Ak) bzw. durch Antikörper gegen das angefügte Streptag IIPeptid (Streptag-Ak). Konzentrierter Überstand des HEK-Transfektanten H10 (Ü) und STC2rek (100 ng) wurden ebenfalls unter reduzierenden Bedingungen analysiert. Der aufgetragene Überstand entspricht jeweils der Proteinexpression von $0,5 \times 10^{6}$ Zellen (s. Kap. 3.4.3).

\section{$\underline{\text { Puffer W }}$}

Tris/ $\mathrm{HCl}(\mathrm{pH} 8) \quad 100 \mathrm{mM}$

$\mathrm{NaCl} \quad 150 \mathrm{mM}$
Puffer W wurde als 10-fach Lösung angesetzt und autoklaviert. Zum Herstellen von Puffer E und Puffer R wurden Desthiobiotin $(2,5 \mathrm{mM})$ bzw. HABA (1 mM) als sterile Stammlösungen zugesetzt. 


\subsubsection{Zymographie}

Bei der Zymographie wird die Aktivität von Enzymen durch die Umsetzung geeigneter Substrate nachgewiesen. Das Substrat wird in ein Polyacrylamid-Gel (SDS-PAGE) einpolymerisiert und die zu untersuchenden Proteinfraktionen dann elektrophoretisch in diesem Gel aufgetrennt. Nach Renaturierung der aufgetrennten Proteine kann die Enzymaktivität anhand der Substratumsetzung im Gel nachgewiesen werden (Heussen \& Dowdle, 1980; Kleiner \& Stetler-Stevenson, 1994).

Im Rahmen meiner Arbeit wurden Zymographien zum Nachweis der Aktivität von MMP2 (66 kDa) und MMP9 (86 kDa) in Zellkulturüberständen eingesetzt.

Diese Enzyme sind in der Lage, Gelatine abzubauen und werden deshalb auch als Gelatinase A und B

\begin{tabular}{|lc|}
\hline Reaktionspuffer & \\
Tris/ $\mathrm{HCl}(\mathrm{pH} 7.6)$ & $50 \mathrm{mM}$ \\
$\mathrm{CaCl}_{2}$ & $5 \mathrm{mM}$ \\
$\mathrm{NaN}_{3}$ & $0,02 \%$ \\
\hline
\end{tabular}
bezeichnet. Die 10-fach konzentrierten Zellkulturüberstände (s. Kap. 3.2.7 und 3.4.3) wurden mit 6x SDS-Probenpuffer ohne DTT versetzt und ohne Kochen für die anschließende SDSPAGE (s. 3.4.5) verwendet. In den $12 \%$ igen Polyacrylamidgelen war zusätzlich $0,1 \%$ Gelatine einpolymerisiert. Nach der elektrophoretischen Auftrennung wurde das Gel zur Renaturierung der Proteine 3 x für 20 min in $0,1 \%$ Triton X 100 inkubiert. Die Substratumsetzung erfolgte für $12-20$ h bei $37^{\circ} \mathrm{C}$. Anschließend wurde das Gel wie in Kap. 3.4.6 beschrieben mit Coomassie-Blau gefärbt. Die Coomassie-Färbung des Substrats führt zu einem blauen Hintergrund, auf dem Banden aktiver Proteasen durch den Substratabbau ungefärbt erscheinen.

\subsection{Zellkultur-Assays}

\subsubsection{Proliferationsassay}

Um die Teilungsgeschwindigkeit von Zelllinien bestimmen und vergleichen zu können wurde die Proliferation über 6 Tage gemessen. Durch Kristallviolett-Färbung der Zellen, bei der die gebundene Farbstoffmenge proportional zur Zellzahl ist, wurde die Zellpopulation quantifiziert (Bernhardt et al, 1992). Die zu untersuchenden Zellen wurden geerntet, gezählt, in frischem RPMI-Medium resuspendiert und in einer Dichte von $5 \times 10^{3}$ Zellen pro $150 \mu 1$ auf 96well-Platten ausplattiert (s. Kap. 3.2.4 und 3.2.6). Für jeden zu messenden Zeitpunkt wurde eine eigene Platte angelegt und jede Zelllinie jeweils in 8 Replikaten darauf ausplattiert. Die Platten wurden bei $37^{\circ} \mathrm{C}$ unter $5 \% \quad \mathrm{CO}_{2}$-Atmosphäre inkubiert und $\mathrm{zu}$ verschiedenen Zeitpunkten geerntet. Als Ausgangswert wurde die 1. Platte $6 \mathrm{~h}$ nach 
Inkubationsstart fixiert. $\mathrm{Zu}$ diesem Zeitpunkt waren die Zellen bereits adhärent, zeigten aber noch keine deutliche Proliferation. Die Fixierung der weiteren Platten erfolgte jeweils im Abstand von $24 \mathrm{~h}$.

Fixierung: Zur Fixierung der Zellen wurden $50 \mu \mathrm{l}$ Glutaraldehyd (5 \%ig) pro $150 \mu 1$ Medium zugesetzt und die Platten für 20 min bei RT auf dem Schüttler inkubiert. Der Überstand wurde verworfen, die fixierten Zellen $2 \mathrm{x}$ vorsichtig mit $\mathrm{H}_{2} \mathrm{O}$ gewaschen und die Platten im Abzug getrocknet.

Kristallviolett-Färbung: Die Färbung mit Kristallviolett erfolgte für alle Platten einer Versuchsserie gleichzeitig: $100 \mu \mathrm{l}$ einer 0,1\%igen Kristallviolettlösung wurden vorsichtig auf die Zellen pipettiert und die Platten 20 min unter Schütteln bei RT inkubiert. Anschließend wurden die Zellen 3 x mit $\mathrm{H}_{2} \mathrm{O}$ gewaschen und die Platten luftgetrocknet. Zum Lösen des gebundenen Farbstoffs wurden $100 \mu$ l Essigsäure (10 \%ig) zu den Zellen gegeben und die Platten so lange geschüttelt bis der Farbstoff gelöst war. Die anschließende Absorptionsmessung erfolgte bei $595 \mathrm{~nm}$ am Tecan Sunrise Mikrotiterplatten-Lesegerät. Zur Auswertung wurden die Absorptionswerte der 1. Platte gleich 100 gesetzt und die Proliferation als Prozent von Tag 0 angegeben.

\subsubsection{Durchflusszytometrie (FACS)}

Die Durchflusszytometrie, auch als FACS (Fluorescence-Activated Cell Sorting)-Analyse bezeichnet, ist eine Methode zur Detektion, Messung und Analyse von einzelnen Zellen oder Partikeln. Während diese in einem Flüssigkeitsstrom durch einen Laserstrahl treten, wird die relative Größe durch die Menge des absorbierten Lichts (Forward Scatter) und die relative optische Dichte (Granularität) durch die Menge des reflektierten Lichts (Side Scatter) berechnet. Außerdem kann gleichzeitig detektiert werden, ob und welche Fluoreszenz emittiert wird. Im Rahmen meiner Arbeit habe ich Zellzyklusanalysen nach Nicoletti et al. (1991) am FACScan-Zytometer durchgeführt. Für die Analysen wurde der Fluoreszenzfarbstoff Propidiumiodid (PI) verwendet, dieser interkaliert nach der Lyse der Zellen mit der DNA im Kern. Die emittierte Fluoreszenz ist proportional zum DNA-Gehalt und gibt dadurch Aufschluss über den Zellzyklusstatus: In der G1-Phase besitzen die Zellen einen einfachen Chromosomensatz. Während der S-Phase wird die DNA repliziert, bis in der G2-Phase der doppelte Chromosomensatz vorhanden ist. Die < G1-Phase bezieht sich auf präapoptotische Kerne, deren DNA-Gehalt unter dem einfachen Chromosomensatz liegt. 
Die zu untersuchenden Zellen wurden durch Trypsinierung geerntet und die Zellzahl

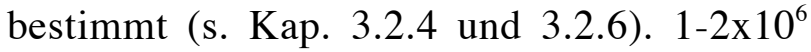
Zellen wurden in 0,5 $\mathrm{ml}$ hypotonem PI-Puffer

\begin{tabular}{|ll|}
\hline$\underline{\text { PI-Puffer }}$ & \\
Natriumcitrat (w/v) & $0,1 \%$ \\
Triton X $100(\mathrm{v} / \mathrm{v})$ & $0,1 \%$ \\
Propidiumiodid & $50 \mu \mathrm{g} / \mathrm{ml}$ \\
\hline
\end{tabular}
resuspendiert und in 5-ml Rundbodenröhrchen

(BD; San Diego, CA) überführt. Die Zellen wurden mit einer Geschwindigkeit von ca. 100 Events/s analysiert und das Durchflusszytometer vor und nach der Analyse mit FACSFlowPuffer (BD, San Diego, CA) gespült. Die Auswertung der gesammelten Daten erfolgte mit Hilfe der FlowJo 6.4.7-Software (Treestar Inc, Ashland, OR) unter Verwendung des DeanJett-Fox Models (Fox et al., 1980).

\subsubsection{Invasionsassay}

Das invasive Potential von Zellen wurde unter Verwendung von BioCoat Matrigel Invasionskammern der Firma BD (San Diego, CA) bestimmt. Diese Kammern bestehen aus einer Membran mit $8 \mu \mathrm{m}$-Poren über der sich eine Schicht Matrigel befindet, ein von Tumorzellen exprimiertes Proteingemisch, das der extrazellulären Matrix vieler Gewebe ähnelt. Durch einen Serumgradienten zur Migration angeregt, können invasive Zellen die Matrigelschicht zersetzen. Sie verbleiben anschließend auf der Unterseite der Membran, wo sie durch Hämatoxylin-Färbung nachgewiesen werden können.

Zur Vorbereitung der Invasionsassays wurden die verwendeten BioCoat-Invasionskammern für $1 \mathrm{~h}$ bei $37^{\circ} \mathrm{C}$ in serumfreiem Medium äquilibriert. In dieser Zeit konnten die Zellen geerntet, gezählt (s. 3.2.4 und 3.2.6) und in einer Dicht von $1 \times 10^{6}$ Zellen/ml in serumfreiem RPMI-Medium resuspendiert werden. Das Medium in den vorinkubierten Kammern wurde entfernt und vorsichtig durch die resuspendierten Zellen $\left(5 \times 10^{5}\right.$ Zellen/0,5 ml) ersetzt. Die Kammern einer 24well-Platte wurden mit 0,5 ml FCS-haltigem Medium befüllt und die mit Zellen gefüllten Invasionskammern hinein gehängt. Nach $24 \mathrm{~h}$ bei $37^{\circ} \mathrm{C}$ und $5 \% \mathrm{CO}_{2}$ wurden die Kammern entnommen und das Matrigel mit den nicht migrierten Zellen mit einem Wattestäbchen entfernt. Die Membranen mit den migrierten Zellen auf der Unterseite wurden für ca. 15 min bei RT getrocknet und anschließend $1 \mathrm{~min}$ in Methanol fixiert.

Hämatoxylin-Eosin-Färbung: Die Kammern wurden mit $\mathrm{H}_{2} \mathrm{O}$ befeuchtet und für 2 min in Hämatoxylinlösung (Roth, Karlsruhe) inkubiert. Anschließend wurde die überschüssige Farbe mit $\mathrm{H}_{2} \mathrm{O}$ abgespült und die Kammern 2x für 1 min in $\mathrm{H}_{2} \mathrm{O}$ gestellt. Es wurde weitere 2x mit 
$\mathrm{H}_{2} \mathrm{O}$ gewaschen und die Kammern für 3 min in einer 1 \%igen Eosinlösung inkubiert. Das überschüssige Eosin wurde ebenfalls durch Waschen entfernt und die Kammern bei RT getrocknet. Hämatoxylin färbt die Kerne während durch Eosin das Zytoplasma der Zellen sichtbar wird. Für die mikroskopische Untersuchung wurden die Membranen ausgeschnitten und mit Aquamount-Lösung luftblasen-frei eingedeckelt. Die Zahl der migrierten Zellen wurde durch Auszählen am Mikroskop (Leica 5000B) bei 200-facher Vergrößerung bestimmt und typische Ausschnitte fotografiert.

\subsubsection{Apoptose-ELISA}

Zur Bestimmung der Apoptoseneigung von Zellen wurde ein Sandwich-ELISA durchgeführt. Unter ELISA (Enzyme-Linked Immunosorbent Assay) versteht man ein Antikörperabhängiges Nachweisverfahren, das auf einer enzymatischen Farbreaktion basiert. Der hier verwendete Cell Death Detection ELISA beruht auf dem Nachweis von Mono- und Oligonukleosomen, die bereits mehrere Stunden vor dem Zusammenbruch der Plasmamembran typischerweise im Zytoplasma der apoptotischen Zellen nachzuweisen sind. Durch einen Biotin-gekoppelten Anti-Histon-Antikörper werden die Nukleosomen an die Streptavidin-beschichtete Oberfläche einer Mikrotiterplatte gebunden. Ein weiterer Peroxidase-gekoppelter Antikörper reagiert mit dem DNA-Anteil der Nukleosomen (Sandwich). Die Antigenmenge und somit die Apoptoseneigung der Zellen kann anschließend anhand der Peroxidase-katalysierten Substratumsetzung relativ quantifiziert werden. Zur Induktion von Apoptose wurde Staurosporin verwendet, eine Proteinkinase, die durch Hemmung von Topoisomerase II Apoptose-induzierend wirkt (Bursztajn et al., 2001).

Den Cell Death Detection ELISA habe ich sowohl zur Bestimmung der Basis-Apoptose als auch zur Bestimmung der Staurosporin-induzierten Apoptose eingesetzt (Bursztajn et al. 2001). Die zu untersuchenden Zellen wurden durch Trypsinierung geerntet und $10^{4}$ Zellen in $100 \mu 1$ RPMI-Medium in 96well-Platten ausplattiert (s. Kap. 3.2.4 und 3.2.6). Nach 12-20 h bei $37^{\circ} \mathrm{C}$ und $5 \% \mathrm{CO}_{2}$ wurden die Zellen lysiert und das Lysat auf die Antikörperbeschichtete Mikrotiterplatte überführt. Anschließend wurde der Biotin-gekoppelte Antikörper zugesetzt und die Platten für 2 h bei RT inkubiert. Nach mehrmaligem Waschen mit Inkubationspuffer wurde das Peroxidasesubstrat zugegeben und die Platten inkubiert, bis eine Farbentwicklung sichtbar wurde (5-20 min). Die anschließende Absorptionmessung erfolgte bei $405 \mathrm{~nm}$ (Referenz-Wellenlänge 490). Sollte die induzierte Apoptose gemessen werden, wurde den Zellen $2 \mathrm{~h}$ nach Inkubationsstart DMSO-gelöstes Staurosporin in 
verschiedenen Konzentrationen $(0 \mu \mathrm{M}, 0,5 \mu \mathrm{M}, 1 \mu \mathrm{M}, 10 \mu \mathrm{M})$ zugesetzt. Die Zellen wurden anschließend für weitere $12 \mathrm{~h}$ inkubiert und die Apoptose wie beschrieben bestimmt.

\subsection{Chorioallantoismembran Assay}

Die Entwicklung von Hühnerembryonen (Gallus gallus domesticus) dauert bis zum Schlüpfen in der Regel 21 Tage. Ab Tag 10 kann die Chorioallantoismembran (CAM) der Hühnerembryonen dazu verwendet werden Tumoren anzuziehen, oder die Wirkung pharmakologischer Substanzen zu testen. Das Assay wurde in drei Phasen durchgeführt: Vor der Entwicklung der CAM wurden die Eier gefenstert und dadurch die später zu nutzenden Bereiche zugänglich gemacht. In der zweiten Phase wurden die Zellen bzw. die gereinigten Substanzen auf die CAM aufgetragen. Abgeschlossen wurde der Versuch durch die Ernte der entstandenen Tumoren bzw. der beeinflussten CAM-Bereiche. Im Rahmen meiner Arbeit wurde mit dem Modell die Tumorbildung von STC2-transfizierten Zellen und die Wirkung des gereinigten STC2-Proteins untersucht.

Anzucht von experimentellen Tumoren auf der CAM: Alle Geräte wurden vor Gebrauch sterilisiert und während der Verwendung mehrfach mit 70 \%igem Ethanol gereinigt. Die befruchteten Eier wurden bei $37^{\circ} \mathrm{C}$ und $80 \%$ relativer Luftfeuchtigkeit inkubiert. An Tag 3 der Inkubation wurde ein etwa $1 \mathrm{~cm}^{2}$-großes Fenster oberhalb des Embryos in die Eierschale gesägt und die darunter liegende Eihaut vorsichtig entfernt. Die angesägte Schale wurde vor dem Entfernen mit Locke-Lösung befeuchtet, um sie leichter abheben zu können. Im Bereich der Luftkammer wurde die Schale ebenfalls angesägt, was zum Entweichen von Luft und damit zum Absenken des Embryos führte. Das Fenster wurde mit Leukosilk S (BSNmedical $\mathrm{GmbH}$, Hamburg) verschlossen und die Eier weiter inkubiert. An Tag 10 wurden die Tumorzellen auf die CAM aufgetragen. Dafür wurden die Zellen durch Trypsinieren geerntet und in einer Dichte von $10^{7}$ Zellen in $40 \mu$ RPMI-Medium resuspendiert. Eine ThermanoxScheibe (Thermanox Plastic Coverslips, Nunc, Rochester NY) wurde in der Mitte mit einer ringförmigen Aussparung versehen und auf die CAM gelegt. Die Membran wurde im Bereich der Aussparung mit einer angerauten Glassonde leicht angekratzt und $40 \mu 1$ Zellsuspension $\left(10^{7}\right.$ Zellen) in die Aussparung pipettiert. Die Eier wurden wieder verschlossen und weiter inkubiert. An Tag 17 wurden die entstandenen Tumoren geerntet. Zur Herstellung von Semidünnschnitten erfolgte eine Fixierung in Karnowsky-Lösung. Für Gefrierschnitte wurde eine Fixierung in 4\% PFA durchgeführt. Zur Dokumentation wurden die Tumoren am 
Stereomikroskop (Leica Microsystems) untersucht und fotografiert. Die Lagerung erfolgt in Fixans bei $4^{\circ} \mathrm{C}$.

Untersuchung von gereinigtem STC2 auf der CAM: Die Hühnereier wurden, wie bei der Anzucht von Tumoren beschrieben, gefenstert und anschließend bis Tag 13 weiter inkubiert. $\mathrm{Zu}$ diesem Zeitpunkt ist die CAM vollständig ausgebildet, wodurch die Effekte der Trägerscheibe minimiert werden. $3 \mu \mathrm{g}$ dialysiertes STC2-Protein (s. Kap 3.4.2) wurde auf Thermanox-Trägerscheiben (etwa $0,25 \mathrm{~cm}^{2}$ ) aufgetragen und unter der Sterilbank eingetrocknet. Als Kontrolle wurden $3 \mu \mathrm{g}$ Bsa in Dialysepuffer verwendet. Die Scheiben wurden mit der Proteinseite nach unten auf die CAM der Embryonen aufgelegt. Nach $24 \mathrm{~h}$ wurde die CAM durch Auftragen von Karnowsky-Lösung fixiert und der unter der Trägerscheibe liegende Bereich sowie Teile des umgebenden Gewebes ausgeschnitten, stereomikroskopisch untersucht und fotografiert. Die Lagerung der fixierten Membranen erfolgte in $0,15 \mathrm{M}$ Sörensen-Puffer $(\mathrm{pH} 7,4)$ bei $4^{\circ} \mathrm{C}$.

Sörensen-Puffer (0,3 M; pH 7,4))

$\mathrm{KH}_{2} \mathrm{PO}_{4}(0,3 \mathrm{M})$

$\mathrm{Na}_{2} \mathrm{HPO}_{4}(0,3 \mathrm{M})$

Locke-Lösung

$\mathrm{NaCl}(1,61 \mathrm{M})$

$\mathrm{KCl}(0,16 \mathrm{M})$

$\mathrm{CaCl}_{2}(0,14 \mathrm{M})$

$\mathrm{H}_{2} \mathrm{O}_{\text {dest }}$
$18,2 \mathrm{ml}$

$81,8 \mathrm{ml}$

$100 \mathrm{ml}$

$37 \mathrm{ml}$

$21 \mathrm{ml}$

ad $1000 \mathrm{ml}$
Karnowsky-Lösung

Glutaraldehyd $\quad 3 \%$

Formaldehyd $\quad 3 \%$

Sörensen-Puffer (pH 7,4) $\quad 0,15 \mathrm{M}$

Nach dem Autoklavieren wurde der Locke-Lösung 1\%ig Pen/Strep-

Lösung (Lonza; Basel, Schweiz) zugesetzt.

\subsubsection{Herstellung von Semidünnschnitten}

Um Tumoren und CAM-Gewebe morphologisch zu untersuchen wurden Semidünnschnitte hergestellt und mit Richardson-Lösung angefärbt. Die fixierten Tumoren wurden für $1 \mathrm{~h}$ in Karnowsky-Lösung (s. Kap. 3.6) und weitere 90 min in Osmium-Lösung inkubiert. Nach der Inkubation folgte jeweils ein Waschschritt mit 0,15 M Sörensen-Puffer (s. Kap. 3.6) für 10 min. Die Proben wurden anschließend in einer aufsteigenden Ethanolserie (30 \%, $50 \%, 70 \%$ und $90 \%$ ) für je 10 min und 2 x für 10 min in $100 \%$ igem Ethanol entwässert. Es folgten zwei 15-minütige Inkubationsschritte in Propylenoxid, eine weitere Inkubation für $1 \mathrm{~h}$ in PropylenEpon-Mix (1:1) und abschließend eine Übernacht-Inkubation in Propylen-Epon-Mix (1:3). 
Die Einbettung der Proben erfolgte für $24 \mathrm{~h}$ bei $60^{\circ} \mathrm{C}$ in Epon. Anschließend wurden 0,5 $\mu \mathrm{m}$ dicke Schnitte am Ultracut E-Schneidegerät hergestellt und für 30 s mit Richardson-Lösung gefärbt. Der überschüssige Farbstoff wurde abgespült und die Schnitte in DPX-Mount (Fluka, Buchs, Schweiz) eingedeckt. Die anschließende Untersuchung erfolgt am Hellfeld-Mikroskop (Leica Microsystems).

Epon besteht aus: 6 vol. Epon A-Lösung + 4 vol. Epon B-Lösung + 0,18 vol. DMP-30:

Epon A-Lösung

Glycidether 100

DDSA

Richardson-Lösung

Azur II-Lösung (1\%)

Methylenblau-Lösung (2\%)

Borax-Lösung (2\%)

\section{Epon B-Lösung}

$31 \mathrm{ml}$ Glycidether 100

MNA

$25 \mathrm{ml}$

$50 \mathrm{ml}$

Osmium-Lösung

2 vol.

Osmium (2\%)

1 vol.

1 vol.

Sörensen-Puffer (0,3 M)

1 vol.

\subsubsection{Herstellung von Gefrierschnitten}

Für immunhistologische Färbungen wurden

\section{$\underline{0,1 \mathrm{M} \mathrm{KPP}}$}

Gewebe in Paraformaldehyd (PFA) fixiert und

$\mathrm{KH}_{2} \mathrm{PO}_{4}$

$0,1 \mathrm{M}$

Gefrierschnitte (Kryoschnitte) hergestellt. Durch

$\mathrm{K}_{2} \mathrm{HPO}_{4}$

$0,1 \mathrm{M}$

die Fixierung mit PFA werden Proteine vernetzt,

um die Zellstrukturen zu erhalten und Gewebezerfall vorzubeugen. Die Wirkung ist allerdings im Vergleich zu Glutaraldehyd schwächer, wodurch die Antigen-Epitope im Präparat besser für Antikörper zugänglich bleiben. Tumormaterial (s. Kap 3.6) wurde zur Fixierung für 90 min in einer 4 \%igen PFA-Lösung inkubiert und anschließend 3x für 20 min in 0,1 M KPP gewaschen. Die Proben wurden $10 \mathrm{~min}$ in $5 \%$ iger und $45 \mathrm{~min}$ in $15 \%$ iger SaccharoseLösung inkubiert. Die Einbettung erfolgte in Tissue Tec (Sakura Finetek, Zoeterwoude, NL) für 30 min bei RT und wurde durch das Einfrieren der Proben bei $-80^{\circ} \mathrm{C}$ abgeschlossen. Für die anschließende Immunfärbung wurden 16-20 $\mu$ m-dicke Schnitte am Leica Kryotom hergestellt und auf Superfrost Objektträger aufgezogen. Die Lagerung erfolgte bei $-20^{\circ} \mathrm{C}$. 


\subsubsection{Immunhistologie von Gefrierschnitten}

Zur Markierung der Gefäßstrukturen auf Gefrierschnitten wurden Immunfärbungen durchgeführt. Der Nachweis von Endothelzellen erfolgte mit grün-fluoreszierendem Sambucus nigra Agglutinin (Fitc-gekoppelt), welches bestimmte Zuckerreste auf der Glykokalyx der Zellen erkennt (Vector laboratories, www.vectorlabs.com). Glatte Muskelzellen wurden durch polyklonale $\alpha$-SMA-Antikörper erkannt und mit einem sekundären rot-fluoreszierenden Ziege anti-Maus IgG-Antikörper (Alexa Fluor 594) nachgewiesen (s. Tab. 2.7).

Die Tumorschnitte wurden aufgetaut und für $1 \mathrm{~h}$ bei RT getrocknet. Vor der Blockierung mit $1 \%$ Bsa-Lösung (in 1x PBS mit 0,1\% Triton X 100) wurden die Schnitte für 10 min bei $-20^{\circ} \mathrm{C}$ in Aceton-Methanol-Lösung (1:1) inkubiert und bei RT getrocknet (10 min). Die Antikörper und das Sambucus Nigra Agglutinin wurden in 1 x PBS verdünnt (1:400) und für eine Doppelfärbung eingesetzt: Der erste Antikörper und das Sambucus Nigra Agglutinin wurden 1:1 gemischt und 100-200 $\mu 1$ auf die Präparate pipettiert. Die Antikörperreaktion wurde für $1 \mathrm{~h}$ in einer dunklen und feuchten Kammer durchgeführt. Anschließend folgten zwei Waschschritt mit 0,1 M KPP (s. Kap. 3.6.2). Der sekundäre Antikörper wurde für 5 min zentrifugiert, damit sich störende Kristalle absetzen konnten (16.000 g). Anschließend wurden 50-100 $\mu \mathrm{l}$ auf das Präparat aufgetragen und die Proben erneut $1 \mathrm{~h}$ im Dunkeln bei hoher Luftfeuchtigkeit inkubiert. Nach mehreren Waschschritten mit 0,1 M KPP wurden die Schnitte mit Fluoromount-G (Southern Biotech; Birmingham, AL) eingedeckt und bis zur Fluoreszenz-mikroskopischen Analyse bei $-20^{\circ} \mathrm{C}$ gelagert.

\subsection{Statistische Methoden}

\subsubsection{Mittelwerte und Standardabweichung}

Forschungsergebnisse bekommen dadurch Bedeutung, dass sie zu unterschiedlichen Zeitpunkten und in unabhängigen Ansätzen reproduziert werden können. Um diese Daten zusammen zu fassen, wurden Mittelwerte errechnet und die Streuung der gemittelten Daten durch ihre Standardabweichung (STABWN) angegeben. Der Median wurde ebenfalls zum Mitteln von Daten verwendet: Sind die Werte nach Größe geordnet, ist der Median der Wert, der in der Mitte der Zahlenreihe liegt. Extrem abweichende Einzelwerte haben bei dieser Methode weniger Gewichtung im Vergleich zum arithmetischen Mittelwert. Diese statistische Aufarbeitung wurde mit Hilfe des Programms Microsoft Excel v. X durchgeführt. 


\subsubsection{Prüfung der statistischen Signifikanz}

Die statistische Signifikanz von Ergebnissen wird durch den sogenannten p-Wert, die Irrtumswahrscheinlichkeit, ausgedrückt. Dieser Wert gibt Auskunft darüber, wie wahrscheinlich ein Zutreffen der ermittelten Ereignisse ist. Liegt die Wahrscheinlichkeit unter einem gewählten Signifikanzniveau von $5 \%$, ist der p-Wert größer als 0,05. Das bedeutet, die ermittelte Korrelation ist nicht statistisch signifikant, da die Wahrscheinlichkeit für ein zufälliges Eintreffen zu hoch ist. Umgekehrt besteht bei p-Werten kleiner als 0,05 statistische Signifikanz, da die Wahrscheinlichkeit für ein zufälliges Eintreffen niedrig ist. Die in Kap. 3.7 aufgeführten Analysen wurden in Kooperation mit der Abteilung für Genetische Epidemiologie (Universität Göttingen) unter Verwendung der SAS v. 9.1.-Software durchgeführt.

\subsubsection{Korrelationskoeffizienten}

Um den Zusammenhang zwischen verschiedenen Faktoren zu untersuchen, wurden Korrelationskoeffizienten berechnet: Diese sind ein dimensionsloses Maß für den Grad des linearen Zusammenhangs, wobei Werte von 1 (positiv) und -1 (revers) eine absolute Korrelation angeben. Um zu entscheiden, welche Berechnungsmethode einzusetzen ist, wurden die Daten zuerst auf Normalverteilung geprüft. Lag diese vor, wurde der PearsonKorrelationskoeffizient verwendet. Der Spearman-Korrelationskoeffizient wurde für nicht normal verteilte Daten berechnet. Zur Prüfung der statistische Signifikanz der ermittelten Korrelation (p-Wert) wurde der T-Test verwendet.

\subsubsection{Proliferationsunterschiede}

Um die statistische Signifikanz von Proliferationsunterschieden zu testen wurden drei unabhängige Proliferationsassays mit je 8 Replikaten untersucht, und dabei die Proliferation von Tag 0 mit der Proliferation an Tag 5 und Tag 6 verglichen. Der Kruskal-Wallis Test und der Wilcoxon-Mann-Whitney Test wurden durchgeführt. Aufgrund von multiplen Vergleichen, also der mehrfachen Verwendung der Daten, mussten die resultierenden p-Werte anschließend nach Holms angepasst werden.

\subsubsection{Unterschiede in der Apoptoseneigung}

Um die statistische Signifikanz von Unterschieden der Apoptoseneigung der Zellen zu testen wurde der Wilcoxon Signed Rank Sum Test durchgeführt. Man benutzt diesen nicht- 
parametrischen Test, wenn man zwei gepaarte Gruppen kontinuierlicher Werte vergleichen möchte, die nicht der Normalverteilung unterliegen. 


\section{Ergebnisse}

\subsection{Untersuchungen der STC2-Expression in humanen NB-Zelllinien}

\subsubsection{STC2-mRNA-Expression in humanen NB-Zelllinien}

Um den STC2-Status im humanen NB zu untersuchen, habe ich in 24 NB-Zelllinien die mRNA-Expression mittels Real-time RT-PCR bestimmt (Abb. 4.1a). Die Ergebnisse einer konventionellen Multiplex RT-PCR Analyse von STC2 und $\beta$-AKTIN wurden ergänzend dargestellt (Abb. 4.1b). Die untersuchten NB-Zelllinien zeigen Unterschiede in der STC2Expression. Die höchste Expression wurde in KB24 und NGP nachgewiesen, eine moderate Expression war u. a. in SH-IN, SMS-KAN und KELLY zu finden. Die Zelllinien SH-SY5Y, GI-MEN und SH-EP sind STC2-negativ. Anzumerken ist, dass es sich bei KB24 um mit Keratoepithelin transfizierte Kelly-Zellen handelt. Im Vergleich zu untransfizierten KellyZellen ist die STC2-Expression in KB24-Zellen mehr als 2-fache erhöht (Becker et al., 2006).

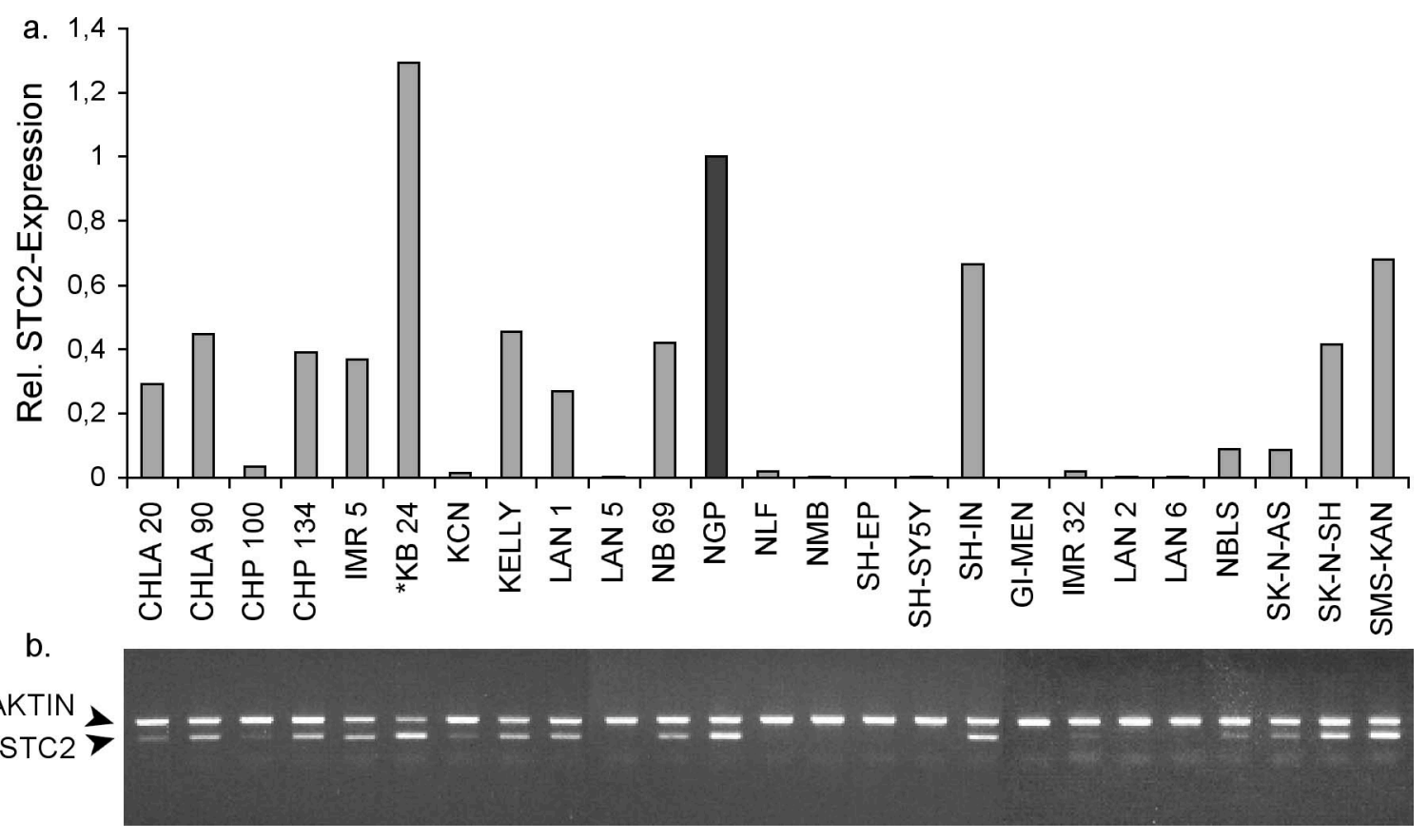

Abb. 4.1: STC2-mRNA-Expression in humanen NB-Zelllinien: (a.) Graphische Auswertung der Realtime RT-PCR Analyse: $\beta$-AKTIN wurde als Referenzgen $(\operatorname{ctSTC} 2-\operatorname{ct} \beta$-AKTIN $=\Delta$ ctSTC2) verwendet und der $\Delta$ ctSTC2 der Zelllinie NGP (dunkelgrau) als Kalibrator gleich 1 gesetzt (= $\Delta \Delta$ ctSTC2). Die relative STC2-Expression ist als $2^{-\Delta \Delta c t}$-Wert angegeben (s. Kap. 3.3.9). (Primer: STC2 Stc2sen/Stc2rev, $\beta$-AKTIN bAkfwdR/bAkrevR) (b.) Zum direkten Vergleich wurde die gelelektrophoretische Auftrennung von STC2- und $\beta$-AKTIN-Multiplex PCR-Produkten (Transkriptgrößen: STC2 300 bp; $\beta$-AKTIN 530 bp; Primer: STC2 Stc2ifwd/Stc2irev; $\beta$-AKTIN bAkfwd/bAkrev) gezeigt. Die untersuchten Zelllinien sind in Tab. 2.9 aufgelistet. * KB24 sind Keratoepithelin-transfizierte Kelly-Zellen.. 


\subsubsection{STC2-Proteinexpression in humanen NB-Zelllinien}

In Vorversuchen konnte bereits gezeigt werden, dass STC2 als sezerniertes Protein im Kulturüberstand vorliegt, die untersuchten Gesamtzelllysate waren STC2-negativ (Daten nicht gezeigt). Um zu untersuchen, ob Unterschiede in der mRNA-Expression zu unterschiedlichen Proteinmengen führen, habe ich Zellkultur-Überstände einer Auswahl charakteristischer NBZelllinien konzentriert und für Western Blot Analysen eingesetzt. Unter reduzierenden PAGE-Bedingungen lag das STC2-Protein als Monomer vor und war bei einem Molekulargewicht von ca. 36 kDa detektierbar (Abb. 4.2b). In der Zelllinie NGP wurde die höchste STC2-Expression nachgewiesen, moderate Proteinexpressionen fanden sich $u$. a. in SMS-KAN und KELLY. In den Zelllinien SH-SY5Y, GI-MEN und SH-EP konnte kein STC2 nachgewiesen werden. Die STC2-Proteinexpression stimmt demnach mit der ermittelten Transkriptmenge überein (Abb. 4.2a).

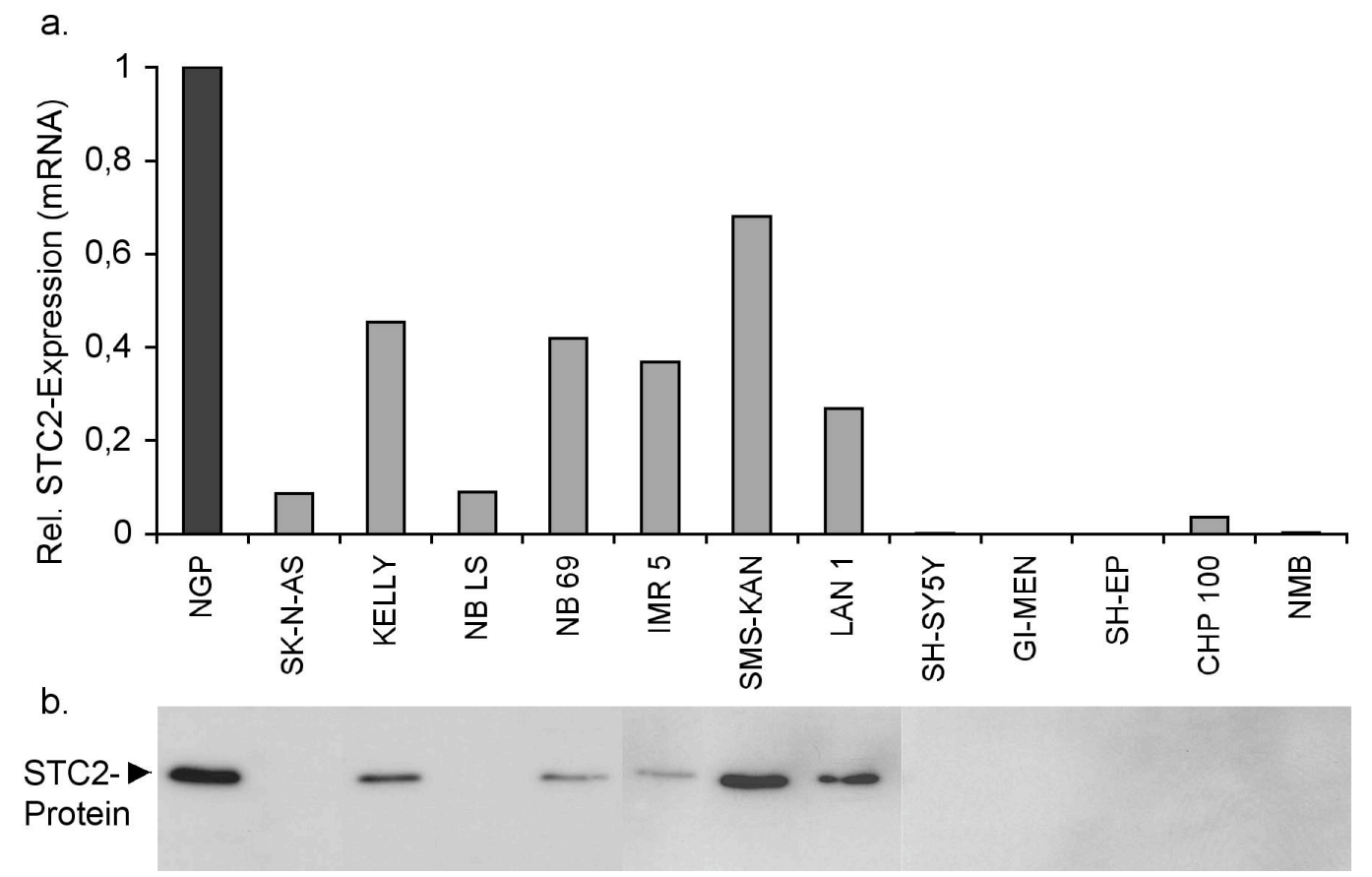

Abb. 4.2: (a.) STC2-mRNA-Expression (s. a. Abb. 4.1) im direkten Vergleich zur (b.) Western Blot Analyse der STC2-Proteinexpression in 13 humanen NB-Zelllinien. Konzentrierte ZellkulturÜberstände wurden durch SDS-PAGE aufgetrennt und die Proteinexpression mit polyklonalen STC2Antikörpern nachgewiesen. Die Zelllinie NGP (dunkelgrau) wurde bei allen Analysen zum Vergleich der Expressionen mitgeführt. Die aufgetragenen Überstände entsprechen jeweils der STC2-Expression von $2 \times 10^{6}$ Zellen. (s. Kap. 3.4.3). 


\subsubsection{Alternative STC2-Transkripte in humanen NB-Zelllinien}

Alternative STC2-mRNA-Transkripte wurden bereits in verschiedenen humanen Geweben nachgewiesen (Chang et al., 2003). Die Sequenz des STC2-Gens enthält laut NCBIDatenbank (http://www.ncbi.nlm.nih.gov/entrez/viewer.fcgi?val=NM_003714.2) zwei Polyadenylierungssignale (PolyA-Signale). Beide können verwendet werden und führen zu unterschiedlich langen Transkripten, wobei bislang vorwiegend das kürzere Transkript identifiziert wurde. Die Unterschiede in der 3'-untranslatierten Region (3'-UTR) der Transkripte können u. a. die Stabilität der mRNA und damit die synthetisierbare Proteinmenge beeinflussen.

\subsubsection{Sequenzierung von STC2-Transkripten aus humanen NB-Zelllinien}

Um zu untersuchen, ob das 2. PolyA-Signal (PolyA $\mathrm{A}_{4032}$ ) in NB-Zelllinien verwendet wird, habe ich die 3'-UTR ober- und unterhalb des 1. PolyA-Signals $\left(\mathrm{PolyA}_{1687}\right)$ durchgehend sequenziert. cDNA der humanen NB-Zelllinien CHP134 und SK-N-SH wurde als Vorlage für die Amplifikation eingesetzt. Die verwendeten STC2-PCR-Primer (Stc2fwd/Stc2-Tvrev, Abb. 4.3) wurden über eine Intron-Exon-Grenze gelegt, um eine Amplifikation der STC2-Sequenz aus DNA-Verunreinigungen auszuschließen. Außerdem wurde für die anschließende Sequenzierung ein zusätzlicher Primer (Stc2p1) eingesetzt, um das gesamte PCR-Produkt abzudecken. Die Sequenzierung und Analyse der so entstandenen PCR-Produkte zeigte, dass in NB-Zelllinien Transkripte vorhanden sind, die an einem distal von PolyA ${ }_{1687}$ liegenden PolyA-Signal adenyliert wurden.

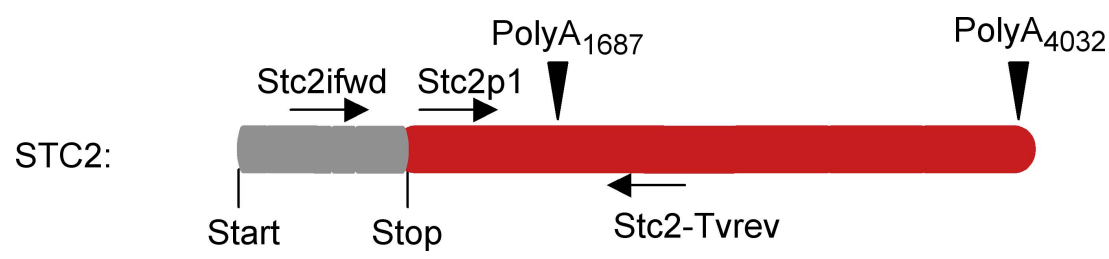

Abb. 4.3: Schematische Darstellung des Anlagerungsbereichs der verwendeten Sequenzierprimer auf der STC2-Prä-mRNA. Die alternativen PolyA-Signale befinden sich laut NCBI Datenbank 1687 bp und $4032 \mathrm{bp}$ in 3'-Richtung unterhalb des Startcodons (http://www.ncbi.nlm.nih.gov/entrez/viewer.fcgi?val=NM_003714.2). Der kodierende Bereich ist in Grau und die 3'-UTR in Rot dargestellt. Die Lage der für die Amplifikation verwendeten Primer $($ Stc2ifwd/Stc2-Tvrev; Transkriptlänge $=1,5 \mathrm{~kb})$ und eines weiteren Sequenzierprimers $(\mathrm{Stc} 2 \mathrm{p} 1)$ sind eingezeichnet. 


\subsubsection{Amplifikation alternativer STC2-Transkripte mittels Multiplex RT-PCR}

Um das Auftreten der beiden möglichen STC2-Transkripte in humanen NB-Zelllinien zu untersuchen, habe ich zuerst versucht, die entsprechende mRNA durch Multiplex RT-PCRAnalysen nachzuweisen. Da sich die beiden möglichen STC2-Transkripte theoretisch ausschließlich in der 3'-UTR unterscheiden, wurde versucht, die kurze STC2-mRNA (STC2K) ausgehend von Poly $\mathrm{A}_{1687}$ mittels verankerter PolyT-Primer nachzuweisen. Neben der PolyT-Sequenz enthielten diese Primer Nukleotide, die komplementär zu den letzten Basen vor dem PolyA-Signal waren (Tvprev1). Dadurch sollte gezielt nur das STC2KTranskript amplifiziert werden. Zum Nachweis der langen STC2-Transkripte (STC2L), bei denen wahrscheinlich PolyA ${ }_{4032}$ polyadenyliert wird, konnten Primer (Stc2ifwd/Stc2-Tvrev; s. Abb. 4.3), die in der zusätzlichen 3'-UTR gelegen sind, eingesetzt werden.

Der Nachweis von STC2L-Transkripten in der cDNA der untersuchten NB-Zelllinien war möglich. In Abbildung 4.4 ist die Gelelektrophorese einer typischen Multiplex RT-PCRAnalyse dargestellt. In den STC2-positiven Zelllinien SK-N-SH und SMS-Kan (Spur 2 und 3), sowie in dem Gemisch verschiedener NB-cDNAs (NB-Mix, Spur 6) konnte neben $\beta$ AKTIN die 3'-UTR des STC2L-Transkripts bei einer Größe von ca. 1,5 kb nachgewiesen werden. Die Zelllinie SH-EP (Spur 4) wurde als Negativkontrolle für STC2-Expression verwendet. Um eine Amplifikation der Transkripte aus DNA-Rückständen auszuschließen, wurde außerdem genomische DNA der NB-Zelllinie IMR5 (Spur 5) als Negativkontrolle eingesetzt. In dieser Probe konnten wegen der Lage der Primer über einer Exongrenze weder STC2 noch $\beta$-AKTIN amplifiziert werden.

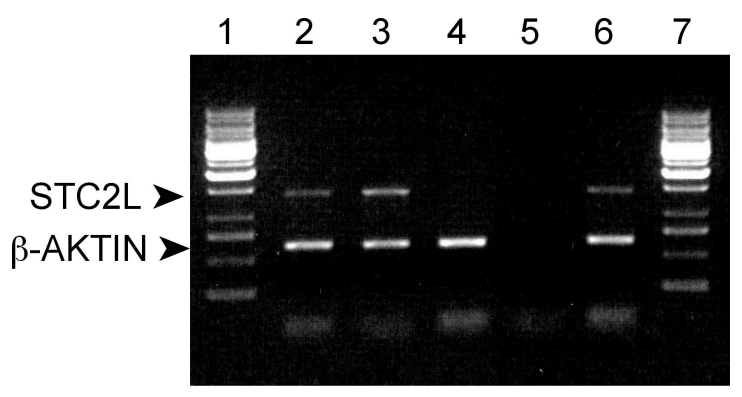

Abb. 4.4: Multiplex PCR-Analyse der langen STC2-Transkripte (STC2L; Primer Stc2ifwd/ Stc2Tvrev; Transkriptgröße 1,5 kb) im Vergleich zur $\beta$-AKTIN-Expression (Primer bAks/bAkas; Transkriptlänge 0,63 kb). Für die dargestellte PCR-Analyse wurde cDNA der STC2-positiven NBZelllinien SK-N-SH (Spur 2), SMS-KAN (Spur 3) und der STC2-negativen NB-Zelllinie SH-EP (Spur 4), sowie ein Gemisch aller untersuchten NB-cDNAs (Spur 6) verwendet. Für die PCR-Analyse auf Spur 5 wurde die entsprechende Menge genomischer DNA von IMR5 als Template eingesetzt. Auf Spur 1 und 7 wurde ein 1-kb-DNA-Marker aufgetragen. 
Die spezifische Amplifikation des STC2K-Transkripts mittels verankerter PolyT-Primer war nicht möglich. Trotz Modifikation verschiedener Parameter wie Anlagerungstemperatur der Primer, Reaktionspuffer und Verwendung alternativer Primer konnte das Transkript nicht in ausreichender Qualität und Quantität amplifiziert werden. Der Vergleich der Transkripte STC2L und STC2K war mittels Multiplex RT-PCR nicht möglich.

\title{
4.1.3.3 Nachweis alternativer STC2-Transkripte mittels Real-time RT-PCR
}

Da eine direkte Amplifikation von PolyA ${ }_{1687}$-adenylierten STC2K-Transkripten (s. Kap. 4.1.3.2) nicht möglich war, habe ich Real-time RT-PCR Analysen zum indirekten Nachweis dieser Transkriptvariante durchgeführt. Wie in Abbildung 4.5 dargestellt, waren die Primer zur Bestimmung der STC2-Gesamtexpression komplementär zur kodierenden Region, die für beide Transkripte gleich ist (STC2total). Die zum Nachweis der STC2L-Transkripte verwendeten Primer erkannten Sequenzen in der 3'-UTR, die ausschließlich bei der langen Transkriptvariante vorkommt. Die Differenz von STC2-Gesamtmenge und STC2LTranskripten ergibt somit die Menge der STC2K-Transkripte.

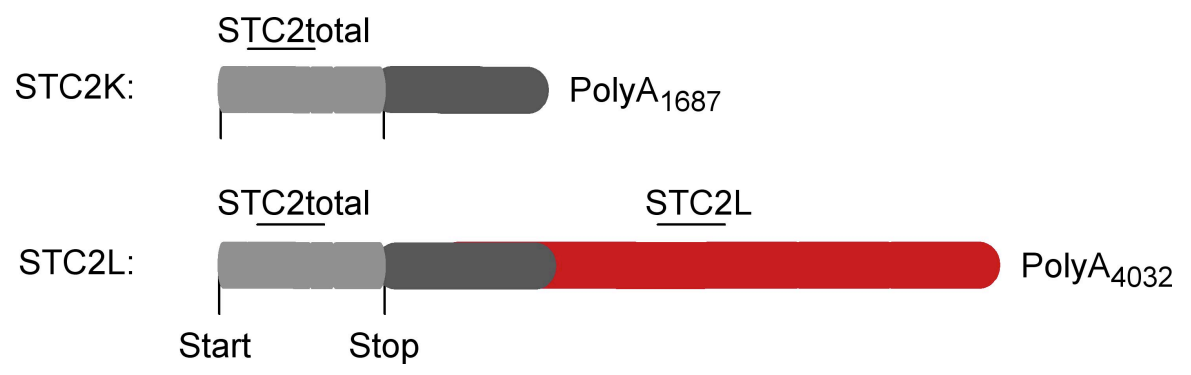

\begin{abstract}
Abb. 4.5: Schematische Darstellung des Anlagerungsbereichs der verwendeten Primer für die beiden möglichen STC2-Transkripte. Die Transkripte unterscheiden sich ausschließlich in der 3'-UTR unterhalb von PolyA $A_{1687}$ (rot), der kodierende Bereich (hellgrau) und die 3'-UTR vor PolyA $A_{1687}$ (dunkelgrau) sind gleich. Zur Bestimmung der STC2-Gesamtexpression wurden Primer verwendet, die die kodierende Region beider Transkripte erkannten (STC2total: Primer Stc2sen/Stc2rev). Die PrimerSequenzen zum Nachweis von STC2L-Transkripten lagen in der 3'-UTR (rot), die nur auf diesem Transkript zu finden ist (STC2L: Primer Stc2Lfwd/Stc2Lrev).
\end{abstract}

Die Menge der beiden STC2-Transkripte ist graphisch in Abbildung 4.6 dargestellt. In CHLA20, IMR5, NBLS und SMS-Kan konnte ausschließlich die STC2L-mRNA nachgewiesen werden, bei der die Polyadenylierung wahrscheinlich an PolyA $\mathrm{A}_{4032}$ stattfindet. In den anderen Zelllinien variierte die Expression der STC2L-Transkripte zwischen $45 \%$ und 95 $\%$. Die errechnete STC2K-Expression lag somit zwischen $0 \%$ und $55 \%$ der Gesamtmenge. Der STC2-Transfektant ST1 (s. Kap. 4.2), der nur die kodierende Region des Gens beinhaltet, 
wurde als Negativkontrolle für die Expression der STC2L-Transkripte verwendet. Wie erwartet, konnte in ST1 kein STC2L-Transkript nachgewiesen werden. Besonders zu beachten ist, dass die STC2-Gesamtexpression in der Keratoepithelin-transfizierten NBZelllinie KB24 doppelt so hoch war wie im Wildtyp Kelly (s. a Abb. 4.1), die relative Expression der beiden STC2-Transkripte zueinander aber annährend gleich blieb.

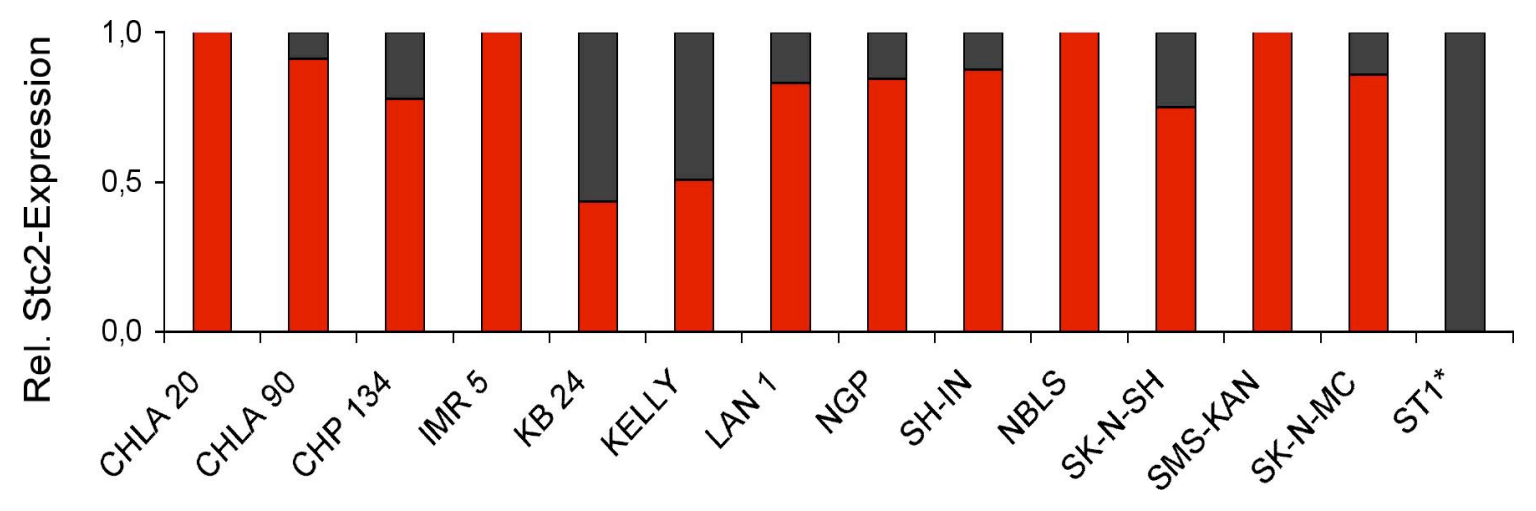

Abb. 4.6: Real-time RT-PCR Analyse der Expression von STC2L und STC2K-Transkripten in NBZelllinien mit endogener STC2-Expression. $\beta$-AKTIN wurde als Referenzgen verwendet (ctSTC2L $\operatorname{ct} \beta$-AKTIN $=\Delta$ ctSTC2L) und die STC2-Gesamtexpression $(\operatorname{ctSTC2total}-\operatorname{ct} \beta$-AKTIN $=$ $\Delta$ ctSTC2total $)$ als Kalibrator gleich 1 gesetzt $(=\Delta \Delta$ ctSTC2L). Die relative Expression der STC2Transkripte ist als $2^{-\Delta \Delta c t}$-Wert angegeben (s. Kap. 3.3.9): Dabei entspricht der rote Bereich der Menge der STC2L-Transkripte und der graue Bereiche stellt die Expression der STC2K-Transkripte dar. ST1*: Die STC2-negative NB-Zelllinie SH-SY5Y ist nur mit der kodierenden Region der STC2Transkripte transfiziert und wurde als Negativkontrolle für die STC2L-Expression verwendet. Die STC2-Primer sind in Abbildung 4.5 angegeben. ( $\beta$-AKTIN-Primer: bAks/bAkas).

\subsubsection{Die STC2-Gesamtmenge korreliert nicht mit dem Auftreten alternativer STC2- Transkripte}

Um zu testen, ob ein Zusammenhang zwischen STC2-Gesamtmenge und dem Auftreten der langen STC2-Transkripte besteht, habe ich die STC2-Gesamtexpression mit der prozentualen Expression von STC2L (s. Abb. 4.6) korreliert. Der in Abbildung 4.7 dargestellte Scatter Blot zeigt die Streuung der Datenpunkte. Der absteigende Verlauf der eingefügten Trennlinie scheint für eine reverse Korrelation der Faktoren zu sprechen. Ob eine signifikante Korrelation vorliegt wurde im Folgenden statistisch bestimmt. 


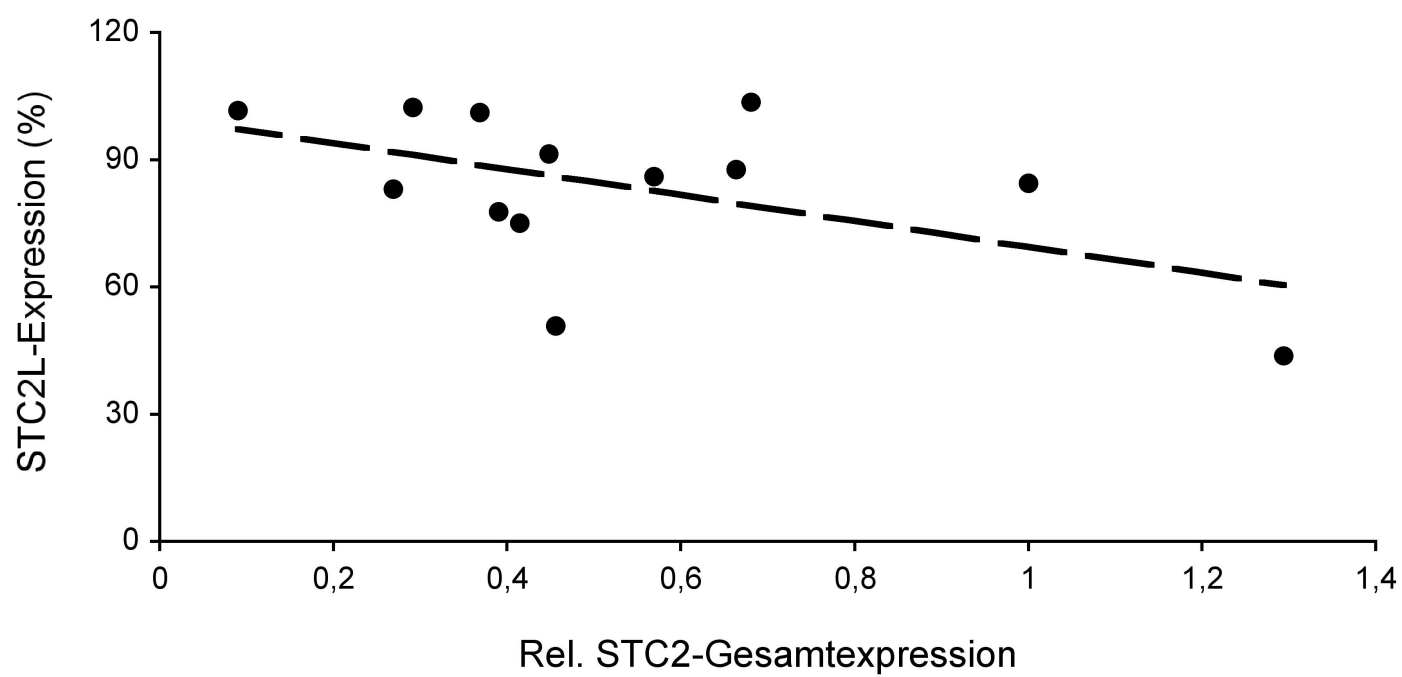

Abb. 4.7: Korrelation der STC2-Gesamtexpression und des prozentualen Anteils der STC2LTranskripte in 13 humanen NB-Zelllinien. Die Expression wurde mittels Real-time RT-PCR bestimmt. Zur Berechnung der STC2-Gesamtexpression wurde $\beta$-AKTIN als Referenzgen verwendet (ctSTC2 $\operatorname{ct} \beta$-AKTIN $=\Delta \operatorname{ctSTC})$ und der $\Delta$ ctSTC2 der Zelllinie NGP als Kalibrator gleich 1 gesetzt $(=$ $\Delta \Delta$ ctSTC2). Die relative STC2-Gesamtexpression ist als $2^{-\Delta \Delta c t}$-Wert angegeben (s. Kap. 3.3.9). Für die Berechnung von STC2L wurde ebenfalls $\beta$-AKTIN als Referenzgen verwendet $(\operatorname{ctSTC} 2 \mathrm{~L}-\operatorname{ct} \beta$ AKTIN $=\Delta$ ctSTC2L $)$ und die jeweilige STC2-Gesamtmenge $(\operatorname{ctSTC} 2-\operatorname{ct} \beta$-AKTIN $=\Delta \operatorname{ctSTC} 2)$ als Kalibrator gleich 1 gesetzt ( $\Delta \Delta$ ctSTC2L) (s. a. Abb. 4.6). Die so ermittelte STC2L-Expression (angegeben als $2^{-\Delta \Delta c t}$-Wert) wurde dann als Prozentsatz der relativen STC2-Gesamtexpression (STC2 = $100 \%)$ dargestellt. STC2-Primer sind in Abbildung 4.5 angegeben. ( $\beta$-AKTIN-Primer: bAks/bAkas)

Zur weiteren Auswertung wurden Korrelationskoeffizienten berechnet. Bei einer absoluten Korrelation der Faktoren betragen die untersuchten Koeffizienten 1 bzw. -1. Die p-Werte geben Aussage darüber, wie wahrscheinlich ein Zutreffen der ermittelten Korrelation ist. Liegt die Wahrscheinlichkeit über einem gewählten Signifikanzniveau von $5 \%$, ist der pWert größer als 0,05. Das heißt, die Korrelation ist nicht statistisch signifikant, da die Wahrscheinlichkeit für ein zufälliges Eintreffen zu groß ist. Die untersuchten Daten (Abb. 4.7) unterliegen der Normalverteilung, deshalb wurde der Pearson-Korellationskoeffizient ermittelt: Für die dargestellten Werte beträgt dieser -0,2857 ( $\mathrm{p}=0,344)$. Aufgrund der geringen Größe des untersuchten Datensatzes wurde zusätzlich der SpearmanKorrelationskoeffizient berechnet. Dieser beträgt -0,5227 ( $\mathrm{p}=0,0668)$. Die Koeffizienten zeigen keinen statisch signifikanten Zusammenhang zwischen der STC2-Gesamtexpression und dem Auftreten der STC2L-Transkripte. Die berechneten p-Werte sind größer als 0,05. Damit ist die Wahrscheinlichkeit für ein zufälliges Eintreten einer Korrelation zu groß. 


\subsubsection{Nachweis von Sequenzvariationen in der Intronregion des STC2-Gens}

Um zu überprüfen, ob Unterschiede in der Gensequenz einen Einfluss auf die Transkriptverteilung haben, habe ich Exon 1-4 und die flankierenden Intronbereiche des STC2-Gens aus DNA der NB-Zelllinie Kelly sequenziert. Diese Zelllinie wurde für die Analysen ausgewählt, da beide STC2-Transkripte in annährend gleicher Menge vorliegen (s. Abb. 4.6). In den kodierenden Exon-Bereichen der Kelly-DNA konnten keine Unterschiede zur publizierten STC2-Gensequenz gefunden werden.

In der Exon 4 flankierenden 5'-Intron-Region (17 bp vor Exon 4) der STC2-Gensequenz wurde eine Deletion von drei CT-Repeats auf einem der Allele gefunden. Die in NCBI publizierte Sequenz besitzt an dieser Position 17 CT-Repeats (http://www.ncbi.nlm.nih.gov/: Gene: STC2). Bei Kelly wurden eine Sequenz mit 14 CT-Repeats und eine mit 17 CTRepeats gefunden. Weitere NB-Zelllinien wurden daraufhin sequenziert (Tab. 4.1). Alle untersuchten NB-Zelllinien waren heterozygot, neben der 17 CT-Repeat-langen Sequenz konnte in allen Fällen eine zusätzliche Sequenz nachgewiesen werden. Die Veränderungen auf dem zweiten Allel variierten von einer CT-Insertion bis zur Deletion von drei CTRepeats. Ein Zusammenhang zwischen CT-Deletion bzw. -Insertion und der Expression der beiden STC2-Transkripte war nicht zu erkennen. So zeigen die Zelllinien Kelly und CHLA20 beide eine Deletion von 3 CT-Repeats, unterscheiden sich aber deutlich in der Expression des STC2L-Transkripts.

\begin{tabular}{|l|c|c|}
\hline NB-Zelllinie & Insertion / Deletion & Expression von STC2L \\
\hline Kelly & $-3 \mathrm{CT}$ & $50 \%$ \\
\hline IMR5 & $-1 \mathrm{CT}$ & $100 \%$ \\
\hline SMS-Kan & $+1 \mathrm{CT}$ & $100 \%$ \\
\hline CHLA20 & $-3 \mathrm{CT}$ & $100 \%$ \\
\hline Lan 1 & $-1 \mathrm{CT}$ & $80 \%$ \\
\hline
\end{tabular}

Tab. 4.1: Tabellarische Darstellung der Sequenzierung von CT-Repeats in der Exon 4-flankierenden Intronregion des STC2-Gens aus DNA von NB-Zelllinien. Die verwendeten Primer waren E1fwd/rev-E4fwd/rev und Stc2p1/Tvrev. Sequenzbereiche in denen die Überlappung von zwei Sequenzen sichtbar war, wurden nach der Auswertung am Computer manuell weiter analysiert (s. Kap. 3.3.1.4). Die Abweichungen (Insertion/Deletion) von dem beschriebenen 17-fachen CT-Repeat sind tabellarisch dargestellt, und die prozentuale Expression von STC2L-Transkripten (s. Kap. 4.1.3.3) in den jeweiligen Zelllinien ist angegeben. 


\section{2 Überexpression von STC2 in humanen SH-SY5Y NB-Zellen}

Um die Funktion von STC2 im humanen NB zu untersuchen, habe ich die Zelllinie SH-SY5Y mit der kodierenden Region des STC2-Transkripts transfiziert und die Effekte der STC2Überexpression in vitro und in vivo untersucht.

\subsubsection{Herstellung von STC2-Expressionsvektoren}

RNA aus NB-Zelllinien wurde reverse transkribiert und die resultierende cDNA für die Amplifikation des STC2-Transkripts eingesetzt. Durch die Verwendung spezieller Primer wurden NheI- und XhoI-Schnittstellen angefügt und das STC2-Transkript anschließend gerichtet in den Expressionsvektor pIRES2-EGFP kloniert. Das Konstrukt wurde in E. coli eingebracht und die transformierten Bakterien mittels einer auf dem Plasmid vorhandenen Kanamycin-Resistenz selektioniert. Das Plasmid wurde aus den so gewonnenen Klonen reisoliert und seine Identität mittels Restriktionsverdau (Abb. 4.8) und Sequenzierung bestätigt.

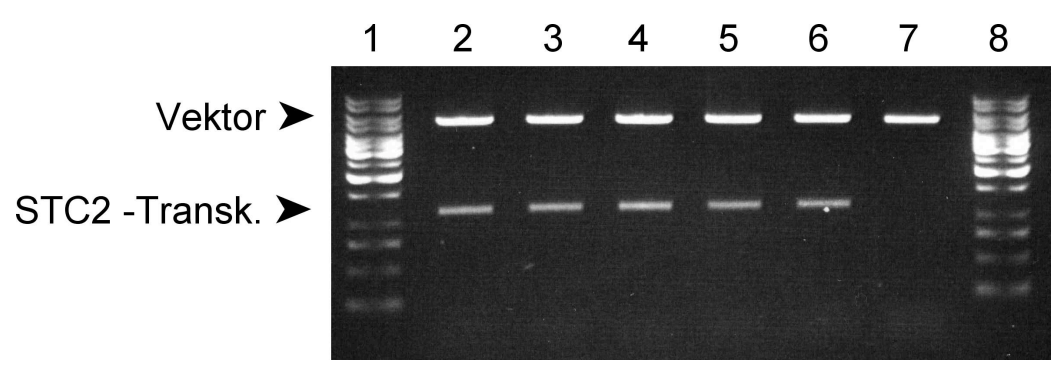

Abb. 4.8: Agarosegelelektrophorese der STC2-Konstrukte nach Restriktionsverdau. Durch einen NheI/XhoI-Doppelverdau wurde die Identität der STC2-Konstrukte (Spuren 2-6; 1,18 kb und 5,3 kb) im Vergleich zum Leervektor (Spur 7; 5,3 kb) bestätigt. Auf den Spuren 1 und 8 wurde ein 1-kbDNA-Marker aufgetragen.

\subsubsection{STC2-Transfektion der humanen NB-Zelllinie SH-SY5Y}

Der STC2-Expressionsvektor wurde mittels Elektroporation in die NB-Zelllinie SH-SY5Y übertragen. Diese Zelllinie weist keine endogene STC2-Expression auf (s. Abb. 4.2). Die transfizierten Zellen wurden einer Selektion mit G418 unterzogen, um stabil transfizierte Einzelzellklone zu erhalten. Das entsprechende Resistenzgen ist auf dem verwendeten Vektorplasmid enthalten. Außerdem ist auf dem Plasmid die Sequenz eines grünfluoreszierenden Proteins (enhanced green fluorescent protein, EGFP) kodiert, das in den Zellen co-exprimiert wird und dessen Fluoreszenz mittels Fluoreszenzmikroskopie nachgewiesen werden kann (Abb. 4.9). Der Vergleich fluoreszierender und nicht fluoreszierender Zellen zeigte, dass die Transfektionseffizienz bei ca. 20-30 \% lag. 
In gleicher Weise wurden auch Zellen mit dem Leervektor, also ohne STC2-Konstrukt, transfiziert. Sie dienen in den folgenden Versuchen als Transfektionskontrolle (Vektorkontrolle), um unspezifische Effekte durch die Behandlung und Selektion ausschließen zu können.

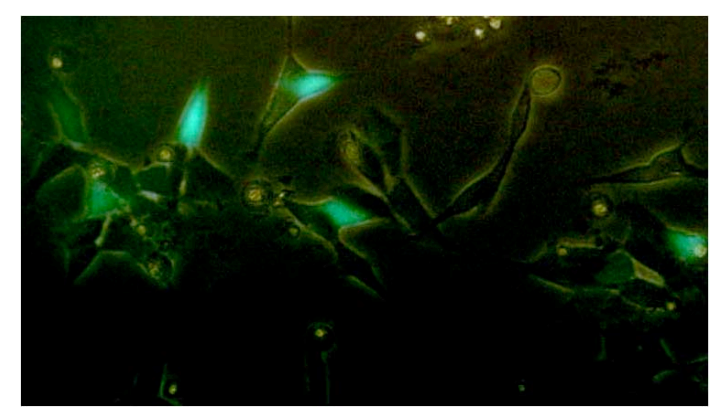

\begin{abstract}
Abb. 4.9: Fluoreszenz-mikroskopische Aufnahme von SH-SY5Y-Zellen nach Transfektion. Im Mischbild zwischen Phasenkontrast- und Fluoreszenz-Beleuchtung sind transfizierte Zellen aufgrund der Expression des grün-fluoreszierenden EGFP von den nicht transfizierten Zellen zu unterscheiden (200x).
\end{abstract}

\title{
4.2.3 Nachweis der STC2-Expression in transfizierten SH-SY5Y NB-Zellen
}

Die STC2-Expression in den transfizierten Zellen wurde mittels Real-time RT-PCR bestimmt. In 25 von 30 untersuchten Transfektanten konnte STC2-mRNA-Expression nachgewiesen werden. Die Proteinexpression wurde in den STC2-positiven Transfektanten mittels Western Blot analysiert. Wie bereits für andere NB-Zelllinien beschrieben (s. Kap. 4.1.2) wurde das STC2-Protein in Zellkultur-Überständen nachgewiesen, die untersuchten Zelllysate waren STC2-negativ. In Abbildung 4.10 sind die Transfektanten mit der stärksten STC2-Expression im Vergleich zu SH-SY5Y Wildtyp, Vektorkontrolle und der NB-Zelllinie NGP dargestellt. Die mRNA- (a.) und Protein-Expression (b.) in den untersuchten Zelllinien und Transfektanten (c.) stimmten überein. Der Transfektant ST1 zeigt die höchste STC2Expression, gefolgt von ST2, ST3 und ST4. Der SH-SY5Y Wildtyp und die Vektorkontrolle sind STC2-negativ. Die am stärksten STC2 exprimierende NB-Zelllinie NGP (s. a. Abb. 4.2) wurde ebenfalls analysiert, um die STC2-Expression in den Transfektanten in Relation zu unbehandelten humanen NB-Zelllinien darzustellen. Die Transfektanten ST1-3 besitzen im Vergleich zu NGP eine 7-11-fach erhöhte Expression. Bei den ST4-Zellen ist die STC2Expression dagegen nur 3-fach erhöht. 


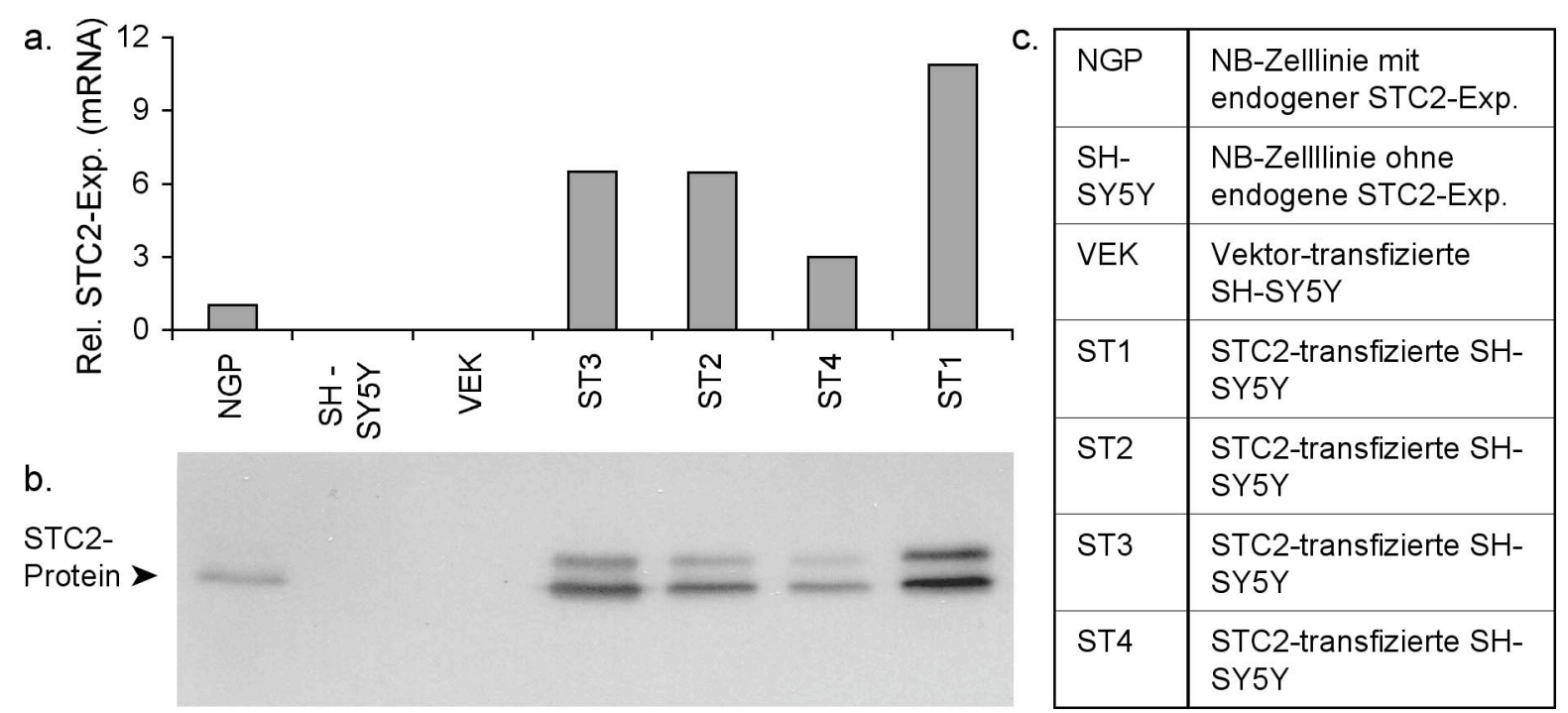

Abb. 4.10: (a.) Real-time RT-PCR Analyse der STC2-mRNA-Expression und (b.) Western Blot Analyse der Proteinexpression in tranfizierten SH-SY5Y-Zellen (ST1-ST4) im Vergleich zu Wildtyp, Vektorkontrolle (VEK) und NB-Zelllinie NGP. Zur Auswertung der Real-time RT-PCR wurde $\beta$ $A K T I N$ als Referenzgen $(\operatorname{ctSTC} 2-\operatorname{ct} \beta$-AKTIN $=\Delta \operatorname{ctSTC} 2)$ verwendet und der $\Delta \operatorname{ctSTC} 2$ der Zelllinie NGP als Kalibrator gleich 1 gesetzt $\left(=\Delta \Delta\right.$ ctSTC2). Die relative STC2-mRNA-Expression ist als $2^{-\Delta \Delta c t}$ Wert angegeben (s. Kap. 3.3.9; Primer: STC2 Stc2sen/Stc2rev, $\beta$-AKTIN bAkfwdR/bAkrevR). Zur Bestimmung der Proteinexpression wurden konzentrierte Zellkultur-Überstände durch SDS-PAGE unter reduzierenden Bedingungen aufgetrennt und STC2 mittels polyklonaler Antikörper nachgewiesen. Die aufgetragenen Überstände entsprechen jeweils der Proteinexpression von $2 \times 10^{6}$ Zellen (s. Kap. 3.4.3). (c.) Auflistung der untersuchten Zelllinien und Transfektanten mit kurzer Beschreibung.

\subsubsection{STC2 liegt im Überstand von transfizierten SH-SY5Y-Zellen als Dimer vor}

Das STC2-Protein kommt unter physiologischen Bedingungen als Disulfid-gebundenes Homodimer vor (Moore et al., 1999). Um zu zeigen, dass in transfizierten SH-SY5Y-Zellen STC2 in nativer Form sezerniert wird, habe ich Western Blot Analysen von konzentrierten Überständen des STC2-Transfektanten ST1 unter reduzierenden (red.) und nichtreduzierenden (n.r.) Bedingungen durchgeführt (Abb. 4.11). Unter nicht-reduzierenden Bedingungen bleiben die Disulfidbrücken zwischen den STC2-Molekülen erhalten und der Proteinkomplex ist bei ca. $75 \mathrm{kDa}$ als Dimer nachweisbar. Unter reduzierenden Bedingungen sind die Disulfidbrücken gespalten und die Monomere sind bei ca. 36 kDa nachweisbar. Diese Größe entspricht auch der aus der Aminosäuresequenz berechneten Größe. Zum Vergleich wurde STC2 aus der NB-Zellline NGP unter reduzierenden und nicht-reduzierenden Bedingungen aufgetrennt. Dabei zeigte sich, dass die Größe der STC2-Monomere und Dimere aus dem Transfektanten ST1 mit denen aus NGP-Zellen übereinstimmt. 


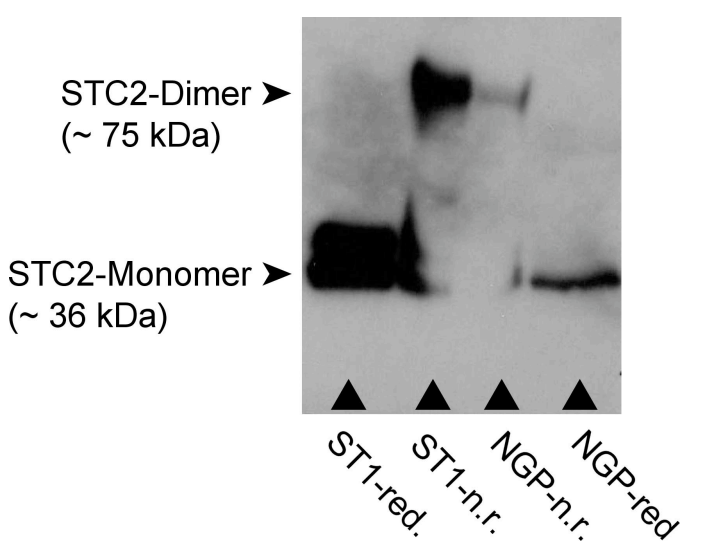

Abb. 4.11: Western Blot Analyse der STC2Proteinexpression in STC2-transfizierten SH-SY5YZellen (ST1) im Vergleich zu NGP-Zellen. Konzentrierte Überstände wurden unter reduzierenden (red.) und nicht-reduzierenden (n.r) Bedingungen im SDS-Gel aufgetrennt und STC2 durch polyklonale Antikörper nachgewiesen. Die aufgetragenen Überstände entsprechen jeweils der Proteinexpression von $2 \times 10^{6}$ Zellen (s. Kap. 3.4.3). Da die Proben direkt nebeneinander aufgetragen wurden, ist es im Grenzbereich zu einer teilweisen Reduktion der nichtreduzierten Proben gekommen.

\subsubsection{STC2-Expression vermindert die Adhärenz von SH-SY5Y-Zellen}

Die STC2-transfizierten Zellen (s. Kap. 4.2.3) wurden am Phasenkontrast-Mikroskop untersucht (Abb. 4.12). Dabei zeigte sich, dass die ST1-Zellen abgerundeter und kleiner wirkten, im Vergleich zur Vektorkontrolle. Die Morphologie der transfizierten Zellen war ähnlich, der Vergleich zeigte aber, dass im Überstand des STC2-Transfektanten (ST1) gegenüber der Vektorkontrolle vermehrt abgeschwommene Zellen zu finden waren.
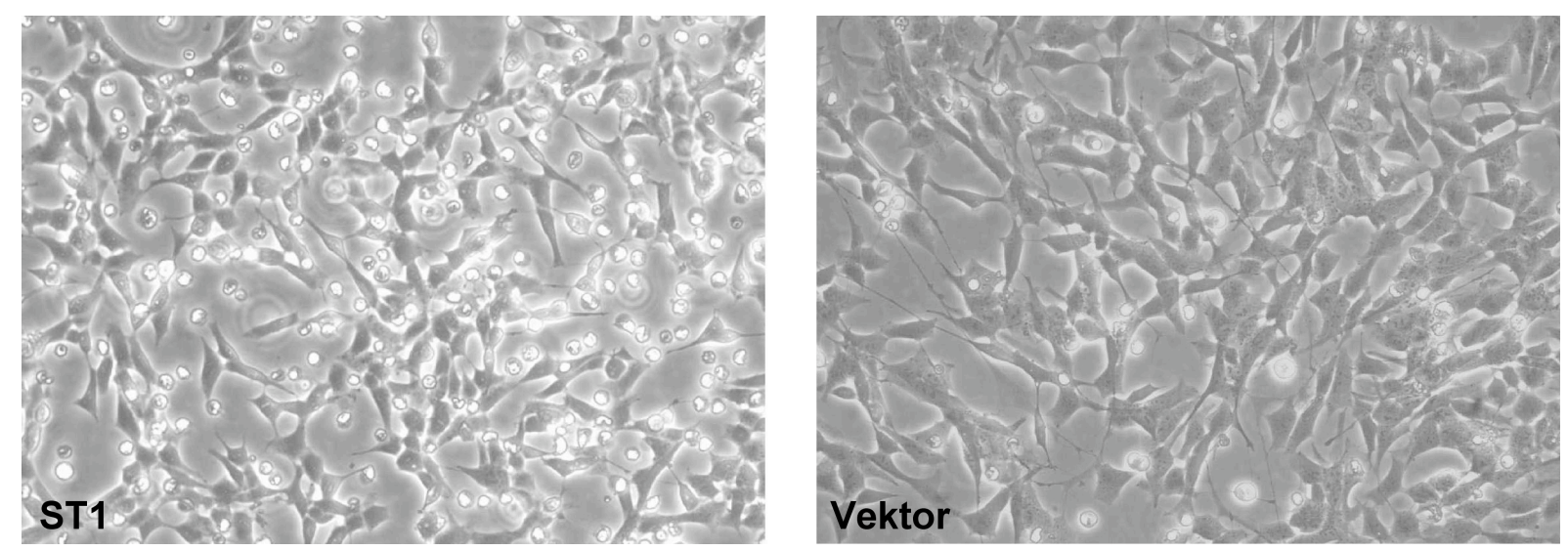

Abb. 4.12: STC2- (ST1) und Vektor-transfizierte SH-SY5Y-Zellen. Subkonfluent bewachsene Zellkultur-Platten wurden am Phasenkontrastmikroskop bei 200 -facher Vergrößerung fotografiert. Im Überstand des Transfektanten ST1 waren vermehrt abgeschwommene Zellen zu erkennen. Die starke Lichtbrechung zeigt die geringere Adhärenz der ST1-Zellen.

\subsubsection{STC2-Expression inhibiert die Proliferation von SH-SY5Y-Zellen}

Um die Effekte der STC2-Expression auf die Proliferationsfähigkeit der transfizierten SHSY5Y NB-Zellen zu untersuchen, habe ich das Wachstum der Transfektanten ST1, ST2, ST3 und ST4, sowie der SH-SY5Y Wildtyp- und Vektorkontrolle über 6 Tage gemessen. Die in 
Abbildung 4.13 dargestellten Proliferationskurven zeigen, dass das Wachstum der STC2transfizierten Zellen ST1, ST2 und ST3 im Vergleich zu Wildtyp- und Vektorkontrolle signifikant $(\mathrm{p}<0,05)$ gehemmt ist. Die mäßig erhöhte STC2-Expression in ST4-Zellen (s. Abb. 4.10) führte nicht zu einer Hemmung der Proliferation, die ST4-Zellen wuchsen ähnlich schnell wie Wildtyp- und Vektorzellen.

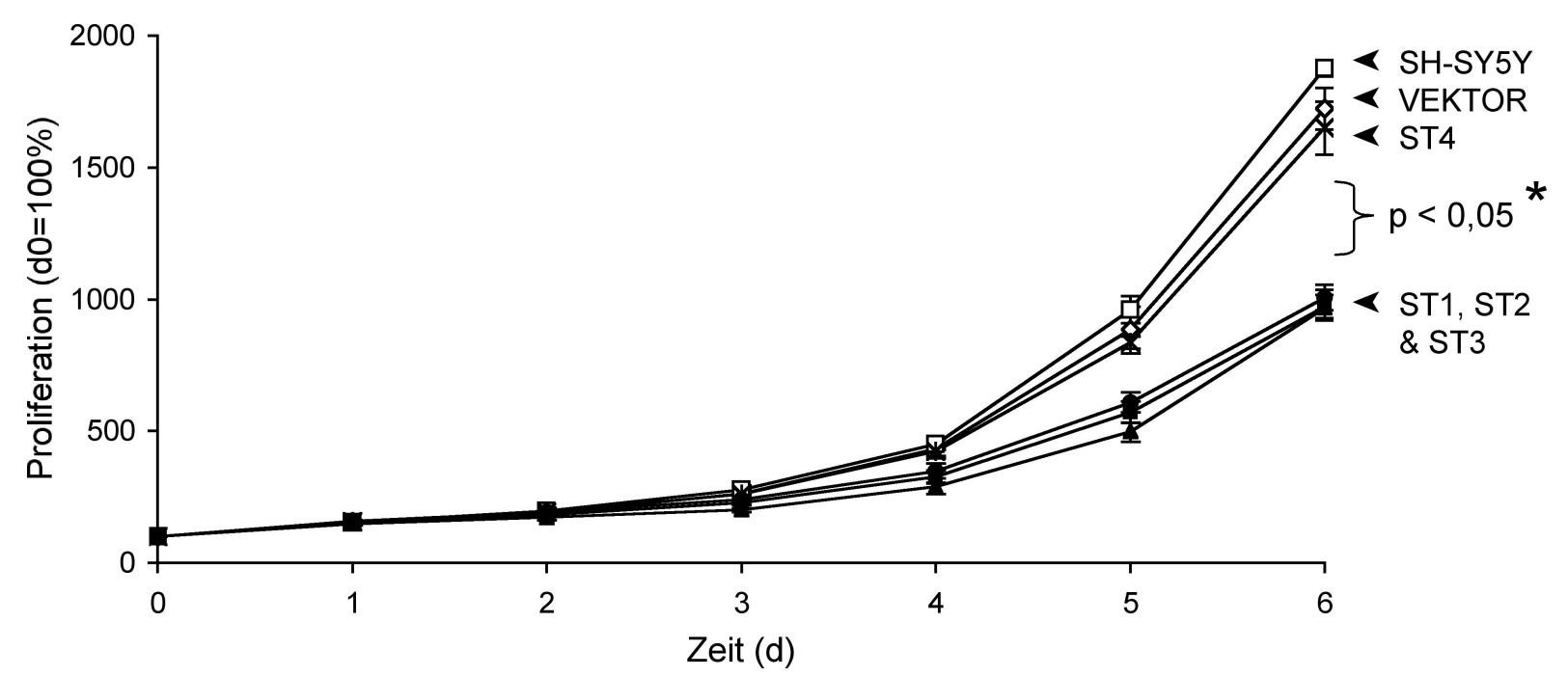

Abb. 4.13: Graphische Darstellung der Proliferationsrate der STC2-Transfektanten ST1, ST2, ST3 und ST4 im Vergleich zu SH-SY5Y Wildtyp- und Vektorkontrolle, gemessen über 6 Tage. 5x10 Zellen wurden in 96well-Platten ausgesät und zu den angegebenen Zeitpunkten fixiert. Nach Kristallviolett-Färbung wurde die Absorption bei $595 \mathrm{~nm}$ gemessen und prozentual auf die für Tag 0 bestimmten Werte bezogen $(\mathrm{d} 0=100 \%)$. Die Absorption von Kristallviolett korreliert mit der Zahl der adhärenten Zellen. * Die Proliferation von STC2-transfizierten ST1, ST2 und ST3-Zellen unterscheidet sich in drei unabhängigen Proliferationsassays mit je 8 Replikaten signifikant $(p<0,05)$ von Wildtyp, Vektorkontrolle und ST4.

\subsubsection{STC2-Expression in SH-SY5Y führt zu erhöhter DNA-Replikation}

Um zu prüfen, ob Veränderungen im Zellzyklus zu der beobachteten Wachstumshemmung führen, wurden STC2- und Vektor-transfizierte SH-SY5Y-Zellen nach $24 \mathrm{~h}$ und $72 \mathrm{~h}$ Wachstum geerntet und mittels Durchflusszytometrie untersucht. Abbildung 4.14 zeigt, dass in STC2-transfizierten SH-SY5Y-Zellen (schwarze Balken) die Zahl der Zellkerne in der SPhase nach 24 h (a.) von $28 \%$ auf $40 \%$ und nach 72 h (b.) von $27 \%$ auf $34 \%$ erhöht war. Die Zahl der Kerne in der G1-Phase war dementsprechend erniedrigt. Die G2-Phasen von STC2- und Vektor-transfizierten Zellen unterschieden sich kaum. Die STC2-Expression in SH-SY5Y führt somit nicht zu einer verminderten Teilung der Zellen, sondern zu einer Erhöhung der DNA-Replikation im Zellzyklus. Dies kann nicht zu der beobachteten Hemmung der Proliferation führen (s. Kap. 4.2.6). 
a.

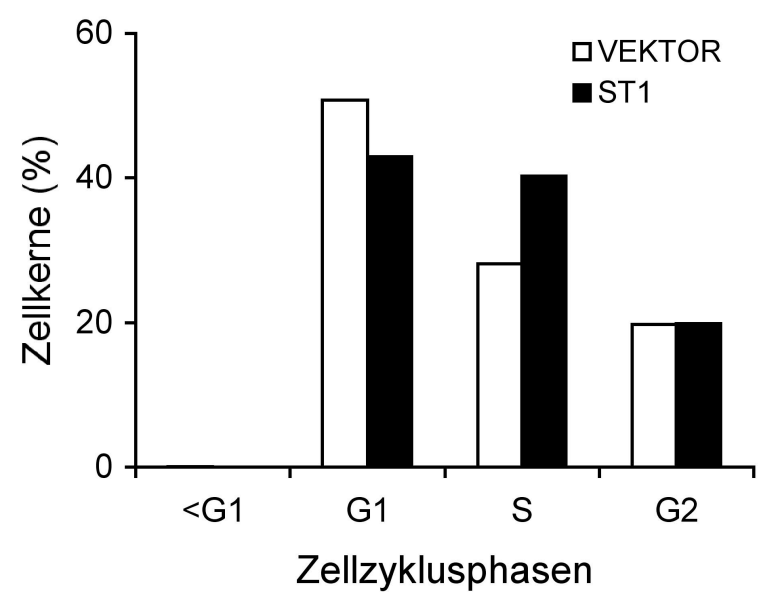

b.

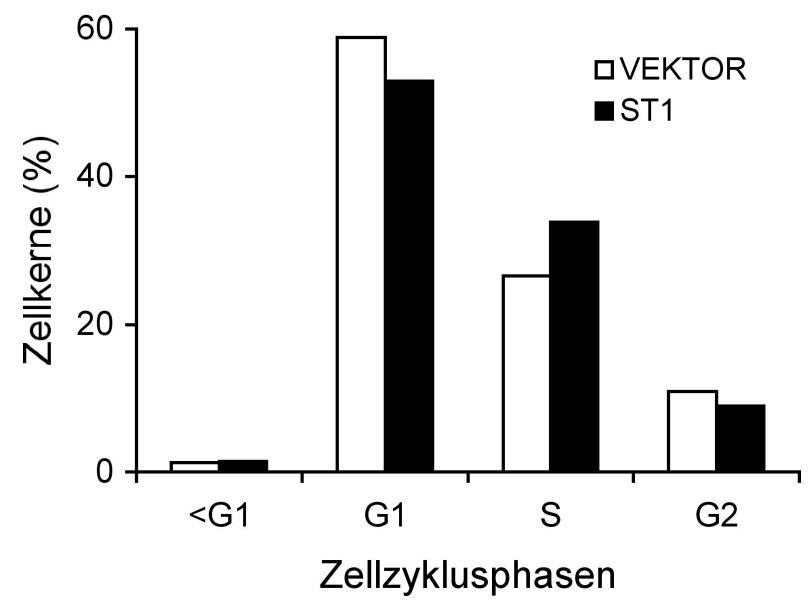

Abb. 4.14: Verteilung der Zellzyklusphasen in STC2-transfizierten ST1- und Vektorkontrollzellen. Die prozentuale Verteilung der Zellkerne von ST1-und Vektorzellen (y-Achse) auf die verschiedenen Stadien des Zellzyklus (x-Achse) nach (a.) $24 \mathrm{~h}$ und (b.) $72 \mathrm{~h}$ Wachstum wurde analysiert und graphisch dargestellt. Für die Untersuchung im Durchflusszytometer wurden die lysierten Zellen mit Propidiumiodid (PI) behandelt. PI interkaliert mit der DNA im Kern und erfährt dadurch eine Verschiebung seines Absorptionsmaximums. Die gemessene Fluoreszenzintensität gibt Aufschluss über die DNA-Menge im Kern und dadurch auf das Zellzyklus-Stadium in dem sich die untersuchten Zellen befinden. Kerne mit einfachem Chromosomensatz sind in der G1-Phase, mit doppeltem Chromosomensatz in der G2-Phase. In der Synthesephase (S-Phase) findet die DNA-Replikation statt, der DNA-Gehalt liegt dann zwischen dem von G1 und G2. Präapoptotische Kerne werden als < G1 (sub-G1) zusammen gefasst.

\subsubsection{STC2-Expression in SH-SY5Y erhöht die Zahl nicht vitaler Zellen im Überstand}

Bei mikroskopischen Untersuchungen (s. Kap. 4.2.5) zeigte sich, dass der ZellkulturÜberstand von STC2-Transfektanten vermehrt nicht adhärente Zellen enthielt. Der Wildtyp SH-SY5Y ist als vorwiegend adhärente NB-Zelllinie beschrieben und wies, genauso wie die Vektorkontrolle, wenige nicht adhärente Zellen im Überstand auf. Um die in STC2transfizierten Zellen beobachteten Unterschiede deutlich zu machen, habe ich die Zahl der nicht adhärenten Zellen im Überstand bestimmt und prozentual mit der Gesamtzellzahl verglichen. Abbildung 4.15 zeigt, dass die Zahl der nicht adhärenten Zellen im Überstand des Transfektanten ST1 im Vergleich zur Vektorkontrolle 2,5-fach erhöht war. 


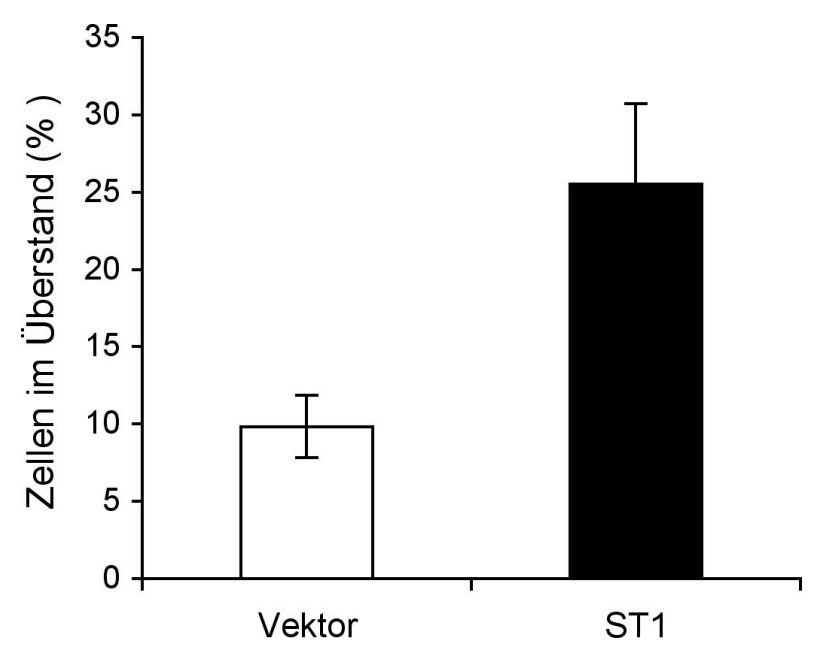

Abb. 4.15: Vergleich der Anzahl von Zellen im Überstand von STC2-transfizierten SHSY5Y - und Vektorkontrollzellen. Zellkulturplatten der untersuchten Transfektanten wurden geerntet und die Zahl der adhärenten und nicht adhärenten Zellen in einem Partikelzähler bestimmt. Die Zahl der nicht adhärenten Zellen wurde prozentual auf die Gesamtzellzahl bezogen und die Standardabweichung für drei unabhängige Messungen bestimmt.

Das Ablösen adhärenter Zellen vom Kulturgefäß ist in der Regel ein Zeichen für das Absterben der Zellen. Um die Vitalität der nicht adhärenten ST1-Zellen zu untersuchen, wurden sie mit Trypan-Blau gefärbt. Dieser Farbstoff kann bei toten Zellen die sich auflösende Zellmembran passieren, lebende Zellen bleiben dagegen ungefärbt. Die Zahl der gefärbten und ungefärbten Zellen wurde in einer Neubauer-Zählkammer bestimmt und es konnte gezeigt werden, dass $95 \%$ der Zellen im Überstand nicht vital waren. Unter den adhärenten ST1-Zellen der jeweiligen Platten fanden sich nur $2 \%$ tote Zellen.

Um dieses Ergebnis mit einer zweiten Methode zu verifizieren, habe ich ST1-Zellen aus dem Überstand und adhärente ST1-Zellen für Zellzyklus-Analysen am Durchflusszytometer eingesetzt (Abb. 4.16). Das fluoreszierende Agens Propidiumiodid (PI) interkaliert dabei mit der DNA der Zellen und erfährt dadurch eine Verschiebung seines Absorptionsmaximums. Durch Messung der Fluoreszenz-Intensität kann dann die Größe und die relative optische Dichte (Granularität) der markierten Nukleinsäure-Komplexe und damit ihr Zellzyklusstadium bestimmt werden. Im Kulturüberstand (Abb. 4.16a) konnten keine Kernfraktionen gleicher Größe und Granularität, wie bei der Messung von adhärenten Zellen (s. Abb. 4.16c), gefunden werden. Die in Abbildung 4.16b dargestellte Häufigkeitsverteilung der in (a.) dargestellten DNA-Komplexe zeigt, dass die Zellen nur eine geringe FluoreszenzIntensität besaßen und sich somit in der < G1-Phase befanden. Zum Vergleich zeigt Abbildung 4.16d ein Kontrollhistogramm der in (c.) dargestellten Zellen bei dem die einzelnen Zellzyklen (< G1, G1, S, G2; s. Legende) deutlich zu erkennen sind. Der Nachweis von apoptotischen Kerne und das Fehlen von Zellzyklusstadien im ST1-Kulturüberstand bestätigt die Ergebnisse der Zählung mit Trypan-Blau. Es handelte sich bei den Zellen im Überstand um absterbende Zellen. Die Trypan-Blau-Färbung und die Zellzyklusanalyse 
wurden auch mit Kontrollzellen (Vektor) durchgeführt. Die Untersuchung ergab, dass im Überstand genauso wie bei ST1 keine vitalen Zellen zu finden waren. Abbildung 4.15 zeigt aber, dass sich die Zahl der Zellen in den Überständen von ST1 und Vektor deutlich unterschieden. Somit sind $25 \%$ der ST1-Zellen, aber nur etwa $10 \%$ der Vektorzellen nicht vital.
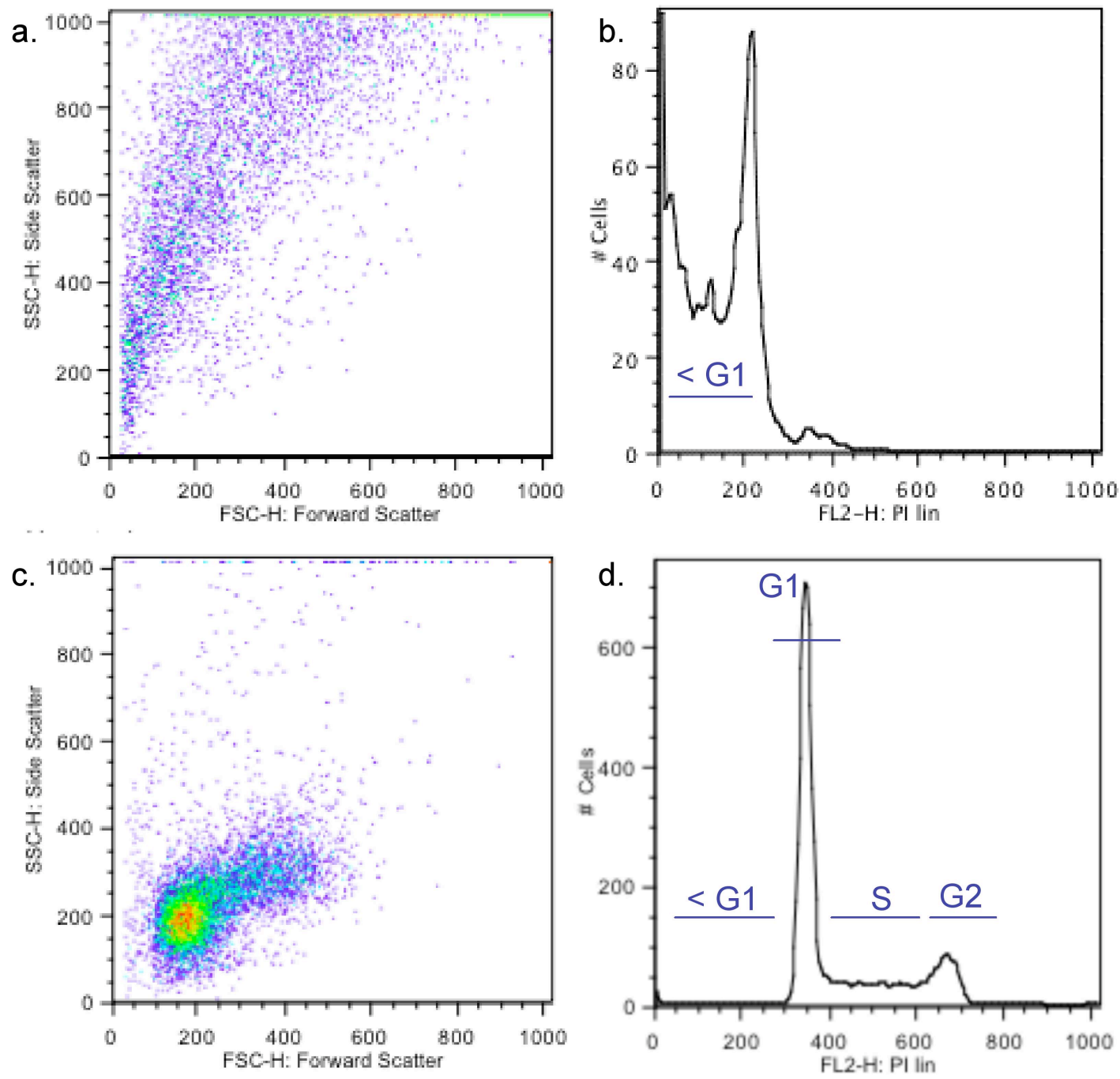

Abb. 4.16: Zellzyklus-Analyse von ST1-Zellen im Überstand und bei adhärenten ST1-Zellen am Durchflusszytometer. (a./c.) Graphische Darstellung von Größe (y-Achse) und Granularität (x-Achse) der fluoreszierenden Komplexe aus Überstand (a.) und adhärenten Zellfraktionen (c.). (b.) Histogramm, in dem die in (a.) dargestellten Partikel gegen die für sie bestimmte FluoreszenzIntensität (x-Achse) aufgetragen wurden. Das Histogramm in (d.) basiert auf den in (c.) dargestellten Kernen. Kerne mit einfachem Chromosomensatz sind in der G1-Phase, mit doppeltem Chromosomensatz in der G2-Phase. In der S-Phase findet die DNA-Replikation statt, der DNA-Gehalt liegt hier zwischen dem von G1 und G2. Präapoptotische Kerne werden als < G1 (sub-G1) zusammen gefasst. 


\subsubsection{STC2-Expression in SH-SY5Y erhöht die Basis-Apoptose der Zellen}

Bisher konnte gezeigt werden, dass die STC2-Expression in SH-SY5Y-Zellen scheinbar die Proliferation inhibiert (s. Kap. 4.2.6), obwohl der Zellzyklus der transfizierten Zellen nicht gehemmt ist (s. Kap. 4.2.7). Dabei ist die Zahl nicht-vitaler Zellen im Überstand von STC2exprimierenden SH-SY5Y-Zellen erhöht (s. Kap. 4.2.8). Um zu untersuchen, ob die scheinbaren Proliferationsunterschiede durch eine Erhöhung der Apoptose in STC2transfizierten Zellen vermittelt wird, habe ich Apoptose-ELISA (enzyme linked immunosorbent assay) durchgeführt: Mit dieser Methode kann fragmentierte DNA, die typischerweise bereits mehrere Stunden vor dem Zusammenbruch der Plasmamembran im Zytoplasma von apoptotischen Zellen entsteht, mittels Peroxidase-gekoppelter Antikörper nachgewiesen werden. Nach Substratzugabe wird die Peroxidase-Aktivität photometrisch bestimmt und so die Apoptose in den untersuchten Zellen relativ quantifiziert. Abbildung 4.17 zeigt, dass die Basis-Apoptose in STC2-transfizierten SH-SY5Y-Zellen im Vergleich zur Vektorkontrolle statistisch signifikant erhöht war $(\mathrm{p}=0,0313)$. Für Vektorzellen betrug die gemessene Absorption 0,14 und für ST1-Zellen 0,24. Das ist eine Steigerung von etwa $70 \%$.

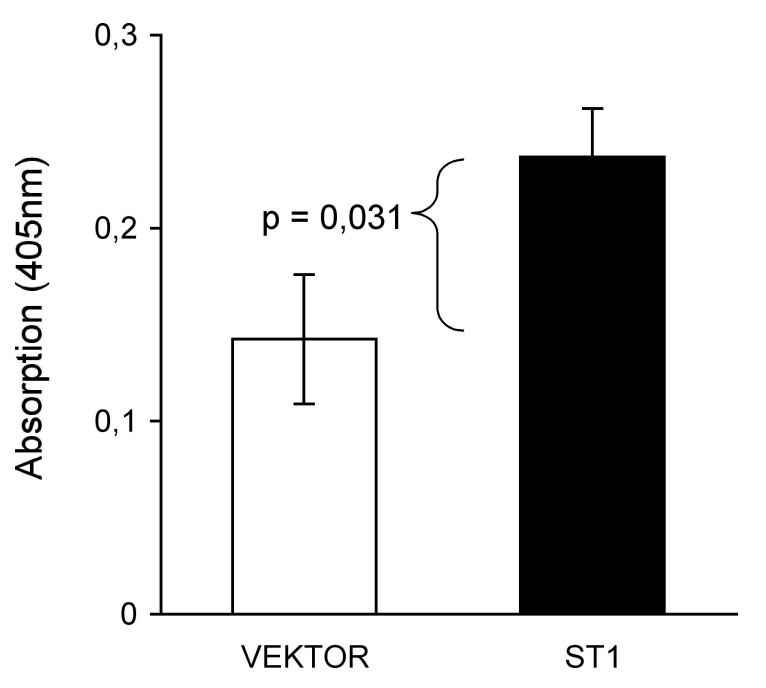

Abb. 4.17: Graphische Darstellung der BasisApoptose von ST1- und Vektor-transfizierten Zellen. Der hier benutzte Cell Death Detection ELISA weist die typische Anreicherung fragmentierter DNA im Zytoplasma apoptotischer Zellen durch Peroxidasegekoppelte Antikörper nach. Die Apoptoseneigung der Zellen wird durch Absorptionsmessung bei $405 \mathrm{~nm}$ relativ quantifiziert. Dargestellt ist der prozentuale Mittelwert aus sechs unabhängigen Messungen mit Standardabweichung und statistischem Signifikanzwert $(p=0,0313)$.

\subsubsection{In STC2-exprimierenden SH-SY5Y ist die Apoptose nach Staurosporin- Induktion erniedrigt}

Ito et al. (2004) haben beschrieben, dass durch die Inhibierung von STC2 Maus-NB-Zellen empfänglicher für apoptotische Reize werden (Ito et al., 2004). Um zu untersuchen, ob umgekehrt die STC2-Expression in humanen NB-Zellen die Induktion von Apoptose verhindert, wurde die Apoptoseneigung in STC2-transfizierten Zellen nach der Behandlung mit dem Apoptose-induzierenden Topoisomerase II-Inhibitor Staurosporin bestimmt. STC2- 
und Vektor-transfizierte SH-SY5Y-Zellen wurden für $12 \mathrm{~h}$ mit 0-10 $\mu \mathrm{M}$ Staurosporin inkubiert und die Apoptose mittels Cell Death Detection ELISA (s. Kap. 3.5.4) bestimmt. Abbildung 4.18 zeigt, dass die, auf die unbehandelte Kontrolle $(0 \mu \mathrm{M})$ bezogene, induzierte Apoptose in STC2-exprimierenden ST1-Zellen nach Behandlung mit 0,5 $\mu \mathrm{M}$ und $1 \mu \mathrm{M}$ Staurosporin um mehr als $50 \%$ reduziert war. Nach der Behandlung mit $10 \mu \mathrm{M}$ Staurosporin war kein Unterschied in der induzierten Apoptose von STC2-transfizierten und Vektorzellen zu erkennen. Sehr hohe Staurosporin-Konzentrationen können zytotoxisch wirken und so zur sofortigen Lyse der Zellen führen, wodurch die Induktion von Apoptose nicht mehr messbar ist.

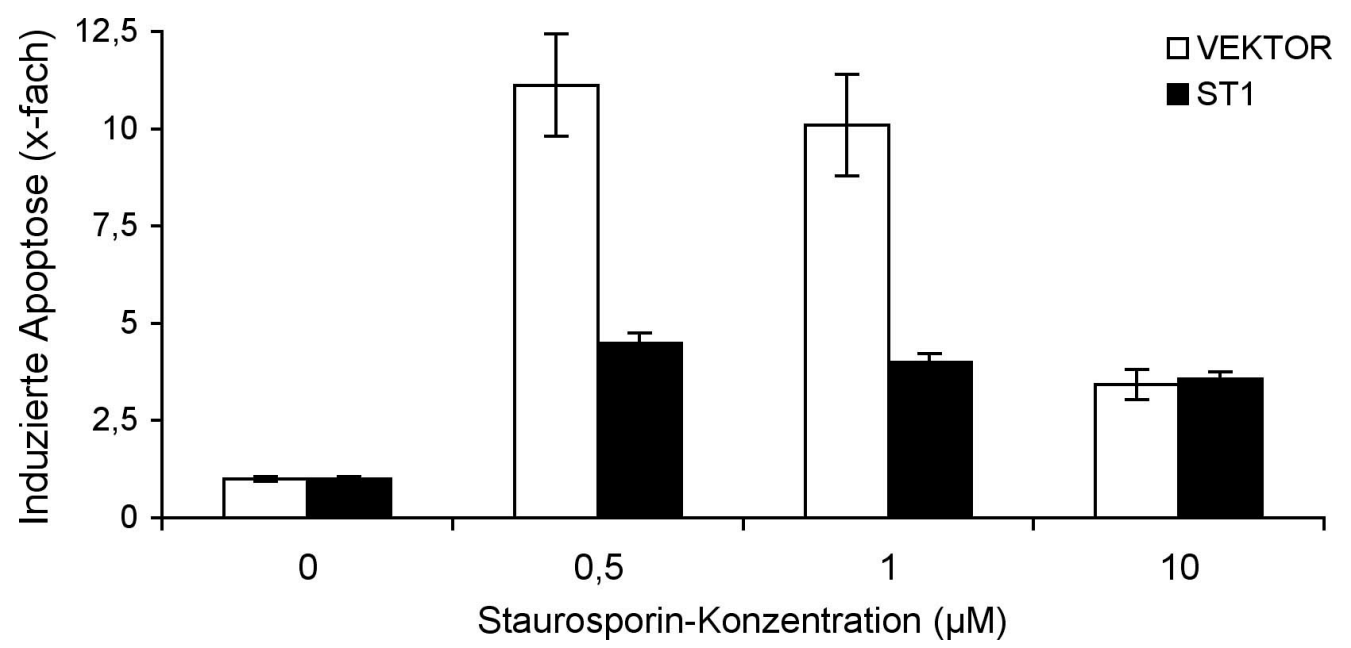

Abb. 4.18: Staurosporin-induzierte Apoptose von STC2- und Vektor-transfizierten SH-SY5Y-Zellen. Das Apoptose-induzierende Agenz Staurosporin wurde dem Zellkulturmedium in verschiedenen Konzentrationen $(0 \mu \mathrm{M}, 0,5 \mu \mathrm{M}, 1 \mu \mathrm{M}$, und $10 \mu \mathrm{M})$ zugesetzt und die Zellen $\left(1 \times 10^{4}\right)$ für weitere $12 \mathrm{~h}$ kultiviert. Die Apoptoserate wurde mit dem Cell Death Detection ELISA (Roche, s. Kap. 3.5.4 und 4.2.9) durchgeführt. Die induzierte Apoptose wurde als Vielfaches der Basisapoptose (=1) angegeben und die Standardabweichung aus vier Replikaten bestimmt. Dargestellt ist ein repräsentativer Versuch von 6 unabhängigen Bestimmungen.

\subsubsection{STC2-Expression erhöht die Invasivität von SH-SY5Y-Zellen in vitro}

Invasivität ist ein wichtiger Parameter zur Charakterisierung von Tumorzellen und in der Klinik für die Prognosestellung und Therapiewahl von besonderer Bedeutung. Um den Einfluss von STC2 auf die Invasivität von humanen NB-Zellen zu untersuchen, habe ich Invasionsassays mit STC2-und Vektor-transfizierten SH-SY5Y-Zellen durchgeführt. Hierbei wurde getestet, ob die Zellen in der Lage sind, extrazelluläre Matrix (Matrigel) zu zersetzen und invasiv zu migrieren. Die Zellen wurden dazu auf einer mit Matrigel beschichteten Membrane mit $8 \mu \mathrm{m}$ Porengröße kultiviert und einem Serumgradienten ausgesetzt, der sie zur 
Wanderung anregen sollte. Der Nachweis der gewanderten invasiven Zellen auf der Unterseite der Membran erfolgte über Kernfärbung mit Hämatoxylin. In Abbildung 4.19 wurde die Invasivität der STC2-Transfektanten ST1 und ST2 (s. Kap. 4.2.3) mit der Vektorkontrolle verglichen. Abbildung 4.19a. zeigt die Hämatoxylin-Färbung der Zellen, die auf die Unterseite der Membran gewandert sind. Es ist zu erkennen, dass mehr STC2transfizierte Zellen (ST2) als Vektorzellen in der Lage waren, invasiv durch die Membran zu migrieren. Die Zahl der gefärbten Kerne wurde am Mikroskop quantifiziert. Dabei zeigte sich, dass die Invasivität der STC2-Transfektanten ST1 und ST2 im Vergleich zur Vektorkontrolle sechsfach erhöht war (Abb. 4.19b).
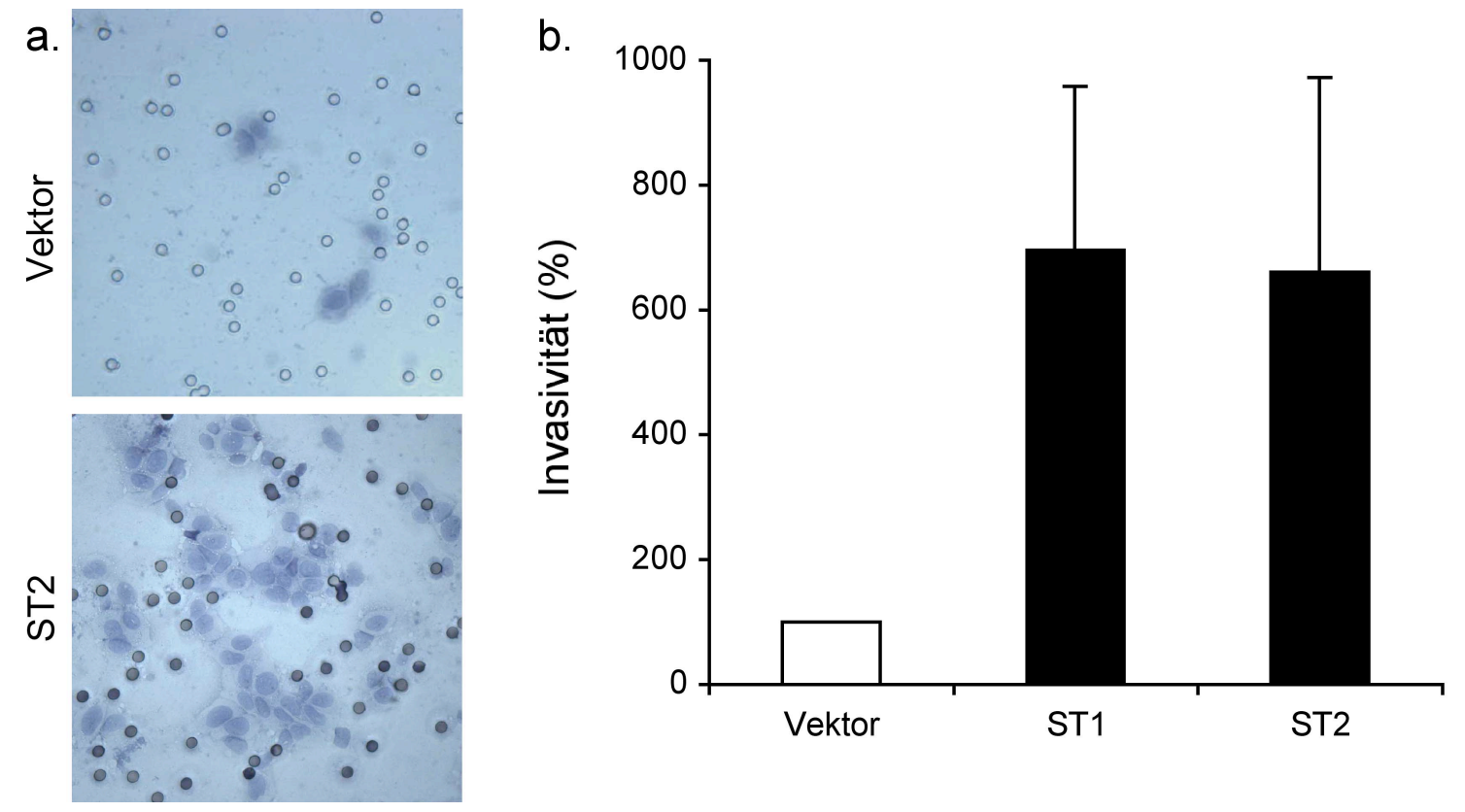

Abb. 4.19: Invasivität von STC2- und Vektor-transfizierten SH-SY5Y NB-Zellen im MatrigelInvasionsassay. $5 \times 10^{3}$ Zellen (ST1, ST2 und Vektor) wurden in serumfreiem Medium resuspendiert und in Einsätze mit einer Matrigel-beschichteten Membran pipettiert. (a.) Nach $24 \mathrm{~h}$ wurden die gewanderten invasiven Zellen auf der Unterseite der Membran fixiert und mit Hämatoxylin gefärbt. (b.) Die Zahl der migrierten ST1- und ST2-Zellen wurde prozentual auf die Vektorkontrolle bezogen $($ Vektor $=100 \%)$. Die dargestellten Mittelwerte wurden aus drei unabhängigen Assays errechnet und die Standardabweichung bestimmt.

\subsubsection{In STC2-exprimierenden SH-SY5Y ist die Aktivität der MMP 2 erhöht}

Für invasives Wachstum und Metastasierung ist der Abbau der extrazellulären Matrix von großer Bedeutung. Der Abbau erfolgt in vivo u. a. durch extrazelluläre Matrixmetalloproteinasen (MMPs). Um zu untersuchen, ob der beobachtete Anstieg der Invasivität durch MMPs vermittelt wird, wurde die proteolytische Aktivität im Zellüberstand 
mittels Zymographie bestimmt. MMP 2 und 9 sind in der Lage, Gelatine proteolytisch abzubauen. Zur Bestimmung ihrer Aktivität wurde Gelatine als Substrat in SDS-Gele einpolymerisiert. Nach der Auftrennung und Renaturierung der Proteasen konnte die Substratumsetzung durch Gegenfärbung mit Coomassie-Blau nachgewiesen werden. Die Stellen, an denen die Enzyme aktiv waren, blieben ungefärbt. Für die in Abbildung 4.20 dargestellte Zymographie wurden konzentrierte Überstände der STC2- und Vektortransfizierten SH-SY5Y-Zellen verwendet. Die untersuchten MMPs lassen sich durch ihr Molekulargewicht von $66 \mathrm{kDa}$ (MMP2) und $86 \mathrm{kDa}$ (MMP9) auf dem SDS-Gel unterscheiden. Es konnte gezeigt werden, dass die Aktivität von MMP2 (66 kDa) in dem Transfektanten ST1 erhöht war. MMP 9 Aktivität, die im SDS-Gel in einer Bande bei 86 kDa resultieren sollte, konnte weder in STC2-transfizierten ST1-Zellen noch in der Vektorkontrolle nachgewiesen werden.

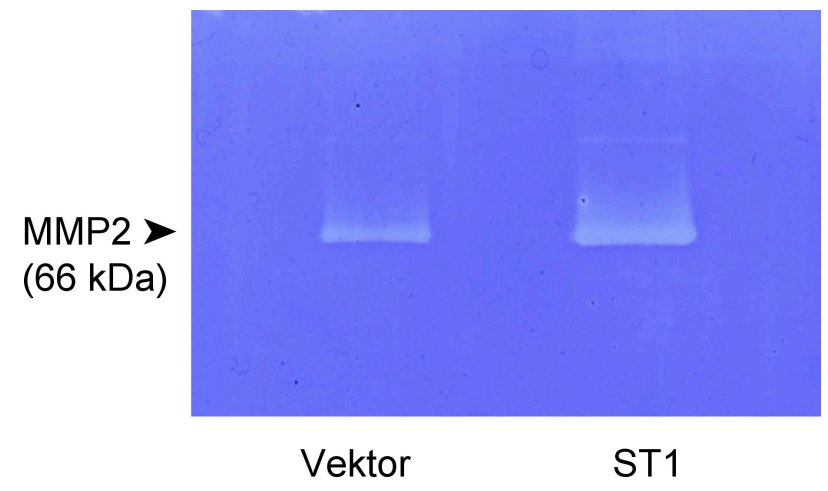

Abb. 4.20: Bestimmung der Enzymaktivität von Matrixmetalloproteinasen (MMPs) aus Überständen von STC2- und Vektortransfizierten SH-SY5Y-Zellen mittels Zymographie. Gleiche Mengen konzentrierter Überstände des STC2-Transfektanten ST1 und der Vektorkontrolle wurden in Gelatine-SDSPAGE aufgetrennt und renaturiert. Nach Coomassie-Färbung ist die nicht abgebaute Gelatine als blauer Hintergrund sichtbar. Stellen, an denen die Enzyme aktiv waren, blieben ungefärbt (weiße Banden).

\subsubsection{In vivo-Effekte der STC2-Expression in SH-SY5Y-Zellen}

Um die Effekte von STC2 auf die Tumorbildung in vivo zu untersuchen, habe ich STC2exprimierende SH-SY5Y-Zellen und Vektor-transfizierte Kontrollzellen auf die Chorioallantoismembran (CAM) von Hühnerembryonen aufgetragen. Aggressive Tumorzellen wachsen invasiv in die CAM und können solide Tumoren bilden, die Anschluss an die embryonalen Gefäße finden. Nach einwöchiger Inkubation wurde die Morphologie der Tumoren makroskopisch und anhand von Semidünn- und Gefrierschnitten untersucht. In Vorversuchen wurde gezeigt, dass die Fähigkeit zur Tumorbildung von SH-SY5Y Wildtypund Vektor-transfizierten SH-SY5Y-Zellen vergleichbar ist. 


\subsubsection{Die Morphologie der STC2-exprimierenden Tumoren ist verändert}

ST1- und Vektorzellen wurden auf die CAM aufgebracht und das Tumorwachstum makroskopisch untersucht und fotografiert (Abb. 4.21). Die Vektortumoren $(n=28)$ waren klein und massiv, einzelne Blutlakunen waren in der soliden Tumormasse zu identifizieren. Das Volumen der ST1-Tumoren $(\mathrm{n}=26)$ ist im Vergleich dazu stark erhöht. Es handelte sich dabei aber nicht um solide Tumorzellmassen, sondern um Blut gefüllte Zysten mit kaum sichtbarem Tumorzellanteil.
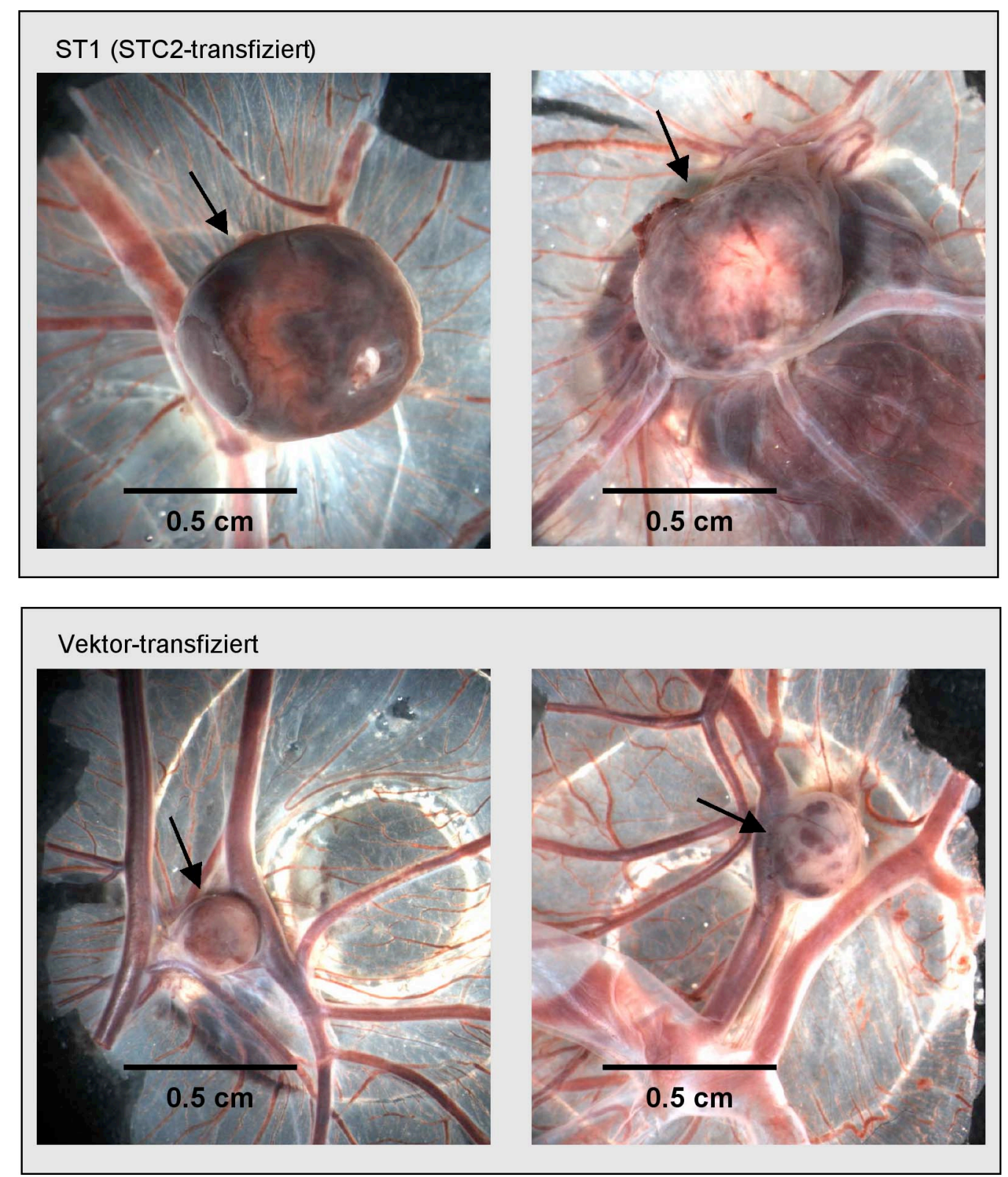

Abb. 4.21: Tumoren von STC2- (ST1) und Vektor-transfizierten SH-SY5Y-Zellen auf der Chorioallantoismembran (CAM) von Hühnerembryonen. Die Tumorbildung von STC2exprimierenden NB-Zellen wurde im Vergleich zu Vektor-transfizierten Kontrollzellen untersucht. Modifizierte Thermanox-Trägerscheiben wurden auf die CAM von Tag 10 Hühnerembryonen gelegt 
und $1 \times 10^{7}$ Zellen in $40 \mu \mathrm{l}$ Medium aufgetragen. Die Eier wurden verschlossen und für weitere 7 Tage inkubiert. Nach der Ernte wurden die Tumoren am Binokular untersucht und fotografiert. Die dargestellten Aufnahmen wurden bei einer 20-fachen Vergrößerung aufgenommen und zeigen typische Tumoren des STC2-Transfektanten (ST1) und der Vektorkontrolle. In drei unabhängigen Assays wurden insgesamt 28 Eier mit Vektorzellen und 26 Eier mit ST1-Zellen untersucht. Die Tumoren wurden mit einem Pfeil gekennzeichnet.

\subsubsection{STC2-Expression in SH-SY5Y korreliert in vivo mit invasivem Verhalten und erhöhter Blutigkeit}

Um die morphologischen Unterschiede zwischen Tumoren von ST1- und Vektorzellen näher zu untersuchen, habe ich von den Tumoren Semidünnschnitte angefertigt. Abbildung 4.22 zeigt die Schnitte von Tumoren des Transfektanten ST1 im Vergleich zu Vektor-transfizierten Kontrolltumoren. Neben dem eigentlichen Tumorgewebe ist auch die CAM der Hühnerembryonen dargestellt.

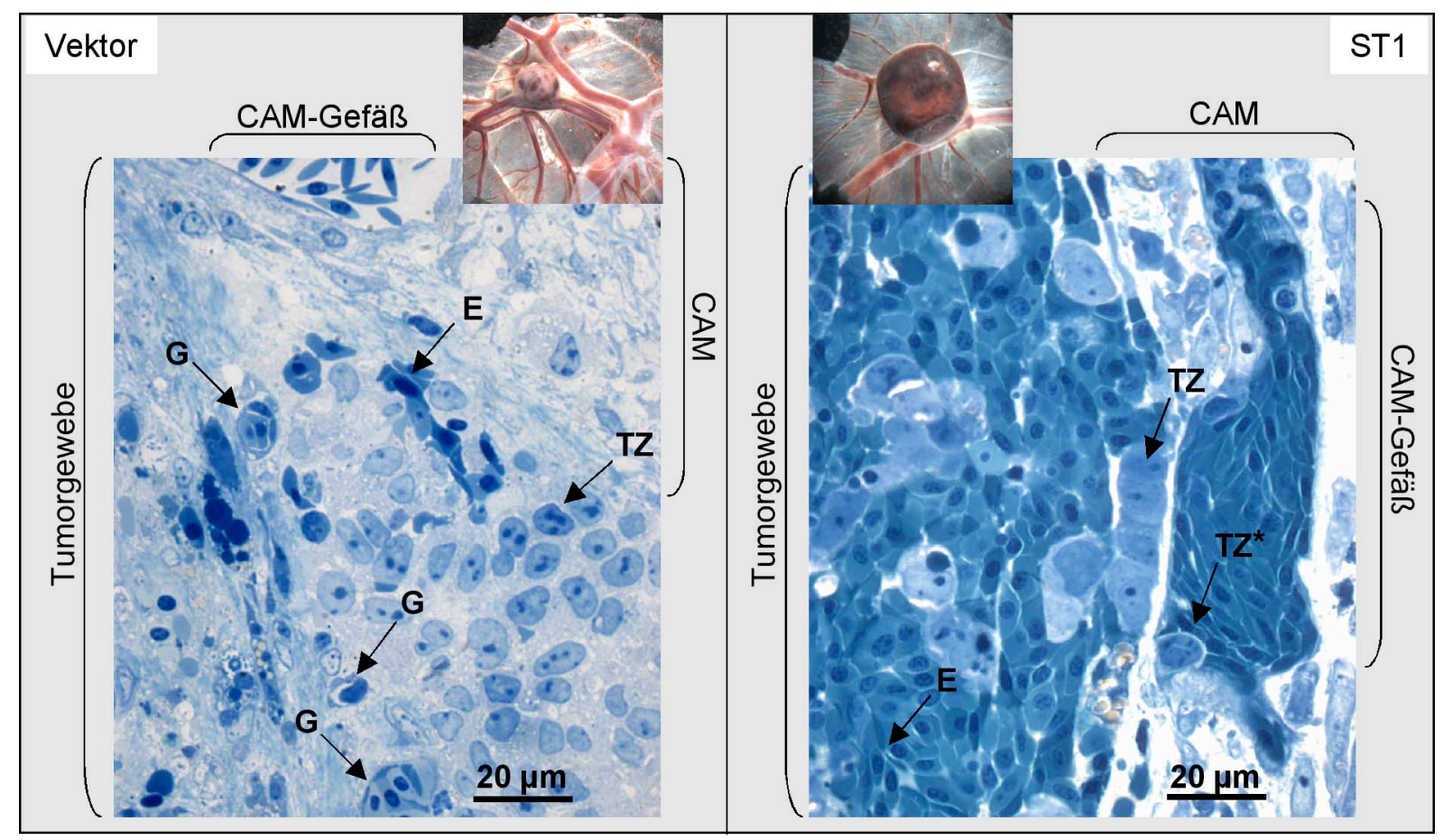

Abb. 4.22: Semidünnschnitte von ST1-Tumoren im Vergleich zu Kontrolltumoren (Vektor). Tumorzellen wurden auf die CAM von Tag 10 Hühnerembryonen aufgetragen und die entstandenen Tumoren nach 7-tägiger Inkubation fixiert und untersucht. Aus repräsentativen Tumorgeweben wurden Semidünnschnitte hergestellt und mit Richardson-Lösung gefärbt. An den Rändern der Tumoren befindet sich die mit Gefäßen durchzogene CAM. Das Tumorgewebe besteht aus Tumorzellen (TZ) und Erythrozyten (E), die im Vogel kernhaltig sind. In den Kontrolltumoren sind Gefäße (G) sichtbar. Die ST1-Zellen bilden große, blutige Zysten. 
Der Tumor aus Vektorzellen enthielt fast ausschließlich Tumorzellen (TZ), die an den großen gelappten Kernen mit deutlichem Nukleolus zu erkennen waren. Die wenigen Erythrozyten (E), die sich im Tumorgewebe befanden, waren kleiner und durch ihr kompaktes Zytoplasma und den gleichmäßig-geformten Zellkern gut zu differenzieren. An mehreren Stellen im Tumor waren außerdem Erythrozyten-gefüllte Gefäße (G) erkennbar. Im Vergleich dazu fanden sich in den Tumoren der ST1-Zellen sehr viele Erythrozyten (E), jedoch waren keine Gefäße erkennbar. Die wenigen Tumorzellen (TZ) befanden sich vermehrt am Rand der Blut gefüllten Zyste, wo sie dem CAM Stroma unmittelbar anlagen. Sie standen in Interaktion mit den CAM-Gefäßen und hatten diese zum Teil bereits infiltriert (TZ*).

\subsubsection{Gefäßbildung und -Arrosion in STC2-exprimierenden Tumoren}

Um die Gefäßstruktur von Tumoren der STC2-exprimierenden SH-SY5Y-Zellen genauer zu untersuchen, wurden Gefrierschnitte hergestellt. Die Gefäße konnten anschließend durch Sambucus nigra-Agglutinin (Sna-fitc; grün), welches Endothelzellen markiert, sowie durch Antikörper gegen $\alpha$-Glattmuskelaktin ( $\alpha$ SMA; rot) dargestellt werden. Während Endothelzellen alle Gefäße auskleiden, finden sich Glattmuskelzellen nur in der Tunica media größerer Gefäße. Die Überlagerung der Fluoreszenzen ist an einer Orangefärbung zu erkennen. In Abbildung 4.23 sind 100- und 200-fache Vergrößerungen der Gefrierschnitte dargestellt. Die 100-fache Vergrößerung der Schnitte dient der Orientierung: Die HühnerCAM enthält große Gefäße (CG), bei denen Endothel- und Muskelzellen markiert wurden. Die Kapillaren der CAM fluoreszieren grün, hier wurde nur Endothel markiert. Das Tumorgewebe wurde in beiden Abbildungen durch einen weißen Kreis markiert. Bei der 200fachen Vergrößerung sind in diesem Gewebe große dunkle Bereiche zu erkennen, die auf ein Gemisch aus Erythrozyten und Tumorzellen (E+T) zurück zu führen sind. Bei den grünfluoreszierenden Bereichen handelt es sich um Endothelzellen. Eine strukturierte Anordnung dieser Zellen, wie in den intakten Gefäßen (IG, grün) außerhalb des Tumorgewebes, ist nicht zu erkennen. 


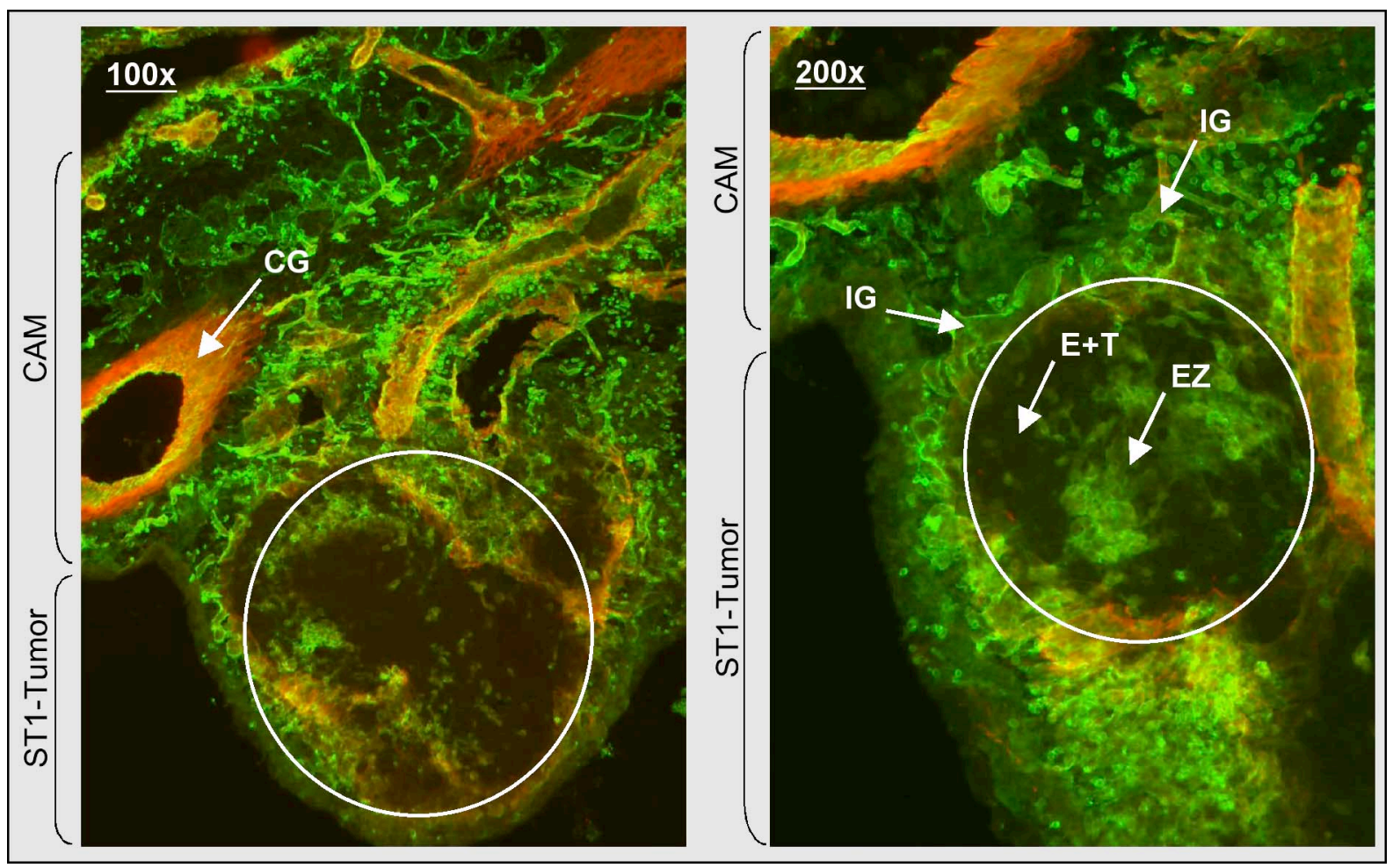

Abb. 4.23: Epi-Fluoreszenz-mikroskopische Aufnahme der immunhistologischen Färbung von Endothel- und glatten Muskelzellen an Gefrierschnitten von ST1-Tumoren. Repräsentative Tumoren wurden zur Herstellung von Gefrierschnitten eingesetzt. Fitc-konjugiertes Sambucus nigra Agglutinin (grün-fluoreszierend) wurde zur Markierung von Endothelzellen verwendet und glatte Muskelzellen wurden mit $\alpha$ SMA-Antikörpern und einem rot-fluoreszierenden sekundären Antikörper nachgewiesen. Die verschiedenen Vergrößerungen (100x und 200x) zeigen einen ST1-Tumor und Bereiche des CAM-Stromas. Das Tumorgewebe mit Erythrozyten und Tumorzellen (E+T) sowie Endothelzellen (EZ) wurde mit einem weisen Kreis markiert. Intakte Gefäße (IG) außerhalb des Tumorgewebes wurden ebenfalls markiert.

\subsection{Untersuchungen der Effekte von gereinigtem rekombinantem STC2-Protein}

Um zu überprüfen, ob die mit STC2-überexprimierenden Zellen gezeigten Ergebnisse (s. Kap. 4.2) tatsächlich auf die Wirkung von STC2 zurückzuführen sind, habe ich im Folgenden CAM-Assays mit rekombinantem STC2 aus E. coli (STC2rek) durchgeführt. Vor der Verwendung wurde STC2rek im Vergleich zu STC2 aus Zellüberständen untersucht. Außerdem musste das kommerziell erworbene STC2rek-Protein (Abcam, Cambridge, UK) dialysiert werden, da es unter reduzierenden Bedingungen vorlag.

\subsubsection{Untersuchung und Dialyse des rekombinanten STC2 aus E. coli}

STC2rek wurde mit STC2 aus Zellüberständen des Transfektanten ST1 (s. Kap. 4.2.3f) verglichen. Die Western Blot Analyse zeigte, dass STC2rek, wie das STC2-Protein aus dem 
Überständ von ST1, als Doppelbande vorlag (Abb. 4.24a). Allerdings ist anzumerken, dass STC2rek im SDS-Gel im Vergleich zu STC2 aus Überständen wenige kDa leichter war.

STC2rek musste vor der Verwendung gegen PBS dialysiert werden, da es in einem Puffer mit dem reduzierenden Agens DTT sowie dem Atmungsketteninhibitor Na-Azid als Stabilisator geliefert wird. Das dialysierte Protein wurde anschließend direkt verwendet oder für $24 \mathrm{~h}$ bei $4^{\circ} \mathrm{C}$ gelagert. Der Vergleich von STC2rek vor (V_Dial) und nach der Dialyse (Dial) zeigte, dass die dialysierten Proben weniger konzentriert waren (Abb. 4.24b). Für 24 h gelagertes, dialysiertes STC2rek (Dial_24h) unterschied sich dagegen nicht von dem frisch dialysierten Protein, es fand kein Konzentrationsverlust durch die Lagerung statt. Der dialysebedingte Proteinverlust wurde in den nachfolgenden CAM-Assays berücksichtigt.

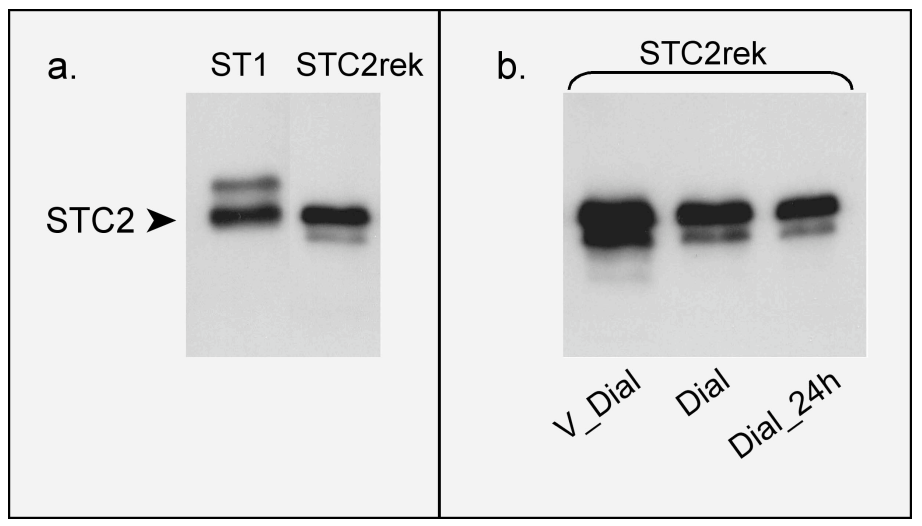

Abb. 4.24: Western Blot Analyse von STC2rek. (a.) STC2rek (100 ng) im Vergleich zu STC2-Protein aus Zellüberständen des STC2Transfektanten ST1. Der aufgetragene Überstand entsprach der STC2Expression von $2 \times 10^{6}$ Zellen (s. Kap. 3.4.3). (b.) Untersuchung von STC2rek

(250 ng) vor (V_Dial) und nach Dialyse (Dial), sowie dialysiertem STC2rek nach 24-stündiger Lagerung bei $4^{\circ} \mathrm{C}$ (Dial_24h). Der Proteinnachweis erfolgte durch polyklonale STC2-Antikörper. Alle Proben lagen in einem Volumen von $30 \mu$ vor.

\subsubsection{STC2rek liegt nach der Dialyse teilweise als Dimer vor}

In Kapitel 4.2.4 wurde gezeigt, dass STC2 in Überständen von humanen NB-Zelllinien als Dimer vorliegt. Das kommerziell erworbene STC2rek wurde in einem reduzierenden, DTThaltigen Puffer geliefert, der die Dimerisierung verhindert. Um zu untersuchen, ob durch die Dialyse eine Dimerisierung stattgefunden hat, wurde das Protein in Western Blot Analysen unter nicht reduzierenden Bedingungen getestet. Abbildung 4.25 zeigt, dass rekombinantes STC2 nach der Dialyse teilweise als Dimer vorlag, vorwiegend jedoch in der monomeren Form verblieb. 


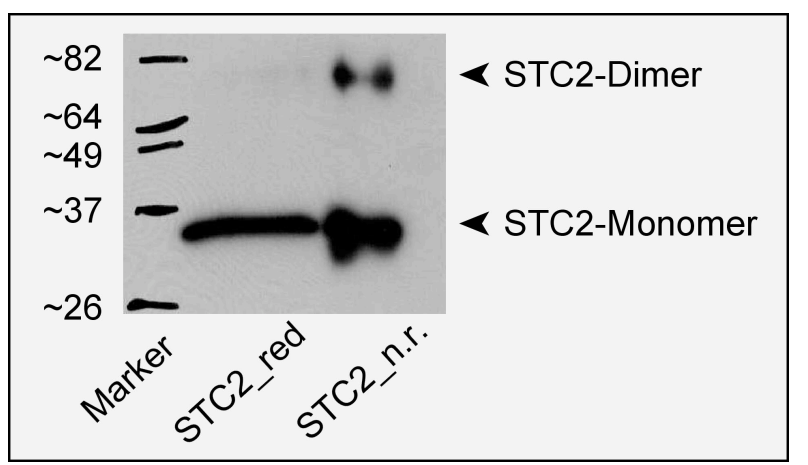

Abb. 4.25: Western Blot Analyse von dialysiertem STC2rek. $500 \mathrm{ng}$ Stc2rek wurden unter reduzierenden (red) und nichtreduzierenden (n.r.) Bedingungen im SDS-Gel aufgetrennt und durch polyklonale Antikörper im Western Blot nachgewiesen. Der verwendete Proteinmarker wurden nachgezeichnet und die Bandengröße in $\mathrm{kDa}$ angegeben.

\subsubsection{STC2rek induziert Effekte auf der CAM von Hühnerembryonen}

Das dialysierte STC2rek wurde auf einer Trägerscheibe eingetrocknet und diese dann auf die Chorioallantoismembran (CAM) von Hühnerembryonen aufgelegt. Als Kontrolle wurde in Dialysepuffer gelöstes Bsa unter entsprechenden Bedingungen eingesetzt. Insgesamt wurden 13 Ansätze mit dialysiertem STC2rek und 15 mit Bsa durchgeführt. STC2rek induzierte Granulationsgewebe und Blutungen in der CAM (Abb. 4.26, Pfeil). Im Vergleich dazu wurden nach Inkubation mit Bsa typischerweise keine Bildungen von Granulationsgewebe beobachtet.
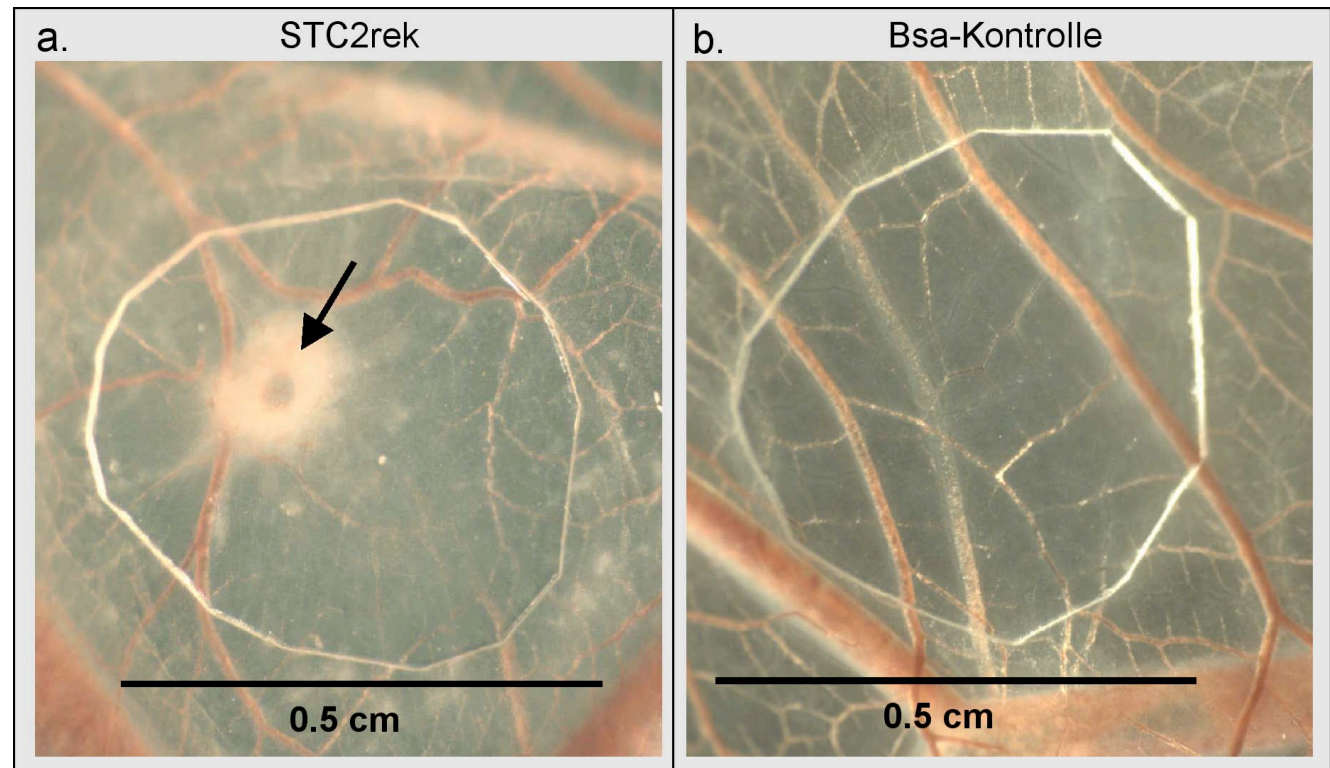

Abb. 4.26: Makroskopische Aufnahme von fixierten CAMs nach Behandlung mit (a.) STC2rek oder (b.) Bsa. STC2rek wurde gegen DPBS dialysiert und $3 \mu \mathrm{g}$ des Proteins auf Thermanox-Trägerscheiben aufgetragen. Die Scheiben wurden bei RT getrocknet und anschließend mit der Proteinseite nach unten auf die CAM von Tag 13 Hühnerembryonen gelegt $(n=13)$. Nach Inkubation wurde die fixierte CAM ausgeschnitten und makroskopisch am Binokular (2x) untersucht (Pfeil zeigt Granulationsgewebe und Blutung). Als Kontrolle wurden entsprechende Ansätze mit Dialysepuffer und Bsa verwendet $(n=15)$. 


\subsubsection{STC2rek induziert Blutungen und die Bildung von Granulationsgewebe}

Von den behandelten Arealen der CAM (s. Abb. 4.27a) wurden Semidünnschnitte hergestellt und mikroskopisch untersucht. Abbildung 4.27b und 4.27d zeigen die Anreicherung extravasaler Erythrozyten (E) im Stroma der CAM, an der mit STC2 behandelten Stelle. Das Chorionepithel (C) hatte sich abgesenkt und war an mehreren Stellen durchbrochen (Abb. 4.27b./ c.). Ober -und unterhalb des Chorionepithels hatte sich Granulationsgewebe (G) gebildet, und das Allantoisepithel (A) war in dem betroffenen Bereich ebenfalls reaktiv verdickt. Die Versuche zeigen, dass STC2 offensichtlich zur Zerstörung von Gefäßen und Extravasation von Erythrozyten führt, begleitet von der Bildung von Granulationsgewebe und Metaphasie der CAM-Epithelien.

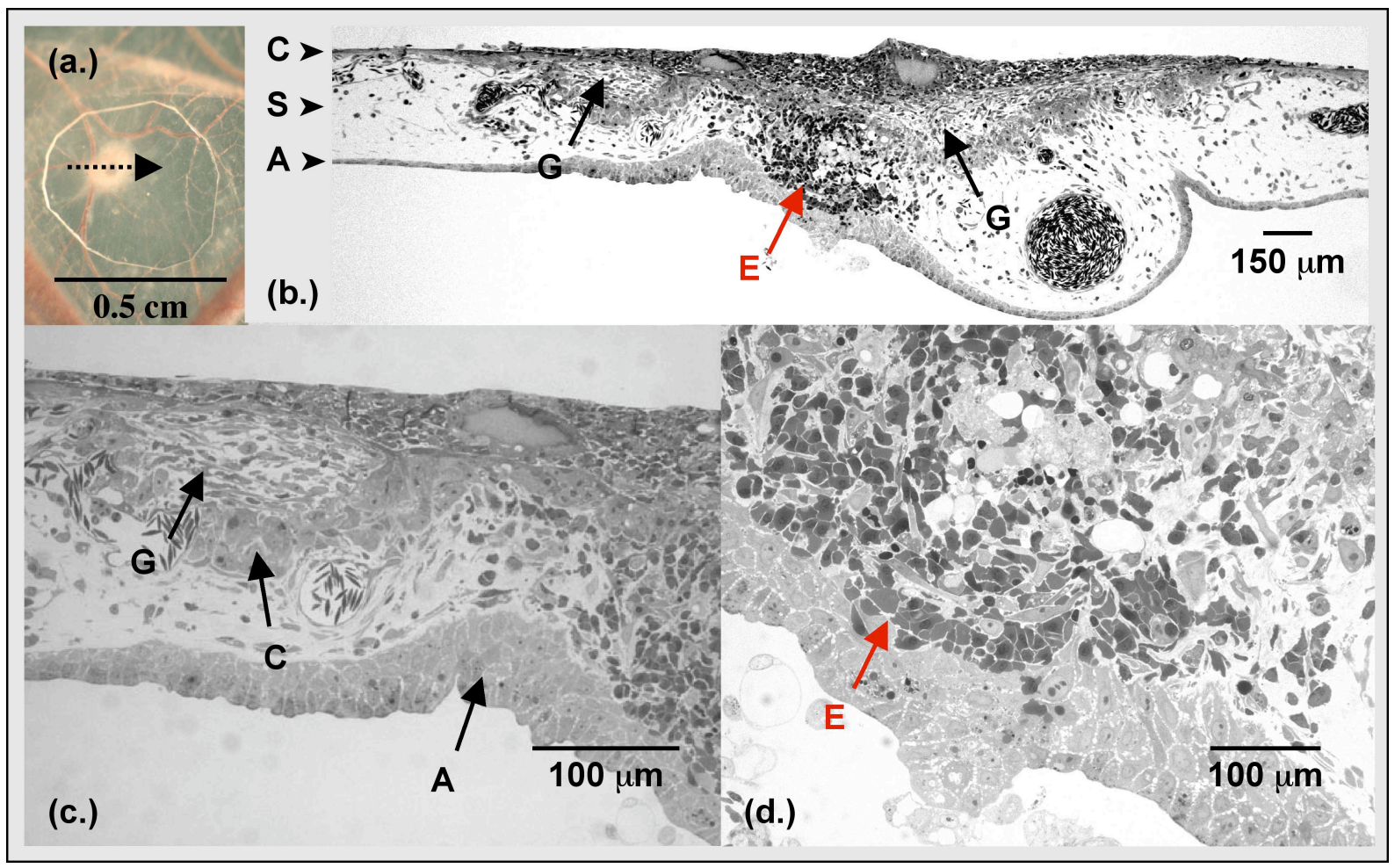

Abb. 4.27: STC2rek-behandelte CAM-Bereiche: Von repräsentativen Proben wurden Semidünnschnitte hergestellt: (a.) Makroskopische Ansicht der mit STC2rek behandelte Bereiche der CAM (s. Kap. 4.3.3), der gestrichelte Pfeil markiert den Bereich, aus dem Semidünnschnitte (b.-d.) hergestellt wurden. (b.) Im Überblick (10x) sind die verschiedenen Schichten der CAM zu erkennen: Chorionepithel (C), Stroma (S) und Allantoisepithel (A). (c. und d.) Bei 40-facher bzw. 63-facher Vergrößerung ist die Bildung von Granulationsgewebe (G) über dem abgesenkten Chorionepithel (C), die Verdickung des Allantoisepithel (A), sowie die Ansammlung extravasaler Erythrozyten (E) deutlich zu erkennen.

Da das rekombinanten STC2 (STC2rek) nur in reduzierter Form kommerziell angeboten wurde und auch nach Dialyse nur ein Teil in Dimerform vorlag, wurde für weitere 
Untersuchungen das humane STC2-Protein in der immortalisierten embryonalen Nierenzelllinie HEK 293 überexprimiert. Das Protein konnte anschließend über ein angefügte Streptag II-Peptid (IBA, Göttingen) mittels Affinitätschromatographie aufgereinigt werden (s. Kap. 3.4.9).

\subsection{Korrelation von STC2-Expression und ungünstigen Faktoren beim NB}

\subsubsection{STC2-Expression ist in metastasierenden Stadium 4 Tumoren erhöht}

In den Kapiteln 4.2.10 und 4.2.11.2 konnte gezeigt werden, dass die STC2-Expression in der humanen NB-Zelllinie SH-SY5Y mit vermehrter Invasivität der Zellen in vitro und in vivo korreliert. Um zu prüfen, ob STC2 in NB-Primärtumoren ebenfalls mit erhöhtem invasivem Potential einhergeht, habe ich die STC2-mRNA-Expression in 50 humanen NB mittels Realtime RT-PCR bestimmt und mit klinischen Tumorstadien (nach INSS, s. Kap 1.2.4) korreliert. Abbildung 4.28 zeigt die mediane relative STC2-Expression in den 5 klinischen Tumorstadien (1-4 und 4s). Die metastasierten NB der Stadien 4 und 4s zeigen eine Erhöhung der STC2-Expression im Vergleich zu den nicht oder wenig metastasierten Tumoren der Stadien 1-3. Die Steigerung der STC2-Expression in dem hoch-aggressiven Tumorstadium 4 ist statistisch signifikant $(\mathrm{p}=0,032)$. Die für Zelllinien gezeigte Korrelation von STC2Expression und erhöhtem invasivem Potential kann demnach auch bei Primärtumoren beobachtet werden.

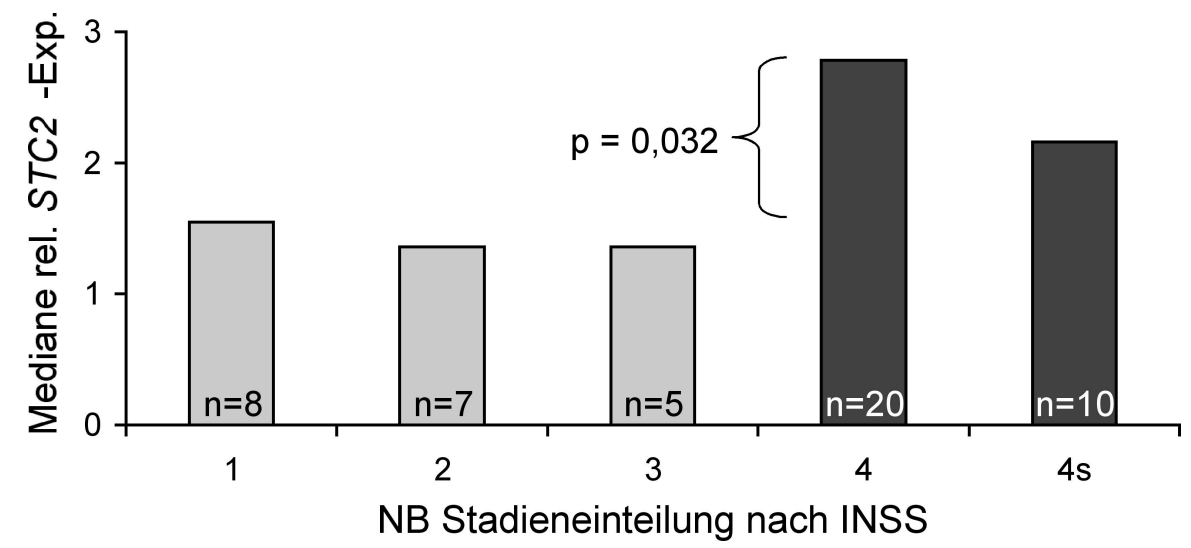

Abb. 4.28: Mediane STC2-mRNA-Expression in 50 humanen NB-Primärtumoren, gruppiert nach INSS-Tumorstadien. Die STC2-mRNA-Expression wurde mittels Real-time RT-PCR untersucht. $\beta$ AKTIN wurde als Referenzgen $(\operatorname{ctSTC} 2-\operatorname{ct} \beta$-AKTIN $=\Delta \operatorname{ctSTC} 2)$ verwendet und der $\Delta \operatorname{ctSTC} 2$ einer beliebigen Tumorprobe als Kalibrator gleich 1 gesetzt $(=\Delta \Delta$ ctSTC2). Die relative STC2-mRNAExpression ist als $2^{-\Delta \Delta c t}$-Wert angegeben (s. Kap. 3.3.9; Primer: STC2 Stc2sen/Stc2rev, $\beta$-AKTIN bAkfwdR/bAkrevR). Die Anzahl der untersuchten Tumoren (n) ist für jedes Stadium angegeben. Der Expressionsunterschied zwischen Stadium 4-Tumoren und Stadium (1-3)-Tumoren ist statistisch signifikant $(\mathrm{p}=0,032)$. 


\subsubsection{STC2-Expression korreliert in NB-Zelllinien mit der Expression von MYCN}

Die Amplifikation von $M Y C N$ korreliert im humanen NB mit aggressivem Tumorwachstum und einer schlechten Prognose (s. Kap 1.2.5; Brodeur, 2003). Um zu überprüfen, ob die Expression von STC2 (s. Abb. 4.1) mit der Expression von MYCN korreliert, habe ich die Expression der Gene in 24 humanen NB-Zelllinien untersucht.

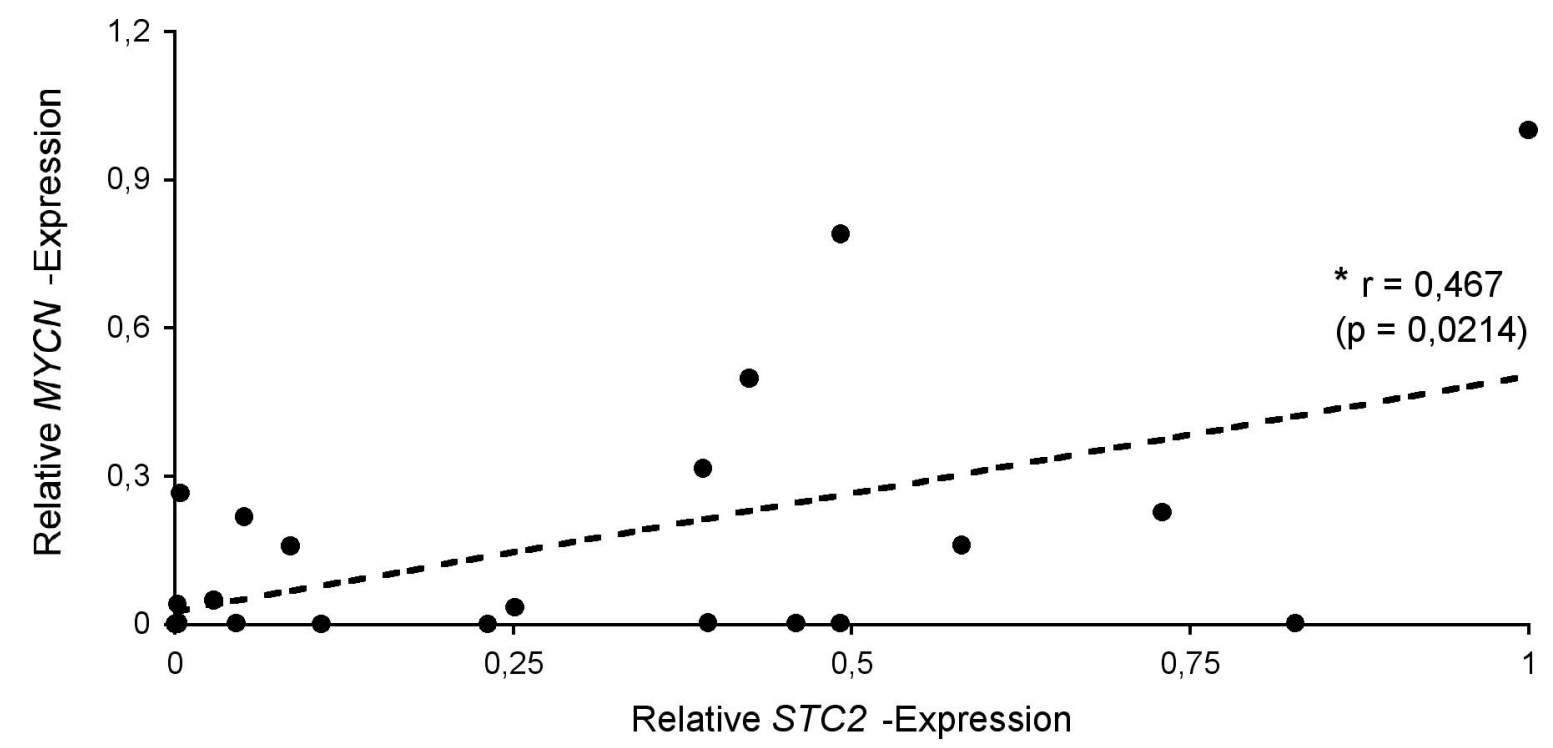

Abb. 4.29: Korrelation zwischen STC2- und MYCN-Expression in 24 humanen NB-Zelllinien. Die mRNA-Expressionen wurde mittels Real-time RT-PCR bestimmt. $\beta$-AKTIN wurde als Referenzgen (ctSTC2 bzw. ctMYCN $-\operatorname{ct} \beta$-AKTIN $=\Delta$ ctSTC2 bzw. $\Delta$ ctMYCN) verwendet und der $\Delta$ ctSTC2 bzw. $\Delta$ ctMYCN der NB-Zelllinie NGP als Kalibrator gleich 1 gesetzt $(=\Delta \Delta$ ctSTC2 bzw. $\Delta \Delta$ ctMYCN). Die relativen Expressionen sind als $2^{-\Delta \Delta c t}$-Werte angegeben (s. Kap. 3.3.9). * Die ermittelte Korrelation $r$ hat statistische Signifikanz $(\mathrm{p}=0,0214)$. Verwendete Primer: STC2 (Stc2sen/Stc2rev), $\beta$-AKTIN (bAkfwdR/bAkrevR) und MYCN (MYCNfwd/MYCNrev).

In Abbildung 4.29 ist der graphische Vergleich von STC2- und MYCN-Expression dargestellt. Da die verwendeten Daten nicht der Normalverteilung unterliegen, wurde der SpearmanKorrelations-Koeffizient berechnet. Dieser betrug 0,467 ( $\mathrm{p}=0,0214)$. Ein Koeffizient von 1 bzw. -1 beschreibt eine absolute Korrelation der untersuchten Faktoren. Der p-Wert gibt Aussage darüber, wie wahrscheinlich ein Zutreffen der ermittelten Korrelation ist. Liegt die Wahrscheinlichkeit unter einem gewählten Signifikanzniveau von $5 \%$, ist der p-Wert kleiner als 0,05 und es besteht statistische Signifikanz, da die Wahrscheinlichkeit für ein zufälliges Eintreffen gering ist. Der ermittelte Koeffizient zeigt eine positive Korrelation von STC2- und MYCN-Expression in den untersuchten humanen NB-Zelllinien. Da der p-Wert kleiner als 0,05 ist, besitzt diese Korrelation statistische Signifikanz. 


\subsubsection{STC2-Expression korreliert in Primärtumoren mit $M Y C N$-Amplifikation}

Um zu untersuchen, ob STC2 in vivo ebenfalls mit dem $M Y C N$-Status korreliert, wurde die STC2-Expression in 50 NB-Primärtumoren mittels Real-time RT-PCR untersucht und mit der in den Krankenakten beschriebenen $M Y C N$-Amplifikation (s. Kap. 1.2.5) verglichen.

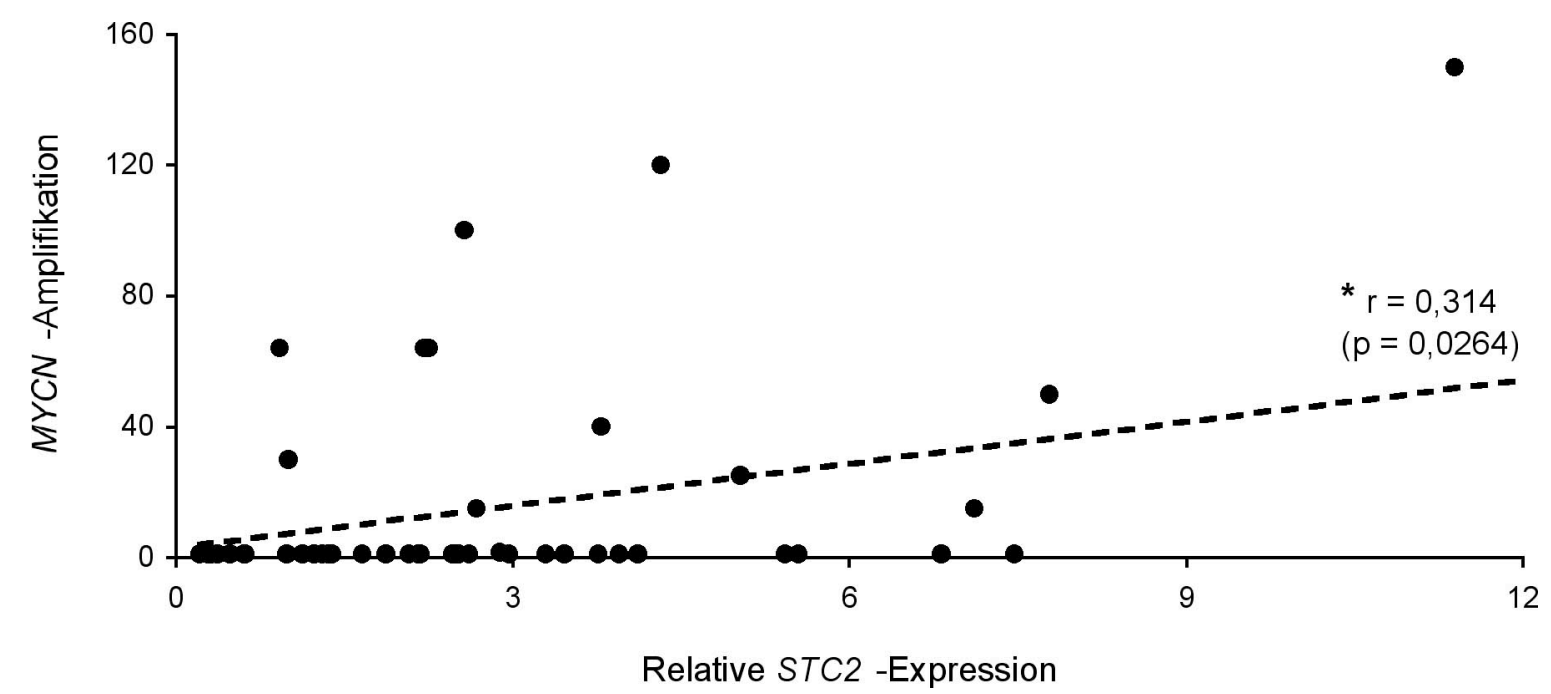

Abb. 4.30: Korrelation von STC2-Expression und $M Y C N$-Amplifikation in 50 primären humanen NB. Die STC2-mRNA-Expression wurde mittels Real-time RT-PCR bestimmt. $\beta$-AKTIN wurde als Referenzgen $(\operatorname{ctSTC} 2-\operatorname{ct} \beta$-AKTIN $=\Delta$ ctSTC2) verwendet und der $\Delta$ ctSTC2 einer beliebigen Tumorprobe als Kalibrator gleich 1 gesetzt $\left(=\Delta \Delta\right.$ ctSTC2). Die relative Expression ist als $2^{-\Delta \Delta t}$-Wert angegeben (s. Kap. 3.3.9). Verwendete Primer: STC2 (Stc2sen/Stc2rev) und $\beta$-AKTIN (bAkfwdR/bAkrevR). Die $M Y C N$-Amplifikation der Tumorproben wurde den Krankenakten entnommen und in der Graphik als Kopienzahl angegeben. * Die ermittelte Korrelation $\mathrm{r}$ hat statistische Signifikanz ( $p=0,0264)$.

In Abbildung 4.30 ist der graphische Vergleich von STC2-Expression und MYCNAmplifikation dargestellt. Der für die untersuchten Daten berechnete SpearmanKorrelationskoeffizient $\mathrm{r}$ betrug 0,314 ( $\mathrm{p}=0,0264)$. Somit besteht eine leichte positive Korrelation von $M Y C N$-Amplifikation und STC2-Expression in den untersuchten Primärtumoren, die statistisch signifikant ist. 


\section{Diskussion}

Das Neuroblastom (NB) ist die häufigste extrakraniale Tumorerkrankung im Kindesalter. Trotz intensiver multimodaler Therapie versterben ca. $30 \%$ der Patienten, hauptsächlich aufgrund von metastasierender und schnell fortschreitender Tumorprogression (Brodeur, 2003; Schwab et al., 2003). Dem gegenüber stehen Differenzierung und spontane Tumorregression, die ebenfalls typischerweise im NB zu beobachten sind. Diese klinische Heterogenität, für die Variationen in der Tumorgenetik verantwortlich gemacht werden, stellt eine besondere Schwierigkeit bei Diagnose und Therapie der Tumoren dar. Die Erforschung des genetischen Hintergrunds war und ist deshalb für die Suche nach neuen Markern zur Risikoklassifizierung und damit der Möglichkeit individueller Therapiestrategien von großem Interesse (Schwab et al., 2003; Maris et al., 2007). Das Ziel der vorliegenden Dissertation war es, die Bedeutung von Stanniocalcin 2 (STC2) im humanen NB zu untersuchen und zu prüfen, ob die Expression des Moleküls mit einer günstigen Prognose korreliert. Das sezernierte Glykoprotein STC2 wurde bereits im Zusammenhang mit Tumorerkrankungen untersucht (Chang et al., 2003). Seine physiologischen Funktionen und seine Wirkung bei der Tumorprogression sind allerdings noch unklar und werden widersprüchlich beschrieben. Bei Brustkrebs scheint die STC2-Expression mit einer günstigen Prognose zu korrelieren (Yamamura et al., 2004). Dem gegenüber konnte kürzlich bei Nierenzellkarzinomen gezeigt werden, dass die Expression von STC2 mit einer erhöhten Aggressivität der Tumoren und einem kürzeren Überleben der Patienten assoziiert ist (Meyer et al., 2008). Vorarbeiten haben gezeigt, dass die STC2-Expression in Keratoepithelin-transfizierten NB-Zellen erhöht ist, während das Tumorwachstum gehemmt wird (Becker et al., 2006). Um den Einfluss von STC2 auf die Progression humaner NB zu untersuchen, wurde die Expression in NBZelllinien und Primärtumoren bestimmt. Des Weiteren wurden funktionelle Analysen mit STC2-überexprimierenden NB-Zellen und gereinigtem STC2-Protein in vitro und in vivo durchgeführt. Hierbei konnte erstmals eine duale Rolle von STC2 bei der Progression von Tumoren beschrieben werden. Die Ergebnisse zeigen, dass das Molekül im NB eine wachstumshemmende Wirkung auf Tumorzellen hat, gleichzeitig aber an invasivem Verhalten und Tumormetastasierung beteiligt sein könnte. Wie meine Ergebnisse sich in die aktuelle Forschung einbringen, wird in den folgenden Abschnitten diskutiert.

\subsection{STC2-Expression im humanen Neuroblastom}

Als Grundlage für die Untersuchungen am NB wurde zunächst der STC2-Status in 24 humanen NB-Zelllinien bestimmt. Eine Expression konnte in mehr als $50 \%$ der untersuchten 
Zelllinien nachgewiesen und dabei gezeigt werden, dass die STC2-Menge zwischen den Zelllinien variiert (s. Kap. 4.1.1). Das in Multiplex PCR Analysen nachgewiesene STC2Transkript wurde mittels Real-time RT-PCR quantifiziert und die Expression durch Western Blot Analysen auf Proteinebene überprüft (s. Kap. 4.1.2). Dabei zeigte sich, dass die STC2mRNA und Proteinexpression in den untersuchten Zelllinien vergleichbar ist. Das STC2Protein wurde unter reduzierenden Bedingungen bei ca. $36 \mathrm{kDa}$ und unter nicht-reduzierenden Bedingungen bei ca. 75 kDa im Überstand der Zelllinien nachgewiesen (s. Kap. 4.2.4). Die Größe der identifizierten Proteine, genauso wie die Tatsache, dass STC2 im Kulturüberstand und nicht in den Zellen gefunden werden konnte, stimmt mit den Beobachtungen von Moore et al. (1999) überein. Diese berichteten, dass es sich bei STC2 um ein homodimeres Protein handelt, dessen Disulfidbrücken unter reduzierenden Bedingungen gespalten werden und das bei 35-40 kDa (Monomer) und 70-75 kDa (Dimer) im Zellkulturüberstand nachgewiesen werden kann. In Maus-NB-Zellen konnte Stc2 im Gegensatz zu meinen Beobachtungen auch intrazellulär, im endoplasmatischen Retikulum (ER) und im Golgi Apparat, gefunden werden (Ito et al., 2004). STC2 ist ein N-terminal glykosyliertes Protein (Luo et al., 2005) und diese Modifikation wird in ER und Golgi Apparat ausgeführt (Berg, 2002). Deshalb könnte es sich bei dem in ER und Golgi Apparat nachgewiesenen STC2 um gerade posttranslational modifizierte Proteine handeln und nicht um intrazellulär verbleibende Proteinfraktionen.

Die Expression von STC2 wurde in 50 Tumorgewebeproben überprüft. Es konnten ebenfalls variierende STC2-Transkriptmengen gefunden werden (s. Kap. 4.4). Dass STC2 in den untersuchten Zelllinien und Primärtumoren in unterschiedlichen Mengen vorliegt, spricht dafür, dass die STC2-Expression im NB einer Regulation unterliegt. Da das Molekül in unterschiedlichen Geweben exprimiert wird (Chang et al., 2003; Wagner \& DiMattia, 2006) und bislang nicht im Serum nachgewiesen werden konnte (Deol et al., 2000), ist anzunehmen, dass das sezernierte STC2-Protein autokrin oder parakrin wirkt. Ein endokriner Effekt, wie er in Fischen beschrieben wurde, ist unwahrscheinlich (Chang et al., 2003).

\subsection{Korrelation von STC2 mit klinisch relevanten Faktoren}

Die Amplifikation des Onkogens $M Y C N$ steht für aggressive Tumorprogression und Metastasierung und wird als bislang zuverlässigster genetischer Faktor zur Risikostratifizierung beim humanen NB verwendet (Brodeur et al., 1984; Seeger et al., 1985, Maris et al., 2007). Durch Expressionsanalysen konnte im Rahmen dieser Arbeit gezeigt werden, dass STC2 in NB-Zelllinien $(r=0,47)$ und Primärtumoren $(r=0,31)$ positiv mit der 
Expression von MYCN korreliert (p < 0,05; s. Kap. 4.4.2 und 4.4.3) und somit mit aggressiver Tumorprogression einher gehen könnte. Außerdem konnten die Untersuchungen zeigen, dass die STC2-Expression in Stadium 4-Tumoren signifikant erhöht ist ( $p=0,032$; $s$. Kap. 4.4.1) im Vergleich zu Stadium 1-3-Tumoren. Stadium 4s-Tumoren besitzen ebenfalls eine erhöhte STC2-Expression, für die aber keine statistische Signifikanz gezeigt werden konnte. Ein wichtiger Faktor zur Bestimmung klinischer Tumorstadien ist die Bildung von Metastasen (Brodeur et al., 1993), für die das invasive Potential der Tumorzellen ausschlaggebend ist (Woodhouse et al., 1997). In den NB-Stadien 4 und 4s, in denen die STC2-Expression erhöht ist, liegen per Definition systemische Metastasen vor. In den Stadien 1-3 tritt höchstens ein lokoregionaler Befall der Lymphknoten auf (persönliche Auskunft Dr. Barbara Hero, Studienverwaltung „NB 2004“, Pädiatrische Onkologie und Hämatologie, Kinderklinik Köln, s. a. Kap. 1.2.4,). Interessant ist, dass Stadium 4s-Tumoren zwar typischerweise Metastasen bilden, aber meist eine gute Prognose besitzen, da häufig eine spontane Regression der bereits metastasierten Tumoren zu beobachten ist (D'Angio et al., 1971; Maris et al., 2007). Das wirft die Frage auf, ob STC2 die Bildung von Metastasen fördert und dadurch mit aggressiver Tumorprogression korreliert. Außerdem bleibt zu klären, ob eine direkte Interaktion zwischen MYCN und STC2 besteht.

\subsection{STC2-Überexpression in humanen NB-Zellen}

Um STC2-Effekte unabhängig vom Einfluss des $M Y C N$-Onkogens untersuchen zu können, wurde die STC2-negative NB-Zelllinie SH-SY5Y für die Überexpression des Proteins verwendet. Diese Zelllinie wurde aus metastasierten Zellen im Knochenmark eines vierjährigen Mädchens isoliert, besitzt einen epithelialen Phänotyp und keine $M Y C N$ Amplifikation (Biedler et al., 1978). Die STC2-Expression in den Transfektanten wurde auf mRNA- und Proteinebene charakterisiert und die Dimerbildung unter physiologischen Bedingungen nachgewiesen (s. Kap. 4.2.3 f). Somit entspricht das überexprimierte Protein dem nativen STC2 und ist für funktionelle Untersuchungen geeignet. Um G418-induzierte Effekte auszuschließen wurden Leervektor-transfizierte Zellen als Kontrolle verwendet. Die STC2-Doppelbande, die bei Western Blot Analysen der Transfektanten zu sehen war, konnte bei höherer Konzentration auch in Überständen der NB-Zelllinie NGP beobachtet werden. STC2 wird innerhalb der Zellen N-terminal glykosyliert (Luo et al., 2005) und nach Sezernierung phosphoryliert (Jellinek et al., 2000). Deshalb ist anzunehmen, dass wegen der hohen STC2-Expression in den Transfektanten, die posttranslationale Modifikation in einem Teil der Proteine nicht vollständig zu Stande kam und dadurch Protein-Doppelbanden 
auftraten. Moore et al. (1999) konnten bei der Analyse von nativem Hamster- und rekombinant-exprimiertem humanen STC2 ebenfalls eine Protein-Doppelbande identifizieren. Eine N-terminale Sequenzanalyse der beiden isolierten Banden zeigte, dass es sich bei beiden Proben um STC2-Protein handelte.

\subsection{Einfluss von STC2 auf Proliferation und Apoptose von humanen NB-Zellen}

Die Hemmung der Tumorproliferation und die Induktion von Apoptose sind Grundlagen bei der Krebstherapie und dementsprechend wichtige Parameter bei der Charakterisierung von Tumorzellen. Die Effekte von STC2 auf die Proliferation von NB-Zellen wurden in vitro untersucht und es konnte gezeigt werden, dass das Wachstum der NB-Zellen durch STC2 signifikant inhibiert wird ( $\mathrm{p}<0,05$; s. Kap. 4.2.6). Bei der Untersuchung der Tumorbildung in vivo schien die Zahl der STC2-exprimierenden Tumorzellen ebenfalls vermindert zu sein (s. Kap. 4.2.11.2). Nachdem Veränderungen im Zellzyklus als Grund für die Wachstumsinhibierung ausgeschlossen werden konnten (s. Kap. 4.2.7), wurde die Apoptoseneigung der Zellen untersucht und es zeigte sich, dass eine signifikante Erhöhung der Basisapoptose ( $p=0,031$; s. Kap. 4.2.9) in den STC2-exprimierenden Zellen vorliegt. Diese Daten werden auch durch die deutlich erhöhte Zahl nicht-vitaler Zellen im Kulturüberstand der STC2-Transfektanten bestätigt (s. Kap. 4.2.8) und durch Beobachtungen im Mausmodel unterstützt: Chang et al. (2008) zeigen, dass die Inhibierung von Stc2 in Mäusen zu einer Erhöhung des postnatalen Wachstums um 10-15 \% führt und beschreiben das Molekül deshalb als einen negativen Regulator des postnatalen Wachstums. Passend dazu führt die Überexpression des humanen STC2-Proteins in Mäusen zu einer prä- und postnatalen Wachstumshemmung und Zwergenwuchs (Gagliardi et al., 2005). Kürzlich konnte außerdem gezeigt werden, dass die konstitutive Expression von STC2 in Brustkrebszellen zu einer Verminderung von Zellwachstum und -vitalität führt (Raulic et al., 2008).

Eine Veröffentlichung von Ito et al. (2004) veranlasste mich dazu, die STC2-Expression auch im Zusammenhang mit induzierter Apoptose zu untersuchen. Ito und Kollegen konnten zeigen, dass die Inhibierung von Stc2 Maus-NB- und HeLa-Zellen empfänglicher für apoptotische Reize macht. Die Vermutung, dass im Gegenzug die STC2-Expression die Induktion von Apoptose verringert, konnte bestätigt und gezeigt werden, dass die induzierte Apoptose in STC2-exprimierenden Zellen im Vergleich zu Vektor-transfizierten Zellen um 50-60 \% vermindert ist (s. Kap. 4.2.9.1). Eine ähnliche protektive Wirkung von STC2 konnte 
auch bei Brustkrebszellen beobachtet werden. Joensuu et al. (2008) berichten, dass die Expression von STC1 und STC2 mit dem Auftreten von späten Rezidiven korreliert und vermuten, dass die Moleküle damit das Überleben von Brustkrebszellen fördern. Grundlage für diese Untersuchungen war eine Veröffentlichung von Serlachius et al. (2004), die beschreibt, dass STC zum Überleben von neuronalen und anderen Säugetierzellen beiträgt.

Der beobachtete Apoptose-mindernde Effekt von STC2 konnte bei der Induktion mit sehr hohen Staurosporinkonzentrationen $(10 \mu \mathrm{M})$ nicht nachgewiesen werden (s. Kap 4.2.9.1). In eukaryotischen Zellen wird zwischen zwei Arten des Zelltods unterschieden: Apoptose und Nekrose (Wyllie, 1980; Duvall \& Wyllie, 1986). Dass Staurosporin in geringen Konzentrationen $(0,1-1 \mu \mathrm{M})$ in NB-Zelllinien Apoptose induziert, wurde bereits durch Bursztajn et al. (2001) gezeigt. Die Vermutung liegt nahe, dass die sehr hohe Staurosporinkonzentration zytotoxisch auf die NB-Zellen gewirkt hat und dabei keine Apoptose sondern Nekrose induziert wurde. Dieser Effekt konnte auch von Bonfoco et al. (1995) bei der Verwendung von N-methyl-D-Aspartat oder Stickstoffsuperoxid beobachtet werden. Die Forscher zeigten, dass abhängig von der verwendeten Konzentration in neuronalen Zellen entweder Apoptose oder Nekrose ausgelöst wurde.

Bei der Untersuchung des Zellwachstums fiel außerdem auf, dass der STC2-Transfektant mit der niedrigsten Proteinexpression (ST4) keine Wachstumsinhibierung zeigte (s. Kap. 4.2.6). Dies könnte ein Hinweis darauf sein, dass der STC2-Effekt dosisabhängig vermittelt wird und eine bestimmte Grundexpression nötig ist, um die entsprechende Funktion auszuführen. Dass bestimmte Effekte dosisabhängig vermittelt werden, ist hinlänglich bekannt (Szende et al., 2000; Shires et al., 2007). Des Weiteren konnte ich bei Voruntersuchungen feststellen, dass auch in vivo eine Dosisabhängigkeit vorzuliegen scheint. Der STC2-Transfektant ST2 war in CAM Assays nicht in der Lage, vergleichbar blutige Tumoren wie ST1 zu bilden. Grund dafür könnte die um etwa 40 \% reduzierte STC2-Expression sein (s. Kap. 4.2.3).

\subsection{Einfluss von STC2 auf Tumorbildung und Invasivität von NB-Zellen}

Trotz des gezeigten antiproliferativen Effekts weist die positive Korrelation der STC2Expression mit dem metastasierten Tumorstadium 4 darauf hin, dass das Molekül weitere, ungünstige Effekte vermittelt. Das invasive Potential der transfizierten NB-Zellen wurde in vitro getestet, und ich konnte zeigen, dass eine deutliche Steigerung der Invasivität in den STC2-exprimierenden Zellen vorliegt (s. Kap. 4.2.10). Dies könnte mit der erhöhten Aktivität 
der MMP2, die in den Zellen nachgewiesen werden konnte, in Zusammenhang stehen (s. Kap. 4.2.10.1). Matrixmetalloproteinasen (MMPs) tragen durch den Verdau extrazellulärer Matrix zum Überwinden von epithelialen Barrieren bei, und schaffen so eine Vorraussetzung für die Metastasierung von Tumoren (Ray \& Stetler-Stevenson, 1994). Eine erhöhte Expression der MMP2 wurde bereits in vielen invasiven Erkrankungen gefunden und korreliert mit ungünstiger Prognose und Metastasenbildung (Deryugina \& Quigley, 2006). Die erhöhte Invasivität der STC2-exprimierenden NB-Zellen zeigt sich auch in vivo (s. Kap. 4.2.11). In CAM Assays bilden Vektor-transfizierte Zellen solide, gering vaskularisierte Tumoren. Die STC2-exprimierenden Tumoren erscheinen dagegen als blutgefüllte Zysten, die von makroskopisch sichtbaren Blutungen und Einblutungen in die CAM begleitet werden. In Semidünn- und Gefrierschnitten sind die Anreicherung von extravasalen Erythrozyten und Gefäßtrümmern sowie das Fehlen intakter Gefäße im Tumorinneren zu beobachten (s. Kap. 4.2.11.2-3). Außerhalb der Tumoren sind dagegen intakte Gefäße sichtbar. Trotz des aggressiven Verhaltens scheint in STC2-exprimierenden Tumoren die Zahl der Tumorzellen reduziert zu sein. Die Lokalisation der wenigen Tumorzellen im Außenbereich der Zysten und ihre Migration in CAM-Gefäße sind Hinweise auf eine Interaktion mit dem Stroma und das invasive Potential der Zellen. Aufgrund der extremen Blutigkeit der Tumoren und dem Auftreten von Gefäßtrümmern ist anzunehmen, dass die STC2-Expression zur Arrosion von Gefäßen führt, wodurch Invasivität und Metastasierung gefördert werden. Unterstützt wird diese Vermutung durch eine Veröffentlichung von Xiao et al. (2006), in der die Implantation von Blastozysten im Uterus untersucht wurde: Ein natürlich vorkommender, hochinvasiver Prozess, ähnlich der Tumorinvasion, bei dem der Blastozyst die Schleimhaut des Uterus infiltriert und durch die Zerstörung von Gefäßen eine Verbindung mit dem Blutkreislauf der Mutter herstellt. Die Forscher konnten bei Versuchen an Ratten zeigen, dass Stc1 und Stc2 während dieses invasiven Vorgangs im Endometrium hoch reguliert vorliegen. Des Weiteren haben Jellinek et al. (2000) die Sekretion und Phosphorylierung von STC1 und STC2 in einer Fibrosarkom-Zelllinie studiert, in der beide Moleküle hoch exprimiert vorkommen. Dass gerade diese Tumorzelllinie für die Untersuchungen gewählt wurde, scheint kein Zufall zu sein. Fibrosarkome imponieren klinisch als rot-bläuliche Hämatome und erinnern in ihrer Erscheinung an Hautmetastasen beim NB. Die Tumoren zeichnen sich durch hohe lokale Destruktivität aus und das Metastasieren des Tumors über das Lymph- und Blutgefäßsystem ist häufig zu beobachten (McKie, 1998). Hinweise auf eine erhöhte Aggressivität der STC2exprimierenden Tumorzellen konnte ich auch bei der Analyse des Zellzyklus finden. Trotz scheinbar reduzierter Proliferation lag keine Hemmung der Zellteilung vor, vielmehr konnte 
in den STC2-exprimierenden Zellen eine leichte Erhöhung der Synthese-Phase und somit eine verstärkte DNA-Replikation nachgewiesen werden (s. Kap. 4.2.7). Für die scheinbare Hemmung der Proliferation ist, wie bereits diskutiert, der Anstieg der Apoptoserate verantwortlich.

\section{6 Überprüfung der STC2-Effekte mit rekombinantem Protein}

Bei weiteren in vivo-Analysen mit gereinigtem, rekombinantem Protein konnte ich feststellen, dass STC2 für die beobachteten Effekte verantwortlich ist und nicht andere Tumor-abhängige Faktoren. Das rekombinante Protein war in der Lage, innerhalb von 24 Stunden Blutungen und die Bildung von Granulationsgewebe in der CAM zu induzieren (s. Kap. 4.3.4). Granulationsgewebe wird als Folge von Verletzungen gebildet und könnte als Reaktion auf die durch STC2 induzierte Blutung entstanden sein. Weitere im CAM Assay beobachtete Effekte waren das Absenken des Chorion- und die Verdickung des Allantoisepithels in der betroffenen Region, genauso wie die Anreicherung extravasaler Erythrozyten, wie sie auch in STC2-exprimierenden Tumoren beobachtet werden konnten. Meine Beobachtungen zeigen, dass das rekombinante Protein ebenfalls Blutungen induziert und STC2, wie vermutet, Einfluss auf Endothelzellen hat. Erhöhte Blutigkeit erleichtert Tumorzellen das Eindringen in den Blutkreislauf und somit die Metastasierung (Woodhouse et al., 1997). STC1 wurde bei einer Untersuchung von Nakagawa et al. (2007) als Marker für zirkulierende Brustkrebszellen beschrieben. Da STC1 und STC2 in bestimmten Bereichen überlappende Funktionen besitzen (Wagner \& DiMattia, 2006), wäre ein vergleichbares Auftreten von STC2 denkbar. Wie bereits diskutiert stehen beide Moleküle auch im Zusammenhang mit dem Auftreten später Rezidive bei Brustkrebs (Joensuu et al., 2008).

Humanes STC2 liegt in seiner nativen Form als Dimer vor (Moore et al., 1999). Das rekombinante STC2-Protein ist dagegen kommerziell nur unter reduzierenden Bedingungen erhältlich, unter denen eine Dimerbildung ausgeschlossen ist. Deshalb wurden die reduzierenden Agenzien vor der Verwendung des Proteins gegen physiologischen Puffer ausgetauscht. Ich konnte die Dimerbildung daraufhin in einem Teil des Proteins nachweisen, ein größerer Anteil verblieb aber in der monomeren Form (s. Kap. 4.3.2). Außerdem zeigte sich, dass die Größe des in E. coli synthetisierten Proteins nicht mit endogenem STC2 aus humanen Zelllinien übereinstimmt (s. Kap. 4.3.1). Es ist bekannt, dass humanes STC2 posttranslational modifiziert wird (Moore et al., 1999; Jellinek et al., 2000; Luo et al., 2005). Deshalb ist anzunehmen, dass diese Modifikationen in E. coli nicht vollständig ausgeführt werden konnten und sich das in der reduzierten Größe des rekombinanten Proteins zeigt. E. 
coli-Zellen fehlen die nötigen Enzyme und die zelluläre Maschinerie für bestimmte posttranslationale Modifikationen wie beispielsweise Glykosylierung oder Spaltung von Signalpeptiden. Außerdem wird humanes STC2 erst nach der Sekretion, wahrscheinlich durch die Caseinkinase II, phosphoryliert (Jellinek et al., 2000). Die Expression von aktiven eukaryotischen Proteinen, bei denen eine posttranslationale Modifikation beschrieben ist, sollte deshalb nach Sambrook \& Russel (2001; Abschnitt 15.2) in einem eukaryotischen Expressionssystem durchgeführt werden. Da die angesprochenen Komplikationen bereits vor der Verwendung des rekombinanten Proteins absehbar waren, habe ich parallel mit der Überexpression von STC2 in der humanen Expressionszelllinie HEK 293 begonnen. Das produzierte Protein konnte durch Affinitätschromatographie selektiv aufgereinigt, und konzentriert werden. Außerdem wurde gezeigt, dass es unter physiologischen Bedingungen als Dimer vorliegt (s. Kap. 3.4.9). Die Größe des Proteins stimmt im Western Blot mit endogenem humanen STC2 überein, so dass davon ausgegangen werden kann, dass die posttranslationalen Modifikationen entsprechend ausgeführt werden. Das gereinigte humane STC2 steht somit zur Verwendung in weitere Untersuchungen zur Verfügung, wodurch die bisherigen Komplikation zukünftig umgangen werden können.

\subsection{Alternative STC2-Transkripte im Neuroblastom}

Die alternative Polyadenylierung von mRNAs wird bereits seit einiger Zeit intensiv untersucht und ihre Bedeutung bei der Regulation der Genexpression wird zunehmend deutlicher (Edwalds-Gilbert et al., 1997). Das STC2-Gen enthält laut NCBI-Datenbank zwei PolyA-Signale. Diese befinden sich in der gespleißten Sequenz 1687 bp und 4032 bp in 3'Richtung unterhalb des Startcodons. Ich konnte zeigen, dass in humanen NB-Zelllinien zwei STC2-Transkripte exprimiert werden und somit wahrscheinlich beide Signale bei der Polyadenylierung Verwendung finden (s. Kap. 4.1.3.3). Die untersuchten NB-Zellen unterscheiden sich in der relativen Expression der Transkriptvarianten. In 4 von 13 Zelllinien konnte ausschließlich das längere STC2L-Transkript nachgewiesen werden, die restlichen Zelllinien exprimieren unterschiedliche Mengen beider mRNAs. Ein Zusammenhang zwischen Expressionsmuster und Wachstumsparametern oder Differenzierungsgrad der Zelllinien war nicht zu erkennen. Da die STC2-Expression Gewebe-abhängig variiert (Chang \& Reddel, 1998; DiMattia et al., 1998, Ishibashi et al., 1998; Moore et al., 1999), wäre es möglich, dass auch die Verteilung der Transkriptisonsvarianten vom Ursprungsort der Zelllinien bzw. des resezierten Tumors abhängig ist. 
Die Amplifikation von STC2K mittels Multiplex RT-PCR unter Verwendung von verankerten PolyT-Primern, wie in anderen Veröffentlichungen beschrieben (Fleischmann \& Liu, 2001), war nicht möglich (s. Kap. 4.1.3.2). Die verankerten PolyT-Primer bestanden aus 10 bis 15 TNukleotiden und einer kurzen, zu dem vor dem PolyA-Signal liegenden Abschnitt komplementären Sequenz. Für eine spezifische Amplifikation sollte die Sequenz direkt vor dem PolyA-Signal möglichst mehrere G- oder C-Basen enthalten (Mülhardt, 2002). Die drei Wasserstoffbrücken, die zwischen diesen Basen entstehen, sorgen für eine stärkere Bindung der Primer und erleichtern dadurch die Amplifikation von schwierigen Abschnitten. Da die Sequenz von STC2K in dem entsprechenden Bereich vermehrt A- und T-Basen besitzt, ist anzunehmen, dass die Amplifikation aufgrund der geringen Affinität der Primer nicht möglich war.

Auf Grundlage der in NCBI-beschriebenen STC2-Sequenz ist zu erwarten, dass bei Nutzung der beiden PolyA-Signale die Größe der STC2-Transkripte bei ca. 2 und 4,4 kb liegt. Verschiedene Forschergruppen konnten diese Transkripte bereits mittels Northern Blot Analysen in Geweben wie Herz, Nieren, Pankreas oder Milz nachweisen (Chang et al., 2003). Die publizierten Daten variieren bezüglich der exprimierten Transkriptmenge und Größe. Die beobachteten Transkriptgrößen liegen bei 2-2,4 kb und 4,3-4,5 kb. In zwei Arbeiten konnte zusätzlich ein etwa 1,4 kb-Transkript und in einer anderen Arbeit ein $5 \mathrm{~kb}$-Transkript nachgewiesen werden, die aber in späteren Untersuchungen keine Erwähnung mehr finden (Chang \& Reddel, 1998; DiMattia et al., 1998, Ishibashi et al., 1998; Moore et al., 1999; Chang et al., 2003). Auffällig ist, dass in den Northern Blot Analysen vorwiegend die Expression des etwa $2 \mathrm{~kb}$-großen Transkripts gezeigt werden konnte, wogegen ich in humanen NB-Zelllinien vermehrt das längere STC2L-Transkript nachgewiesen habe (s. Kap. 4.1.3.3).

Welchen Einfluss die zusätzliche 3'-UTR auf die Expression des STC2-Proteins hat, bleibt bislang offen. Dass regulatorische Elemente in 3'-UTRs verschiedene Parameter wie mRNAStabilität, translationale Effizienz (Knirsch \& Clerch, 2000) und intrazelluläre Lokalisation (Kislauskis et al., 1994) der Transkripte beeinflussen können, ist seit längerem bekannt. Shaw \& Kamen (1986) zeigten erstmals, dass AU-reiche Elemente in der 3'-UTR die Stabilität von mRNAs drastisch beeinflussen. Nach der Insertion einer AT-reichen Sequenz in ein $\beta$ Globulin Gen konnten die Forscher den rapiden Abbau der ansonsten stabilen mRNA beobachten. Mittlerweile gibt es eine so genannte ARED, eine humane AU-reiche Elemente- 
enthaltende mRNA Datenbank (http://rc.kfshrc.edu.sa/ared), in der mRNAs mit bestimmten Sequenzelementen gesammelt werden (Bakheet et al., 2001 \& 2003). In der zusätzlichen 3'UTR des STC2L-Transkripts konnten keine ARE identifiziert werden. Da aber immer neue regulierende Elemente in 3'-UTRs identifiziert werden, bleiben viele Möglichkeiten offen, wie die alternative Transkriptverwendung die STC2-Expression beeinflussen könnte. Welche regulierende Kraft 3'-UTRs besitzen wird durch Arbeiten von Fred et al. (2006 \& 2008) deutlich. Die Forscher untersuchten die Bindung von PTB (Polypyrimidine tract binding protein) an die 3'-UTR von Insulin-mRNA und die damit verbundene Stabilisierung der Transkripte und vermuten, dass so eine Glukose-induzierte Erhöhung der Insulinkonzentration erzielt wird.

Mindestens $20 \%$ aller mRNAs werden alternativ polyadenyliert (Beaudoing et al., 2000). Wie das verwendete PolyA-Signal selektioniert wird, ist aber bislang unklar (Legendre \& Gautheret, 2003). Beaudoing et al. (2000) haben bei der Analyse von 3'-UTRs und polyadenylierten EST-Sequenzen eine schwache Bevorzugung des distal gelegenen PolyASignals zeigen können. Auch in den untersuchten NB-Zelllinien wird das zweite PolyASignal anscheinend stärker verwendet, da vermehrt STC2L-Transkripte nachgewiesen wurden (s. Kap. 4.1.3.3). Ich konnte außerdem ausschließen, dass eine Abhängigkeit zwischen der STC2-Gesamtmenge und der STC2L-Expression in den untersuchten NB-Zelllinien besteht (s. Kap. 4.1.4). Die dafür durchgeführten Korrelationsanalysen wurden durch den Vergleich der STC2-Expression in Kelly und KB24-Zellen bestätigt. Die Zelllinie KB24 wurde durch die stabile Transfektion von Kelly-NB-Zellen mit Keratoepithelin generiert und weist eine zweifach erhöhte STC2-Expression auf (Becker et al., 2006). Meine Analysen zeigen, dass trotz Verdoppelung der STC2-Menge (s. Kap. 4.1.1) die relative Expression der beiden mRNAs unverändert ist. Die Transkripte liegen in den Zelllinien im Verhältnis von ca. 1:1 vor (s. Kap. 4.1.3.3).

Des Weiteren weist die Sequenzierung von Kelly-DNA darauf hin, dass die alternative Nutzung der Transkripte nicht auf sequenziellen Variationen im STC2-Gen beruht (s. Kap. 4.1.5). Lediglich in der Intronregion, 17 bp vor Exon 4, konnte die Deletion bzw. Insertion von CT-Repeats in einigen NB-Zelllinien gezeigt werden. Diese genetische Variation wurde bereits in der NCBI-Datenbank für STC2-DNA aus gesunden Zellen beschrieben (http://www.ncbi.nlm.nih.gov/SNP/snp_ref.cgi?rs=4041247). Dort konnte eine Insertion von 4 bis 5 Repeats gefunden werden (rs 4041247), die aber bislang nicht auffällig geworden ist. 
Im Allgemeinen wird angenommen, dass die 20bp-lange Intronregion vor Exongrenzen einen Einfluss auf den Spleißvorgang hat. Da durch die beschriebene Insertion bzw. Deletion von CTs aber aufgrund des Repeats keine wirklichen Veränderungen in diesem Bereich der Sequenz zu Stande kommen, ist ein Einfluss auf die Transkriptverteilung sehr unwahrscheinlich.

\subsection{Die duale Rolle von STC2 bei der Tumorprogression}

Meine Untersuchungen weisen darauf hin, dass STC2 im humanen NB eine duale Funktion ausübt. Einerseits konnte gezeigt werden, dass STC2 einen wachstumsmindernden Effekt hat (s. Kap. 4.2.6), der in STC2-exprimierenden NB-Zellen durch Erhöhung der Apoptoseneigung vermittelt wird (s. Kap. 4.2.9). Auf der anderen Seite weisen die Ergebnisse darauf hin, dass die STC2-Expression Invasivität und Metastasierung fördert (s. Abb. 5.1). STC2exprimierende NB-Zellen zeigen eine Erhöhung der Invasivität in vitro (s. Kap. 4.2.10). Außerdem ist als Folge der STC2-Expression die Tumorbildung der NB-Zellen in vivo verändert (s. Kap. 4.2.11). Es ist davon auszugehen, dass die dort beobachteten Blutungen und Gefäßtrümmer auf invasive und aggressive Gewebeinteraktionen von STC2 zurück zu führen sind, die eine Arrosion der Gefäße zur Folge haben. Den Tumorzellen wird der Eintritt in den Blut- oder Lymphkreislauf erleichtert und die Tumormetastasierung dadurch gefördert. Die Korrelation der STC2-Expression mit metastasierenden Tumorstadien und MYCN-Expression in Primärtumorproben unterstützt diese Annahme (s. Kap. 4.4), genauso wie die durch gereinigtes STC2-Protein induzierten Blutungen und Bildung von Granulationsgewebe (s. Kap. 4.3.4). Außerdem wurde in den STC2-exprimierenden NB-Zellen eine erhöhte Aktivität von MMP2 nachgewiesen (s. Kap. 4.2.10.1), die den NB-Zellen das Überschreiten von Gewebegrenzen erleichtern kann.

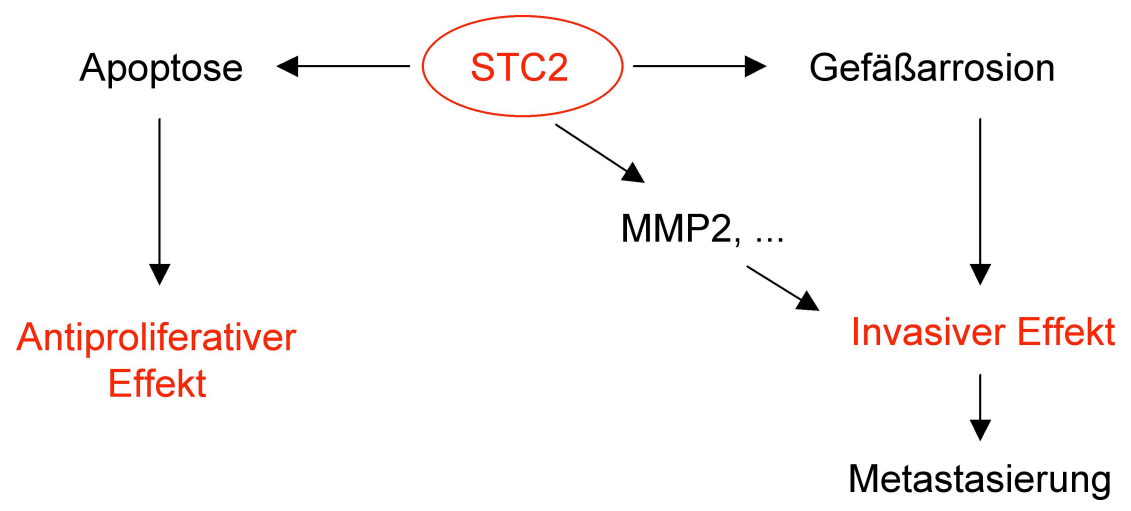

Abb. 5.1: Die duale Rolle von STC2 bei der Tumorprogression 
Die im Zuge dieser Arbeit generierten Forschungsergebnisse stehen im Einklang mit den Daten anderer Forscher, die die Funktion von STC2 bei der Tumorprogression ebenfalls in heterogener Weise beschreiben (s. Abb. 5.2).

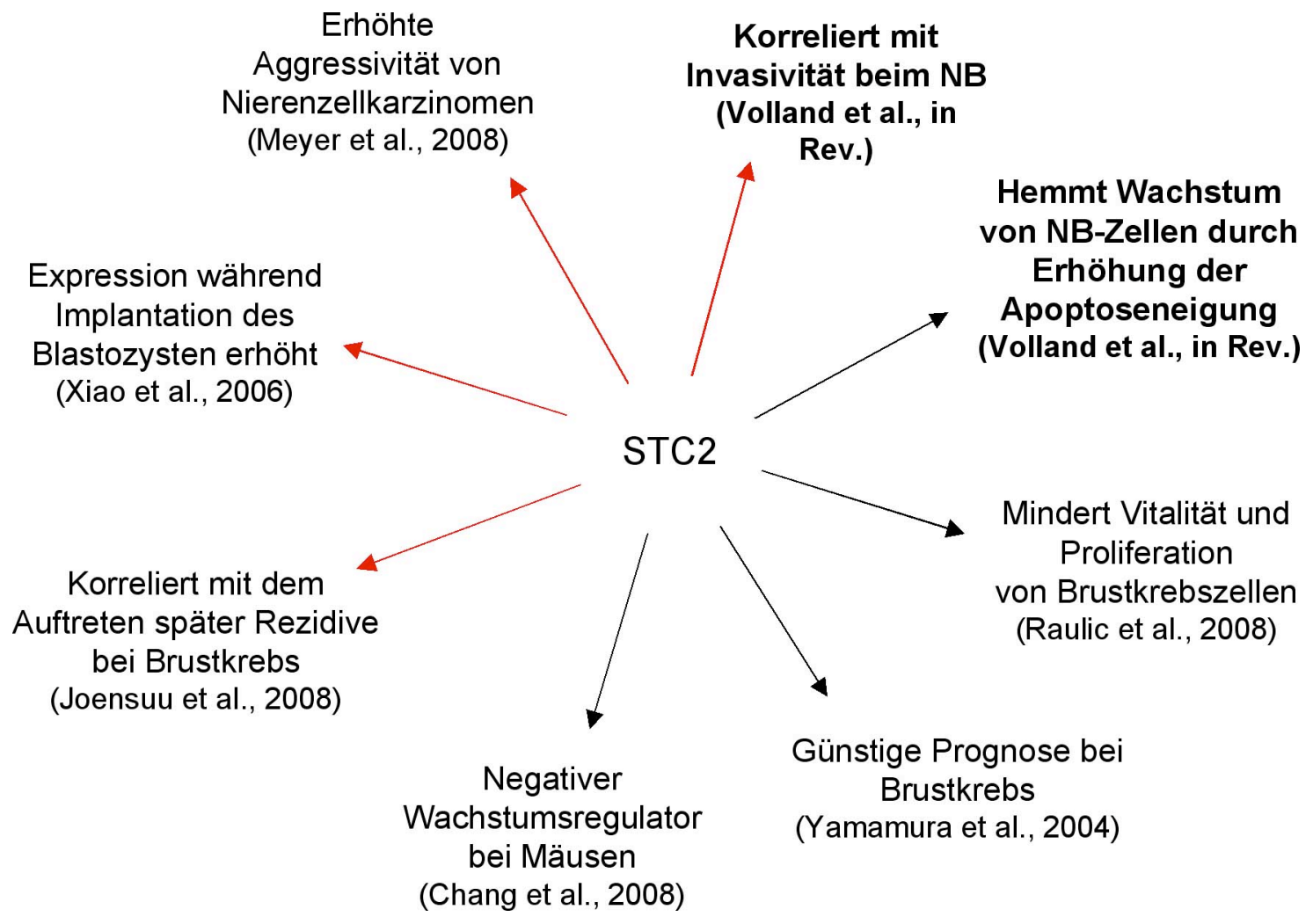

Abb. 5.2: Die duale Funktion von STC2 beim humanen NB, im Kontext der aktuellen Forschung. Rote Pfeile kennzeichnen Effekte die bei Krebs eine schlechte Prognose begünstigen, die schwarzen Pfeile sind kennzeichnend für günstige Bedingungen.

Ich konnte zeigen, dass STC2 beim humanen NB mit invasivem Verhalten und Metastasierung zu korrelieren scheint. Passend dazu wurde erst kürzlich beschrieben, dass die Expression von STC2 bei Nierenzellkarzinomen mit einer erhöhten Aggressivität der Tumoren und einem kürzeren Überleben der Patienten assoziiert ist (Meyer et al., 2008). Das Auftreten von STC2 während des hochinvasiven und blutigen Vorgangs der BlastozystenImplantation im Uterus zeigt, dass die STC2-Expression auch unter physiologischen Bedingungen mit invasivem und aggressivem Verhalten einher geht (Xiao et al., 2006). Bei Brustkrebs konnte zwischenzeitlich eine Korrelation zwischen STC2-Expression und dem Auftreten später Rezidive beobachtet werden (Joensuu et al., 2008). Die Korrelation von STC2 mit einer günstigen Prognose (Yamamura et al., 2004) wurde aber gleichzeitig durch weitere Untersuchungen bestätigt: Raulic et al. (2008) zeigen, dass die STC2-Expression die 
Proliferation und Vitalität von Brustkrebszellen mindert, ähnlich der von uns beobachteten Minderung der Proliferation in STC2-exprimierenden NB-Zellen durch Erhöhung der Apoptose. Die wachstumsinhibierende Wirkung von STC2 wurde auch bei Mäusen weiter untersucht und es konnte gezeigt werden, dass STC2 als negativer Regulator des postnatalen Wachstums fungiert (Chang et al., 2008).

Die Hypothese, dass STC2 beim humanen NB mit einer günstigen Prognose korreliert, muss aufgrund der im Zuge dieser Arbeit generierten Ergebnisse abgelehnt werden. Die Korrelation der STC2-Expression mit metastasierenden Tumorstadien und MYCN-Amplifikation, zusammen mit den funktionellen Untersuchungen weisen vielmehr darauf hin, dass die STC2Expression beim NB mit einer ungünstigen Prognose assoziiert ist. Die Gegenläufigkeit der STC2-Effekte macht außerdem deutlich, dass eine Reduktion der Tumorzellzahl in vitro nicht automatisch eine Aussage über die Aggressivität von Tumoren in vivo zulässt. 


\section{Ausblick}

Das humane Neuroblastom (NB) ist eine klinisch sehr heterogene Tumorentität. Daher ist die Charakterisierung des genetischen Hintergrunds für die Risikostratifizierung und die Möglichkeit individualisierter Tumortherapie sehr bedeutend. Im Rahmen dieser Arbeit konnte gezeigt werden, dass die Expression von STC2 mit metastasierenden Tumorstadien und invasivem Verhalten der Tumorzellen korreliert. Um zu prüfen, ob STC2 als prognostischer Marker zur Risikostratifizierung beim humanen NB eingesetzt werden kann, muss in weiteren Studien an primären Gewebeproben die STC2-Expression im Zusammenhang mit dem klinischen Verhalten der Tumoren untersucht werden. Des Weiteren wurden im Verlauf der Arbeit Hinweise darauf gefunden, dass STC2 NB-Zellen vor induzierter Apoptose schützt. Bei Brustkrebs ist die STC2-Expression zudem mit dem Auftreten später Rezidive korreliert. Deshalb wäre es interessant, im Zuge der Untersuchungen auch den Hinweisen auf eine Tumor-protektive Wirkung von STC2 nachzugehen und zu zeigen, ob eine Korrelation mit fehlendem Therapieerfolg oder dem Auftreten später Rezidive besteht.

Der Wert von STC2 als prognostischer Marker für die Risikostratifizierung hängt auch davon ab, ob STC2 unabhängig von anderen Markern eine Aussage zu lässt. In NB-Zelllinien und Primärgewebeproben konnte eine Korrelation von STC2 und MYCN-Amplifikation gezeigt werden. Damit STC2-Effekte unabhängig betrachtet werden konnten, wurden funktionelle Untersuchungen von STC2 in einer NB-Zelllinie ohne $M Y C N$-Amplifikation durchgeführt. Auch hier konnte der Zusammenhang mit invasivem Verhalten und Metastasierung beobachtet werden. Damit bleibt zu klären, ob STC2 auch in $M Y C N$-amplifizierten Tumoren eine unabhängige prognostische Aussage zulässt oder ob die STC2-Expression in Tumoren ohne MYCN-Amplifikation als prognostischer Marker für Tumorprogression und Metastasierung das Onkogen MYCN ersetzen könnte. Hierfür sollte die STC2-Expression in weiteren NB-Gewebeproben in Abhängigkeit der $M Y C N$-Amplifikation untersucht werden. Zudem könnte durch die Verwendung eines induzierbaren oder reprimierbaren MYCNExpressionssystems in Zellkulturversuchen mit STC2-exprimierenden Zellen gezeigt werden, ob eine direkte Interaktion von STC2 und MYCN besteht.

Nachdem zwei verschiedene STC2-mRNAs im humanen NB nachgewiesen werden konnten, stellt sich die Frage, ob die Expression der Transkriptvarianten einen Einfluss auf die Funktion von STC2 hat. Nach der Überprüfung der mRNAs mittels Northern Blot Analysen 
und Sequenzierung könnte der Vergleich der Transkriptstabilität erste Hinweise auf die Funktion der alternativen Polyadenylierung geben. Es wäre außerdem möglich, durch die Deletion bestimmter Abschnitte der 3'-UTR zu untersuchen, ob und welche Sequenzbereiche funktionelle Bedeutung haben.

Das in HEK 293-Zellen produzierte humane STC2-Protein steht nach Aufreinigung zur Überprüfung der beobachteten in vitro- und in vivo-Effekte zur Verfügung. Des Weiteren könnte in einer NB-Zelllinie mit endogenem STC2 durch RNA-Interferenz die Expression des Moleküls gehemmt und die Zellen im Bezug auf Proliferation, Apoptose, Invasivität und Tumorbildung im Vergleich zu STC2-exprimierenden Wildtypzellen untersucht werden. Interessant wäre außerdem, die STC2-Expression in den für die funktionellen Analysen verwendeten ST1-Zellen (transfizierte NB-Zellen mit hoher STC2-Expression) durch siRNA zu hemmen. Aufgrund des viralen Promoters in dem verwendeten Expressionssystem ist vermutlich nur eine teilweise Hemmung möglich, was erlauben würde, die Dosisabhängigkeit der STC2-Effekte zu untersuchen. Langfristig wäre es zudem sinnvoll, die Wirkung von STC2 auf die Tumormetastasierung im Mausmodel zu untersuchen. STC2-exprimierende NBZellen und entsprechende Kontrollen stehen hierfür zur Verfügung.

Die Identifikation eines STC2-Rezeptors oder Interaktionspartners ist der erste Schritt, um den Wirkmechanismus hinter den beobachteten STC2-Effekten zu erforschen. Humanes STC2-Protein aus HEK 293-Zellen steht für diese Suche zur Verfügung. Es ist möglich, das mit STC2 verlinkte Peptid Streptag II einzusetzen, um die STC2-Rezeptorkomplexe zu markieren und über Affinitätschromatographie zu isolieren.

Im Rahmen dieser Arbeit konnten erste Hinweise auf die Bedeutung von STC2 bei der Progression humaner NB gefunden werden. Die generierten Daten sind viel versprechend und ermutigen dazu, die Funktion von STC2 auch in Zukunft weiter zu erforschen. 


\section{Zusammenfassung}

Das humane Neuroblastom (NB) ist die häufigste extrakraniale Tumorerkrankung im Kindesalter. Diese Krebsform zeichnet sich besonders durch ihre Heterogenität aus, bei der aggressive Progression und Metastasierung im extremen Gegensatz zur häufig auftretenden Spontanregression und Differenzierung stehen. Die Erforschung des genetischen Hintergrunds der Tumoren ist ausschlaggebend für die Suche nach neuen prognostischen Markern und damit der Möglichkeit individueller Therapiestratifizierung bei den betroffenen Säuglingen und Kleinkindern. Für meine Untersuchungen habe ich das sezernierte Glykoprotein Stanniocalcin 2 (STC2) ausgewählt, das bislang noch nicht näher im Zusammenhang mit dem NB untersucht wurde. Beim Menschen konnte dem Protein noch keine eindeutige Funktion zugeordnet werden und bei der Progression von Tumoren wird STC2 widersprüchlich beschrieben. Das Ziel meiner Arbeit war es, die Funktion von STC2 im humanen Neuroblastom zu untersuchen und zu prüfen, ob STC2, wie es sich in Vorversuchen angedeutet hatte, mit einer günstigen Prognose korreliert. Die STC2-Expression wurde in NBZelllinien und Primärtumoren bestimmt und es konnte gezeigt werden, dass das Molekül mit metastasierenden Tumorstadien und der Amplifikation des $M Y C N$-Onkogens positiv korreliert. Außerdem konnte die Expression von zwei STC2-mRNAs nachgewiesen werden, die vermutlich aufgrund alternativer Transkript-Polyadenylierung entstehen. Die funktionelle Analyse transfizierter NB-Zellen zeigte, dass die Überexpression von STC2 die Apoptoseneigung der Zellen erhöht und dadurch einen wachstumsmindernden Effekt vermittelt. Gleichzeitig konnte in vitro bei den STC2-transfizierten Zellen eine deutliche Steigerung der Invasivität und eine erhöhte Aktivität der Matrixmetalloproteinase 2 nachgewiesen werden. In vivo bildeten die STC2-exprimierenden Zellen Tumoren, die im Vergleich zu den Tumoren der Kontrollzellen weniger solide waren und in ihrer Erscheinung blutgefüllten Zysten glichen. In ihrem Inneren konnten neben den wenigen Tumorzellen, die sich im Randbereich befanden, Gefäßtrümmer, aber keine intakten Gefäße nachgewiesen werden. Diese Arrosion von Gefäßen war auch bei Untersuchungen mit gereinigtem Protein zu beobachten. Rekombinantes STC2-Protein war in der Lage, Blutungen und die Bildung von Granulationsgewebe in der Chorioallantoismembran von Hühnerembryonen zu induzieren. Die im Zuge dieser Arbeit generierten Daten weisen auf eine duale Funktion von STC2 bei der Progression des NB hin. STC2 hat eine wachstumshemmende Wirkung auf NBZellen, scheint aber gleichzeitig invasives Verhalten und Tumormetastasierung zu fördern. Somit muss die Hypothese, dass STC2 mit einer günstigen Prognose korreliert, abgelehnt werden. Ob die Korrelation von STC2 mit ungünstigem Tumorverhalten zukünftig als 
prognostischer Marker für die Risikostratifizierung beim humanen NB eingesetzt werden kann, muss in weiteren Studien geprüft werden. 


\section{Summary}

Human neuroblastoma (NB) is the most common extra-cranial tumor entity in childhood. This malignancy is characterized by its remarkable clinical heterogeneity: aggressive progression and metastasis formation on the one hand and spontaneous regression and differentiation of tumors on the other hand. Investigation of the genetic background is therefore crucial for the search of new genetic markers to improve individual therapy stratification for affected infants and toddlers. For my investigations, the secreted phosphoprotein stanniocalcin 2 (STC2), which has not yet been analyzed in the context of NB, was chosen. In the human, no physiological functions of STC2 have been assigned but conflicting results concerning the progression of tumors have been published. The intention of my study was to investigate the function of STC2 in human NB and to analyze whether it is associated with a favorable prognosis as indicated in preliminary trials. STC2 expression was determined in NB cell lines and primary tumors and I could show that expression correlates positively with metastatic tumor stages and amplification of the $M Y C N$ oncogene. Furthermore expression of two STC2 mRNAs could be detected, which are probably the result of alternative transcript polyadenylation. Functional analyses of transfected NB cells revealed that STC2 overexpression increases apoptosis and thereby mediates growth-inhibitory effects. At the same time, invasive potential of STC2-transfected cells and activity of matrix metalloproteinase-2 are increased in vitro. Moreover, tumors formed by STC2 expressing cells on the chick chorioallantoic membrane (CAM) in vivo appear like blood-filled cysts and are less solid than control tumors. Inside the STC2 expressing tumors erythrocytes and vessel fragments, but no intact vessels, can be found. The few tumor cells found are located at the border of the cysts. Similar vessel destruction can also be observed after the application of purified STC2 protein. Recombinant STC2 was able to induce bleeding and formation of granulation tissue in CAM of chicken embryos. Data generated within this project indicate a dual role of STC2 for progression of human NB. STC2 mediates a growth inhibitory function by increasing apoptosis, but at the same time it seems to promote invasive behavior and tumor metastasis. Therefore, the hypothesis that STC2 correlates with favorable prognosis has to be rejected. Whether the observed correlation of STC2 with unfavorable tumor behavior might determine prognosis and risk stratification in human NB has to be confirmed by further investigation. 


\section{Literaturverzeichnis}

Ambros IM, Zellner A, Roald B, Amann G, Ladenstein R, Printz D, Gadner H \& Ambros PF (1996). "Role of ploidy, chromosome 1p, and Schwann cells in the maturation of neuroblastoma." N Engl J Med 334(23): 1505-11.

Ambros IM \& Ambros PF (2000). "The role of Schwann cells in Neuroblastoma." In: Neuroblastoma. Brodeur GM, Sawada T \& Tsuchida Y, Elsevier, Amsterdam, NL: A229243.

Ambros PF, Ambros IM, Strehl S, Bauer S, Luegmayr A, Kovar H, Ladenstein R, Fink FM, Horcher E, Printz G \& et al. (1995). "Regression and progression in neuroblastoma. Does genetics predict tumour behaviour?" Eur J Cancer 31A(4): 510-5.

Attiyeh EF, London WB, Mosse YP, Wang Q, Winter C, Khazi D, McGrady PW, Seeger RC, Look AT, Shimada H, Brodeur GM, Cohn SL, Matthay KK \& Maris JM (2005). "Chromosome 1p and 11q deletions and outcome in neuroblastoma." N Engl J Med 353(21): 2243-53.

Bachmann KD, Dominick HC \& Mildenberger H (1990). "Neuroblastom, Ganglioneurom, Phäochromozytom." In: Pädiatrie in Praxis und Klinik. Bachmann KD, Urban \& Fischer Verlag, München. 3: 16.48-16.54.

Bakheet T, Frevel M, Williams BR, Greer W \& Khabar KS (2001). "ARED: human AUrich element-containing mRNA database reveals an unexpectedly diverse functional repertoire of encoded proteins." Nucleic Acids Res 29(1): 246-54.

Bakheet T, Williams BR \& Khabar KS (2003). "ARED 2.0: an update of AU-rich element mRNA database." Nucleic Acids Res 31(1): 421-3.

Beaudoing E, Freier S, Wyatt JR, Claverie JM \& Gautheret D (2000). "Patterns of variant polyadenylation signal usage in human genes." Genome Res 10(7): 1001-10.

Becker J, Erdlenbruch B, Noskova I, Schramm A, Aumailley M, Schorderet DF \& Schweigerer L (2006). "Keratoepithelin suppresses the progression of experimental human neuroblastomas." Cancer Res 66(10): 5314-21.

Becker J, Volland S, Noskova I, Schramm A, Schweigerer LL \& Wilting J (2008). "Keratoepithelin reverts the suppression of tissue factor pathway inhibitor 2 by MYCN in human neuroblastoma: A mechanism to inhibit invasion." Int J Oncol 32(1): 235-40.

Berg JM, Tymoczko JL \& Stryer L (2002). Biochemistry. (5th ed.), W. H. Freeman and Company, New York, New York.

Bernhardt G, Reile H, Birnbock H, Spruss T \& Schonenberger H (1992). "Standardized kinetic microassay to quantify differential chemosensitivity on the basis of proliferative activity." J Cancer Res Clin Oncol 118(1): 35-43.

Berthold F, Hero B, Kremens B, Handgretinger R, Henze G, Schilling FH, Schrappe M, Simon T \& Spix C (2003). "Long-term results and risk profiles of patients in five consecutive 
trials (1979-1997) with stage 4 neuroblastoma over 1 year of age." Cancer Lett 197(1-2): 117.

Biedler JL, Roffler-Tarlov S, Schachner M \& Freedman LS (1978). "Multiple neurotransmitter synthesis by human neuroblastoma cell lines and clones." Cancer Res 38(11 Pt 1): 3751-7.

Blum H, Beier H \& Gross HJ (1987). "Improved silver staining of plant proteins, RNA and DNA in polyacrylamide gels." Electrophoresis 8(2): 93-99.

Bonfoco E, Krainc D, Ankarcrona M, Nicotera P \& Lipton SA (1995). "Apoptosis and necrosis: two distinct events induced, respectively, by mild and intense insults with N-methylD-aspartate or nitric oxide/superoxide in cortical cell cultures." Proc Natl Acad Sci U S A 92(16): 7162-6.

Bown N, Cotterill S, Lastowska M, O'Neill S, Pearson AD, Plantaz D, Meddeb M, Danglot G, Brinkschmidt C, Christiansen H, Laureys G, Speleman F, Nicholson J, Bernheim A, Betts DR, Vandesompele J \& Van Roy N (1999). "Gain of chromosome arm 17q and adverse outcome in patients with neuroblastoma." N Engl J Med 340(25): 1954-61.

Breit S, Ashman K, Wilting J, Rossler J, Hatzi E, Fotsis T \& Schweigerer L (2000). "The $\mathrm{N}$-myc oncogene in human neuroblastoma cells: down-regulation of an angiogenesis inhibitor identified as activin A." Cancer Res 60(16): 4596-601.

Brodeur GM, Seeger RC, Schwab M, Varmus HE \& Bishop JM (1984). "Amplification of $\mathrm{N}$-myc in untreated human neuroblastomas correlates with advanced disease stage." Science 224(4653): 1121-4.

Brodeur GM, Pritchard J, Berthold F, Carlsen NL, Castel V, Castelberry RP, De Bernardi B, Evans AE, Favrot M, Hedborg F \& et al. (1993). "Revisions of the international criteria for neuroblastoma diagnosis, staging, and response to treatment." $\mathbf{J}$ Clin Oncol 11(8): 1466-77.

Brodeur GM \& Maris JM (2002). "Neuroblastoma." In: Principles and Practice of Pediatric Oncology. Pizzo PA \& Poplack DG, Lippincott Williams \& Wilkins, Philadelphia, Pennsylvania: 895-937.

Brodeur GM (2003). "Neuroblastoma: biological insights into a clinical enigma." Nat Rev Cancer 3(3): 203-16.

Brodeur GM \& Maris JM (2006). Neuroblastoma. In: Principles and Practice of Pediatric Oncology. Pizzo PA \& Poplack DG, J B Lippincott Company, Philadelphia, Pennsylvania: 933-970.

Bursztajn S, Feng JJ, Nanda A \& Berman SA (2001). "Differential responses of human neuroblastoma and glioblastoma to apoptosis." Brain Res Mol Brain Res 91(1-2): 57-72.

Caron H, van Sluis P, de Kraker J, Bokkerink J, Egeler M, Laureys G, Slater R, Westerveld A, Voute PA \& Versteeg R (1996). "Allelic loss of chromosome 1p as a predictor of unfavorable outcome in patients with neuroblastoma." N Engl J Med 334(4): 225-30. 
Casadaban MJ \& Cohen SN (1980). "Analysis of gene control signals by DNA fusion and cloning in Escherichia coli." J Mol Biol 138(2): 179-207.

Chang AC, Janosi J, Hulsbeek M, de Jong D, Jeffrey KJ, Noble JR \& Reddel RR (1995). "A novel human cDNA highly homologous to the fish hormone stanniocalcin." Mol Cell Endocrinol 112(2): 241-7.

Chang AC \& Reddel RR (1998). "Identification of a second stanniocalcin cDNA in mouse and human: stanniocalcin 2." Mol Cell Endocrinol 141(1-2): 95-9.

Chang AC, Jellinek DA \& Reddel RR (2003). "Mammalian stanniocalcins and cancer." Endocr Relat Cancer 10(3): 359-73.

Chang AC, Hook J, Lemckert FA, McDonald MM, Nguyen MA, Hardeman EC, Little DG, Gunning PW \& Reddel RR (2008). "The murine stanniocalcin 2 gene is a negative regulator of postnatal growth." Endocrinology 149(5): 2403-10.

Chomczynski P \& Sacchi N (1987). "Single-step method of RNA isolation by acid guanidinium thiocyanate-phenol-chloroform extraction." Anal Biochem 162(1): 156-9.

D'Angio GJ, Evans AE \& Koop CE (1971). "Special pattern of widespread neuroblastoma with a favourable prognosis." Lancet 1(7708): 1046-9.

Deol HK, Varghese R, Wagner GF \& Dimattia GE (2000). "Dynamic regulation of mouse ovarian stanniocalcin expression during gestation and lactation." Endocrinology 141(9): 3412-21.

Deryugina EI \& Quigley JP (2006). "Matrix metalloproteinases and tumor metastasis." Cancer Metastasis Rev 25(1): 9-34.

DiMattia GE, Varghese R \& Wagner GF (1998). "Molecular cloning and characterization of stanniocalcin-related protein." Mol Cell Endocrinol 146(1-2): 137-40.

Duvall E \& Wyllie AH (1986). "Death and the cell." Immunology Today 7(4): 115-119.

Edwalds-Gilbert G, Veraldi KL \& Milcarek C (1997). "Alternative poly(A) site selection in complex transcription units: means to an end?" Nucleic Acids Res 25(13): 2547-61.

Fleischmann J \& Liu H (2001). "Polyadenylation of ribosomal RNA by Candida albicans." Gene 265(1-2): 71-6.

Fotsis T, Zhang Y, Pepper MS, Adlercreutz H, Montesano R, Nawroth PP \& Schweigerer L (1994). "The endogenous oestrogen metabolite 2-methoxyoestradiol inhibits angiogenesis and suppresses tumour growth." Nature 368(6468): 237-9.

Fox MH (1980). "A model for the computer analysis of synchronous DNA distributions obtained by flow cytometry." Cytometry 1(1): 71-7.

Fred RG, Tillmar L \& Welsh $\mathbf{N}$ (2006). "The role of PTB in insulin mRNA stability control." Curr Diabetes Rev 2(3): 363-6. 
Fred RG \& Welsh $\mathbf{N}$ (2008). "The importance of RNA binding proteins in preproinsulin mRNA stability." Mol Cell Endocrinol.

Gagliardi AD, Kuo EY, Raulic S, Wagner GF \& DiMattia GE (2005). "Human stanniocalcin-2 exhibits potent growth-suppressive properties in transgenic mice independently of growth hormone and IGFs." Am J Physiol Endocrinol Metab 288(1): E92105.

Grant SG, Jessee J, Bloom FR \& Hanahan D (1990). "Differential plasmid rescue from transgenic mouse DNAs into Escherichia coli methylation-restriction mutants." Proc Natl Acad Sci USA 87(12): 4645-9.

Guo C, White PS, Weiss MJ, Hogarty MD, Thompson PM, Stram DO, Gerbing R, Matthay KK, Seeger RC, Brodeur GM \& Maris JM (1999). "Allelic deletion at 11q23 is common in MYCN single copy neuroblastomas." Oncogene 18(35): 4948-57.

Gurney JG, Ross JA, Wall DA, Bleyer WA, Severson RK \& Robison LL (1997). "Infant cancer in the U.S.: histology-specific incidence and trends, 1973 to 1992." J Pediatr Hematol Oncol 19(5): 428-32.

Hasilo CP, McCudden CR, Gillespie JR, James KA, Hirvi ER, Zaidi D \& Wagner GF (2005). "Nuclear targeting of stanniocalcin to mammary gland alveolar cells during pregnancy and lactation." Am J Physiol Endocrinol Metab 289(4): E634-42.

Heussen C \& Dowdle EB (1980). "Electrophoretic analysis of plasminogen activators in polyacrylamide gels containing sodium dodecyl sulfate and copolymerized substrates." Anal Biochem 102(1): 196-202.

Higuchi R, Dollinger G, Walsh PS \& Griffith R (1992). "Simultaneous amplification and detection of specific DNA sequences." Biotechnology (N Y) 10(4): 413-7.

Ishibashi K, Miyamoto K, Taketani Y, Morita K, Takeda E, Sasaki S \& Imai M (1998). "Molecular cloning of a second human stanniocalcin homologue (STC2)." Biochem Biophys Res Commun 250(2): 252-8.

Ishibashi K \& Imai M (2002). "Prospect of a stanniocalcin endocrine/paracrine system in mammals." Am J Physiol Renal Physiol 282(3): F367-75.

Islam A, Kageyama H, Takada N, Kawamoto T, Takayasu H, Isogai E, Ohira M, Hashizume K, Kobayashi H, Kaneko Y \& Nakagawara A (2000). "High expression of Survivin, mapped to $17 \mathrm{q} 25$, is significantly associated with poor prognostic factors and promotes cell survival in human neuroblastoma." Oncogene 19(5): 617-23.

Ito D, Walker JR, Thompson CS, Moroz I, Lin W, Veselits ML, Hakim AM, Fienberg AA \& Thinakaran G (2004). "Characterization of stanniocalcin 2, a novel target of the mammalian unfolded protein response with cytoprotective properties." Mol Cell Biol 24(21): 9456-69. 
Jellinek DA, Chang AC, Larsen MR, Wang X, Robinson PJ \& Reddel RR (2000). "Stanniocalcin 1 and 2 are secreted as phosphoproteins from human fibrosarcoma cells." Biochem J 350 Pt 2: 453-61.

Joensuu K, Heikkila P \& Andersson LC (2008). "Tumor dormancy: elevated expression of stanniocalcins in late relapsing breast cancer." Cancer Lett 265(1): 76-83.

Kaatsch P, Spix C \& Schüz J (2006). "Epidemiologie, Ätiologie, Prävention." In: Pädiatrische Hämatologie und Onkologie. Gadner H, Gaedicke G, Niemeyer C \& Ritter J, Springer Medizin Verlag Heidelberg: 421-435.

Kaneko Y \& Knudson AG (2000). "Mechanism and relevance of ploidy in neuroblastoma." Genes Chromosomes Cancer 29(2): 89-95.

Kang JH, Rychahou PG, Ishola TA, Qiao J, Evers BM \& Chung DH (2006). "MYCN silencing induces differentiation and apoptosis in human neuroblastoma cells." Biochem Biophys Res Commun 351(1): 192-7.

Katzenstein HM, Bowman LC, Brodeur GM, Thorner PS, Joshi VV, Smith EI, Look AT, Rowe ST, Nash MB, Holbrook T, Alvarado C, Rao PV, Castleberry RP \& Cohn SL (1998). "Prognostic significance of age, MYCN oncogene amplification, tumor cell ploidy, and histology in 110 infants with stage $\mathrm{D}(\mathrm{S})$ neuroblastoma: the pediatric oncology group experience--a pediatric oncology group study." J Clin Oncol 16(6): 2007-17.

Kislauskis EH, Zhu X \& Singer RH (1994). "Sequences responsible for intracellular localization of beta-actin messenger RNA also affect cell phenotype." J Cell Biol 127(2): 441-51.

Kleiner DE \& Stetler-Stevenson WG (1994). "Quantitative zymography: detection of picogram quantities of gelatinases." Anal Biochem 218(2): 325-9.

Knirsch L \& Clerch LB (2000). "A region in the 3' UTR of MnSOD RNA enhances translation of a heterologous RNA." Biochem Biophys Res Commun 272(1): 164-8.

Knudson AG, Jr. \& Strong LC (1972). "Mutation and cancer: neuroblastoma and pheochromocytoma." Am J Hum Genet 24(5): 514-32.

Kogner P, Barbany G, Dominici C, Castello MA, Raschella G \& Persson H (1993). "Coexpression of messenger RNA for TRK protooncogene and low affinity nerve growth factor receptor in neuroblastoma with favorable prognosis." Cancer Res 53(9): 2044-50.

Ladenstein R, Ambros IM, Potschger U, Amann G, Urban C, Fink FM, Schmitt K, Jones R, Slociak M, Schilling F, Ritter J, Berthold F, Gadner H \& Ambros PF (2001). "Prognostic significance of DNA di-tetraploidy in neuroblastoma." Med Pediatr Oncol 36(1): 83-92.

Ladenstein R, Berthold F, Ambros I \& Ambros P (2006). "Neuroblastome." In: Pädiatrische Hämatologie und Onkologie. Gadner H, Gaedicke G, Niemeyer C \& Ritter J, Springer Medizin Verlag Heidelberg: 829-846. 
Laemmli UK (1970). "Cleavage of structural proteins during the assembly of the head of bacteriophage T4." Nature 227(5259): 680-5.

Lala PK \& Graham CH (1990). "Mechanisms of trophoblast invasiveness and their control: the role of proteases and protease inhibitors." Cancer Metastasis Rev 9(4): 369-79.

Legendre M \& Gautheret D (2003). "Sequence determinants in human polyadenylation site selection." BMC Genomics 4(7): http://www.biomedcentral.com/1471-2164/4/7.

Livak KJ \& Schmittgen TD (2001). "Analysis of relative gene expression data using realtime quantitative PCR and the 2(-Delta Delta C(T)) Method." Methods 25(4): 402-8.

Look AT, Hayes FA, Nitschke R, McWilliams NB \& Green AA (1984). "Cellular DNA content as a predictor of response to chemotherapy in infants with unresectable neuroblastoma." N Engl J Med 311(4): 231-5.

Look AT, Hayes FA, Shuster JJ, Douglass EC, Castleberry RP, Bowman LC, Smith EI \& Brodeur GM (1991). "Clinical relevance of tumor cell ploidy and N-myc gene amplification in childhood neuroblastoma: a Pediatric Oncology Group study." J Clin Oncol 9(4): 581-91.

Lu M, Wagner GF \& Renfro JL (1994). "Stanniocalcin stimulates phosphate reabsorption by flounder renal proximal tubule in primary culture." Am J Physiol 267(5 Pt 2): R1356-62.

Luo CW, Pisarska MD \& Hsueh AJ (2005). "Identification of a stanniocalcin paralog, stanniocalcin-2, in fish and the paracrine actions of stanniocalcin-2 in the mammalian ovary." Endocrinology 146(1): 469-76.

MacKie RM (1998). "Soft Tissue Tumors." In: Textbook of Dermatology. Rook A, Wilkinson DS \& Ebling FS, Blackwell Science Ltd., Oxford, UK.

Maris JM, Weiss MJ, Guo C, Gerbing RB, Stram DO, White PS, Hogarty MD, Sulman EP, Thompson PM, Lukens JN, Matthay KK, Seeger RC \& Brodeur GM (2000). "Loss of heterozygosity at $1 \mathrm{p} 36$ independently predicts for disease progression but not decreased overall survival probability in neuroblastoma patients: a Children's Cancer Group study." J Clin Oncol 18(9): 1888-99.

Maris JM \& Denny CT (2002). "Focus on embryonal malignancies." Cancer Cell 2(6): 44750.

Maris JM, Weiss MJ, Mosse Y, Hii G, Guo C, White PS, Hogarty MD, Mirensky T, Brodeur GM, Rebbeck TR, Urbanek M \& Shusterman S (2002). "Evidence for a hereditary neuroblastoma predisposition locus at chromosome 16p12-13." Cancer Res 62(22): 6651-8.

Maris JM, Hogarty MD, Bagatell R \& Cohn SL (2007). "Neuroblastoma." Lancet 369(9579): 2106-20.

McCudden CR, James KA, Hasilo C \& Wagner GF (2002). "Characterization of mammalian stanniocalcin receptors. Mitochondrial targeting of ligand and receptor for regulation of cellular metabolism." J Biol Chem 277(47): 45249-58. 
Meyer HA, Tolle A, Jung M, Fritzsche FR, Haendler B, Kristiansen I, Gaspert A, Johannsen M, Jung K \& Kristiansen G (2008). "Identification of Stanniocalcin 2 as Prognostic Marker in Renal Cell Carcinoma." Eur Urol.

Mittapalli VR, Prols F, Huang R, Christ B \& Scaal M (2006). "Avian stanniocalcin-2 is expressed in developing striated muscle and joints." Anat Embryol (Berl) 211(5): 519-23.

Miura W, Mizunashi K, Kimura N, Koide Y, Noshiro T, Miura Y, Furukawa Y \& Nagura H (2000). "Expression of stanniocalcin in zona glomerulosa and medulla of normal human adrenal glands, and some adrenal tumors and cell lines." Apmis 108(5): 367-72.

Moore EE, Kuestner RE, Conklin DC, Whitmore TE, Downey W, Buddle MM, Adams RL, Bell LA, Thompson DL, Wolf A, Chen L, Stamm MR, Grant FJ, Lok S, Ren H \& De Jongh KS (1999). "Stanniocalcin 2: characterization of the protein and its localization to human pancreatic alpha cells." Horm Metab Res 31(7): 406-14.

Mülhardt C (2002). Der Experimentator: Molekularbiologie/Genomics. (3. Aufl.), Spektrum Akademischer Verlag, Heidelberg.

Mullis KB \& Faloona FA (1987). "Specific synthesis of DNA in vitro via a polymerasecatalyzed chain reaction." Methods Enzymol 155: 335-50.

Nakagawa T, Martinez SR, Goto Y, Koyanagi K, Kitago M, Shingai T, Elashoff DA, Ye $X$, Singer FR, Giuliano AE \& Hoon DS (2007). "Detection of circulating tumor cells in early-stage breast cancer metastasis to axillary lymph nodes." Clin Cancer Res 13(14): 410510 .

Nakagawara A, Arima-Nakagawara M, Scavarda NJ, Azar CG, Cantor AB \& Brodeur GM (1993). "Association between high levels of expression of the TRK gene and favorable outcome in human neuroblastoma." N Engl J Med 328(12): 847-54.

Nakagawara A, Azar CG, Scavarda NJ \& Brodeur GM (1994). "Expression and function of TRK-B and BDNF in human neuroblastomas." Mol Cell Biol 14(1): 759-67.

Nakagawara A (2001). "Trk receptor tyrosine kinases: a bridge between cancer and neural development." Cancer Lett 169(2): 107-14.

Nara K, Kusafuka T, Yoneda A, Oue T, Sangkhathat S \& Fukuzawa M (2007). "Silencing of MYCN by RNA interference induces growth inhibition, apoptotic activity and cell differentiation in a neuroblastoma cell line with MYCN amplification." Int J Oncol 30(5): 1189-96.

Neumann E \& Rosenheck K (1972). "Permeability changes induced by electric impulses in vesicular membranes." J Membr Biol 10(3): 279-90.

Nicoletti I, Migliorati G, Pagliacci MC, Grignani F \& Riccardi C (1991). "A rapid and simple method for measuring thymocyte apoptosis by propidium iodide staining and flow cytometry." J Immunol Methods 139(2): 271-9. 
Nieder ML \& Gauderer MW (1991). "Recent developments in the management of neuroblastoma." Prog Pediatr Surg 26: 124-36.

Oberthür A \& Hero B (2004). "Molekulargenetische Veränderungen beim Neuroblastomwegweisend für Prognose und Therapie." Journal Onkologie (online) http://www.journalonko.de/aktuellview.php?id=1051.

Olshan AF, De Roos AJ, Teschke K, Neglia JP, Stram DO, Pollock BH \& Castleberry RP (1999). "Neuroblastoma and parental occupation." Cancer Causes Control 10(6): 53949.

Perez CA, Matthay KK, Atkinson JB, Seeger RC, Shimada H, Haase GM, Stram DO, Gerbing RB \& Lukens JN (2000). "Biologic variables in the outcome of stages I and II neuroblastoma treated with surgery as primary therapy: a children's cancer group study." $\mathbf{J}$ Clin Oncol 18(1): 18-26.

Radman DP, McCudden C, James K, Nemeth EM \& Wagner GF (2002). "Evidence for calcium-sensing receptor mediated stanniocalcin secretion in fish." Mol Cell Endocrinol 186(1): 111-9.

Raulic S, Ramos-Valdes Y \& DiMattia GE (2008). "Stanniocalcin 2 expression is regulated by hormone signalling and negatively affects breast cancer cell viability in vitro." J Endocrinol 197(3): 517-29.

Ray JM \& Stetler-Stevenson WG (1994). "The role of matrix metalloproteases and their inhibitors in tumour invasion, metastasis and angiogenesis." Eur Respir J 7(11): 2062-72.

Ribatti D, Raffaghello L, Pastorino F, Nico B, Brignole C, Vacca A \& Ponzoni M (2002). "In vivo angiogenic activity of neuroblastoma correlates with MYCN oncogene overexpression." Int J Cancer 102(4): 351-4.

RKI \& GEKID (2008). Krebs in Deutschland 2003-2004. Häufigkeiten und Trends. (6. überarbeitete Aufl.), Robert Koch-Institut (RKI) und die Gesellschaft der epidemiologischen Krebsregister in Deutschland e. V. (GEKID), Berlin.

Saiki RK, Gelfand DH, Stoffel S, Scharf SJ, Higuchi R, Horn GT, Mullis KB \& Erlich HA (1988). "Primer-directed enzymatic amplification of DNA with a thermostable DNA polymerase." Science 239(4839): 487-91.

Saito-Ohara F, Imoto I, Inoue J, Hosoi H, Nakagawara A, Sugimoto T \& Inazawa J (2003). "PPM1D is a potential target for 17q gain in neuroblastoma." Cancer Res 63(8): 1876-83.

Sambrook J \& Russel DW (2001). Molecular Cloning: A laboratory manual. (3rd ed.), Cold Spring Harbor Laboratory Press, Cold Spring Harbor, New York.

Sanger F, Nicklen S \& Coulson AR (1977). "DNA sequencing with chain-terminating inhibitors." Proc Natl Acad Sci U S A 74(12): 5463-7. 
Schilling FH, Spix C, Berthold F, Erttmann R, Fehse N, Hero B, Klein G, Sander J, Schwarz K, Treuner J, Zorn U \& Michaelis J (2002). "Neuroblastoma screening at one year of age." N Engl J Med 346(14): 1047-53.

Schramm A, von Schuetz V, Christiansen H, Havers W, Papoutsi M, Wilting J \& Schweigerer L (2005). "High activin A-expression in human neuroblastoma: suppression of malignant potential and correlation with favourable clinical outcome." Oncogene 24(4): 6807.

Schüz J (2002). "Leukämien im Kindesalter und die Rolle von Umwelteinflüssen bei deren Entstehung." Umweltmed Forsch Prax 7: 309-320.

Schüz J \& Kaatsch P (2002). "Epidemiology of pediatric tumours of the central nervous system." Expert Rev Neurotherapeutics 2(4): 469-479.

Schwab M, Westermann F, Hero B \& Berthold F (2003). "Neuroblastoma: biology and molecular and chromosomal pathology." Lancet Oncol 4(8): 472-80.

Seeger RC, Brodeur GM, Sather H, Dalton A, Siegel SE, Wong KY \& Hammond D (1985). "Association of multiple copies of the N-myc oncogene with rapid progression of neuroblastomas." N Engl J Med 313(18): 1111-6.

Serlachius M, Zhang KZ \& Andersson LC (2004). "Stanniocalcin in terminally differentiated mammalian cells." Peptides 25(10): 1657-62.

Shaw G \& Kamen R (1986). "A conserved AU sequence from the 3' untranslated region of GM-CSF mRNA mediates selective mRNA degradation." Cell 46(5): 659-67.

Shimada H, Ambros IM, Dehner LP, Hata J, Joshi VV, Roald B, Stram DO, Gerbing RB, Lukens JN, Matthay KK \& Castleberry RP (1999). "The International Neuroblastoma Pathology Classification (the Shimada system)." Cancer 86(2): 364-72.

Shires GT, Fisher O, Murphy P, Williams S, Barber A, Johnson G, Davis B \& Pahulu S (2007). "Recombinant activated protein $C$ induces dose-dependent changes in inflammatory mediators, tissue damage, and apoptosis in in vivo rat model of sepsis." Surg Infect (Larchmt) 8(3): 377-86.

Srivastava A, Laidler P, Hughes LE, Woodcock J \& Shedden EJ (1986). "Neovascularization in human cutaneous melanoma: a quantitative morphological and Doppler ultrasound study." Eur J Cancer Clin Oncol 22(10): 1205-9.

Stannius H (1839). "Über Nebennieren bei Knochenfischen." Arch Anat Physiol Wiss Med 6: $97-101$.

Stanton BR \& Parada LF (1992). "The N-myc proto-oncogene: developmental expression and in vivo site-directed mutagenesis." Brain Pathol 2(1): 71-83.

Sundell K, Bjornsson BT, Itoh H \& Kawauchi H (1992). "Chum salmon (Oncorhynchus keta) stanniocalcin inhibits in vitro intestinal calcium uptake in Atlantic cod (Gadus morhua)." J Comp Physiol [B] 162(6): 489-95. 
Szende B, Tyihak E \& Kiraly-Veghely Z (2000). "Dose-dependent effect of resveratrol on proliferation and apoptosis in endothelial and tumor cell cultures." Exp Mol Med 32(2): 8892.

Talhouk RS, Bissell MJ \& Werb Z (1992). "Coordinated expression of extracellular matrixdegrading proteinases and their inhibitors regulates mammary epithelial function during involution." J Cell Biol 118(5): 1271-82.

Tanega C, Radman DP, Flowers B, Sterba T \& Wagner GF (2004). "Evidence for stanniocalcin and a related receptor in annelids." Peptides 25(10): 1671-9.

Touriol C, Morillon A, Gensac MC, Prats H \& Prats AC (1999). "Expression of human fibroblast growth factor $2 \mathrm{mRNA}$ is post-transcriptionally controlled by a unique destabilizing element present in the 3 '-untranslated region between alternative polyadenylation sites." $\mathbf{J}$ Biol Chem 274(30): 21402-8.

Varghese R, Gagliardi AD, Bialek PE, Yee SP, Wagner GF \& Dimattia GE (2002). "Overexpression of human stanniocalcin affects growth and reproduction in transgenic mice." Endocrinology 143(3): 868-76.

Virchow R (1863). "Hyperplasie der Zirbel und der Nebennieren." In: Die krankhaften Geschwülste. Hirschwald A. 2: 148-150.

Volland S, Kugler W, Schweigerer L, Wilting J, Becker J (2008). "Stanniocalcin 2 promotes invasion and is associated with progressed stages in neuroblastoma." Int $\mathbf{J}$ Cancer, (in Revision)

Voss S \& Skerra A (1997). "Mutagenesis of a flexible loop in streptavidin leads to higher affinity for the Strep-tag II peptide and improved performance in recombinant protein purification." Protein Eng 10(8): 975-82.

Wagner GF, De Niu P, Jaworski E, Radman D \& Chiarot C (1997). "Development of a dose-response bioassay for stanniocalcin in fish." Mol Cell Endocrinol 128(1-2): 19-28.

Wagner GF \& Dimattia GE (2006). "The stanniocalcin family of proteins." J Exp Zoolog A Comp Exp Biol 305(9): 769-80.

White PS, Thompson PM, Gotoh T, Okawa ER, Igarashi J, Kok M, Winter C, Gregory SG, Hogarty MD, Maris JM \& Brodeur GM (2005). "Definition and characterization of a region of 1p36.3 consistently deleted in neuroblastoma." Oncogene 24(16): 2684-94.

Wilting J, Hawighorst T, Hecht M, Christ B \& Papoutsi M (2005). "Development of lymphatic vessels: tumour lymphangiogenesis and lymphatic invasion." Curr Med Chem 12(26): 3043-53.

Wong CK, Yeung HY, Mak NK, DiMattia GE, Chan DK \& Wagner GF (2002). "Effects of dibutyryl cAMP on stanniocalcin and stanniocalcin-related protein mRNA expression in neuroblastoma cells." J Endocrinol 173(1): 199-209.

Woodhouse EC, Chuaqui RF \& Liotta LA (1997). "General mechanisms of metastasis." Cancer 80(8 Suppl): 1529-37. 
Woods WG, Gao RN, Shuster JJ, Robison LL, Bernstein M, Weitzman S, Bunin G, Levy I, Brossard J, Dougherty G, Tuchman M \& Lemieux B (2002). "Screening of infants and mortality due to neuroblastoma." N Engl J Med 346(14): 1041-6.

Wyllie AH, Kerr JF \& Currie AR (1980). "Cell death: the significance of apoptosis." Int Rev Cytol 68: 251-306.

Xiao LJ, Yuan JX, Song XX, Li YC, Hu ZY \& Liu YX (2006). "Expression and regulation of stanniocalcin 1 and 2 in rat uterus during embryo implantation and decidualization." Reproduction 131(6): 1137-49.

Yamamura J, Miyoshi Y, Tamaki Y, Taguchi T, Iwao K, Monden M, Kato K \& Noguchi $\mathbf{S}$ (2004). "mRNA expression level of estrogen-inducible gene, alpha 1-antichymotrypsin, is a predictor of early tumor recurrence in patients with invasive breast cancers." Cancer Sci 95(11): 887-92.

Zimmermann U, Pilwat G \& Riemann F (1974). "Dielectric breakdown of cell membranes." Biophys J 14(11): 881-99. 


\section{Abkürzungsverzeichnis}

\begin{tabular}{|c|c|}
\hline$\alpha-\mathrm{SMA}$ & $\alpha$-Glattmuskelaktin \\
\hline${ }^{\circ} \mathrm{C}$ & Grad Celsius \\
\hline A & Amper \\
\hline AA & Acrylamid \\
\hline Abb. & Abbildung \\
\hline $\mathrm{AgNO}_{3}$ & Silbernitrat \\
\hline APS & Ammoniumpersulfat \\
\hline ARE & AU-reiche Elemente \\
\hline ARED & Humane AU-reiche Elemente-enthaltende mRNA Datenbank \\
\hline AS & Aminosäure \\
\hline ATP & Adenosintriphosphat \\
\hline BDNF & Brain-derived neurotrophic factor \\
\hline $\mathrm{bp}$ & Basenpaare \\
\hline Bsa & Bovines Serumalbumin \\
\hline ca. & circa \\
\hline $\mathrm{CaCl}_{2}$ & Calciumchlorid \\
\hline CAM & Chorioallantoismembran \\
\hline cDNA & Komplementäre DNA \\
\hline $\mathrm{cm}$ & Zentimeter \\
\hline $\mathrm{CO}_{2}$ & Kohlendioxid \\
\hline $\mathrm{ct}$ & Schwellenwertzyklus (cycle threshold) \\
\hline $\mathrm{Da}$ & Dalton \\
\hline dbcAMP & Dibutyryl zyklisches Adenosinmonophosphat \\
\hline ddNTP & Didesoxynukleosidtriphosphat \\
\hline DDSA & 2-Dodencenylsuccinic acid anhydride \\
\hline del & Deletion \\
\hline DKKR & Deutsches Kinderkrebsregister \\
\hline DMP-30 & 2,4,6-tris(dimethylaminomethyl)phenol \\
\hline DMSO & Dimethylsulfoxid \\
\hline DNA & Desoxyribonukleinsäure (Desoxyribonucleic acid) \\
\hline DNase & Desoxyribonuklease \\
\hline dNTP & Desoxynukleotidtriphosphat \\
\hline DPBS & Dulbecco's Phosphate Buffered Saline \\
\hline DTT & Dithiothreitol \\
\hline E. coli & Escherichia coli \\
\hline EDTA & Ethylendiamintetraessigsäure \\
\hline EGFP & enhanced green fluorescent protein \\
\hline ELISA & $\begin{array}{l}\text { Enzymgekoppelter Immunadsorptionstest } \quad \text { (Enzym-linked } \\
\text { immunosorbent assay) }\end{array}$ \\
\hline ER & Endoplasmatisches Retikulum \\
\hline et al. & und andere (lateinisch: et alli) \\
\hline $\mathrm{EtBr}$ & Ethidiumbromid \\
\hline $\mathrm{F}$ & Fraktion \\
\hline FACS & $\begin{array}{l}\text { Fluoreszenzaktivierte Zellsortierung (fluorescence activated cell } \\
\text { sorting) }\end{array}$ \\
\hline FCS & Fetales Kälberserum \\
\hline Fitc & Fluoreszeinthiocyanat \\
\hline fStc & Fisch-Stanniocalcin \\
\hline $\mathrm{g}$ & Gramm \\
\hline
\end{tabular}




\begin{tabular}{|c|c|}
\hline G418 & Geneticin \\
\hline GEKID & Gesellschaft der epidemiologischen Krebsregister e.V. \\
\hline GN & Ganglioneurom \\
\hline GNB & Ganglioneuroblastom \\
\hline GPOH & Gesellschaft für Pädiatrische Onkologie und Hämatologie \\
\hline h & Stunde (hour) \\
\hline $\mathrm{H}_{2} \mathrm{O}$ & Wasser \\
\hline $\mathrm{H}_{2} \mathrm{O}_{\text {dest }}$ & Destilliertes Wasser \\
\hline HABA & 2-(4-Hydroxyphenylazo)benzoic acid \\
\hline $\mathrm{HCl}$ & Salzsäure \\
\hline HEPES & 2-(4-(2-Hydroxyethyl)-1-piperazinyl)-ethansulfonsäure \\
\hline HRP & Meerrettichperoxidase (horseradish peroxidase) \\
\hline $\operatorname{Ig}$ & Immunglobulin \\
\hline in utero & Im Uterus \\
\hline in vitro & Im Glas \\
\hline in vivo & Im Lebendigen \\
\hline INPC & Internationale Neuroblastom Pathologie Klassifikation nach Shimada \\
\hline INSS & $\begin{array}{l}\text { Internationales Neuroblastom Klassifikationssystem (International } \\
\text { neuroblastoma staging system) }\end{array}$ \\
\hline $\mathrm{K}_{2} \mathrm{HPO}_{4}$ & di-Kaliumhydrogenphosphat \\
\hline Kap. & Kapitel \\
\hline $\mathrm{kb}$ & Kilobasenpaare \\
\hline $\mathrm{KCl}$ & Kaliumchlorid \\
\hline $\mathrm{KH}_{2} \mathrm{PO}_{4}$ & Kaliumdihydrogenphosphat \\
\hline $\mathrm{k}-$ & Kilo- $\left(1 \times 10^{3}\right)$ \\
\hline KPP & Kaliumphosphatpuffer \\
\hline 1 & Liter \\
\hline LB-Medium & Luria-Bertani-Medium \\
\hline $\mathrm{LOH}$ & Verlust der Heterozygotie (loss of heterozygosity) \\
\hline M & Molar \\
\hline m- & Milli- $\left(1 \times 10^{-3}\right)$ \\
\hline $\mathrm{MgSO}_{4}$ & Magnesiumsulfat \\
\hline$\mu$ & Mikro- $\left(1 \times 10^{-6}\right)$ \\
\hline $\min$ & Minute \\
\hline MMP & Matrixmetalloproteinase \\
\hline MNA & Methylnadic anhydride \\
\hline MRI & Kernspinresonanztomographie (magnetic resonance imaging) \\
\hline mRNA & Boten-RNA (messengerRNA) \\
\hline$M Y C N$ & v-myc myelocytomatosis viral related oncogene \\
\hline $\mathrm{n}$ & Anzahl \\
\hline $\mathrm{n}-$ & Nano- $\left(1 \times 10^{-9}\right)$ \\
\hline $\mathrm{N} 2 \mathrm{~A}$ & Maus-NB-Zelllinie \\
\hline $\mathrm{Na}_{2} \mathrm{CO}_{3}$ & Natriumcarbonat \\
\hline $\mathrm{Na}_{2} \mathrm{HPO}_{4}$ & di-Natriumhydrogenphosphat \\
\hline $\mathrm{Na}_{2} \mathrm{~S}_{2} \mathrm{O}_{3} \times 5 \mathrm{H}_{2} \mathrm{O}$ & wässriges Natriumthiosulfat \\
\hline $\mathrm{NaCl}$ & Natriumchlorid \\
\hline $\mathrm{NaN}_{3}$ & Natriumazid \\
\hline NB 2004 & $\begin{array}{l}\text { Aktuelles Studienprotokoll der Gesellschaft für Pädiatrische Onkologie } \\
\text { und Hämatologie zur Risiostratifizierung und Therapie von NB }\end{array}$ \\
\hline NB & Neuroblastom \\
\hline
\end{tabular}




\begin{tabular}{|c|c|}
\hline NCBI & $\begin{array}{l}\text { National Center for Biotechnology Information } \\
\text { (http://www.ncbi.nlm.nih.gov/) }\end{array}$ \\
\hline NGF & Nerve growth factor \\
\hline NTC & Ansatz ohne Template (no template control) \\
\hline OD & Optische Dichte \\
\hline $\mathrm{Pa}$ & Pascal \\
\hline PAGE & Polyacrylamidgelelektrophorese \\
\hline pA-Signal & Polyadenylierungssignal \\
\hline PBS & Phosphat-gepufferte Kochsalzlösung (phosphate buffered saline) \\
\hline PCR & Polymerase-Kettenreaktion \\
\hline PFA & Paraformaldehyd \\
\hline $\mathrm{pH}$ & negativer dekadischer Logarithmus der Hydroniumionenkonzentration \\
\hline PI & Propidiumiodid \\
\hline PolyA $_{1687}$ & Erstes Polyadenylierungssignal in 3'-UTR von STC2 bei 1687 bp \\
\hline PolyA $_{4032}$ & Zweites Polyadenylierungssignal in 3'-UTR von STC2 bei 4032 bp \\
\hline PPM1D & protein phosphatase $1 D$, magnesium-dependent \\
\hline PVDF & Polyvinylidenfluorid \\
\hline $\mathrm{r}$ & Korrelationskoeffizient \\
\hline Rev. T. & Reverse Transkription \\
\hline RKI & Robert-Koch-Institut \\
\hline RNA & Ribonukleinsäure (Ribonucleic acid) \\
\hline RNase & Ribonuklease \\
\hline $\mathrm{rpm}$ & Umdrehungen pro Minute (rounds per minute) \\
\hline rRNA & Ribosomale RNA \\
\hline RT & Raumtemperatur \\
\hline RT-PCR & $\begin{array}{l}\text { Polymerase-Kettenreaktion auf Grundlage einer reversen } \\
\text { Transkriptionsreaktion }\end{array}$ \\
\hline $\mathrm{S}$ & Sekunde \\
\hline s. & siehe \\
\hline s. a. & siehe auch \\
\hline SDS & Natriumdodecylsulfat (sodium-dodecylsulfate) \\
\hline SNP & Einzelnukleotidpolymorphismus (single nucleotide polymorphism) \\
\hline STABWN & Standardabweichung \\
\hline STC & Stanniocalcin \\
\hline STC1 & Stanniocalcin 1 \\
\hline STC2 & Stanniocalcin 2 \\
\hline STC2K & $\begin{array}{l}\text { STC2-mRNA-Transkript mit kurzer 3'-UTR, polyadenyliert am } 1 . \\
\text { Poly(A)-Signal }\end{array}$ \\
\hline STC2L & $\begin{array}{l}\text { STC2-mRNA-Transkript mit langer } 3^{\prime} \text {-UTR, wahrscheinlich } \\
\text { polyadenyliert am 2. Poly(A)-Signal }\end{array}$ \\
\hline STC2rek & Rekombinates STC2, produziert in Escherichia coli \\
\hline Tab. & Tabelle \\
\hline TAE & Tris-Acetat-EDTA \\
\hline $\mathrm{Taq}$ & Thermus aquaticus \\
\hline TBS & Tris gepufferte Kochsalzlösung (Tris buffered saline) \\
\hline TBST & Tris gepufferte Kochsalzlösung mit Tween 20 \\
\hline TEMED & $\mathrm{N}, \mathrm{N}, \mathrm{N}^{\prime}, \mathrm{N}^{\prime}-$ Tetramethylendiamin \\
\hline Tris & Tris-hydroxymethyl-aminomethan \\
\hline Triton $\mathrm{X}-100$ & Octylphenoxypolyethoxyethan \\
\hline TRKA & Neurotrophin-Rezeptor A (neurotrophic tyrosine kinase, type 1) \\
\hline TRKB & Neurotrophin-Rezeptor B (neurotrophic tyrosine kinase, type 2) \\
\hline
\end{tabular}


Tween

Polyoxyethylensorbitanmonolaurat

$\mathrm{u}$ Einheit (unit)

u. a. unter anderem

UTR

Untranslatierte Region

$\mathrm{V}$

Volt

$\mathrm{v} / \mathrm{v}$

Volumen/Volumen

vol.

Volumen

$\mathrm{w} / \mathrm{v}$

WT

Gewicht/Volumen (weight/volume)

z. B.

Wildtyp

zum Beispiel 


\section{Lebenslauf}

\section{Persönliche Daten}

Sonja Lena Volland, geboren am 24.10.1977 in Rotenburg an der Fulda

\section{Berufliche und praktische Erfahrungen}

08/2005 - 02/2009

Universitätsmedizin Göttingen, Abteilung Pädiatrie I

Promotion im Schwerpunktfach „Onkologie“, im Rahmen eines

Stipendiums des Graduiertenkollegs 1034 (Prof. Jörg Wilting)

$06 / 2008+11 / 2008$

Laborjournal, LJ-Verlag Herford und Sailer, Merzhausen

Freie Mitarbeiterin: Journal Club Göttingen

$01 / 2005-07 / 2005$

Georg-August-Universität Göttingen: Genomlabor G2L

Wissenschaftliche Mitarbeiterin (Prof. Gerhard Gottschalk)

$03 / 2002-10 / 2002$

Max-Planck-Institut für experimentelle Medizin

Studentische Hilfskraft (Prof. Norbert Hilschmann)

Auslandserfahrungen

$10 / 2003-11 / 2004$

University of Wisconsin, Milwaukee: Dep. of Biotechnology

Wissenschaftliche Mitarbeiterin (Prof. Uwe Deppenmeier)

$01 / 2004-05 / 2004$

University of Wisconsin: Dep. of Biological Science, Lehrassistentin (Prof. Arthur Brooks)

\section{Hochschul- und Schulbildung}

$10 / 1997-10 / 2003$

08/1994 - 05/1997

Ämter

$11 / 2005-03 / 2008$
Georg-August-Universität Göttingen, Biologiestudium

- Hauptfach: Mikrobiologie

- Nebenfächer: Immunologie und Anorganische Chemie

- Diplomarbeit am Institut für Mikrobiologie und Genetik, unter Anleitung von Prof. Uwe Deppenmeier

Jakob-Grimm-Schule (JGS), Rotenburg/ Fulda

Allgemeine Hochschulreife

\section{Graduiertenkolleg 1034, Universitätsmedizin Göttingen}

Stipendiatensprecherin 


\section{Veröffentlichungen}

\section{Publikationen}

Becker J, Volland S, Noskova I, Schramm A, Schweigerer L, Wilting J (2008). "Keratoepithelin reverts the suppression of tissue factor pathway inhibitor 2 (TFPI2) by MYCN in human neuroblastoma: a mechanism to inhibit invasion". Int J Oncol, 32: 235-240

Volland S, Kugler W, Schweigerer L, Wilting J, Becker J (2008). "Stanniocalcin 2 promotes invasion and is associated with progressed stages in neuroblastoma." Int $\mathrm{J}$ Cancer, (in Revision)

\section{Kongressbeiträge}

Volland S, Becker J, Schweigerer L (2006). "Stanniocalcin 2 in human neuroblastoma." Klinische Pädiatrie, 218 (3): 197

Volland S, Becker J, Schweigerer L, Wilting J (2007). "Effects of Stanniocalcin 2 on the progression of human neuroblastoma. Klinische Pädiatrie, 219 (3): 194

Volland S, Wilting J, Becker J (2008). "Stanniocalcin 2 in human neuroblastoma." Klinische Pädiatrie, 20 (3): 211

Volland S, Wilting J, Becker J (2008). "Effects of Stanniocalcin 2 on vessel formation in human neuroblastoma." 25th Conference of the European Society for Microcirculation, 2629.08.2008; Budapest, Ungarn 


\section{Danksagungen}

Für die freundliche und unkomplizierte Betreuung meiner Arbeit seitens der Biologischen Fakultät möchte ich Herrn Prof. Dr. Bernd Herrmann danken.

Herrn PD Dr. Dieter Kube danke ich herzlich für die Bereitschaft das Korreferat der Arbeit zu übernehmen und für all die Unterstützung und guten Ratschläge, die er mir darüber hinaus gegeben hat.

Mein Dank gilt außerdem Herrn Prof. Dr. Jörg Wilting, der bereitwillig die offizielle Anleitung der Arbeit übernommen hat, immer mit Rat zur Seite stand und wenn nötig, auch zur Tat geschritten ist.

Herrn Dr. Jürgen Becker möchte ich für die Betreung meiner Arbeit, für die gute praktische und theoretische Anleitung sowie die vielen konstruktiven Diskussionen herzlich danken.

Dem Graduiertenkolleg 1034 "Die Bedeutung genetischer Polymorphismen in der Onkologie" danke ich für die Finanzierung meiner Arbeit und dafür, dass ein Austausch mit Gleichgesinnten über die Laborgrenzen hinaus ermöglicht wurde.

Ein großes Dankeschön geht an Frau Jingky Lozano für die statistischen Auswertungen im Rahmen dieser Arbeit, die sie mit Geduld und Freundlichkeit ausgeführt hat. Frau Monika Hoch sei gedankt für ihre praktische Unterstützung. Herrn Dr. Wilfried Kugler möchte ich herzlich dafür danken, dass er immer ein offenes Ohr hatte und für Fragen jeglicher Art zur Verfügung stand.

Außerdem danke ich Herrn Prof. Dr. Max Lakomek für die Bereitstellung meines Arbeitsplatzes. Meinen Kollegen aus der Pädiatrie I und der Abteilung Hämatologie und Onkologie danke ich von Herzen dafür, dass sie dort eine Atmosphäre geschaffen haben, in der man gerne arbeitet, wo wissenschaftlicher Austausch möglich ist und man immer einen Grund findet, gemeinsam zu lachen. Vielen Dank auch an meine Kollegen aus der Anatomie und Zellbiologie, die oft sehr hilfreich waren. 
Ein Dankeschön von ganzem Herzen geht an alle Freunde, die mit kleinen Taten und Worten viel geholfen haben. Besonders erwähnen möchte ich Corinna Rehwald, Pouye Imani und Alexandra Schautz. Danke für die vielen Glücksmomente, das Lachen und eine aufregende und interessante Zeit, Danke für den Zuspruch und die Unterstützung, aber auch für Diskussionen und offene Gespräche.

Von ganzem Herzen möchte ich meiner Familie danken, die mich durch alle Höhen und Tiefen begleitet hat: meinen Eltern, meinem Bruder Peter und der Familie Flohr. Ganz besonders möchte ich mich bei meiner Freundin Katrin und meinem Bruder Michael bedanken für den Halt und Unterschlupf in stürmischen Zeiten. Vielen Dank auch an Emily und Johanna, die mich auf ihre Art beeinflußt haben. 